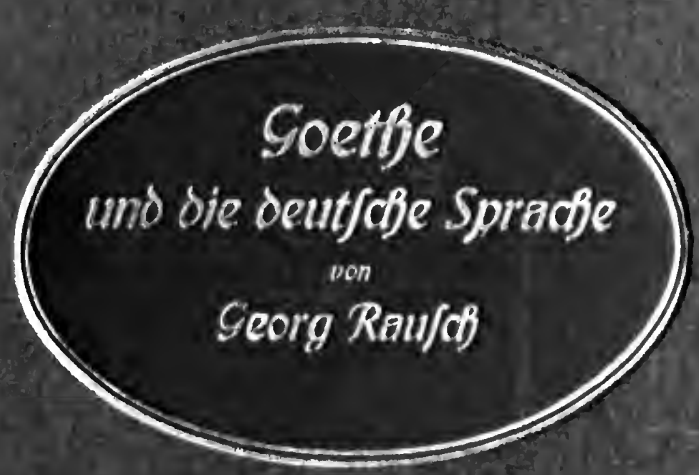

MUसVI LEITY

(I)

IOCRIUNTO IIIBAABS 
$\cdots$ 
0 


$$
\text { - }
$$




\section{GOETHE UND DIE DEUTSCHE SPRACHE}

\section{GEKRÖNTE PREISSCHRIFT}

DES ALLGEMEINEN DEUTSCHEN SPRACHVEREINS

VON

DR. GEORG RAUSCH

\section{㝝}



1909

LEIPZIG UND BERLIN

DRUCK UND VERLAG VON B. G. TEUBNER 


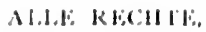

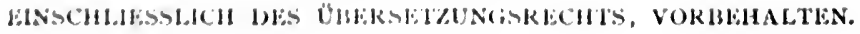




\section{Vorwort.}

Ein neues Goethebuch ist in unseren Tagen, in denen man $a b$ und $z u$ schon ein beschwörendes „Weniger über Goethe und mehr Goethe" hören kann, ein etwas gewagtes Unterfangen. Die Verantwortung für den ins Rollen gebrachten Stein trägt der Allgemeine Deutsche Sprachverein, der im Juli Igo5 sein I2. Preisausschreiben über "Die Anschauungen Goethes von der deutschen Sprache" erließ. Die vorliegende Arbeit wurde im Januar 1909 von dem aus den Herren Geh. Hofrat Prof. Dr. O. Behaghel (Gießen), Prof. Dr. O. Brenner (Würzburg), Prof. Dr. F. Muncker (München), Prof. Dr. P. Pietsch (Berlin), Prof. Dr. Scheidemantel (Weimar) und Geh. Regierungsrat Prof. Dr. W. Wilmanns (Bonn) bestehenden Preisrichterkollegium mit einem von zwei ersten Preisen ausgezeichnet. Wir übergeben sie hiermit nach einer eingehenden Überarbeitung und mannigfachen Ergänzung der Öffentlichkeit in der Hoffnung, da $\beta$ sie an ihrem bescheidenen Teil mitwirken wird, das Verständnis unseres Goethe zu fördern. Wir haben es uns zur vornehmsten Pflicht gemacht, jedes Hineinerklären, jede gesuchte Interpretation $\mathrm{zu}$ vermeiden und glauben uns damit den Dank aller wahren Goetheverehrer verdient zu haben.

Goethes Orthographie und Interpunktion ist nach dem Text der Weimarer Ausgabe getreu beibehalten. Die Sperrungen in den Zitaten stammen vom Verfasser.

Schotten (Hessen), im Juni 1909.

Dr. Rausch. 


\section{Inhalt.}

Seite

Einleitung

I. Goethe und die Sprache . . . . . . . . . . . 3-70

Kap. I: Wort und Begriff . . . . . . . . . . 7

" 2: Geschriebene und gesprochene Rede . . . 40

" 3: Werturteile uiber die Sprache . . . . . 5 I

" 4: Allgemeine Sprachwissenschaft . . . . 60

II. Goethe und die deutsche Sprache . . . . . . . .71-186

Kap. 5: Tadel und Lob der Muttersprache . . . . 76

" 6: Schrift, Orthographie und Interpunktion . . 92

" 7: Grammatik und Stil . . . . . . . . 100

" 8: Schriftsprache und Mundart . . . . . . I22

" 9: Sprachreinigung und Sprachbereicherung . . 136

" I0: Metrik und Phonetik . . . . . . . . . 172

III. Goethe und die fremden Sprachen . . . . . . . 187-242

Kap. II: Goethes Sprachkenntnisse . . . . . . . 189

" 12: Fremde Sprachen. Alte Sprachen . . . . 205

" 13: Französisch, Italienisch und Englisch . . . 219

"14: Slawische und orientalische Sprachen . . . 230

" I5: Übersetzung . . . . . . . . . . . . 233

Schlußwort. . . . . . . . . . . . . . 243-245

Anhang. . . . . . . . . . . . . . . . 247-266

Register. . . . . . . . . . . . . . . 267-268

Literaturnachweise und Abkürzungen vgl. Anhang IV, S. 265. 


\section{EINLEITUNG.}

Daß Goethes, des gewaltigen Sprachmeisters Anschauungen und Urteile von der deutschen Sprache trotz unserer mächtig angeschwollenen Goetheliteratur, trotz der ihre Kräfte manchmal an unfruchtbaren Aufgaben verschwendenden Goethephilologie noch keine zusammenhängende Behandlung gefunden haben, ist eine Tatsache, die wohl darin ihre Erklärung findet, daß der Umfang des uns überlieferten Schrifttums Goethes von einer Untersuchung abschreckte und eine oberflächliche Übersicht die Ausbeute als wenig lohnend erscheinen lassen mußte. Im folgenden ist, der Anregung des Allgemeinen deutschen Sprachvereins folgend, der Versuch unternommen, diese Lücke auszufüllen. Es sollen Goethes Äußerungen über sprachliche Fragen in möglichster Vollständigkeit zusammengestellt und einer Würdigung nach Inhalt, Zusammenhang und Zeitumständen unterzogen werden. Eine Ausdehnung der Untersuchung ergab sich mit Notwendigkeit. Denn Goethes Anschauungen von der deutschen Sprache erscheinen nur dann in richtiger Beleuchtung, wenn ihnen die über Sprache überhaupt als Unterlage und die über die fremden Sprachen als Spiegel dienen können.

Rein zahlenmäßig betrachtet muß auf den ersten Blick die geringe Ausbeute überraschen, die die Untersuchung gefördert hat. Die Gesamtzahl der gefundenen und verwerteten Belegstellen beläuft sich auf rund 650; davon entfallen ungefähr 200 auf die Briefe, 100 auf die Tagebücher, 80 auf die Gespräche und ebensoviel auf die naturwissenschaftlichen Schriften. Der Rest, also ein knappes Drittel, verteilt sich

Rausch, Goethe u. die deutsche Sprache. 
auf die Werke im eigentlichen Sinne. Unter diesen sind die Aufsätze zur Literatur mit rund 60, die Gedichte mit 40, Dichtung und Wahrheit mit 30, die Annalen mit 20, die Sprüche, Maximen und Reflexionen mit 40 Belegen vertreten, während alle anderen Werke nur ganz Vereinzeltes geliefert haben.

Schon diese statistischen Nachweisungen lassen einen dreifachen Schluß zu, einmal, daß Goethe mehr gelegentlich und aphoristisch als zusammenhängend sich zur Sache geäußert hat, sodann daß er es mehr in wissenschaftlichen als in dichterischen Werken tut, und endlich daß er im Alter viel häufiger seine Gedanken über Sprache mitteilt als in jüngeren Jahren. ${ }^{1}$ )

I) Literaturnachweise vgl, Anhang IV S. $265^{\circ}$

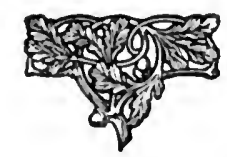


ERSTER TEIL

GOETHE UND DIE SPRACHE 

Die vornehmste Quelle über Goethes tägliche Beschäftigung sind seine Tagebücher, die für die letzten 15 Jahre seines Lebens uns unschätzbare Aufschlüsse über sein künstlerisches und wissenschaftliches Tun geben. Da für die früheren Jahre Regesten in solcher Ausführlichkeit fehlen, dürfen wir freilich aus den Tagebuchnotizen allein keine voreiligen Schlüsse ziehen. Des weiteren ist zu beachten, daß Riemer und Eckermann, die Genossen und Gehilfen seines Alters, Philologen von Fach sind, mit denen sprachliche Unterhaltungen sehr nahe lagen. So ist denn auch Riemer meist bei derartigen Unterhaltungen genannt. Aus dem lakonischen Wortlaut der Tagebuchaufzeichnungen ergibt sich sehr oft nicht, ob das Gespräch die Sprache an sich oder die deutsche im besonderen zum Thema hat. Naturgemäß wird das letztere der Fall sein, und wir verweisen deshalb einen Teil der Belege in den zweiten Hauptteil, indem wir uns hier darauf beschränken festzustellen, daß nach Ausweis der Tagebücher Goethe sehr oft sprachliche Fragen in den Bereich seiner Unterhaltungen zog. Ganz allgemein gehaltene Notizen seien hier angeführt: III. 4. 269. 2I Riemer Gespräch über Sprachverhältnisse (18. IV. 1812). III. 5. 75. IO Sprachbildung (17. IX. I8I3); III. 5. 99. I2 Riemer Sprachelemente (8. III. I8I4); III. 5. 145. I2 Mit Riemer Mittag Sprach Verhandlungen (9. IV. I814); III. I45. 12 Mit Riemer... Sprache; III. 5. 158. IO Periodenbau (25. IV. 18I5); III. 5. 197. Io Mit Riemer über Poetisches und Rhetorisches (25. XII. 1815); III. 5. 212. 5 Prof. Riemer Sprachforschung (5. III. I816); III. 5. 225. 5 Abends Riemer ïber Sprachverhältnisse und Pedanterie (Puris- 
mus?) (21. IV. I8I6); III. 5. 245. I I Prof. Riemer die vorgefundenen Collektaneen über Sprache mit ihm durchgegangen (23. VII. I8I6); III. 5. 296. 18 Wörtersammlung (22. XII. I8I6); III. 8. 7I. 24 Verschiedenes die Sprachforschung betreffend (24. VII. I82 I); III. 9. 270. 4 Auch anderes auf Sprache und Sprachbildung Bezügliches gesprochen (17. IX. I824); III. II. 155. I8 Über Sprachen und Literatur (29. XII. I827); III. I 2. 233. 2 I Wir unterhielten uns über litterarische Gegenstände besonders die Sprachen betreffend (29. IV. I830); ähnlich III. I2. 254. I4; III. I3. I57. 26 Schöne allgemein sprachliche Bemer. kung (I8. X. I831).

Riemer selbst, der bei all diesen Unterhaltungen der.gebende Teil gewesen zu sein scheint, bestätigt im allgemeinen diese Aufzeichnungen: G. VIII. 177: „Die Unterhaltungen mit Goethe sowohl bei Tische als in den Arbeitsstunden bezogen sich außer den vorliegenden Gegenständen häufig auf Sprachen, alte wie moderne" (1804-12). Auffällig ist, daß er in seinen zweibändigen „Mitteilungen über Goethe“"1) nirgends Bezug nimmt auf diese philologischen Gespräche, auch kaum eine Äußerung Goethes über Sprachliches verzeichnet, obgleich er doch mit rührendem Fleiß und größter Gelehrsamkeit Goethes Wesen nach allen Seiten unter liebevolle Beleuchtung stellt, seine Eigenschaften, seine Beziehungen zu und Urteile über andere sorgfältig verzeichnet. Auch dieser Umstand dürfte zu dem Schluß berechtigen, daß Gocthes Anteil an diesen Gesprächen gering war und er sich nur von Riemer über die betreffenden Fragen berichten und belehren ließ. $\mathrm{Da} B$ er jedenfalls einer Anregung zu sprachlichen $\ddot{A}$ ußerungen bedurfte und kaum aus sich heraus das Thema aufgriff, geht auch aus weiteren Notizen hervor. Auf der Badereise 1807 ist es der Bergrat Werner, der sprachliche Stoffe anregt. III. 3. 215. 10. Uber Sprache und veraltete Worte unterhalten (27. V. 1807 Franzensbad); 111. 3. 270. 16. Uber Sprachen und deren Verwandtschatt (5. IX. 1807 Kartsbad); 111. 3. 271. 3. Gegen Abend Bergrath

1) Kiemer, Fr. W.: Mittheilungen iber Goethe. 2 Bde. Berlin 1841 . 
Werner, der seine Sprachforschungsmanuscripte mitbrachte (6. IX. I807).

Auch der persönliche und schriftliche Verkehr mit W. v. Humboldt regte Goethes Beschäftigung mit Fragen der allgemeinen Sprachwissenschaft an, die bis zu seinem Lebensende rege blieb. Humb. 302. Theilen Sie mir aber auch etwas von ihren Arbeiten mit. Riemer ist, wie Sie wissen, an die gleichen und ähnlichen Studien geheftet und unsere Abendgespräche führen oft auf die Grenzen dieses Faches (I7. III. I832). Damit berührt sich offenbar folgende Mitteilung des Kanzlers Müller G. VIII. I 55: „Am Abend des I6. März sah und sprach der Kranke... den Hofrath Riemer und bat denselben, ihn von seinen Sprachstudien zu unterhalten" (I6. III. I832. K. W. Müller: Goethes letzte liter. Thätigkeit).

Die Titel aus den den Tagebüchern angefügten „Büchervermehrungslisten" als Beweisstoff heranzuziehen, ist deswegen nicht angängig, weil diese Bücher vom Dichter zum größten Teil nicht seinen Bedürfnissen und Interessen entsprechend angeschafft, sondern ihm von Verfassern und Verlegern zugeeignet wurden, also an sich keinerlei Schluß auf seine literarische Beschäftigung zulassen, solange die Tagebücher selbst schweigen.

\section{ERSTES KAPITEL.}

\section{WORT UND BEGRIFF.}

So verhältnısmäßig spärlich sich Goethe über andere sprachliche Verhältnisse äußert, so zahlreich sind die Stellen seiner Werke, die von den Beziehungen zwischen Wort und Begriff handeln. Schon Bouke findet: „Die wenigen sprachtheoretischen Betrachtungen Goethes beziehen sich fast ausschließlich auf das Verhältnis zwischen Wort und Begriff." Der Grundgedanke, der alle unten verzeichneten Belege durchzieht, ist der eine: Die Sprache ist unzulänglich und ungenügend, sie ist unfähig, den Begriff, den sie wiedergeben soll, voll aus- 
zudrücken. Zwischen Wort und Begriff besteht keine Übereinstimmung, da das Wort sich mit dem Begriff, den der menschliche Geist sprachlich zum Ausdruck bringen will, nicht deckt. Worte sind nur Aushilfen, Notbehelfe, keine vollgültigen Äquivalente der Begriffe. Goethe ist weder der erste noch der einzige, der diesen Gedanken zum Ausdruck bringt. Der Vater desselben scheint W. v. Humboldt zu sein, wenn man nicht noch weiter zurückgreifen will; denn schon die Philosophie des 17. Jahrhunderts (Comenius, Montaigne, Bacon) stellt die Forderung auf, daß die Dinge über die Worte zu setzen sind. Noch älter ist die Anschauung von der Willkürlichkeit des Worts; Locke griff sie wieder auf, Lessing, Herder, Schiller ${ }^{\mathbf{1}}$ ), Möser ${ }^{2}$ ) vertreten sie. Es kommt uns hier jedoch nicht darauf an, den Spuren dieser Ideen nachzugehen, als vielmehr eine Erklärung dafür zu finden, warum sie gerade Goethe so nachdrücklich vertritt. Lassen wir zunächst einige Belegstellen reden und suchen wir dann dem gespannten Verhältnis zwischen Dichter und Sprache auf den Grund zu kommen. Bei weitem die kleinere Zahl derselben finden wir in poetischen Werken und auch hier nur wieder in solchen späterer Jahre:

I. 2. 279. I Ihr miißt mich nicht durch Widerspruch verwirren, Sobald man spricht, beginnt man schon zu irren (Spruch, Widerspruch I 8 I 5). -

1. 4. 7I. I Worte sind der Seele Bild-

Nicht ein Bild! sie sind ein Schatten!

Sagen herbe, deuten mild,

Was wir haben, was wir hatten. -

Was wir hatten, wo ist's hin?

1) Michel, Herm.: Schillers Ansichten über die Sprache. (Euphorion XII, 1. Heft 1905. S. $25-42$.) S. $32 \mathrm{ff}$.

2) Hofmann: J. Möser und die deutsche Sprache (I.yon, Z.f.d.U. XXI, s. 220). In einem Briefe an Nikolai von 1767 klagt Möser, „daß das Kostüm der Worte und der damit verknüpften modernen Begriffe dem feschichtrchreiber unendliche Mühe macht". Ich glaube, daß sich ähnliche \%eugnimse mit wenig Mühe beibringen ließen. 
Und was ist's denn, was wir haben? Nun wir sprechen! Rasch im fliehn Haschen wir des Lebens Gaben.

(IO. I. I818; auch Boisserée II. 209.)

Dazu gehört die ,,aufklärende Bemerkung": I. 4. 84. 28 Der Worte, flüchtiger wie bleibender, Werth und Wirkung.

1. 14. 62: Geschrieben steht: „im Anfang war das Wort!“ Hier stock' ich schon! Wer hilft mir weiter fort? Ich kann das Wort so hoch unmöglich schätzen, Ich mu $\beta$ es anders übersetzen.

[Es folgen die Übersetzungen Sinn - Kraft - Tat.]

(Faust I. Studierzimmer v. I234.)

I. 14. 93 Meph.: Im ganzen - haltet Euch an Worte!

Dann geht Ihr durch die sichre Pforte Zum Tempel der Gewißheit ein.

Schüler: Doch ein Begriff muß bei dem Worte sein. Meph.: Schon gut! Nur muß man sich nicht allzu ängstlich quälen;

Denn eben wo Begriffe fehlen, Da stellt ein Wort zur rechten Zeit sich ein. Mit Worten läßt sich trefflich streiten, Mit Worten ein System bereiten, An Worte läßt sich trefflich glauben, Von einem Wort läßt sich kein Fota rauben.

(Faust I. Schülerszene v. 1990.)

Diese Verhöhnung des Wortes im Munde Mephistos bezieht sich auch auf seine Unzulänglichkeit dem Begriff gegenüber, nicht wie Kluge (a. a. O. 47) erklärt, auf seine Leerheit an sich. Goethe zitiert nämlich die Fauststelle selbst in unserem Sinne. G. VI. 361: um Gedanken und Anschauungen ist es den Leuten (Kritikern der Farbenlehre) auch gar nicht zu thun. Sie sind zufrieden, wenn sie nur Worte haben, womit sie verkehren, welches schon mein Mephistopheles geroußt 
und nicht übel ausgesprochen hat: Vor allem haltet euch am Worte... Da stellt ein Wort zur rechten Zeit sich ein (16. XII. I828 mit Eckermann).

I. 14. 174: Und wenn du ganz in dem Gefühle selig bist, Nenn es dann, wie du willst, Nenn's Glück! Herz! Liebe! Gott!

Ich habe keinen Namen

Dafür! Gefühl ist alles;

Name ist Schall und Rauch, Umnebelnd Himmelsgluth.

(Faust I. Marthens Garten v. 345I.)

I. 14. 292: Das was uns trennt, das ist die Wircklichkeit, Was uns verbindet, das sind Worte, Was uns zerspaltet ist die Wircklichkeit, Doch was uns einigt, das sind Worte.

(Paralip. zu Faust I. Mephist.)

I. I5. I. I 84: Doch red ich in die Lüfte; denn das Wort bemüht Sich nur umsonst Gestalten schöpfrisch aufzubauen. (Faust II. 869I.)

Wenn Mauthner ${ }^{1}$ ) auch die Worte Klärchens aus dem 5. Akte des Egmont „Und so wechseln wir Worte, sind müssig, verraten ihn" herbeizieht, so geht er damit doch wohl zu weit. $\mathrm{DaB}$ Klärchen in dem fieberhaften Bestreben, den Geliebten durch eine kühne Tat zu retten, jedes Wort für unnütze Zeitvergeudung hält, entspricht doch völlig der allgemeinen Anschauung von Wort und Tat. Die Goethes von der Unzulänglichkeit des Wortes kommt hier kaum zum Ausdruck.

Bei weitem zahlreicher fließen die Belege aus den Prosa. schriften, vor allem den wissenschaftlichen.

1. 30. 243. 16: Man mag au gunsten einer schrifllichen und mïndlichen Uberlieferung sagen, was man will, in den wenigsten Fällen ist sie hinreichend, denn den eigentlichen Charakter irgend

1) Manthner, Fr.: Beiträge zu einer Kritik der Sprache. I. Stuttgart 1901. 
eines Wesens kann sie doch nicht mitteilen, selbst nicht in geistigen Dingen. (Ital. Reise 2. I. I787.)

I. 3I. 55. 2I: Wenn ich Worte schreiben will, so stehen mir immer Bilder vor Augen des fruchtbaren Landes, des freien Meeres, des rauchenden Berges, und mir fehlen die Organe, das alles darzustellen. (Ital. Reise I7. III. I787.)

Heinem. XV. I4: Ich will auch nicht mehr ruhen, bis mir nichts mehr Wort und Tradition, sondern lebendiger Begriff ist. (Ital. Reise 27. VI. 1787.)

"Derselbe Ausspruch in etwas veränderter Fassung auch Heinem. XV. 29. (Ital. Reise 5. V. I787.)

II. $5^{1}$. I20. 2 I: Doch was sind Worte gegen die grossen und herrlichen Wirkungen der Natur? Diese wollen wir soviel uns möglich ist, beobachten, genau beschreiben und natïrlich ordnen, so werden wir Nahrung genug für unseren Geist finden. Worte entzweien, Sinn vereinigt die Gemüther. (Von d. farb. Schatten I792.)

II. 5. I. I62: Von diesem Augenblick an [bei Baco of Verulam] scheint Beobachtung über Grillenfängerei zu siegen, an die Stelle des Wortes die Sache zu treten, indem das Wort eine wohlbeobachtete Sache bezeichnet. (Über Newtons Hypothese d. div. Refrag bilität 1793:)

I. 23. 38. I : Die Zeit entschuldigt, wie sie tröstet, Worte sind in beiden Fällen von wenig Kraft. (Therese- W. M. L. VII. 5. I $795 / 96$.

I. 40. 279. I 2: Ihn [Voß] befriedigte nicht allein jene Gediegenheit des Ausdrucks, wo jedes Wort richtig gewählt ist, keines einen Nebenbegriff zulässt, sondern bestimmt und einzig seinen Gegenstand bezeichnet. (Rez. v. Voß Gedichten Lit. Ztg. I804.)

I. 46. 56. 22: Er [Winckelmann] sieht mit den Augen, er faßt mit dem Sinn unaussprechliche Werke, und doch fïhlt er den unwiderstehlichen Drang mit Worten und Buchstaben ihnen beizukommen. (Winckelmann I. I805.)

III. 3. 245. I6: ,Wir bemerken nicht, daß oft, wenn wir richtig sprechen, wir doch was Falsches sagen" (Quelle?) (22. VII. I807.) 
I1. I. XXXIX. 20: Er [der Praktiker] empfindet viel geschwinder das Hohle, das Falsche einer Theorie, als der Gelehrte, dem zuletzt die hergebrachten Worte für baare Münze gelten. (Didakt. Farbenl. Einitg. I806.)

11. 9. 349: Doch wird man immer je weiter und genauer man das Wesen und das Werden unorganischer Naturen beschreiben will, die Unzulänglichkeit der Worte und Begriffe gewahr werden. Fa sogar ist merkwürdig, daß wir, indem wir die äußere Gestalt und die Beschaffenheit eines gewordenen Wesens beschreiben wollen, wir oft genöthigt sind, uns solcher Ausdrücke zu bedienen, die der eigentlichen Natur des Gegenstandes zuwider sind. Beispiele hievon werden sich kïnftig anfïhren lassen und sie sind um so bedeutender, als sie zeigen können, daß selbst die hohe Ausbildung einer Terminologie, einer wissenschaftlich Sprache für die wahre Einsicht gefährlich werden kann. (Konzept an H. v. Leonhard 1808.)

II. 3. 136. I: Ein ausgesprochenes Wort tritt in den Kreis der übrigen nothwendigen wirkenden Naturkräfte mit ein. Es wirkt um so lebhafter als in dem engen Raume, in welchem die Menschheit sich ergeht, die nämlichen Bedürinisse, die nämlichen Forderungen immer wiederkehren. Und doch ist jede Wortüberlieferung so bedenklich. Man soll sich, heißt es, nicht an das Wort sondern an den Geist halten. Gewöhnlich aber vernichtet der Geist das Wort, oder verwandelt es doch dergestalt, daß ihm von seiner früheren Art und Bedeutung wenig übrig bleibt. (Histor. Farbenl., Lücke, 3. Abt. 1810 .)

11. 3. 198. 26: Von einer eigentlichen Naturanschauung ist hier [bei simon Portius] gar die Rede nicht. Das ausgesprochene Worl, die gebildete Phrase, die mehr oder weniger sulängliche Definition werden zum Grund gelegt; das Original, die Ubersetzung, eine Worterklärung, cine Umschreibung ergreifen sich wechselweise. (Histor. Farbenl. IV. Abt, 1810.)

"Wortarbeit" uennt Goethe veräclitlich dieses Verfahren. 
II. 3. 203. 3: So einfach auch die Farben in ihrer ersten elementaren Erscheinung sein mögen, so werden sie doch unendlich mannichfaltig, wenn sie ... sich in der Wirklichkeit manifestiren... Dadurch entspringt eine Individualisirung bis in's Grenzenlose, wohin keine Sprache, ja alle Sprachen der Welt zusammengenommen nicht nachreichen... Nun sind aber die meisten Farben. benennungen davon ausgegangen, da $\beta$ man einen individuellen Fall als Beispiel ergriffen, um nach ihm und an ihm andere ähnliche zu bezeichnen ... So ist in der Folge der Zeit . . . bei jeder Nation ein neuer Zuwachs von Terminologie entstanden, die immer aufs Neue wieder auf bekannte und unbekannte Gegen. stände angewendet, neue Bedenklichkeiten, neue Zweifel und Irrungen hervorbringt. (Histor. Farbenl. IV. Abt. I810.)

I. 36. 330. 9: Wie tief war er [Wieland] überzeugt, dass nicht das Wort, sondernder $S i n n$ belebe. Man betrachte, wie er [in seinen Ubbersetzungen] in seinen Einleitungen uns erst in die Zeit zu versetzen und mit den Personen vertraut zu machen bemüht ist, wie er alsdann seinen Autor auf eine uns schon verwandte Weise sprechen läßt. (Wieland 18I3.)

IV. 25. 307.24: Die Zahlen sind wie unsere ar me $n$ Wor te nur Versuche, die Erscheinungen zu fassen und auszudrücken, earig unzureichende Annäherungen. (I9 II. I8I 5 an C. H.Schlosser auch G. III. I25 u. Riemer 353 unter dem Datum 27. III. I 874.) Blosse Worte und Truggespinnste heißt es auch in einem Briefe vom 29. VI. 1829 an Schultz. (IV. 45. 3I4. I2.)

I. 28. 100. 27 : Denn schon damals [1773 bei den Bibelstudien] hatte sich bei mir eine Grundmeinung festgesetzt ... nämlich die: bei allem was uns überliefert, besonders aber schriftlich überliefert werde, komme es auf den Grund, das Innere, den Sinn, die Richtung des Werkes an, hier liege das Ursprïngliche, Göttliche, Wirksame, Unantastbare, Unverwïstliche, und keine Zeit, keine äussere Einwirkung noch Bedingung könne diesem innern Unwesen etwas anhaben, wenigstens nicht mehr als die Krankheit des Körpers einer wohlgebildeten Seele. So sei nun 
Sprache, Dialect, Eigentïmlichkeit, Stil und zuletzt die Schrift als Körper eines jeden geistigen Werkes anzusehen; dieser, zwar nah genug mit dem Innern verwandt, sei jedoch der Verschlimmerung, dem Verderbnis ausgesetzt. (D. W. I2. I813.)

Besonders wertvoll erscheint uns folgende Briefstelle: IV. 26. 289 18: Da die Sprache das Organ gewesen, wodurch ich mich während meines Lebens am meisten und liebsten den Mitlebenden mittheilte; so musste ich darüber, besonders in späteren Zeiten, reflectiren und hierbey hat mir's niemals an trefflichen Freunden gefehlt, die, zu Forschern in diesem Fach berufen, grossen und anhaltenden Fileiss darauf verwendeten. - Wenn ich nun gleich nach meiner eingebornen Art und Unart auf Correctheit und Reinlichkeit niemals genugsamen Fleiss zuwenden im Stande war; so habe ich doch aufs deutlichste begreifen lernen, dass die Sprache nur ein Surrogat ist, wir mögen nun das, was uns innerlich beschäftigt, oder das, was uns von aussen anregt, ausdrücken wollen. - Auf meinem Wege bin ich diese $U n z u l a ̈ n g$ lichkeit der Sprache nur allzu oft gewahr geworden und habe mich dadurch abhalten lassen, das zu sagen, was ich hätte sagen können und sollen. Ich durfte nur der Zeit vertrauen, dass diese redlichen Ausdrücke eines Einzelnen von mehrern wïrde verstanden $d . h$. in ihre Sprachen übersetst werden. - Fene Scheu, deren ich mich eben anklage, überwand ich zu Liebe der Farbenlehre, die mich viele Fahre beschäftigt hatte, und ich liess mich nicht irren, dass die ganze physische Gilde in hergebrachten, hohlen Chiffern zu sprechengewohnt ist, deren Abracadabra ihnen die Geister der lebendigen Natur, die überall zu ihnen spricht, möglichst vom trocknen dogmatischen Leichnam abhält. (11. I11. I 816 an Schultz.) 1)azu vgl. noch dic Lesart IV. 26. 417: Nun ist aber das Unglück, dass uns die Worle ausgehen, wir haben von Brechung und Spiegelung angefangen und die Phänomene deuten auf ein drittes, was keins von beyden ist. Das Ganze klingt bald wie ein lestament, eine Rechtfertigung vor der Nachwelt. Sowohl das allgemeine Verhult nis zur Sprache, die Mithilfe der sach- 
verständigen Freunde, die nie beabsichtigte Korrektheit und Reinheit, worauf wir zurückkommen, werden hier offen eingestanden, als auch die Überzeugung von der Unzulänglichkeit des sprachlichen Ausdrucks, besonders nachdrücklich betont. Lassen wir aber Goethe weiter das Wort, denn in seinen älteren Jahren werden die Belege am zahlreichsten und deutlichsten zu uns sprechen. I. 7. 115. 2: Wenn jemand Wort und Ausdruck als heilige Zeugnisse betrachtet und sie nicht etwa, wie Scheidemünze oder Papiergeld, nur zu schnellem, augenblicklichem Verkehr bringen, sondern im geistigen Handel und Wandel als wahres Äquivalent ausgetauscht wissen will, so kann man ihm nicht verïbeln, dass er aufmerksam macht, wie herkömmliche Ausdrücke, woran niemand mehr Arges hat, doch einen schädlichen Einfluss verüben, Ansichten verdüstern, den Begriff ents telle $n$ und ganzen Fächern eine falsche Richtung geben [folgt Verwahrung gegen die Unterordnung der Poesie in die Rubrik ,Redekunst"]. (Noten z. Divan I819.)

I. 24. 46. 23: ,Und doch wird man auch hier [in der Geologie] deine [der Natur abgelauschten] Lesarten streitig machen." „Eben deswegen", sagte jener [Montan], ,red' ich mit niemanden dariiber und mag auch mit dir, eben weil ich dich liebe, $d$ a s schlechte $Z$ eug von öden Worten nicht weiter wechseln und betrieglich austauschen. (W. M. W. I. 3. I821.)

I. 24. 45. 27: Buchstaben mögen eine schöne Sache sein, und doch sind sie unzulänglich, die Töne auszudrücken; Töne können wir nicht entbehren, und doch sind sie bei weitem nicht ausreichend, den eigentlichen Sinn verlauten zu lassen; am Ende kleben wir am Buchstaben und am Ton und sind nicht besser dran, als wenn wir sie ganz entbehrten. (Montan; W. M. W. I. 3. $182 \mathrm{I}$.)

II. 7. 347: Gedenken wir gegenwärtig der ältesten Zeiten, wo die Naturkunde von Bildern angefangen durch Bilder ohne Schrift und als Schrift mitgetheilt wcrden ... so muß uns bei Vergleichen der neusten Zeit [sc. auffallen], dass, um sich zu vollenden, die Wissenschaft wieder zu Bildern zurïckkehren müsse. 
Denn was hat der Mensch nicht alles mit Worten versucht! Um die reiche Welt zu erfassen, die ihm entgegenstehenden Einzelheiten in geistigen Besitz zu nehmen, wagt er zuerst oberflächlich und trivial zu benennen; womit er sich denn auch lange Zeit begnügte; endlich bei wachsender Kenntniss genauer zu benamsen. Wie nun aber in allen GeistesThätigkeiten keine Grenze gesteckt ist, so ging man in Verfolg der Zeiten zu flüchtigen Halbbeschreibungen über, welche: bei gereinigter ins Einzelne führender Nomenclatur, sich immer mehr und umständlicher verzweigten. Nun ist man in dieser Zeit soweit gelangt, dass man alle bildliche Darstellung zu entbehren zur Pflicht macht. Wenn aber auch die Möglichkeit und Hinlänglichkeit dieses Verfahrens zugegeben wird, so muss man gegenseitig gestehen, dass eine höchst ausgearbeitet-bewegliche, mit einem besonderen Sprachgebrauch innigst vertraute Einbildungskraft vorauszusetzen sei, die sich auf Worte und Wortzeichen jede Gestalt ïberhaupt bis zum allereinzelnsten Theil derselben alsobald im Geist hervorrufen... könne. (Zur Morphol. I 823.)

IV. 42. 38. 17: Es ist schwer ein früher Gedachtes dem Ausdruck nach gelten zu lassen, man möcht' es immer gleich u $m$ sprechen und umschreiben; das geht auch wieder nicht. (I I. X. I826 an Zelter.)

IV. 45. 138. 10: Verzeih diesen abstrusen Worten, ich weiß mich aber nicht anders auszudrïcken; denn wie ich mich immer besser zu verstehen glaube, schein' ich andern undeutlich zu werden. Du bist aber auch ein so wunderlicher Kaus, dass dir von der Art nichts unerklärlich seyn kann. (26. I. 1829 an Zelter.)

Auch zwei Gesprächc bezeugen, wie gerne sich Goethe im Alter mit diesen Gedanken beschäftigte:

G. IV. 284: Goethe mineralogisierte nit ihm [Soret] lange und sprach nachher selır poetisch darüber. Es gebe wohl verschiedene Ansichten in den Wissenschaften; aber sie würden oft nur durch eine papierne Scheidewand ver- 
anlaßt, die leicht mit dem Ellbogen durchzustoßen sei. (2. X. I823. v. Müller.)

Burkhardt I29. 9: hatten eine interessante Unterhaltung ... besonders über die $U \mathrm{nvollkommenheit} \mathrm{der}$ $\mathrm{S}$ p r a $\mathrm{ch}$ e als Ursache langdauernder falscher Anschauungen der Menschheit. (IO. III. I83 I mit Soret.)

Sehr ausführlich endlich spricht sich der greise Dichter Eckermann gegenüber aus. Besonders wichtig wird der Beleg dadurch, weil Goethe seine Überzeugung zu begründen und mit Beispielen zu belegen sucht. G. VIII. 95: „Wir verhandelten... besonders über die $U n v o l 1 k$ om m e h e it und Un$\mathrm{zulänglichkeit} \mathrm{der} \mathrm{Sprache,} \mathrm{wodurch} \mathrm{Irrtümer}$ und falsche Anschauungen verbreitet würden, die später so leicht nicht wieder zu überwinden wären. „Die Sache ist ganz einfach diese, sagte Goethe, alle Sprachen sind aus naheliegenden, menschlichen Bedürfnissen, menschlichen Beschäftigungen und allgemein menschlichen Empfindungen und Anschauungen entstanden. Wenn nun ein höherer Mensch iiber das geheime Wirken und Walten der Natur eine Ahnung und Einsicht gewinnt, so reicht seine ihm überlieferte Sprache nicht hin, um solches von menschlichen Dingen durchaus Fern. liegendes auszudrücken. Es müsste ihm die Sprache der Geister zu Gebote stehen, um seinen eigenthümlichen Wahrnehmungen zu genügen. Da dies aber nicht ist, so muss er bei seiner An. schauung ungewöhnlicher Naturverhältnisse stets nach menschlichen Ausdriicken greifen, wobei er dann fast überall zu kurz kommt, seinen Gegenstand herabzieht oder wohl gar verletzt und vernichtet. [Eckermann meint, die Franzosen wären dabei noch übler dran als die Deutschen, weil sie einen Ausdruck eines höheren Naturverhältnisses durch einen aus der Technik genommenen grob wiedergeben.] Wie sehr Sie recht haben, fiel Goethe ein, ist mir noch neulich bei dem Streite zwischen Cuvier und Geoffroy de St. Hilaire vorgekommen. Geoffroy d. St. H. ist ein Mensch, der wirklich in das geistige Walten und Schaffen der Natur eine hohe Einsicht hat, allein seine französische 
Sprache, insofern er sich herkömmlicher Ausdrücke zu bedienen gezwungen ist, lä $\beta$ ihn $d u r c h a u s i m S t i c h$. Und zwar nicht bloss bei geheimnissvoll-geistigen, sondern auch bei ganz sichtbaren, rein körperlichen Gegenständen und Verhältnissen. Will er die einzelnen Theile eines organischen Wesens ausdriicken, so hat er dafür kein anderes Wort als $M a$ terialien, wodurch dann z. B. die Knochen, welche als gleichartige Theile das organische Ganze eines Armes bilden, mit den Steinen, Balken, Brettern, woraus man ein Haus macht, auf eine Stufe des Ausdrucks kommen. - Ebenso ungehörig, fuhr Goethe fort, gebrauchen die Franzosen, wenn sie von Erzeugnissen der Natur reden, den Ausdruck Composition. Ich kann aber wohl die einzelnen Theile einer stückweise gemachten Maschine zusammensetzen und bei einem solchen Gegenstande von Composition reden, aber nicht, wenn ich die einzelnen lebendig sich bildenden und von einer gemeinsamen Seele durchdrungenen Theile eines organischen Ganzen im Sinne habe... Es ist ein ganz niederträchtiges Wort, ... das wir den Franzosen zu danken haben und das wir so bald wie möglich wieder los zu werden suchen sollen. Wie kann man sagen: Mozart habe seinen Don Fuan componirt! Composition - als ob es ein Stück Kuchen oder Biscuit wäre, das man aus Eiern, Mehl und Zucker zusammenrührt. Eine geistige Schöpłung ist es, das Einzelne wie das Ganze aus einem Geiste und Guss und von dem Hauche eines Lebens durchdrungen." (20. VI. 1831.)

Wir werden bei der Behandlung von Goethes Stellung zum Fremdwort auf dic Stelle zurückkommen müssen. Sovicl aber sei hicr schon angemerkt, daß Gocthe dic Worte Material und Komposition hier keineswegs als Fremdwörter verwirft, wic Lyon ${ }^{1}$ ) annimmt, sondern, wic klar aus dem Zusammenhang hervorgeht, nur wegen ihrer Unzulänglichkeit für den wissenschaftlichen Sprachgebrauch. Ubrigens gebraucht Gocthe dic in der Hitze des Gesprächs so hart verdammten Worte

1) I.yon, Otto: Goethes Gesprilche. \%. f. d. U. V (1891), S. 588. 
Komposition und komponieren selbst in dem getadelten Sinn, wie auch Harnack ${ }^{1}$ ) gefunden hat, recht häufig (vgl. z. B. G. IV. 305; VIII. 10; Heinemann X. 350).

Wir erkennen jetzt schon, von welcher Bedeutung die allgemeine Untersuchung über Goethes Stellung zu Wort und Begriff ist. Seine Urteile über die Muttersprache, über fremde Sprachen, über Sprachbereicherung, Sprachreinigung und Übersetzung werden zu einem guten Teil nur verständlich, wenn wir sie unter dem Gesichtswinkel betrachten, den wir hier gewinnen. Verzeichnen wir nunmehr noch unsere letzten Belege, um dann die Schlußfolgerungen ziehen zu können. Bis an die Schwelle des Todes beschäftigte Goethe die Frage, besonders angeregt durch den auch im Gespräch mit Eckermann gestreiften wissenschaftlichen Streit zwischen Cuvier und St. Hilaire, den Goethe nur auf die ungenügenden Sprachmittel zurückführen möchte.

II. 7. 206. I7: Leider bietet ihm [St. Hilaire] seine Sprache auf manchen Puncten nicht den richtigen Ausdruck, und da sein Gegner sich im gleichen Falle befindet, so wird dadurch der Streit unklar und verworren. Wir wollen suchen, diesen Umstand bescheidentlich aufzuklären. Denn wir möchten diese Gelegenheit nicht versäumen bemerklich $z u$ machen, wie ein bedenklicher Wortgebrauch bei französischen Vorträgen, ja bei Streitigkeiten vortrefflicher Männer zu bedeutenden Irrungen Veranlassung gibt. Man glaubt in reiner Prosa zu reden und man spricht schon tropisch; den Tropen wendet einer anders an als der andere, führt ihn in verwandtem Sinne weiter und so wird der Streit unendlich und das Räthsel unauflöslich. ${ }^{2}$ ) (Zur Morphol. II. März 1832.) Im inneren Zusammenhang mit den letzten Belegen steht offenbar auch die Briefstelle: Sternberg 242: Das Wunderbarste ist dabei [den geologischen

1) Harnack, O.: Goethe in der Epoche seiner Vollendung. 2. Auf. Leipzig 1901. S. 168.

2) Die angeschlossenen Analysen von matériaux, composition, em. branchement, plan stellen wir mit anderen im Anhang zusammen. 
Studien], dass das beste unserer Überzeugungen nicht in Worte zu fassen ist; die Sprache ist nicht auf alles eingerichtet, und wir wissen oft nicht recht, was wir endlich sehen, schauen, denken, erinnern, phantasiren oder glauben. Das ist was mich manchmal betrübt, besonders da in diesem Fache mir gegenwärtig kein Wechselgespräch zu Hülfe kommt. (15. III. I832.)

Zum Schluß noch zehn meist aphoristische Äußerungen aus den nachgelassenen Papieren.

II. I I. I53. 20 (auch G. G. XXI. Nr. 157) Abbildungen, Wortbeschreibung, Maß, Zahl und Zeichen stellen noch immer kein Phänomen dar. (Zur Naturwiss.) II. II. 138. $22 \mathrm{Nicht}$ die $S$ prache an und für sich ist $r i c h t i g$, tüchtig, zierlich, sondern der Geist ist es, der sich darin verkörpert. (Zur Naturwiss.) II. 9. 257. I 3 Was ist die ganze Heberei der Gebirge zuletzt, als ein mechanisches Mittel, ohne dem Verstand irgend eine Möglichkeit, der Einbildungskraft irgend eine Thunlichkeit zu verleihen. Es sind blo $\beta$ Worte, schlechte Worte, die weder Begriff noch Bild geben. (Geol. Probleme.) II. II. 97. I6 (G. G. XXI. I287) Der Sprache liegt zwar die Verstandes- und Vermunftähigkeit des Menschen zum Grunde, aber sie setzt bei dem, der sich ihrer bedient, nicht eben reinen Verstand, ausgebildete Vernunft, redlichen Willen voraus. Sie ist ein Werkzeug, zweckmäßig und willkürlich zu gebrauchen; man kann sie eben so gut zu einer spitzfindig-verwirrenden Dialektik wie zu einer verworren-verdüsternden Mystik verwenden; man mißbraucht sie bequem zu hohlen und nichtigen, prosaischen und poetischen Phrasen, ja man versucht prosodisch untadelhafte doch nonsensicalische Verse zu machen. (Mathem. 1826.)

II. 11. 122. 4 (G. G. XXI. 720) Was ich recht weiß, wei $\beta$ ich nur mir selbst; ein a usgesprochenes Wort för. dert selten; es erregt meistens Widerspruch. Stocken und Stillstehen. (Zur Naturwiss.)

11. I1. 136. 4 Man weiß eigentlich das, was man wei $\beta$, nur fiir sich selbst. Spreche ich mit einem andern, von dem ich was 
$z u$ wissen glaube, unmittelbar glaubt er's besser zu wissen und ich muß mit meinem Wissen immer wieder in mich selbst zurückkehren. (Zur Naturwiss.) Hempel I9. I30 (G. G. XXI. Nr. 887) Es hört doch jeder nur, was er versteht.

Hempel 19. I 29 Das a usgesprochene Wort ist sogleich todt, wenn es nicht durch ein folgendes, dem Hörer gemäßes am Leben erhalten wird.

G. G. XXI. Nr. 9 Fedes ausgesprochene Wort erregt den Gegensinn (I809).

Hempel I9. IO2 (G. G. XXI Nr. 674-675). Wir haben das unabweichliche, täglich zu erneuernde, grundernstliche Bestreben, das Wort mit dem Empfundenen, Gedachten, Erfahrenen, Fmaginierten, Vernünftigen möglichst unmittelbar zusammentreffend zu erfassen. Feder prüfe sich, und er wird finden, daß dies viel schwerer sei als man denken möchte; denn leider sind dem Menschen die Worte gewöhnlich Surrogate, er denkt und weiß es meistenteils besser als er sich ausspricht. ${ }^{1}$ )

G. G. XXI. Nr. $983 K$ e in Wort steht still, sondern es rückt immer durch den Gebrauch von seinem anfänglichen Platz eher hinab als hinauf, eher ins Schlechtere als ins Bessere, ins Engere als ins Weitere und an der Wandelbarkeit des Worts läßt sich die Wandelbarkeit der Begriffe erkennen.

An die vorletzte Äußerung knüpft Bouke die Bemerkung: „Goethe macht es sich zur Pflicht, Wort und Bedeutung sorgfältig gegeneinander abzuwägen, und stellt selbst an sich hinsichtlich des sprachlichen Ausdrucks die höchsten Forderungen." Ich glaube, wir können auf Grund unseres Materials ein eingehenderes Urteil fällen, ohne dabei, um im derben Tone Vischers zu reden, überall "nach Philosophie zu schnüffeln". Goethe, der Dichter und Goethe, der Gelehrte sind dabei auseinanderzuhalten. Jeder ernst arbeitende Dichter wird sich eifrig bemühen, seinen Gedanken eine möglichst schöne und

I) Vgl. Bouke, E. A.: Wort und Bedeutung in Goethes Sprache. Berlin I90I (Literarhistorische Forschungen. Heft 20). S. I; Paul, Prinzipien der Sprachgeschichte 66-84. 
ansprechende Form zu geben. Er wird, je höher der Flug ist, den ihn die Phantasie führt, je erhabener die Gedanken sind, die ihn wie Offenbarungen überkommen, desto höhere Forderungen an die Sprache stellen müssen, um ihr die Ausdrucksformen abzugewinnen. So auch Goethe. Er rang mit der Sprache, und gar oft entsprachen die Worte, die sie ihm liefern konnte, nicht den Anforderungen des Dichters und brachten das nicht oder nur unvollkommen zum Ausdruck, was im Geiste des Gewaltigen webte und sich offenbaren, kundtun wollte. Manches harte Wort gegen die Sprache, naturgemäß auch die Muttersprache ist da gefallen, auf das wir noch zurückkommen werden. Die Unzufriedenheit mit der Sprache führte Goethe bis zur Ungerechtigkeit gegen sie. Er gesteht, daß er nur widerwillig zur schriftlichen Fixierung dichterischer Gedanken schritt, eben weil die Sprache nur eine dürftige Form für den erhabnen Inhalt $z$ u bieten vermochte. G. VII. 244. Ich hatte sie [die Balladen] alle schon seit vielen Fahren im Kopłe, sie beschäftigten meinen Geist als anmutige Bilder, als schöne Träume, die kamen und gingen und womit die Phantasie mich spielend beglückte. Ich entschloss mich ungern dazu, diesen mir seit so lange befreundeten, glänzenden Erscheinungen eine Lebewohl zu sagen, indem ich ihnen durch das ung $e$ n $\mathrm{u}$ e nde dürftige Wort einen Körper verlieh. Als sie auf dem Papier standen, betrachtete ich sie mit einem Gemisch von Weh. muth; es war mir, als sollte ich mich auf immer von einein geliebten Freunde trennen. (14. III. I830 mit Soret.) ${ }^{1}$ )

Ähnlich spricht sich Gocthe schon sechs Jahre früher bricflich aus. IV. 38. 187. I: Der eindringende Antheil an dem

1) Ftwas abweichend in der neuen Ausgabe bei Burkhardt 96, 10: Goethe erklärt Soret gegenüber am 8. März 1830, daß er nur auf Drängen Schillers seine Balladen, die ihn beschäftigten "wie schöne Träume und umschuvebten mil glinzenden Bildern" zu Papier gebracht habe. "Daher ergriff er mit Widerwillen die Feder und sagte diesen schönen Phantasien 1.cbewohl, um sic in dürftige Worte zu kleiden, mit cinem Gefühle des Bedauerns, wie man von cinem Ireunde scheidet." 
Paria $\left.^{1}\right)$ freut mich sehr; ich bewahre diese höchst bedeutende Fabel als einen stillen Schatz vielleicht vierzig Fahre und konnte mich jetat erst entschließen, ihn von meinem Innern durch Worte loszulösen, wo er mir die eigentliche reine Gestaltung zu ver. lieren scheint. Wird das Gebildete jedoch in einem treuen energischen Geiste reproducirt, so gelangt es wieder zu seinem ur. sprünglichem Rechte. (5. VII. I824 an Reinhard.)

Weit häufiger bringt Goethe als Mann der Wissenschaft seine Überzeugung von der Unzulänglichkeit der Sprache zum Ausdruck. Auch das versteht sich ohne Mühe. Seine naturwissenschaftlichen Arbeiten bewegten sich teils auf neuen, kaum beschrittenen Pfaden, teils im Gegensatz zu den herrschenden Anschauungen. Sein Hauptwerk, die Farbenlehre, vertrat im Gegensatz zu Newton und seiner Schule eine neue Auffassung; die Morphologie sollte nach seiner Absicht eine neue Wissenschaft werden; die geologischen, mineralogischen und meteorologischen Arbeiten vertraten vielfach Gedanken, die von denen der zünftigen Wissenschaft abwichen. Goethe war namentlich hinsichtlich seiner Farbentheorie von der Richtigkeit seiner Erkenntnisse felsenfest überzeugt und konnte sich nur schwer mit dem geringen Beifall und der Abweisung durch die Fachgelehrten abfinden. Immer wieder in neuer Form stellte er seine Gedanken dar, immer wieder andere Ausdrucksweisen suchte er für seine wissenschaftlichen Begriffe. Ist es verwunderlich, daß er schließlich an der Sprache verzweifelte, daß er ihr die Schuld an seinen Mißerfolgen zuschob, daß er sie für unfähig erklärte, neue Begriffe in eine adäquate Form zu kleiden? Aus allen ablehnenden Kritiken mußte er herauslesen, daß man ihn auf seiten der Gegner nicht verstand, da $B$ man den Worten die landläufige Bedeutung unterlegte, nicht verstehen konnte oder wollte, daß etwas anderes zum Ausdruck gebracht werden sollte. Bis zur Verbitterung gegen die Sprache, bis zum Hasse

1) Paria (Des Paria Gebet. Legende. Dank des Paria) 1823. 
gegen einzelne Worte wurde der auf allen Seiten mißverstandene Forscher geführt. Dieselbe Sprache, die dem Dichter ihre innersten Tiefen öffnete, die in seiner machtvollen Hand wie ein volltönendes Saitenspiel in allen Tonarten rauschend erklang, die er als Dichter, wie wir sehen werden, mit Ausdrücken des höchsten Lobes preist, um deren Besitz er sich glücklich schätzt, dieselbe Sprache ist dem wissenschaftlich Arbeitenden ein spröder Stoff, ein ungenügendes, dürftiges Werkzeug, das sich seiner Hand nicht fügt, das ihn um die Früchte der Anerkennung bringt, das Schuld trägt an dem Nicht- oder Falschverstandenwerden von seiten der Gelehrtenwelt seiner Zeit, deren Beifall der nichtzünftige Forscher so gern gesehen, der ihn so stolz gemacht hätte. Und von seiner eignen Erfahrung schloß er weiter. Der die ganze gelehrte Welt in Bewegung haltende und vom Alten von Weimar auf das aufmerksamste verfolgte Streit $z$ wischen St. Hilaire und Cuvier über die Organisation der Pflanzen war ihm, wie wir oben sahen, auch nur ein Kampf um Worte. Die beiden Gelehrten drücken dieselben Begriffe verschieden aus und können deshalb nicht zusammenkommen. Schon I8I7 vertritt er dieselbe Anschauung. IV. 28. 261. 20: In früheren Zeiten suchte ich nur an Freunden die zustimmende Seite, da sich denn im Laufe des Umgangs die abstimmende oft von selbst zeigte; jetzt such' ich die Differenzen zuerst, damit die Einig. keit daraus hervorgehe. Es ist doch zuletzt alles eine Artvon Sprache, wodurch wir uns erst mit der Natur, und auf gleiche Weise mit Freunden unterhalten möchten. Diese haben nun einen wenig abweichenden Dialect und da giebt es wohl einmal ein $M$ issverständ $n i s$, das aber wohl zu lösen ist, wenn man sich eines gemeinsamen Idiotikons befleissigt. (24. IX. I8I7 an Schultz.)

Abweichungen von Kiesers physiologischen Ansichten werden cbenfalls auf die Verschiedenheit des sprachlichen Ausdrucks von Gocthe zurückgeführt: IV. 23. 100. Woraus [aus der Beschăfigung mit des Adressaten Aphorismen aus der Phy. 
siologie der Pflanzen I808] ich mir umsomehr Belehrung und Aufmunterung erwarten darf, als Ihre Denkweise in den Grundbegriffen mit der meinigen zusammentrifft und eine Differenz in der Anwendung, vielleicht auch nur in $S$ prache und Terminologie, wohl auszugleichen seyn möchte. X. I8I2 an D. G. Kieser.) So mit Bezug auf Newtons Farbenlehre: IV. 42. 377. 29: Füngere Männer merken und sehen es [das Wahre in Goethes Lehre] zwar, aber sie dürfen und können sich vom Überlieferten nicht losmachen, weil sie ja keine Sprache hätten sich auszudrücken und [so] merken sie wieder, dass man mit falschen Worten das Wahre nicht sagen kann. (21. VI. I827 an Zelter.)

Ebenso beurteilt er sein Verhältnis zu Candolle: Soret 40: An wenig Stellen [von Candolles Organographie végétale] erscheint ein Widerstreit [mit Goethes Ansichten], welcher keiner Auflösung bedarf, es sind nur zwei verschiedene Sprachen, und man versteht sich wohl.

(2I. VI. I 828.)

Im gleichen Jahre setzt er sich ähnlich mit Kechts Theorie über den Weinstock auseinander.

II. 7. 133. 13: Hier tritt nun gerade der Fall ein, den ich gern ergreife, um die Ansicht des Weinstocks noch weiter theoretisch auf das Naturgesetz zurückzuführen, wobei sich erweisen wird, dass die geringe Differenz zwischen seiner und unsrer Denkweise durch eine blosse Änderung des Wortes in der Nomenclatur zu heben ist. (Zur Morphol. II.)

Endlich wird Cousins Philosophie abgelehnt mit der Begründung: wenn man sich seine neuen Worte in die landläufige Sprache überträgt, so stößt man alsbald auf längst bekanntes. (3. II. I830 zu Soret. Burkhardt. 76. 7.)

Auf diesem Wege findet auch die auf den ersten Blick bei einem Goethe merkwürdige, ja unverständliche Abneigung gegen den bildlichen, figürlichen Ausdruck, den Tropus, ihre Erklärung. Der Dichter entzückt uns durch den herrlichsten und reichsten Bilderschmuck seiner Rede; in seiner poetischen 
Sprache umschreibt er fast alles, was er sagen will, mit den prächtigsten Bildern und schönsten Gleichnissen ${ }^{\mathbb{1}}$ ), er nennt sich selbst in einem Briefe an Frau v. Stein vom 8. März I78I den „ewigen Gleichnismacher".") Dem Gelehrten sind Bilder der Rede gefährlich, weil sie den reinen Begriff nicht treffen und den Hörenden auf falsche Bahnen leiten. Sie sind ihm ein Zeichen von Geistesschwäche; nur der greift zu ihnen, der sich nicht klar ist über seine Gedanken oder verschleiern möchte. I. 40. 215. 7: Wer Bilder braucht, um sich einen Begriff zu verschaffen, zeigt eine Schwäche des Geistes an; denn selbst einem Gedanken, den man auf diese Weise klar machen könnte, würde es doch, bis auf einen gewissen Grad, an Abstraction und Feinheit mangeln. Die Abstraction ist weit über alle Bilder, sie hat eine geometrische Genauigkeit, und man kann sie nicht anders als mit ihren bestimmten Zeichen ausdrücken. (1796 Übersetzung von Md. d. Staëls Essai sur les fictions, dessen Gedankengang Goethe ausdrücklich beitritt.)

II. 3. 278. I : Er [Cartesius] findet keine geistigen, lebendigen Symbole, um sich und Andern schwer auszusprechende Erscheinungen anzunähern. Er bedient sich um das Unfassliche, ja das Unbegreifliche zu erklären, der crudesten sinnlichen Gleichnisse. So sind seine Materien, seine Wirbel, seine Schranben, Haken und Zacken $n$ ied erzi ehend fürden Geist. (Histor. Farbenl. V. I8Io.)

Der Kanzler Müller bezeugt, G. V. II8: „Goethe f i e 1 gegen a 11 e Vergleichungen heftig a us; denn man macht sie nur aus Bequemlichkeit, um sich ein selbständiges Urteil au ersparen." (9. XII. I824.)

Über das Vorrecht der poetischen Sprache, bildlich sich aus. zudrücken, und die Grenzen, in welchen es auch der wissen. schaftlichen crlaubt sein soll, läßt sich Gocthe cbenfalls in der Farbenlehre aus: II. 3. 269. II: Dic Poesie hat, in

I) Grimm, H.: Vorlesungen über Goethe. I, 248.

2) Itehn, V.: Gedanken über Goethe. Berlin 1887. S. 311 . 
Absicht auf Gleichnissreden und uneigentlichen Ausdruck sehr grosse Vortheile vor allen übrigen Sprachweisen; denn sie kann sich eines jeden Bildes, eines jeden Verhältnisses nach ihrer Art und Bequemlichkeit bedienen; sie vergleicht Geistiges mit Körperlichem, und umgekehrt, den Gedanken mit dem Blitz, den Blitz mit dem Gedanken... Die Philosophie auf ihren höchsten Punkten bedarf auch uneigentlicher Ausdrücke und Gleichnissreden ... Nur leiden die philosophischen Schulen ... meistentheils daran, dass sie nach Art und Weise ihrer Stifter und Hauptlehrer, meist nur einseitige Symbole brauchen, um das Ganze auszudrücken und zu beherrschen, und besonders die einen durchaus das Körperliche durch geistige Symbole, die andern das Geistige durch körperliche Symbole bezeichnen wollen. Auf diese Weise werden die Gegenstände niemals durchdrungen; es entsteht vielmehr eine Entzweiung in Dem, was vorgestellt und bezeichnet werden soll, und also auch eine $D$ iscrepanz in denen, die davon handeln, woraus alsbald ein Widerwille aut beiden Seiten entspringt und ein Parteisinn sich befestigt. (Histor. Farbenl. V. 1810.)

Während Goethe noch 1819 nach einem Zeugnis des Kanzlers Müller das Überspringen von einem Bild ins andere tadelt, und die „,Keuschheit der Tropen" fordert, hat er sich in späteren Jahren offenbar unter Riemers Einfluß zu einer milderen Auffassung bekehrt.

III. 4. 356. 5: Nachher bis Abends über Sprache, besonders originelle Proprietät. Festhalten des Gegenstandes durchs Wort. Vermeidung abgeleiteter Tropen. Flucht vor Phrasen. (25. XII. I812.)

G. X. 86: „Er [Goethe] kritisierte meine Rede und bemerkte, ich habe mich vor zu ausgedehntem Gebrauche der Tropen zu hüten, wohin mein Stil neige. Es ist unrichtig zu sagen: ein abgeschlossenes Leben fordert. Ein abgeschlossenes Leben ist kein Leben mehr, es ist todt; jenes kann nichts fordern. Die Keuschheit der Tropen, ihre Proprietät ist Hauptmaxime des Stils im westlichen Europa. Ausserdem 
fällt man ins Bodenlose, Verwirrte, Absurde. Bloß durch strenge Angeschlossenheit der Begriffe am Bilde, wodurch unmittelbare Anschaulichkeit erlangt wird, durch den eigensten, keuschesten Gebrauch der Tropen, habe er, Goethe, sich die Jugendlichkeit des Stils bewahrt." (I9. IV. I8I9 mit Müller.)

Dagegen G. IV. 282: „Nach Tische sprachen Riemer und Goethe über die Tropen und deren Durchführung. Die neuern Pedanten verlangen letztere bis zum äussersten Punkt; Goethe springt gerne $a b$, wie ja auch die Phantasie es thut, häuft daran mehrere, um eine durch die andere zu erklären. Riemer erläuterte an Beispielen aus dem gemeinen Sprachgebrauch, wie man ohne Vermischung der Tropen gar nicht fortkommen könne z. B. etwas in (so) Werk setzen." (29. IX. I823 mit Müller.) ${ }^{1}$ )

Der stete Kampf mit der Sprache, die Einsicht in das Verhältnis zwischen Wort und Begriff führen Goethe zu den Anfängen einer Sprachsymbolik, von der zwei Äußerungen aus dem Nachlaß Kunde geben:

G. G. XXI. Nr. II13: Die Symbolik verwandelt die Erscheinung in Idee, die Idee in ein Bild, und so dass die Idee im Bild immer unendlich wirksam und unerreichbar bleibt und, selbst in allen Sprachen ausgesprochen, doch un a us prech. lich bliebe (c. I807).

II. I I. 167-169: Durch Worte sprechen wir weder die Gegenstände noch uns selbst völlig aus. - Durch die Sprache entsteht gleichsam eine neue Welt, die aus Nothwendigem und Zufäligem besteht. Verba valent sicut nummi. Aber es ist ein

1) Es darf in diesem Zusammenhang hier wohl auch auf das von Goethe selbst in den Annalen verzeichnete Urteil des Phrenologen Gall hingewiesen werden. I. 35. 204. 15. Er (Gall) . . behauptete, meinem Stirnbau zufolge: ich könne den Mund nicht aufthun, ohne cinen Tropus auzzusprechen; . . Mein ganzes Wesen betrachtet, versicherte er ganz ernstlich, dass ich eigentlich zum Volksredner geboren sei. (Tag- u. Jahreshefte 1805.) 
Unterschied unter dem Gelde. Es gibt goldne, silberne, kupferne Münzen und auch Papiergeld. In dem ersteren ist mehr oder weniger Realität in dem letzten nur Convention. Im gemeinen Leben kommen wir mit der Sprache nothdürftig fort, weil wir nur oberflächliche Verhältnisse bezeichnen. Sobald von tiefen Verhältnissen die Rede ist, tritt sogleich eine andre Sprache ein, die poetische. Indem wir von innern Verhältnissen der Natur sprechen wollen, bedürfen wir gar mancherlei Bezeichnungsweisen. Ich erwähne hier vier derselben: $S$ y mbole

I. die mit dem Gegenstand physisch-real identisch sind, wie wir die magnetischen Erscheinungen erst aus. gesprochen und dann als Terminologie bei den Verwandten gebraucht haben.

2. die mit dem Gegenstand ästhe $i$ s $c h \cdot i d$ e a l identisch sind. Hierher gehören alle guten Gleichnisse, wobei man sich nur vor dem Witz zu hüten hat, welcher nicht das Ver. wandte aufsucht, sondern das Unverwandte scheinbar annähert.

3. die einen $B$ ezug ausdrücken, der nicht ganz nothwendig, vielmehr einiger Willkür unterworfen ist; aber doch auf eine innere Verwandtschaft der Erscheinungen hindeutet. Ich möchte sie mnemonisch im höheren Sinne nennen, da die gemeine Mnemonik sich völlig willkürlicher Zeichen bedient.

4. Die vonder $M$ athe matikhergenommen sind, und weil ihnen gleichfalls Anschauungen zum Grunde liegen, im höchsten Sinne identisch mit den Erscheinungen werden können.

Von den drei ersten Symbolen haben wir Beispiele in der Sprache:

I. Wenn z. B. das Wort ein Tönendes ausdrückt, wie Knall.

2. Wenn durch den Ton eine übereinstimmende Empfindung ausgedrückt wird, wie es bei Flexionen vielmals der Fall ist: Knallen. 
3. Wenn Worte, die sich auf einander beziehen, gleichen Klang haben, wie mein, dein, sein, da sie auch zufälig nicht ähnlich sein könnten wie ich und $d u$; da hingegen moi und toi auf gedachte Weise verwandt ist.

Von der vierten Art, welche bloss auf Anschauungen ruht, kann in der Sprache nichts vorkommen. (Zur Naturwiss.)

Das sind aphoristische Gedanken, die den Anspruch auf ein System nicht machen, aber Goethes eindringende Beschäftigung mit derartigen sprachphilosophischen Problemen verraten.

Wenn ich recht sehe, sind die Anfänge von Goethes Überzeugung von der Unzulänglichkeit der Sprache auf die Erkenntnis zurückzuführen, daß wissenschaftliche Terminologien sehr viel Schaden anrichten, wenn es gilt, ntuen Ideen zur Anerkennung $z u$ helfen. Schon aus früheren Jahren finden sich Äußerungen, die in späterer Zeit an Schärfe zunehmen. Der alte Goethe bringt den festgeprägten Kunstwörtern, die sich jeder andersartigen Verwendung spröde gegenüber verhalten, die nur Schall ohne bestimmten Inhalt sind, einen ehrlichen $\mathrm{Ha}$ B entgegen, der mit seiner von Jugend auf unverhohlen geäußerten Abneigung gegen hohles Phrasentum und spitzfindige Dialektik Hand in Hand geht. Schon 1774 wird Lavater wegen seiner ablehnenden Haltung der Terminologie gegenüber gerühmt.

IV. 2. 175. 26: Aber weil seine [Lavaters] Empfindungen ihm die wahrsten, so sehr verkannten Verhälnisse der Natur in seine Seele prägen, er also jede Terminologie wegschme is $s t$, aus vollem Herzen spricht und handelt und seine Zuhörer in eine fremde Welt zu versetzen scheint... so kan er dem Vorwur/ eines Phantasten nicht entgehen [d. h. bei denen, die ihn nicht verstehen]. (4. VII. 1774 an Schönborn.) Im Werther, der ja im gleichen Jahre erscheint, lesen wir: 1. 19. 112.6: Der Fürst fïhlt in der Kunst und wïrde noch stärker fühlen, wenn or nicht durch das garstige wissenschaftliche Wesen und durch diegewöhnliche Terminologie eingeschränkt 


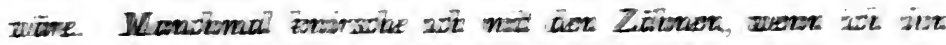

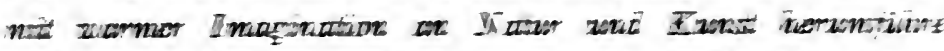

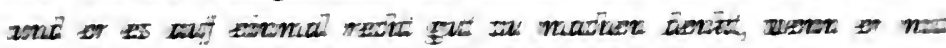
einen

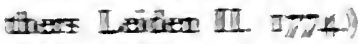

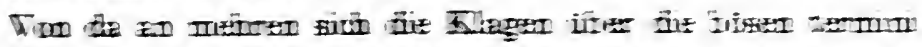

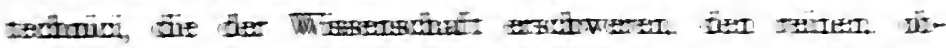

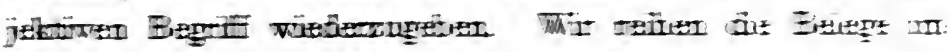

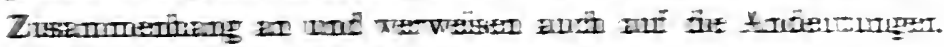

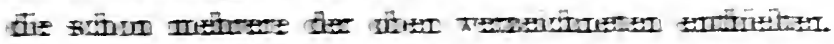

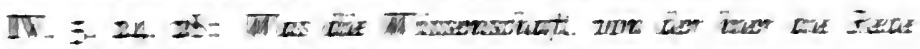

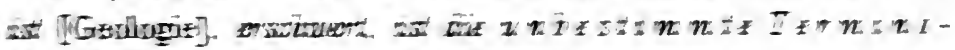

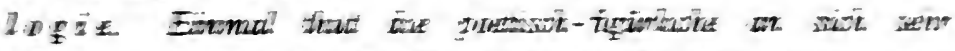

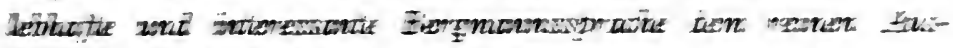

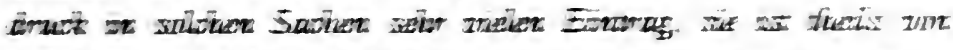

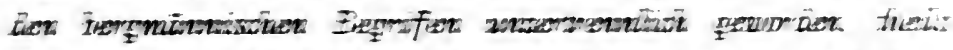

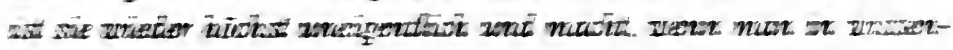

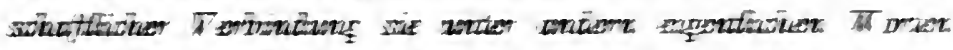


Lus Den

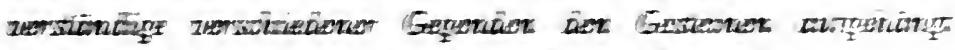

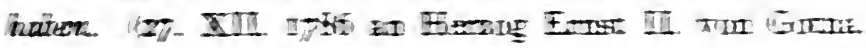

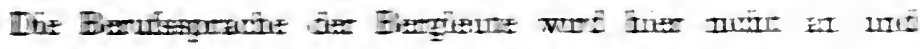

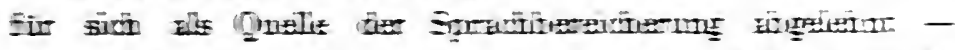



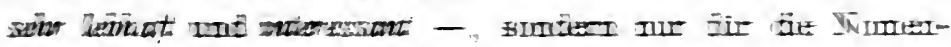



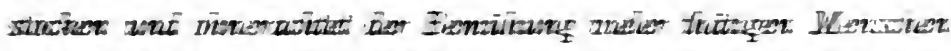

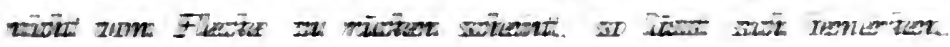



az

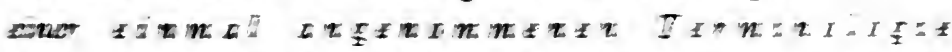



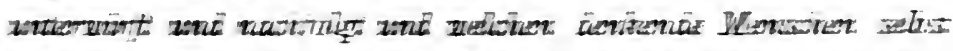

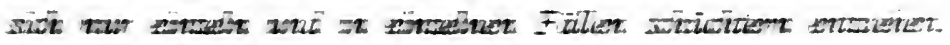
Zur Mugitui. II. 
IV. I6. 59. 8: Sehr merkwürdig war mir ein Blick in das Original von Browns medicinischen Elementen. Es sieht einem daraus ein ganz trefflicher Geist entgegen, der sich Worte, Ausdrücke, Wendungen schafft und sich deren mit bescheidener Consequenz bedient, um seine Überzeugung darzustellen. Man spürt nichts von dem terminologischen Schlen. dri a $n$ seiner Nachfolger. (19. III. I802 an Schiller.)

Bekannte Töne klingen an in einer längeren Auseinandersetzung aus dem Jahre I807:

II. I. 302. 14: Man bedenkt niernals genug, das eine Sprache eigentlich nur $s$ y bolis $c h$, nur bildlich sei und die Gegen. stände niemals unmittelbar, sondern nur im Widerscheine ausdrücke. Dieses ist besonders der Fall, wenn von Wesen die Rede ist, welche an die Erfahrung nur herantreten und die man mehr Thätigkeiten als Gegenstände nennen kann, dergleichen im Reiche der Naturlehre immerfort in Bewegung sind. Sie lassen sich nicht festhalten und doch soll man von ihnen reden; man sucht daher alle Arten von Formeln auf, um ihnen wenig. stens gleichnisweise beizukommen... Fedoch wie schwer ist es, das Zeichen nicht an die Stelle der Sache zu setzen, das Wesen immer lebendig vor sich zu haben und es nicht durch das Wort zu töten. Dabei sind wir in den neuern Zeiten in eine noch grössere Gefahr gerathen, indem wir aus allem Erkenn- und Wissbaren Ausdrücke und Terminologien herübergenommen haben, um unsre Anschauungen der einfachen Natur auszudrücken ... Wir kennen das Bedürfniss recht gut, wodurch eine solche Sprache entstanden ist und sich ausbreitet; wir wissen auch, daß sie sich in einem gewissen Sinne unentbehrlich macht: allein nur ein mässiger anspruchloser Gebrauch mit Überseugung und Bewusstsein kann Vortheil bringen. Am wünschenswerthesten wäre jedoch, dass man die Sprache, wodurch man die Einzelheiten eines gewissen Kreises bezeichnen will, aus dem Kreise selbst nähme, die einfache Erscheinung als Grundformel behandelte und die mannigfaltigen von daher ableitete und entwickelte. Die Nothwendigkeit und 
Schicklichkeit einer Zeichensprache, wo das Grundzeichen die Erscheinung selbst ausdrückt, hat man recht gut gefühlt indem man die Formel der Polarität dem Magneten abgeborgt auf Elektricität usw. hinübergeführt hat ... So haben wir seit langer Zeit den Ausdruck der Polarität in die Farbenlehre einzuführen gewïnscht ... Vielleicht finden wir künttig Raum, durch eine solche Behandlung und Symbolik, welche ihr Anschauen jederzeit mit sich führen müsste die elementaren Naturphänomene nach unsrer Weise an einander zu knüpten und dadurch dasjenige deutlicher zu machen, was hier nur im Allgemeinen und vielleicht nicht bestimmt genug ausgesprochen. (Did. Farbenl. § 75 I-757. I807.) Die ausführlichere Behandlung der Fragen, die hier in Aussicht gestellt ist, vermissen wir; vielleicht dürfen die oben gebrachten Leitsätze über "Symbolik" als Ansätze dazu gelten. Die weiteren Belege lenken wieder in das alte Geleise ein.

I. 20. 55. II: Man sollte dergleichen [chemische Beispiele], versetzte der Hauptmann, nicht mit Worten abthun ... Fetzt müsste ich Sie mit schrecklichen Kunstworten hinhalten, die Ihnen doch keine Vorstellung gäben... Ich leugne nicht, sagte Eduard, dass die seltsamen Kunstwörter demjenigen, der nicht durch sinnliches Anschauen, durch Begriffe mit ihnen versöhnt ist beschwerlich, ja lächerlich werden müssen. (Wahlverwandtsch. IV. I809.)

II. 2. 288: 8: Man höre nur, wie seltsan sich Neroton benimmt, um dem Phänomen seine Terminologie anzupassen. (Polem. Farbenl. 664. 1810.)

IV. 24. 262. 17: freylich wäre zu rë̈nschen, dass das so glücklich angefangene Präparaten-Kabinett immer fleissig fortgesetzt wïrde, weil dadurch allein eine bleibende sinnliche Anschaung an die Stelle einer oft abstrusen Terminologie gesetzt werden kann. (IO. V. $18 \mathrm{I} 4$ an C. G. v. Voigt.)

IV. 28. 259. 19: Aus vieljähriger Erfahrung ... weiss ich, dass diese Lehre [Farbenlehre], wie ich sie vortrage, unmittelbar in's Leben übergeht ... Ist einer Ihrer jungen Männer von

Rausch, Goethe u. die deutsche Sprache. 
herkömmlichen Vorurtheilen frey, hat man ihm die $R$ eden $s$. arte $n$, mit denen man sich seit hundert Fahren trägt, noch nicht eingelernt, so wird er sich sehr bald darein finden. (24. IX. I8I7 an P. E. v. Fellenberg.)

IV. 43. 77. 9: Den wohlmeinend-strebenden jüngeren Männern steht zweierlei entgegen [Goethes Farbenlehre sich anzuschließen]: die herkömmliche Terminologie, die sie wenig. stens theilweise fortbrauchen müssen, sogar wenn sie es auch schon besser verstehen, weil sie sich doch der Mitwelt verständlich machen und es mit der Zunft nicht ganz verderben möchten. (25. IX. I827 an Sulpiz Boisserée.)

G. VI. 269: Ohnehin bedeutet solch ein Parteiname [Plutonist - Neptunist] späterhin nichts mehr, löst sich in Rauch auf; die Leute wissen schon jetzt nicht mehr, was sie damit bezeichnen wollen. (6. III. I828 mit v. Müller.)

II. 6. 355. 7: Bei einer noch so ausgearbeiteten $N$ o m e n cla. $t$ ur haben wir zu denken, dass es nur eine Nomenclatur ist, cin Wort, irgend einer Erscheinung angepasstes, aufgeheftetes Silben-Merkmal sei, und also die Natur keineswegs vollkommen ausspreche, und deshalb nur als Behelf zu unserer Bequemlichkeit angesehen werden sollte. (Zur Morphol. I. I829.)

II. 6. 143. 17: Sie [die Freunde] antworteten [auf die Metamorphose der Pflanzen] alle mehr oder weniger in Bonnets Redensarten: denn seine Contemplation der Natur hatte, durch scheinbare Fasslichkeit, die Geister gewonnen und eine Sprache in Gang gebracht, in der man etzas zu sagen, sich unter. einander zu verstehen glaubte. Zu meiner Art sich auszudrücken, wollte sich niemand bequemen. Es ist die grösste Qual, nicht verstanden zu werden, wenn man nach grosser Bemühung und Anstrengung, sich endlich selbst und die Sache zu verstehen glaubt, es treibtzumWahnsinn, den Irrthum immer reiederholen zu hören. (Zur Morphol. I.)

Goethe ist ubrigens auch freimütig genug, einzugestehen, faß es ihm als Dichter besondere Schwicrigkeiten machte, sich auf ejne wissenschaftliche Terminologie einzuschwören: 
IV. 43. $25 \mathrm{I}$ 5: Der Botaniker, der diese Pflanze [eine vorher beschriebene Lilienart selbst beobachtet, wird über meine Beschreibung lächeln; ich habe mir die botanische Terminologie, so sehr ich sie bezundere, niemals zueignen können. (I8. I. I828 an Sternberg.) Eine ausführlichere Begründung dazu gibt er in den morphologischen Fragmenten, in denen das Material für uns besonders reichhaltig ist; mußte Goethe doch bei diesen Studien, mit denen er eine neue Wissenschaft begründen wollte, besonders hart mit den unzulänglichen Sprachmitteln zusammenstoßen, ihm die Kunstsprache der Wissenschaft besonders hinderlich in den Weg treten: II. 6. I 16. 5: Soll ich nun über jene Zustände mit Bewusstsein deutlich werden, so denke man mich als einen ge bor e n e $n$ D $i$ chter, der seine Worte, seine Ausdrücke unmittelbar an den jedes. maligen Gegenständen zu bilden trachtet, um ihnen einigermaßen genug zu thun. Ein solcher sollte nun eine fertige Termino. logie ins Gedächtnis aufnehmen [Linnés System], eine gewisse Anzahl Wörter und Beiwörter bereit haben, damit er, wenn ihm irgend eine Gestalt vorkäme, eine geschickte Auswahl treffend, sie zu charakteristischer Bezeichnung anzuwenden und zu ordnen wisse. Dergleichen Behandlung erschien mir immer, als eine Art von Mosaik, wo man einen fertigen Stift neben den andern setzt, um aus tausend Einzelheiten endlich den Schein eines Bildes hervorzubringen; und so war mir die Forderung in diesem Sinne gewissermassen widerlich. (Zur Morphol. I.)

Auch in der Farbenlehre führt er den Kampf gegen die Widersacher, namentlich die Newtonsche Schule, vielfach derart, daß er den Gegnern Gebrauch einer falschen Terminologie vorwirft, der sie zu falschen Erkenntnissen verführe.

II. 2. 217. I7: Man brauchte neben der verschiedenen Brechbarkeit auch noch den Ausdruck einer verschiedenen Zerstreuung, indem man das unbestimmte... Wort Zerstreuung hier in einem ganz eignen Sinne anwendete... und eine Lehredurch $R$ edensarten ret tete, die eigentlich nur aus Redensarten bestand. (Polem. Farbenl. 472.) - II. 2.226. I: Was hilft 
es aber! Ihm und seiner Schule sind Worte lieber als die Sache. (Polem. Farbenl. 500.)

II. 2. 229. 2: (er) möchte gar zu gern aus ihnen [den Farben] Weiß hervorbringen; welches ihm zwar in der Erfahrung nicht geräth, ob er gleich mit Worten immer versichert, das es möglich und thulich (so) sei. (Polem. Farbenl.. 508.)

II. 4. 476: Weil sie [die Theorie von der Brechung] eigentlich $n u r$ in Worten lebt, so war sie auch durch ein Wort zu heilen ... Man fasste daher das Wort Zerstreuung auf und setzte hinter diese Brechung und Brechbarkeit noch eine von ihr unabhängige Zerstreuung und Zerstreubarkeit, und dieses Flickwerk wurde in der wissenschaftlichen Welt... ohne Widerspruch aufgenommen. (Histor. Farbenl. VI. Paralip.)

Die Beibehaltung einer früher geschaffenen wissenschaftlichen Kunstsprache bei Erweiterung und Vertiefung der betr. Wissenschaft ist es nach Goethes Überzeugung, die die Verwirrung schafft. Den Verlauf skizziert er so: II. 10. 7. 2: Erfahrungswissenschaften. - Deren kleine und dunkle Anfänge. - Erste Terminologie. - Sinnlich-figürlich. - Beschränkt. - Erweiterung der Erfahrung. - Fortgebrauch der ersten Terminologie. - Erweiterung derselben. - Ablenkung derselben. - Verwirrung. - Immer wachsend. - Noth. wendigkeit einer neuen Terminologie. Die neue wird vorbereitet. - Durch Betrachtung der bisherigen. (Gesteinbildung 1812.) - Goethe lehnt, wie ja auch schon hier und da anklang, keineswegs Terminologie an sich ab oder verkennt ihre Notwendigkeit für die Wissenschaft. Insofern sie den neuen Errungenschaften der Wissensgebiete entsprechend geschaffen ist, läßt er sic sich gefallen. IV. 42. 95. I5: Verzeih diese abstrusen Ausdrücke [entelechische Monade]! Man hat sich aber von jeher in solche Regionen verloren, in solchen Sprecharten sich mitzutheilen versucht, da wo die $V$ ernunft nicht hinreichte und wo man doch die $U n$ vernunft nicht wollte walten lassen (I9. III. I827 an Zelter). (Vgl. auch S. 16 11.) 
Auch der Linnéschen versagt er seine Anerkennung nicht, wenn er sich auch, wie wir gesehen haben, als Dichter nur schwer mit ihr befreunden kann. II. 8.63. 16: So hat Linné die botanische Terminologie $m u s t e r h a f t$ ausgearbeitet. (Zur Morphol. III. I796.) Für seine Entdeckung des os intermaxillare arbeitet er sogar selbst. eine lateinische Terminologie aus und ändert in anderen morphologischen Schriften die bestehende nach seinen neuen Ergebnissen um und tut notgedrungen selbst das, wogegen er bei anderen eifert.

II. 8. 95. 20: Eine lateinische Terminologie, die ich mit Beihülfe des Herrn Hofrath Loder verfertigt habe ... wird . . zum Leitfaden dienen können. Es hatte solche viele Schwierigkeiten, wenn sie auf alle Theile passen sollte. (Zur Morphol. Zwischenknochen. 1784.) - II. 8. I59. 7: Durch die sonderbare Gestalt dieses Schädels, womit er von den bisher beschriebenen abweicht, sind wir genöthigt der festgesetzten Terminologie Gewalt anzuthun oder sie zu verändern. (Ebenda.)

II. 8. 265. 8: Nun ist zwar... die Terminologie der thierisichen Teile, soviel es sich wollte thun lassen, auf die Terminologie der menschlichen Teile reducirt worden und es möchte wohl die Base der vergleichenden Anatomie auf immer festgestellt worden sein. (Morphol. III. Gestalt d. Tiere. 1790.)

Nur dem freilich, der die Sprache meistert, steht ein solches Verfahren zu, und eingehende Sprachstudien sind erforderlich, um eine derartige Sprachbereicherung schaffen zu können. I. 36. 21. 8: Der Sprachforschung war er [Bergrat Werner] diessmal ganz eigentlich ergeben; deren Ursprung, Ableitung, Verwandtschaft gab seinem scharfsinnigen Fleiss hinreichende Beschäftigung, und es bedurfte nicht viel Zeit, so hatte er uns auch für diese Studien gewonnen ... Damit aber dieses nicht allzu paradox erscheine, so denke man an die Nöthigung wodurch dieser Treffliche in ein solches Fach hineingedrängt worden ... Werner hat sich in seinem Fach, wie er herankam, für die Einzelheiten solcher Namen bedient, wie sie seinem Vorgänger beliebt; da er aber zu unterscheiden anfing, da sich 
täglich neue Gegenstände aufdrangen, so fühlte er die Noth. wendigkeit selbst Namen zu ertheilen:-Namen zu geben ist nicht so leicht, wie man denkt und ein recht gründlicher Sprachforscher wïrde zu manchen sonderbaren Betrachtungen aufgeregt werden, wenn er eine Kritik der vorliegenden oryktognostischen Nomenclatur schreiben wollte. Werner fühlte das gar wohl und holte freilich weit aus, indem er, um Gegenstände eines gewissen Fachs zu benennen, die Sprachen überhaupt in ihrem Entstehen, Entwicklungs- und Bildungssinne betrachten und ihnen das, was zu seinem Zwecke gefordert ward, ablernen wollte. (Tag- u. Jahreshefte 1807.)

II. 3. 250. 26: Da er [Kepler] die Sprache völlig in seiner Gewalt hat, so wagt er gelegentlich kühne, seltsame Ausdrücke, aber nur dann, wenn der Gegenstand ihm unerreichbar scheint. So verfährt er bei Gelegenheit der Farbe ... Er bedient sich so wunderbarer Worte, um ihrer Natur einigermassen beizukommen, dass wir sie nicht zu übersetzen wagen. [Color est lux in potentia, lux sepulta in pellucidi materia.] (Histor. Farbenl. V. I8 ro.)

Nur zur Bezeichnung des „Urphänomens", der isoliert stehenden Erscheinung, ist das Kunstwort angängig; jede Übertragung auf ein Verwandtes, Abgeleitetes ist vom Übel; jede voreilige Bezeichnung des Phänomens bringt Verwirrung, zeitigt Theorien und Hypothesen; jeder Versuch, es zu erklären, ist verfehlt. Die Belege über diese allgemeinen Gedanken erschöpfen unser reichhaltiges Material.

II. 11. 148. 20: Der Magnet ist ein Urphänomen, das man nur aussprechen darf, um es erklärt wu haben; dadurch wird es denn auch ein Symbol für alles Ubrige, wofür wir keine Worte noch Nanen zu suchen brauchen. (Zur Naturwiss. i. Allg.)

II. I1. 160. 14: Wenn wir ein Phänomen vorzeigen, so sieht der andre wohl, was wir schen; wenn wir ein Phänomen aussprechen, beschreiben, besprechen, so übersetsen wir es schon in unsere Menschensprache. Was hier schon für $S c h$ wierig. li e it en sind, was für $M$ ängel uns bedrohen, ist offenbar. 
Echte Terminologie passt auf ein beschränktes, isoliertes Phänomen; wird auch angewendet auf ein weiteres. Zuletzt wird das nicht mehr Passende doch noch fortgebraucht (Zur Naturwiss.). In einer Lesart zu dieser Stelle steht für echte das besser passende erste (II. I I. 367). - II. I I. I46. I I Theo$r$ i en sind gewöhnlich Übereilungen eines ungeduldigen Verstandes, der die Phänomene gern los sein möchte und an ihrer Stelle desswegen Bilder, Begriffe, ja oft nur Worte einschiebt. (Zur Naturwiss.)

II. I I. 29. I I: Der Mensch erfreut sich ... mehr an der Vorstellung als an der Sache, oder wir müssen vielmehr sagen: der Mensch erfreut sich nur einer Sache in so fern er sich dieselbe vorstellt; sie muss in seine Sinnesart passen, und er mag seine Vorstellungsart noch so hoch über die gemeine erheben, noch so reinigen, so bleibt sie doch gewöhnlich nur ein Versuch, viele Gegenstände in ein gewisses fassliches Verhältniss zu bringen, das sie, streng genommen, unter einander nicht haben; daher die Neigung zu Hypothesen, zu Theorien, Ter. minologien und Systemen, die wir nicht missbilligen können, weil sie aus der Organisation unseres Wesens nothwendig entspringen. (Zur Naturwiss. I792 Objekt u. Subjekt.)

So müht sich Goethe, namentlich der alte Goethe jahrelang, man kann ohne Übertreibung sagen, täglich und stündlich $\mathrm{ab}$, Wort und Begriff in Übereinstimmung $\mathrm{zu}$ bringen ein gewaltiger Geisteskampf, der aber zu keinem Sieg führen konnte. Er scheiterte an den Grenzen, die menschlichem Denken gesteckt sind. Daß die aus diesem Kampf sich ergebende Verachtung der Sprache sich auch bisweilen gegen die Muttersprache im besonderen wendet, und daß Goethe im Ringen mit dem Wort Formen für seine Begriffe ohne Rücksicht auf die Herkunft da nahm, wo sie ihm am reinsten dünkten, wird uns unten noch beschäftigen. Wir wissen jetzt, aus welchen Quellen das eine wie das andere entspringt. 
$\mathrm{Ob}$ auch hier wie bei anderen sprachlichen Anschauungen Herder auf Goethe eingewirkt hat? Wahrscheinlich wird es durch dessen Ausspruch im 4. krit. Wäldchen: Mit jedem Worte, was die Seele lernt, erschwert sie sich gleichsam das Verständnis der Sache, die es bedeutet. ${ }^{1}$ )

\section{ZWEITES KAPITEL.}

\section{GESCHRIEBENE UND GESPROCHENE REDE.}

Schreiben ist ein Missbrauch der Sprache, stille für sich lesen ist ein trauriges Surrogat der Rede (I. 27. 373. IO. D. W. Io. I8II). Dieser oft zitierte Ausspruch Goethes ${ }^{2}$ ) versteht sich, abgesehen von seiner unanfechtbaren Gültigkeit, denn die Sprache leitet ja, wie Kluge sagt, ihren Namen doch vom Sprechen her, im Zusammenhange mit des Dichters Erkenntnis, daß die Sprache ein untaugliches, unzulängliches Werkzeug sei. Wer wie er in stetem Kampf mit dem Sprachstoff liegt, wer stets nach besseren, den Sinn genauer wiedergebenden Worten sucht, wem das Wort vielfach nicht oder kaum genügt, der muß selbstverständlich auch vor dem Niederschreiben und Druckenlassen seiner Gedanken zurückschrecken. Das gesprochene Wort läßt sich durch ein anderes erklären, verbessern, zurücknehmen; das geschriebene steht fest und starr vor dem Auge des Lesenden. Dazu kommen freilich noch andere Überlegungen. Das gesprochene Wort lebt; Stimme, Ausdruck, Tonfall, Rhythmus kommen ihm zu Hilfe; das geschriebene entbchrt dieser Hilfen, es ist tot. IV. I3. I8. 6: Wenn ich genötigt wäre, diese (Farben-) Lehre nur zwei halbe Fahre öffentlich zu lesen, so wäre alles getan, aber die Gelehrsam-

1) Vgl. Gocbel: Gocthe-Jahrbuch XXV, 157, und Mauthner a. a. O. 129-137. Zum weiteren Beweis für Goethes Art, der Bedeutung des Worts bis an die Grenze des Frrklärbaren nachzugehen, vgl. dic im Anhang (S. 249 fr.) femachte \%usammenstellung von Begriffsbestimmungen und Übersetzungen.

2) Vgl. Kluge, Fr.: Gocthe und die deutsche Sprache. Wiss. Heihefte \%. \%. d. allg. d. Sprachver. Nr. 22. S. 33 ff. und Kluge: Unser Detitsch, S. 117 . 
keit auf dem Papiere und zum Papiere hat gar wenig Reiz für mich (12. I. 1798 an Knebel). I. 30. 260. 6: Auch da [beim Vortrag der Iphigenie] entdeckte ich manche Stelle, die mir gelenker aus dem Munde ging, als sie auf dem Papier stand. Freilich ist die Poesie nicht tïrs Auge gemacht. (Ital. Reise 22. I. 1787 .)

IV. 2 I. 483 Lesarten: Begegnete mir das angenehme Ereigniss, Sie irgendwo zu treffen, so würde ich aufrichtig meine Gedanken über manches eröffnen. Schriftlich ist es nicht rathsam: denn man kann weder Gedanken noch Gesinnungen so leicht die gehörige Folge geben. (? XI. 1810 an Perthes Entwurf.) Ähnlich IV. 38. 38 an Nees v. Esenbeck (29. I. I 824); IV. 38 . I 85 an Reinhard (5. VI. I824).

I. 6. 5. I7: Wie das Wort so wichtig dort war, Weil es ein gesprochen Wort war.

(Divan. Buch d. Sängers.)

Die von Kluge a. a. O. 35 angezogene Briefstelle (IV. 7. 217), in der Goethe Schreiben im Gegensatz zur Unterhaltung halbe Sache nennt, läßt - wie auch andere ausgeschaltete Äußerungen - in ihrem Zusammenhang keine besondere Mißachtung der geschriebenen Rede erkennen. Deutlich konmt sie dagegen zum Ausdruck in den auch ebenda zitierten Versen: I. I. I I. I :

Wie nimmt ein leidenschaftlich Stammeln Geschrieben sich so seltsam aus!

(Vorklage. I 8 I5.)

In dieser Abneigung gegen das Schreiben berührt sich unser Dichter mit Klopstock, dessen Wortschatz, wie Löper (Hempel I. 268) nachweist, auch der Ausdruck stammeln entnommen ist, sowie mit Herder, der in dem Überhandnehmen des Schreibens und Lesens an Stelle des Sprechens und Hörens den Grund der Verderbnis unserer Sprache sah. ${ }^{1}$ )

1) Vgl. R. Hildebrand: Vom deutschen Sprachunterricht. 9. Aufl. Leipzig 1905. S. 34 . 
Am weitesten geht Goethe in der Verwerfung des Geschriebenen für die Poesie in einem auch von Kluge (a. a. O. 34) angeführten und erläuterten Bruchstück des geplanten Kommentars zum Briefwechsel mit Schiller: G. J. XIX. 15: Gewi $\beta$ schwarz auf weiß sollte durchaus verbannt sein: Das Epische sollte rezitiert, das Lyrische gesungen und getanzt und das Dramatische persönlich mimisch vorgetragen werden (1824). Auch die Tagebuchnotiz III. 7. I58. 3. vom I3. IV. I820 Sprache und Schrift deutet auf eine Behandlung der Frage.

Des Dichters persönliche Vorliebe, sich durch Diktieren mitzuteilen, hat ihren Hauptgrund wohl auch in der Mißachtung geschriebener Rede. Daß dabei aber auch andere Gründe mitsprechen, geht aus manchen Briefstellen hervor, in denen Goethe sich wegen der fremden Hand des Schreibers entschuldigt. IV. 20. 179. 15: Wenn ich im Zimmer auf und $a b$ gehe, mich mit entfernten Freunden laut unterhalten kann und eine vertraute Feder meine Worte auffängt, so kann etwas in die Ferne gelangen. Mich hinzusetzen und selbst zu schreiben, hat etwas Peinliches und Ängstliches für mich, das den guten Humor, ja die Vertraulichkcit lähmt. (I4. X. I808 an Dor. v. Knabenau). ${ }^{1}$ )

Andere Begründung gibt er in einer längeren Briefstelle an eine zweite Dame, die Gräfin O'Donell: IV. 23. I67. I : Nach dieser Klage muss ich mit der Entschuldigung einer andern wunderlichen Idiosyncrasie hervortreten, die Sie schon vor Augen haben, dass ich mich nämlich $\approx u$ dem Gegenwärtigen einer fremden Hand bediene. Alle meine Freunde haben mich verwöhnt, so dass aus einem Mangel eine Gewohnheit, und aus der Gewohnheit eine Untugend geworden ist. Ich bin niemals zerstreuter, als wenn ich mit eigner Hand schreibe; denn weil die Feder nicht so geschwind läuft, als ich denke, so schreibe ich oft den Schlussbuchstaben des folgenden Wortes, ehe das erste noch zu Ende

1) Dic Empfängerin ist crst von 1814 ab Gräin Chasseport, als welche sic von Kluge a. a. O. 35 schon für diesen Brief bezeichnet wird. Der Beleg auch bei Bouke a. a. O. 142. 
ist, und mitten in einem Comma fange ich den folgenden Perioden an; Ein Wort schreibe ich mit dreyerley Orthographie und was die Unarten alle seyn mögen, deren ich mich recht wohl bewusst bin und gegen die ich auch nur im äussersten Notfall zu kämpfen mich unterwinde, nicht zu gedenken, dass äussere Störung mich gleich verwirren und meine Hand wohl dreymal in Einem Brief abwechseln kann. So ist mir's mit Vorstehendem gegangen, das ich zweymal zu schreiben anfing, absetzte und schlecht fortsetzte, jetzt entschliesse ich mich zu dictieren, es ist, als wenn ich mit Ihnen spräche und die Erinnerung Ihrer Persönlichkeil, Ihrer Gestalt, Ihres freundlichen Wesens giebt mir keine Zer. streuung, weil Sie es ja sind, zu der ich mich wende, indem ich dies ausspreche (24. XI. I8I2 an Gräfin Joseph. O’Donell). ${ }^{1}$ )

An Schleiermacher führt er als Entschuldigung des Diktierens an, daß das eigenhändige Schreiben $b$ eschwerlich und fast $u n m \ddot{g} l i c h$ sei (IV. 16. 3I4. I4 vom I4. Sept. I 803); ich unterhalte mich auf diese Weise freier... da ich der Feder fast ganz entwohnt bin, heißt es in einem Briefe an J. v. Müller vom 5. XI. I803 (IV. I6. 339. 8). Im Januar I 805 wird demselben Briefempfänger gegenüber sogar die Jahreszeit für das Diktat verantwortlich gemacht. IV. I7. 249. I : ich komme sonst besonders in dieser traurigen Fahreszeit nicht leicht zum Entschluss mich mit meinen lieben Abwesenden zu unterhalten (25. I. I805). Schnelligkeit und Deutlichkeit der ,fremden Hand" werden Karl August und dem Grafen Sternberg gegenüber als Gründe angegeben: IV. 35. I08. I I : Ew. Königliche Hoheit erlauben mir wohl, da sich bessere und schnellere Federn finden als die meinige die sonst gegönnte Form, damit ich des Glücks einer fortwährenden Mittheilung geniessen möge (25. IX. I82 I an Karl August). IV. 35. I 16. 23: Ew. Excellenz verzeihen, dass ich so redselig werde! Es ist nicht blos die jenaische Einsamkeit, die mich nach aussen gesprächig macht, sondern ich thue mir dabey etwas

I) Vgl. R. M. Werner in der oben zitierten Ausgabe des Briefwechsels. S. 76 . 
zu Gute, dass ich mich schreibend (oder vielmehr dictirend) gegen Hochdieselben als wie in der Gegenwart verhalte. Eben deshalb muss ich auch bitten, dass einer fremden Hand verziehen werde, die leserlicher ist und schneller als die meinige und ohne die ich kaum eine Wirkung in die Ferne haben könnte (26. IX. 182 I an Sternberg). Ähnliche Entschuldigungen finden sich auch anderwärts.

An seine Nichte Luise Nicolovius nennt er die Vorliebe fürs Diktieren eine eingewurzelte Unart und seine Hand faul und unentschlossen (IV. 20. 290. 25 v. 27. I. 1809). Eingewurzelt war die Eigenart schon aus dem Vaterhause, schon der Rat Goethe hatte einen alten Schreiber zur Hand, dem er diktierte. Der Sohn gewann dieser Einrichtung ihre Vorteile ab, sich schnell und ohne selbst die mühselige Schreibarbeit besorgen zu müssen, anderen mitzuteilen. Der riesig anschwellende Briefwechsel wirkte als Notwendigkeit, die Abneigung gegen Schrift, die Vorliebe für Sprechen kam hinzu.

Verzeichnet sei hier auch die Ansicht Hermann Grimms ${ }^{1}$ ), nach cler Goethe nach den ersten Weimarer Jahren das Diktieren mit der Iphigenie deshalb aufnahm, um ,am Klange seiner eignen Worte" zu prüfen, „ob die Worte das Gefühl und die Gedanken wicdergeben“. Es sei eine „Verzweiflungsmaßregel" gewesen, als er begann, sich eine eigene Sprache zu bilden und er daz" keinen anderen Anhalt als sich selbst fand. Goethe selbst hat sich in dem Sinne nie über das Diktieren ausgesprochen.

Bode ${ }^{2}$ ) rechnet die Bewegung unter die neun Musen des Dichters und führt das Diktieren auf das ihm für die geistige Arbeit unentbehrliche Auf- und Abgehen zurück. Er stützt diese Ansicht mit cler Tagebuchbemerkung von 1780: Was ich Gutes finde in Uberlegungen. Gedanken, ja sogar Ausdruck, kommt mir meist im Gehen.

1) A. а. O. 11. 34 .

2) Bode, Wilh.: Goothes Ästhetik. Berlin 1901. S. 111. 
Anderseits fehlt es aber auch nicht an Beweisen dafür, daß Goethe die schriftliche Mitteilung schätzte und sie sogar über die mündliche stellte. In den Zahmen Xenien werden sagen, schreiben, diktieren, sprechen nebeneinander gestellt.

I. 3. 35I. v. I607: Da ich viel allein verbleibe

Pflege weniges zu sagen;

Da ich aber gerne schreibe, Mögen's meine Leser tragen!

Sollte heissen: gern diktiere, Und das ist doch auch ein Sprechen, Wo ich keine Zeit verliere;

Niemand wird mich unterbrechen.

(Zahme Xenien VI. I827.)

Wenn Goethe schon I806 an Wolf die Vorzüge der schriftlichen Mitteilung auseinandersetzt, so mag es ihm dabei in erster Linie darum gegolten haben, den durch die Aufhebung der Universität Halle in seinen Vorlesungen gestörten großen Philologen zu trösten: IV. 19. 336. I I: Sie haben die Leichtigkeit sich mitzutheilen, es sey mündlich oder schriftlich. Fene erste Art hatte bisher einen grösseren Reiz für Sie und mit Recht. Denn bey der Gegenwirkung des Zuhörers gelangt man eher zu einer geistreichen Stimmung als in der Gegenwart des geduldigen Papiers. Auch ist die beste Vorlesung oft ein glückliches Inpromptu, eben weil der Mund kühner ist als die Feder. Aber es tritt eine andere Betrachtung ein. Die schriftliche Mittheilung hat das grosse Verdienst, dass sie weiter und länger wirkt, als die mïndliche und dass der Leser schon mehr Schwierigkeiten findet, das Geschriebene nach seinem Modul umzubilden, als der Zuhörer das Gesagte (28. XI. I806 an Fr. A. Wolf).

Der alte Goethe gewann, nachdem er sich aus dem öffentlichen Leben zurückgezogen hatte, in Stunden der Einsamkeit der schriftlichen Mitteilung - wohlgemerkt, der durch Diktieren vermittelten - den Vorzug $a b$ vor der von Mund zu Mund. 
I. 3. 288: Auch bei mir will sich die Lust verlieren Mit irgend jemand $z u$ conversieren.

(Zahme Xenien IV. - I826.)

IV. 35. 252. I6: Da ich nicht mehr hören und nicht mehr sprechen mag, so lasse immerfort drucken und das kommt denn doch zuletzt auch meiner Pflicht gegen entfernte Freunde zu Gute (3I. I. I822 an C. F. v. Reinhard).

IV. 36. 26. I7: Der Zustand des Schreibenden theilt sich dem wahren Leser sogleich völlig mit (22. IV. I822 an Fr. Rochlitz).

IV. 35. 261. 22: Hören und reden mag ich nicht mehr sondern vertraue, wie des Königs Midas Barbier meine Geheimnisse den verrätherischen Blättern (5. II. I 822 an Zelter). Ähnlich drückt sich Goethe demselben Freunde gegenüber am 2. II. 1829 und I8. VI. 183 I aus. (Zelter VI. 212.)

Am höchsten stellt der Dichter das Geschriebene in folgendem Spruch: I. 2. 225. 43:

Die Dinte macht uns wohl gelehrt, Doch ärgert sie, wo sie nicht hingehört.

Geschrieben Wort ist Perlen gleich;

Ein Dintenklecks ein böser Streich.

(Sprichwörtlich 1812/14.)

Löper ${ }^{1}$ ). weist wohl nicht mit Unrecht darauf hin, daß dieses Lob aus der Zeit stammt, in der, wie wir an anderer Stelle sehen werden, Goethe sich orjentalische Schriftzeichen durch mechanische Schreibübungen anzueignen suchte und so seine Idiosynkrasie gegen Geschriebenes überwand. In zwei aus dem Nachlaß veröffentlichten Aussprüchen setzt sich der Greis leidenschaftslos über beide Arten der Mitteilung aus. cinander.

G. G. XXI. Nr. 891: Uber die vichtigsten Angelegenheiten des Gelïhls, wie der Vernunft, der Erfahrung wie des Nach-

1) II.mpel 111, 23 und 293 . 
denkens soll man nur mündlich verhandeln. Das ausgesprochene Wort ist sogleich todt, wenn es nicht durch ein folgendes, dem Hörer gemässes am Leben erhalten wird. Man merke nur auf ein geselliges Gespräch! Gelangt das Wort nicht schon todt zu dem Hörer, so ermordet er es sogleich durch Widerspruch, Bestimmen, Bedingen, Ablenken, Abspringen und wie die tausendfältigen Unarten des Unterhaltens auch heissen mögen. Mit dem Geschriebenen ist es noch schlimmer. Niemand mag lesen als das, woran er schon einigermassen gewöhnt ist: Das Bekannte, das Gewohnte verlangt er unter veränderter Form. Doch hat das Geschriebene den Vortheil, dass es dauert und die Zeit abwarten kann, wo ihm zu wirken gegönnt ist. (1826.)

I. 4211. 224. I7 (G. G. XXI. Nr. 892): Was man mündlich ausspricht, muss der Gegenwart, dem Augenblick gewidmet sein; was man schreibt, widme man der Ferne, der Folge. (I 826.) Die größere Wertschätzung des Geschriebenen ist also, unbeschadet der persönlichen Vorliebe für das Diktieren, im Alter unverkennbar. Die Beschaulichkeit des Greises kann schrift. lich die Gedankengänge folgerichtiger entwickeln; beim Gespräch, namentlich dem wissenschaftlichen, kommt beim Eifer, in kurzer Zeit möglichst viel zu entwickeln, die Logik oft zu kurz: Prämissen überhüptt man und eilt aufs Resultat; Enthymeme glücken nicht immer, deren geheime Vordersätze leichter zu finden sind. (IV. 37. I58. 4; 6. VIII. I823 an Zauper.)

Die freie Briefsprache wird ihm durch Vermeidung des Selbstschreibens zur Unterhaltung: I. 46. 11. 26: Briefe gehören unter die wichtigsten Denkmäler, die der einzelne Mensch hinterlassen kann. Lebhafte Personen stellen sich schon bei ihren Selbstgesprächen manchmal einen abwesenden Freund als gegenwärtig vor, dem sie ihre innersten Gesinnungen mittheilen und so ist auch der Brief eine Art Selbstgespräch. Denn oft wird ein Freund, an den man schreibt, mehr der Anlass als der Gegenstand des Briefes. (Winckelmann I. Vorrede I 805.) - Aber schließlich ist es einerlei, ob gesprochen, geschrieben 
oder gedruckt: "wenig bedeuten die Worte", das ist schon der Grundgedanke der I. Epistel von I794, und das vorige Kapitel hat uns gezeigt, daß er herrschend geblieben ist:

I. 2. 298. 22 :

Was mein leichter Griffel entwirft, ist leicht zu verlöschen, Und viel tiefer präget sich nicht der Eindruck der Lettern, Die, so sagt man, der Ewigkeit trotzen. Freilich an viele Spricht die gedruckte Kolumne; doch bald wie jeder sein Antlits, Das er im Spiegel gesehen, vergisst, die behaglichen Züge, So vergißt er das Wort, wenn auch von Erze gestempelt. Reden schwanken so leicht herüber, hinüber, wenn viele Sprechen und jeder nur sich im eignen Worte, sogar auch Nur sich selbst im Worte vernimmt, das der andere sagte. Mit den Büchern ist es nicht anders. Liest doch nur jeder Aus dem Buch sich heraus...

Sag' ich, wie ich es denke, so scheint durchaus mir, es bildet Nur das Leben den Mann und wenig bedeuten die Worte.

\section{(I. Epistel I794.)}

Auch die Anlegung einer Handschriftensammlung und die Beschäftigung mit Graphologie beweisen die in den späteren Jahren verstärkte Hinneigung zu Schrift und Geschriebenem, wenn auch nicht verkannt werden soll, daß bei dem Werben um Beiträge für die Sammlung es Goethe außerdem um Erinnerungen an bedeutende Männer zu tun war; es war ja überhaupt ein Zug seines Wesens, durch sinnliche Zeichen Verknüpfungen mit der Vergangenheit herzustellen. In diesem Sinne äuBert er sich auch bei der Rücksendung einer Byronschen Handschrift, von der er sich nur ungern trennt: IV. 36. 205. 8: das Alter, das denn doch zuletzt an sich selbst zu zweifeln antängt, bedarf solcher Zeugnisse, deren anregende Kraft der füngere vielleicht nicht ertragen hätte. (12. XI. I822 an Fr. Benecke; ähnlich IV. 36. 256. 14. Briefstelle vom 3. I. 1822 an Boisseréc.) Auch die sich so mannigfaltig bei ihm außernde Sammelliebhaberei mag hier einen Ausfuß gefunden haben. Mit einem geschworenen Jünger der Handschriften- 
deutung haben wir es jedenfalls nicht zu tun. Er äußert sich in den Annalen selbst zur Sache: I. 36. 52. 18: Auch eine Sammlung von eigenen Handschriften bedeutender Personen ward dieses Fahr durch Freundesgunst ansehnlich vermehrt und so bestärkte sich der Glaube, dass die Handschrift auf den Charakter des Schreibenden und seine jedesmaligen Zustände entschieden hinweise, wenn man auch mehr durch Ahnung als durch klaren Begriff sich und den andern davon Rechenschaft geben könne. (Tag- u. Jahreshefte I809.)

So gibt er auch einem Handschriftensammler, der ihn um seine Ansicht über den Zusammenhang von Handschrift und Charakter bittet, nur unbestimmte und ausweichende Antwort:

IV. 32. 224. 5: Dass die Handschrift des Menschen Bezug auf dessen Sinnesweise und Charakter habe, und dass man daran wenigstens eine Ahndung von seiner Art zu seyn und zu handlen empfinden könne, ist wohl kein Zweitel, sowie man ja nicht allein Gestalt und Züge sondern auch Mienen, Ton, ja Bewegung des Körpers als bedeutend, mit der ganzen Individualität über. einstimmend anerkennen muss. Fedoch möchte auch hierbey mehr das Gefühl als ein klares Bewusstsein statt finden; man dürfte sich wohl darüber im Einzelnen aussprechen, dieses aber in einem gewissen methodischen Zusammenhang zu thun, möchte kaum jemand gelingen. (3. IV. I820 an C. B. Preusker.) Wenn er sich auch im häuslichenKreis nicht ungern mit Handschriftendeutung befaßt hat, wie mehrere von Isabella v. UngernSternberg ${ }^{1}$ ) gesammelte Belege beweisen, ernst wissenschaftlich hat er die Sache niemals betrieben. Wir finden nur einmal ein niedergeschriebenes Urteil von der Handschrift auf den Schreibenden. Es betrifft Eckermann, dessen Manuskript Cotta mit dem sich auf die Schrift beziehenden Hinweis zum Verlag empfohlen wird: IV. 37.62. 26: die Klarheit und

I) Bode: Stunden mit Goethe III (1907), 47 ff. Vgl. die mit Eckermann am 2. IV. 1829 und 2I. I. I 830 gepflogenen graphologischen Unterhaltungen (auch Bode: Goethes Gedanken. Berlin 1907. I. 5).

Rausch, Goethe u. die deutsche Sprache. 
Freyheit der Handschrift besticht schon (II. VI. I823). Graphologie wird das niemand nennen.

In seiner eigenen Sprache scheint Goethe nach dem Zeugnisse von Zeitgenossen große Ausdrucksfähigkeit mit Tonfülle verbunden und dadurch die Wirkungen beim Hörer erzielt zu haben, die ihn die gesprochene Sprache so hoch schätzen ließen.

G. IX. I. I03: „Sein Vorlesen ist ein tieferes Donnern, vermischt mit dem leisesten Regengelispel, es giebt nichts Ähnliches." (J. P. F. Richter. I7. VI. I796.)

G. V. 6I: „Es war ein Genuss eigner Art, ihm zuzuhören, denn nicht allein dass die originelle Kraft und Frische der Gedichte mich in hohem Grade anregte, sondern Goethe zeigte sich auch beim Vorlesen von einer mir bisher unbekannten, höchst bedeutenden Seite. Welche Mannigfaltigkeit und Kraft der Stimme! Welcher Ausdruck und welches Leben des großen Gesichts voller Farben! Und welche Augen." (30. III. 1824. Eckermann.)

G. VI. 4I: „Goethe las nun .. . [verschiedene Gedichte]. Jedes las er in einem andern Tone und andern Schwunge, vortrefflich sodaß man nicht leicht etwas Vollkommneres hören konnte." (29. I. I827. Eckermann.)

G. X. I78: „Höchst merkwürdig aber, ja wahrhaft erstaunenswürdig war die Art wie er sprach. Es war der reinste, ununterbrochenste Fluß der Rede, die höchste Mannigfaltigkeit und Gewandheit des Ausdrucks, über welchen Gegenstand er auch sprechen mochte. Da, wo sichs um tiefere Dinge handelte, wo selbst die Gebildeten, sclbst die geübten Denker in der Regel dic Worte suchen müssen, da bewegte er sich mit derselben Leichtigkeit, als wenn er über das Wetter oder über cine Stadtneuigkeit spräche. Es war mit cinem Worte unsere deutsche Sprache in der Gestalt, wie man sie sich von überirdischen Wesen geredet denken mochte." (3. X. 1829. L. v. Low. $)^{1}$ )

1) Auch G. J. XVII (1896). 
Burkhardt 9. I6: „Nie habe ich einen so vollendeten Vortrag gehört. Welche Blicke, welches Feuer, welche Stimme bald donnernd, bald sanft, welche herrliche Aussprache und Mannigfaltigkeit im Ausdruck." (3. XII. I822. Fr. Soret.)

\section{DRITTES KAPITEL.}

\section{WERTURTEILE ÜBER DIE SPRACHE.}

Goethe hat $z u$ wiederholten Malen sich über Sprache im Gegensatz zu den verschiedenen anderen Arten der Äußerung des menschlichen Denkens und Empfindens ausgesprochen. Auch diese Urteile unterstehen, wie wir wieder betonen müssen, der Anschauung von der Unfähigkeit der Sprache überhaupt und fallen deshalb zum Teil zu deren Ungunsten aus. Musik und Sprache werden in folgenden Äußerungen gegeneinander abgewogen.

G. VIII. I79: Schöne Melodie und Gesang von einem schlechten Text thut nichts zur Sache. Es ist besser die Worte nicht zu verstehen, weil man aus den Geberden mehr herausholt, als die Worte geben können. (1804-I812 zu Riemer.) ${ }^{1}$ )

IV. 33. 9. 12: Die reinste und höchste Mahlerey in der Musik ist die, welche du auch ausübst, es kommt darauf an, den Hörer in die Stimmung zu versetzen, welche das Gedicht angiebt; in der Einbildungskraft bilden sich alsdann die Gestalten nach Anlass des Textes, sie weiss nicht wie sie dazu kommt... Und so verwandle ich Ton- und Gehörloser, obgleich Guthörender, jenen grossen Genu $\beta$ in Begriff und Wort. Ich weiss recht gut, dass mir deshalb ein Drittel des Lebens fehlt; aber man muss sich einzurichten wissen. (2. V. 1820 an Zelter.)

IV. 33. 176. 7: Ein tiefgefühlter Antheil an irgend einer poetischen Production kann nicht schöner ausgedrückt werden, als wenn der Musiker sich darein versenkt, um ihr erst das

I) Über Wert und Macht der Musik vgl. Bode: Goethes Gedanken II. 142. 
eigentliche Leben einzuhauchen und sie durch seine Persönlichkeit eigens zu individualisiren. Es entsteht dadurch ein neues Poem, welches den Dichter selbst ïberraschen muss. (27. VIII. 1820 an C. v. Schlözer.) ${ }^{1}$ )

Die bildende Kunst hat ja dem Dichter sein ganzes Leben hindurch im Vordergrunde des Interesses gestanden, kunst. geschichtliche Betrachtungen haben ihn auf allen seinen Reisen und in den späteren Weimarer Jahren neben den naturwissenschaftlichen am eingehendsten beschäftigt, von Jugend auf hat er sich selbst als ausübender Künstler malend und zeichnend versucht. In den Annalen von 1805 stellt er seine Anschauung vom Wert der bildenden Kunst als Quelle geschichtlicher Überlieferung der Wolfs gegenüber, dem als Philologen die Schrift als vornehmste Quelle gelten muß.

I. 35. 195. 5: Wolf ... hatte sein ganzes Leben den schriftlichen Überlieferungen des Altertums gewidmet... Sein durch. dringender Geist hatte... sein Urtheil auf den höchsten Grad geschärft, dass er in dem Unterschied der Sprache und des Stils zugleich den Unterschied des Geistes und des Sinnes zu entdecken zerusste, und diess vom Buchstaben, von der Sylbe hinauf bis zum rhythmischen und prosaischen Wohlklang, von der ein. fachen Wortfügung bis zur manichfaltigen Verflechtung der Sätze... Aus seinen Unterhaltungen ging hervor: er achte das nur einzig für geschichtlich was durch geprüfte und zu prüfende Schrift aus der Vorzeit zu uns herübergekommen sei. Dagegen hatten die Weimarerischen Freunde [Meyer und Goethe] mit denselben Uberzeugungen einen anderen Weg eingeschlagen; bei leidenschaftlicher Neigung für bildende Kunst mussten sie gar bald gewahr werden, dass auch hier das Geschichtliche sowohl der Grund eines jeden Urtheils als einer praktischen Nacheiferung werden könne Wenn nun im lebhaftesten Gespräch beide Arten die Vergangenheit sich zu vergegenwärtigen sur Sprache kamen,

1) Das bekannte "K'unst ist Sprache des Unaussprechlichen" gehört als Begriffsbestimmung von Kunst iberhaupt nicht hicrher und würde uns in eine Auscinandersetzung über Kunst weit vom Thema abführen. 
so durften die W.K.F. [Weimarer Kunst Freunde] sich wohl gegen den trefflichen Mann im Vortheil dünken, da sie seinen Studien und Talenten volle Gerechtigkeit widerfahren liessen... Dagegen läugnete er hartnäckig die Zulässigkeit ihres Verfahrens. (Tag- u. Jahreshefte I805.)

G. II. 26I: Wir sprechen überhaupt viel zu viel. Wir sollten weniger sprechen und mehr zeichnen. Ich meinerseits möchte mir das Reden ganz abgewöhnen und wie die bildende Natur in lauter Zeichnungen fortsprechen. Fener Feigenbaum, diese kleine Schlange, der Cocon, der dort vor dem Fenster liegt und seine Zukunft erwartet, alles das sind inhaltschwere Signaturen; ja wer nur ihre Bedeutung recht zu entziffern vermöchte, der würde alles Geschriebene und alles Gesprochene bald zu entbehren im Stande sein! $\mathcal{F} e$ mehr ich darüber nachdenke, es ist etwas so Müssiges, ich möchte fast sagen Geckenhaftes im Reden, dass man vor dem stillen Ernste der Natur und ihrem Schweigen erschrickt, sobald man sich ihr vor einer einsamen Felsenwand oder in der Einöde eines alten Berges gesammelt entgegenstellt. (14. VII. I809 zu Falk.) ${ }^{1}$ )

Dieser Wertschätzung entsprechend, schlägt Goethe auch die Wirkung der bildenden Kunst höher an als die der Sprache:

I. 3. 256: Dummes Zeug kann man viel reden,

Kann es auch schreiben,

Wird weder Leib noch Seele töten.

Es wird alles beim Alten bleiben.

Dummes aber vors Auge gestellt

Hat ein magisches Recht.

(Zahme Xenien II. I82I.)

Endlich eine Gegenüberstellung von Sprache auf der einen, Musik, Mimik, Tanz auf der anderen Seite:

I. I3II. I 88 (IV. 34. 234):

Viel ist, gar viel mit Worten auszurichten, Wir zeigen das im Reden wie im Dichten;

I) Von Riemer Mitt. ï. G. I. 27, ohne Grund Goethe abgesprochen. 
Ton und Bewegung aber muss man hören, sehn, Sie schildern darf man sich nicht unterstehn, Unmittelbar sollt Ihr den Reiz empfinden An Sang und Tanz, wenn sie sich selbst verkünden.

(Prolog zur Einweihung des Berliner Schauspielhauses; an Graf Brühl. 3. V. I82I.)

Schiller schlägt in einem Briefe an Körner einmal einen ähnlichen Ton an mit den Worten: „Die Vorstellungen, die die Sprache bietet, sind für den Dichter spröderes Material als für den Bildhauer der sprödeste Stein."

Auf der anderen Seite fehlt es aber auch nicht an Zeugnissen, die der Sprache namentlich der Musik gegenüber das Vorrecht zugestehen.

I. 21. 203. 27: Gebt uns etwas, das Herz und Geist zugleich mit den Sinnen ergetze, sagte Wilhelm [zum Harfenspieler]. Das Instrument sollte nur die Stimme begleiten; denn Melodien, Gänge und Läufe ohne Worte und Sinn scheinen mir Schmetterlingen oder schönen bunten Vögeln ähnlich zu sein, die in der Luft vor unseren Augen herum schweben, die wir allentalls haschen und uns zueignen möchten; da sich der Gesang dagegen wie ein Genius gen Himmel hebt und das bessere Ich in uns zu begleiten anreizt. (W. M. L. II. II. I783.)

Rezitation aber wird verworfen: G. II. 229: „Gegen das Sprechen zur Musik erklärte sich Goethe so: Musik sey die reinste Unvernunft und die Sprache habe es nur mit Vernunft zu thun." (Ricmer. 3. XII. 1808.)

Gerade im Gegensatz zu dem oben zitierten Urteil steht das folgende: G. II. 315: Das Verdienst der schönen menschlichen Rede... übertrifft weit das des Gesanges. Es ist ihm nicht zu vergleichen; seine Abwechslungen und Mannigfaltigkeiten sind für das Gemüth unzählig. Fa dor Gesang selbst muss auf die simple Sprache zurücklehren, wenn er höchst bedeutungsvoll und rührend acerden soll. Dies haben auch schon alle grossen Componisten bemerkl. (16. V. 1810 2u Kncbel.) 
Wort und Bild als Ergänzungen bezeichnet ein Ausspruch aus dem Jahre I823: G. G. XXI. Nr. 188: Wort und Bild sind Correlate, die sich immerfort suchen wie wir an Tropen und Gleichnissen genugsam gewahr werden. So von je her, was dem Ohr nach innen gesagt oder gesungen war, sollte dem Auge gleichfalls entgegenkommen. Und so sehen wir in kindlicher Zeit in Gesetzbuch und Heilsordnung, in Bibel und Fibel sich Wort und Bild immerfort balanciren. Wenn man aussprach, was sich nicht bilden, bildete, was sich nicht aussprechen liess, so war das ganz recht; aber man vergriff sich gar oft und sprach statt zu bilden, und daraus entstanden die doppelt bösen symbolisch. mystischen Ungeheuer. (K. u. A. IV. 2. I823.) ${ }^{1}$ )

So wird auch schon I 808 (Min. u. Geol. II. 9. 76. I4) gesagt: Denn wenn man gleich mit Worten vieles leisten kann, so ist es doch wohlgetan, bei natürlichen Dingen, die Sache selbst oder ein Bild vor sich zu nehmen, indem dadurch jederman schneller mit dem bekannt wird, von dem die Rede ist.

Sehr bedeutungsvoll ist eine von Riemer mitgeteilte Äußerung, in der Goethe die Sprache in die Reihe der Künste stellt und ihr den Vorrang über Plastik, Malerei und Musik zuerkennt. Riemer 340: „Sprache ist ja auch eine Kunst, eine Poesie, d. h. eine Darstellung, und umfassender als alle übrigen Künste. Sie involviert das Ideale, Abstrakte der Plastik, das Mannigfaltige, Sinnliche der Malerei, das Anregende, Andeutende der Musik. Dem, was sie darstellt, giebt sie, vermöge und vermittels des Bewusstseyns, eine Form; aber freilich den Gehalt, den ganzen Gehalt des Dargestellten kann sie nur andeuten, wie die Musik. Sie erhebt sich aber über alle diese Künste, ob sie ihnen gleich im einzelnen nachstehen muss, dadurch, dass sie diese Künste selbst erst zu etwas erhellt, d. h. zu Styl, Geschmack ectr., denn sonst würden alle diese Künste nur rohe Nachahmung der Natur bleiben.

I) Ich beziehe den Ausspruch auf bildliche Darstellungen (Illustrationen) zu Schriftwerken, nicht auf bildlichen, figürlichen Ausdruck. Vgl. auch Bode: Goethes Gedanken I, 114. 
Dem Gehalt, der in dem Verhältniss der Geschlechter zueinander, der Kinder gegen die Eltern liegt und das ein Mannichfaltiges von Empfindungen ectr. ist, giebt die Sprache eine Form, indem sie es Liebe, Zärtlichkeit, Pietät usw. nennt." (Aphorismen. 26. V. I8II.) ${ }^{\mathbf{1}}$ )

In einer Äußerung aus den letzten Jahren wird ebenfalls der Sprache mit allem Nachdruck die Palme vor der Musik gereicht: II. I I. I73. 28: Wäre die Sprache nicht unstreitig das Höchste, was wir haben, so würde ich Musik noch höher als Sprache und als ganz zu oberst setzen. (Zur Naturwiss. Physik. Wirkungen.)

Wort, Bild und Modell sind nach seinem eignen Geständnis die seinem Geist angepaßten Mittel der Verständigung, während ihm Zahl, Zeichen und Figur (geometrisch), das Hexengewirr der mathematischen Formeln, die Chiffern, in ihrer toten Leere nichts sagten, wie ihm ja auch nach verschiedenen ablehnenden Äußerungen die Mathematik überhaupt als zu abstrakt keineswegs zusagte.

IV. 35. 249. 3: Freylich wïrde selbst in früheren Fahren für mich diese Angelegenheit [Kristallographie] manche Schwierigkeit gehabt haben, da mir das Organ für Zahlen und Zeichen gänzlich abzugehen scheint; doch bin ich überzeugt, dass in persönlicher Gegenwart mit Worten und Modellen Ew. Hochwohl. geboren mich doppelt dem Ziele näher bringen würden. (18. I. I 822 an C. C. v. Leonhard.)

IV. 40. 264. 6: Ich bin auf Wort, Sprache und Bild im eigent. lichsten Sinne angewiesen und völlig untähig durch Zeichen und Zahlen, mit welchen sich höchst begabte Geister leicht ver. ständigen, auf irgend eine Weise zu operiren. (18. I. I826 an Fir. Naumann.)

In einem noch freundlicheren Verhältnis zur Sprache werden wir den Dichter finden, wenn wir im Zusammen-

1) Diese bedeutsame Auslassung ist weder von Biedermann noch von Bode in ihre Sammlungen von Goethes mündlichen Äußerungen aufgenommen. 
hang hiermit die rein lobenden Äußerungen über sie zusammenstellen.

Reichhaltig wird diese Zusammenstellung allerdings nicht werden. Einmal hat uns das erste Kapitel Goethe im Kampf mit der ihm ungenügenden Sprache gezeigt, der sein Urteil vielfach ungünstig und manchmal ungerecht beeinflußte. Sodann müssen wir einen Teil der Lobessprüche in die Sonderbetrachtung über deutsche Sprache verweisen. Endlich sind sie an sich nicht zahlreich, denn die Sprache als Wissenschaft lag, wie wir des weiteren sehen werden, Goethe fern, und Urteile über sie, wie sie jeder nicht Sachverständige abgeben konnte, widerstrebten seinem vornehmen Geiste: I. 42II. 138. 3: Ein jeder, weil er spricht, glaubt auch über die Sprache sprechen zu können.

Der Dichter Goethe stand der Sprache anders gegenüber als der Gelehrte. $\mathrm{Er}$ ist als solcher weit entfernt nicht anzuerkennen, welche Macht und Gabe die Sprache dem in die Hand gibt, der als Herrscher über sie waltet: I. IO. 243. v. 3432 :

Und wenn der Mensch in seiner Qual verstummt, Gab mir ein Gott zu sagen, wie ich leide.

$$
\text { (Tasso V. } 5 \text {; I790. })^{1} \text { ) }
$$

Kaum ist der Sprache je ein schöneres und erhabeneres Lob gespendet worden, als es hier der Dichter dem Dichter in den Mund legt.

I. 6. I5. 7: Wisset nur, daß Dichterworte

Um des Paradieses Pforte

Immer leise klopjend schweben

Sich erbittend ew'ges Leben.

(Divan, Buch d. Sängers. I814/I5.)

Oder mit einer selbstverständlichen Einschränkung: Soret 54: Ich glaubte sonst immer, dass mir Worte zur rechten Zeit

I) Auch I, 3. 2 I als Motto der Elegie 1823. Vgl. Kluge a. a. 0.37. 
nicht fehlen könnten, diesmal aber [beim Tode Karl Augusts] find' ich, dass das tiefste Gefühl solcher äusseren Hülfsmittel ermangelt. (14. VII. I828.)

In einzelnen Aussprüchen wird das Wort sehr hoch gestellt, ja geradezu in Parallele gesetzt zur Tat, und es wird ihm die Fähigkeit zugeschrieben, auch die feinsten Unterschiede der Erkenntnis zu benennen. Auch diese Belege stammen aus Goethes Lebensabend, der auch die absprechendsten Urteile über die Unzulänglichkeit der Sprache zeitigte. Der Greis gab seinen Stimmungen spontan nach, die ihn bei seiner im Alter vorherrschenden wissenschaftlichen Tätigkeit freilich zumeist ungünstige Urteile über die Sprache aussprechen ließen.

II. 6. 356. 12: Die schart unterscheidende, genau beschreibende Botanik ist in mehr als einem Sinne höchst ehrwürdig, indem sie... ein Beispiel giebt, wie weit man mit der Sprache, eben jenem ins Einzelnste dringendem Beobachtungstalent, das kaum zu Unterscheidende, sobald es entdeckt worden, zu benennen und zu bezeichnen vermöge. (Zur Morphol. I. I829.)

II. 6. 220. 8: Professor Zaupers deutsche Poetik aus Goethe ... darf dem Dichter wohl einen angenehmen Eindruck machen; es ist ihm, als wenn er an Spiegeln vorbeiginge und sich im giinstigen Licht dargestellt erblickte. Und wäre es denn anders? Was der junge Freund an uns erlebt, ist ja gerade Handlung und That, Wort und Schrift, die von uns in glücklichen Momenten ausgegangen sind, zu denen wir uns immer gern bekennen. (Zur Morphol. I.)

II. G. 293. 16: Alles was wir aussprechen, sind Glaubensbekenntnisse. (Min. u. Gcol. letzte Jahre.)

Vereinzelte Äußerungen zugunsten der Sprache aus früheren Jahren seien abschließend angereiht:

I. 10. 422 (Lesarten):

Du bist nicht einer won den trïglichen, Wie vicle Fremde komen die sich rühmen. 
Und glatte Worte sprechen, wo der Hörer Nicht falsches ahndet und zuletzt betrogen

Sie unvermuthet wieder scheiden sieht.

$D u$ bist ein Mann, ein zuverlässger Mann,

Sinn und Zusammenhang hat deine Rede. Schön

Wie eines Dichters Lied tönt sie dem Ohr

Und füllt das Herz und reisst es mit sich fort.

(Nausikaa. Bruchstück I787.)

I. 4I. I. 53: Shakespeare's Werke sind nicht für die Augen des Leibes . . . Das Auge mag wohl der klarste Sinn genannt werden . . . Aber der innere Sinn ist noch klarer, und zu ihm gelangt die höchste und schnellste Überlieferung durch's Wort: denn dieses ist eigentlich fruchtbringend, wenn das, was wir durch's Auge auffassen, an und für sich fremd und keineswegs so tiefwirkend vor uns steht. Sh. nun spricht durchaus an unsern innern Sinn . . . Betrachtet man aber die Shakespeare'schen Stücke genau, so enthalten sie viel weniger sinnliche That als geistiges Wort. Hamlets Geist, Macbeths Hexen ... gehen beim Lesen leicht und gehörig an uns vorbei; da sie bei der Vorstellung ... störend, ja widerlich wirken. Durch's lebendige Wort wirkt Shakespeare und dieses lässt sich bei'm Vorlesen am besten überliefern. (Shakespeare. Morgenbl. I8I5.)

IV. 25. 4I5 (Lesarten):

Sey das Wort die Braut genannt,

Bräutigam der Geist,

Diese Hochzeit hat gekannt,

Wer Hafisen preist.

(I6. V. I8I 5 an Cotta, auch Divan. I. 6. 3I6.)

Hier finde auch die Verteidigung seines Namens und der Eigennamen überhaupt ihre Stelle, die sich gegen Herder richtet, als er spottete:

„,Der von Göttern du stammst, von

Goten oder vom Kote, Goethe..." 
I. 27. 3II. 6: Es war freilich nicht tein, dass er sich mit meinem Namen diesen Spass erlaubte; denn der Eigenname eines Menschen ist nicht wie ein Mantel, der bloss um ihn hängt, und an dem man allentalls noch rupten und zerren kann, sondern ein vollkommen passendes Kleid, ja wie die Haut selbst ihm über und über angewachsen, an der man nicht schaben und schinden dart, ohne ihn selbst zu verletzen. (D. W. 10. I8I I.)

\section{VIERTES KAPITEL.}

\section{ALLGEMEINE SPRACHWISSENSCHAFT.}

Es wird ja nicht zu leugnen sein, daß für manche der in den vorhergehenden Erörterungen beigebrachten Belege fremde Einflüsse auf Goethe eingewirkt haben, Lektüre einschlagender Bücher, mündlicher und schriftlicher Verkehr mit sprachgelehrten Männern. Aber es dürfte sehr schwierig und fast unmöglich sein, im einzelnen solche Spuren sicher nachzuweisen. Im folgenden sollen deshalb auch nur Goethes deutliche Beziehungen zu Vertretern der allgemeinen Sprachwissenschaft und sein Verhältnis zu ihren Lehren verfolgt werden. Das steht fest: so universal Goethes Geist auch war, mit der Sprachwissenschaft hat er sich nie eingehend beschäftigt. Dadurch aber, daß er den bahnbrechenden Geistern auf diesem Gebiet persönlich oder brieflich nahestand, dadurch, daß, wie erwähnt, die Gehilfen seines Alters Philologen waren, wurden ihm die wichtigsten sprachwissenschaftlichen Fragen vermittelt, und die Äußerungen, die wir darüber finden, bewcisen, daß er auch Verständnis für dies ihm an sich fernliegende Gebict hatte und sich der Führung der Sprachgelehrten gern überließ.

In jungen Jahren hat Goethe einmal selbständig die Behandlung einer sprachwissenschaftlichen Frage aufgegriffen, indem er 1773 das "Mit zungen reden" der Jünger Christi auf eine Art zu crklären suchte, die er in Dichtung und Wahrheit selbst spăter abstrus nennt. 


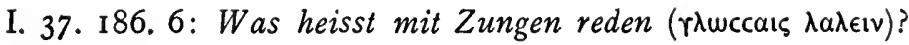
Vom Geist erfüllt, in der Sprache des Geistes des Geistes Geheimnisse verkündigen . . . Der verheissene Geist erfüllt die versammelten Fünger mit der Kraft seiner Weisheit. Die gött. lichste Empfindung strömt aus der Seel' in die Zunge und flammend verkündigt sie die grossen Thaten Gottes in einer neuen

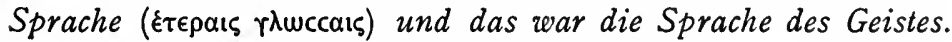
Das war jene einfache, allgemeine Sprache, die aufzufinden mancher grosse Kopt vergebens gerungen... Mehr als Panto. mime, doch unarticulirt muss die Sprache gewesen sein. (Zwo biblische Fragen II. I773.)

I. 28. 104. 14: Auch das neue Testament war vor meinen Untersuchungen nicht sicher; . . . auch in dieser Region glaubte ich allerhand Entdeckungen zu machen. Fene Gabe der Sprachen, am Pfingstfest in Glanz und Klarheit erteilt, deutete ich mir auf eine etwas abstruse Weise, nicht geeignet, sich viele Theilnehmer zu verschaffen.

(D. W. I2. I813.)

Zunächst war es in Straßburg Herder, der den jungen Goethe in seine sprachphilosophischen Gedankengänge einweihte; der Schüler gesteht aber selbst, daß er sich des Lehrers Anschauung vom Ursprung der Sprache nicht anzueignen vermochte:

I. 27. 309. I0: Ich hatte über solche Gegenstände niemals nachgedacht... Auch schien mir die Frage einigermassen müssig; denn wenn Gott den Menschen als Menschen erschaffen hatte, so war ihm ja so gut die Sprache als der aufrechte Gang aner. schaffen; so gut er gleich merken musste, dass er gehen und greifen könne, so gut musste er auch gewahr werden, dass er mit der Kehle zu singen und diese Töne durch Zunge, Gaumen und Lippen auf verschiedene Weise zu modificieren vermöge. War der Mensch göttlichen Ursprungs, so war es ja auch die Sprache selbst, und war der Mensch, in dem Umkreis der Natur betrachtet, ein natürliches Wesen, so war die Sprache gleichtalls natürlich. Diese beiden Dinge konnte ich wie Seel' und Leib niemals aus. einander bringen. Süßmilch, bei einem cruden Realismus doch 
etwas phantastisch gesinnt, hatte sich für den götllichen Ursprung entschieden, das heisst, dass Goll den Schulmeister bei den ersten Menschen gespiell habe. Herders Abhandlung ging darauf hinaus, zu zeigen, wie der Mensch als Mensch wohl aus eignen Kräften zu einer Sprache gelangen könne und müsse. Ich las die Abhandlung mil grossem Vergnügen und zu meiner besonderen Kräftigung; allein ich stand nicht hoch genug, weder im Wissen noch im Denken, um ein Urteil darüber zu begründen. (D. W. IO.)

Auch Hamanns Arbeiten über das Thema waren Goethe, jedenfalls durch Herders Vermittelung, bekannt. Nach IV. 31. 17. 25 besaß er außer den anderen Schriften des nordischen Magus (z. B. Kreuzzüge des Philologen, in denen Hamann seine Ansicht von der Poesie als Muttersprache des Menschen dartut) „ein bedeutendes Manuscript" aus dem Jahre I772, also jedenfalls von „Zwo Rezensionen; nebst einer Beilage betr. den Ursprung der Sprache". (30. XI. I818 an W. Dorow.)

In der Italienischen Reise referiert Goethe eingehender über die im Anschluß an Herder maßgebend gewordenen sprachphilosophischen Ideen, ohne jedoch aus eignem Urteil Stellung dazu zu nehmen; das sog. ,etymologische Spiel", zu dem für den Künstlerkreis in Rom diese Frage Veranlassung gab, kann als wissenschaftliche Beschäftigung nicht angesprochen werden; Goethe selbst legt ihm ja auch nur den Wert eines amüsanten Zeitvertreibs bei.

Heinemann XIV. 14I: Zu jener Zeit war im Gefolg der Herderischen Preisschritt "Uber den Ursprung der Sprache" und in Gemäßheit der damaligen allgemeinen Denkweise die Vorstellung herrschend: Das Menschengeschlecht habe sich nicht von einem Paare aus dem hohen Orient herab über die ganze Erde verbreitet, sondern zu einer gewissen produktiven Zeit des Erdballs sei . . . . da und dort in mancher günstigen Lage die Menschenart mehr oder weniger vollendet hervorgetreten. Ganz im innerlichsten Bezug auf seine Organe sowohl als seine Geistestähigkeilen sei nun dem Menschen die Sprache an. 
geboren. Hier bedürfe es keiner natürlichen Anleitung, so wenig als einer Überlieferung. Und in diesem Sinne gebe es eine allgemeine Sprache, welche zu manifestiren ein jeder autochthonische Stamm versucht habe. Die Verwandtschaft aller Sprachen liege in der Übereinstimmung der Idee, wonach die schaffende Kraft das menschliche Geschlecht und seinen Organismus gebildet. Daher komme denn, dass teils aus innerem Grundtriebe, teils durch äussere Veranlassung die sehr beschränkte Vokal-und Konsonantenzahl zum Ausdruck von Getühlen und Vorstellungen richtig oder unrichtig angewendet worden; da es denn natür. lich, ja notwendig sei, dass die verschiedensten Autochthonen teils zusammengetroffen, teils van einander abgewichen und sich diese oder jene Sprache in Folge entweder verschlimmert oder verbessert habe. Was von den Stammworten gelte, gelte denn auch von den Ableitungen, wodurch die Bezüge der einzelnen Begriffe und Vorstellungen ausgedrückt und bestimmter bezeichnet werden. Dies möchte denn gut sein und als ein Unerforschliches, nie mit Geroißheit zu Bestimmendes auf sich beruhen ....Er [Moritz $]^{1}$ ) hat ein Verstandes- und Empfindungsalphabet erfunden, wodurch er zeigt, dass die Buchstaben nicht willkürlich, sondern in der menschlichen Natur gegründet sind und alle gewissen Regionen des inneren Sinnes angehören, welchen sie denn auch, ausgesprochen, ausdrücken. Nun lassen sich nach diesem Alphabet die Sprachen beurteilen und da findet sich, dass alle Völker versucht haben, sich dem inneren Sinn gemäss auszudrücken, alle sind aber durch Zufall und Willkür vom rechten Wege abgeleitet worden. Demzufolge suchen wir in den Sprachen die Worte auf, die am glücklichsten getroffen sind, bald hat's die eine, bald die andere; dann verändern wir die Worte, bis sie uns recht dünken, machen neue, usw. Fa wenn wir recht spielen wollen, machen wir Namen für Menschen, untersuchen, ob diesem oder jenem sein Name angehöre etc. etc. Das etymologische Spiel beschäftigt schon so viele Menschen

I) Der Kunstgelehrte Karl Philipp Moritz, mit dem Goethe in Rom bekannt wurde, und der damals an einem Armbruch daniederlag. 
und so gibt es auch uns auf diese heitere Weise viel zu tun. Sobald wir zusammenkommen, wird es wie ein Schachspiel vorgenommen, und hunderterlei Kombinationen werden versucht, so dass, wer uns zufällig behorchte, uns für wahnsinnig halten müsste. Auch möchte ich es nur den allernächsten Freunden vertrauen. Genug es ist das witzigste Spiel von der Welt und übt den Sprachsinn unglaublich. (Ital. Reise II. Moritz als Etymolog. Dezbr. I787.)

Lediglich wiedergebend sind auch zwei Äußerungen über Sprachentstehung aus späteren Jahren:

I. 35. 188. 2: Der Conflict zwischen den Anatoliern und Ökumeniern war damals lebhafter als jetzt; man fing an sich zu überzeugen, dass das Menschengeschlecht überall unter gewissen Naturbedingungen habe entstehen können, und dass jede so entstehende Menschenrace sich ihre Sprache nach organischen Gesetzen habe erfinden müssen. (Tag- $u$. Jahreshefte I804.) Anatolier heißen die Vertreter der Ansicht, daß das Menschengeschlecht nur im Orient entstanden sei. Die Ökumenier halten gleichzeitige Entstehung verschiedener Rassen an verschiedenen Orten für möglich. Die hier wiedergegebene Ansicht ist also wie die im vorigen Beleg hervortretende ökumenisch.

I. 4I I. 128. 3: Die Urzeit der Welt, der Nationen, der einzelnen Menschen ist sich gleich. Wüste Leerheit umfängt erst alles, der Geist jedoch brütet schon über Beweglichem und Gebildetem. Indess die Autochthonenmenge staunend umherblickt... schaut ein begünstigter Geist in die grossen Welt. erscheinungen hinein, bemerkt, was sich ereignet und spricht das Vorhandene ahnungsvoll aus, als wenn es entstünde. So haben wir in der ältesten Zeit Betrachtung, Philosophie, Benamsung und Poesie der Natur in Einem. (Geistesepochen. K. u. A. I. 3. 1817.)

Dic Bekanntschaft mit Fr. v. Schlegel, den Brüdern Grimm und Wilhelm v. Humboldt ${ }^{1}$ ) brachte Goethe in nähere Fühlung

1) Dic neue Ausgabe des Briefwechsels Goethes mit den beiden Humboldt von L. Geiger konnte leider nicht mehr eingesehen werden. 
mit der neuen Sprachwissenschaft. Er läßt sich von ihnen klug belehren und anregen, ohne aber tief in die Probleme einzudringen und auch ohne sich ein eingehendes Verständnis anzumaßen, wie er in einem Briefe an Jakob Grimm offen zugesteht. G. G. XIV. 23 I: Lassen Sie mich von Zeit zu Zeit an Ihren Bemühungen Theil nehmen, die ich, wenn gleich nur aus einer gewissen Ferne, zu schätzen weis, auch in dem mir übersehbaren Umfang wahrhaft zu bewundern die Freude habe (30. VIII. I824). Wilhelm Grimm gegenüber bedankt er sich für die Übersendung der dänischen Heldenlieder mit sachlichen Worten: IV. 22. I48. I I: Sehr angenehm ist es auch zu sehen, wie gewisse Gegenstände sich bei mehreren Völkern eine Neigung erworben und von einem jeden nach seiner Art roher oder ausgebilder behandelt werden (I8. VIII. I8II). Die Beziehungen Goethes zu den Brüdern Grimm, die uns, soweit sie sich nicht auf literarische Fragen beziehen, noch weiterhin beschäftigen werden, sind mustergültig von Steig untersucht. ${ }^{1}$ )

Der Besuch Wilhelm v. Humboldts bei Goethe im Jahre I 8 I 2 (III. 4. 294. 2I) ließ bei diesem hauptsächlich lebhaftes Interesse für die Herstellung einer Sprachkarte aller Völker zurück:

IV. 23. 84. 7 : Besonders war mir peinlich, dass ich Ihre schöne Darstellung, wie die Sprachen über die Welt verbreitet seyen, nicht gleich völlig aufgezeichnet, ob mir gleich das Meiste davon geblieben ist ... [Bitte um Aufzeichnung einer Übersicht] ich würde mir eine Hemisphären-Charte darnach illuminieren ... und so würde mir Ihre Sprachcharte in gar vielen Fällen zu Auffrischung des Gedächtnisses und zum Leitfaden bei mancher Lectüre dienen (31. VIII. I8I2 an W. v. Humboldt). IV. 23. 278. Io erfahren wir Näheres über die Anlegung der Karte nach Hauptsprachen und Dialekten nach Humboldts Angaben (8. II. I8I3 an W. v. Humboldt). Die Tagebücher

I) Reinh. Steig: Goethe und die Brüder Grimm. Berlin I892. Hier auch S. I77 bzw. 80 unsere beiden Belege.

R a s ch, Goethe u. die deutsche Sprache. 
weisen vom Januar dieselben Spuren nach: III. 5. I. $5 \mathrm{Nach}$ Tisch mit Riemer Sprachvertheilung über die Welt (I. I. I8I3). III. 5. I. I I Tableau des peuples qui habitent l'Europe par Fréderic Schoell (2. I. I8I3). ${ }^{1}$ ) III. 5. 2. 3 Mittag Prof. Riemer, ïber die Sprachkarte (3. I. 18I3). Die Annalen vermelden: I. 36. 8I. 9 Geographische Karten zu sinnlicher Darstellung der über die Welt vertheilten Sprachen wurden mit Wilh. v. Humboldts Theilnahme bearbeitet, begränzt und illuminirt (Tag- u. Jahreshefte I8I3). Die Frage beschäftigt Goethe bis $182 \mathrm{I}$.

IV. 34. 238. 23: Von Ihrem Herrn Bruder habe lange nichts unmittelbar vernommen, durch Freunde jedoch, dass er einen meiner alten sehnlichsten Wünsche zu erfüllen gedenkt, eine anschauliche Karte auszuarbeiten, wie die Sprachen über das Erdenrund ausgetheilt sind. Er hatte früher die Gefälligkeit, mir in einem ähnlichen Unternehmen beizustehen, wovon ich noch allerliebste Mittheilungen verwahre (I6. V. I82 I an Alexander v. Humboldt) und:

IV. 34. 289. 21 : Sowie ich höre, haben Sie auch die Sprachkarte, die mir früher so wünschenswerth schien, weiter aus. gearbeitet, wodurch auch mir eine grosse Zufriedenheit vorbereitet wird (I8. VI. I82I an W. v. Humboldt).

Aus der geplanten Sprachkarte ist aber schließlich doch nichts geworden. Im gleichen Jahre I82 I bestätigt Goethe dem Freunde seine Übereinstimmung mit den in dessen Abhandlung „Über das vergleichende Sprachstudium" dargelegten Gedanken.

IV. 35. 213. 2: Sie [die Sendung der genannten Arbeit] hat mir und dem wackeren Riemer grosse Freude gemacht; mussten wir doch Ihr treffliches Heft übereinstimmend finden mit unserer Uberzeugung, frisch aufklärend und weiter deutend, alles an-

1) Gemeint ist nach Nachweis der Wcimarer Ausgabe: Tableau des peuples qui habitent l'Europe, classés d'après les langues de l'Europe par Max S. Fr. Sclioell. Paris 1812. 
regend, was dem Sprechenden, das heisst dem verständig vernünftigen Menschen nur Bedeutendes im Innern angehören mag und was sollte nicht noch alles davon zu rühmen seyn. Lassen Sie mich nur noch Folgendes herausheben: indem Sie die Sprache als Hülfsmittel gar trefflich anpreisen, geben Sie uns ferner zu bedenken, dass die Sprache, wenn sie auf einen gewissen Punct gelangt, unveränderlich sey und von ihren anerkannten Mängeln nicht befreyt werden könne; demohngeachtet aber in und aus sich selbst alles Menschliche, vom Tiefsten bis zum Höchsten, aussprechen, ausdrücken, bestimmen und erweitern könne und müsse. Hierdurch haben Sie mir, mein Theuerster, einen Spiegel vorgehalten, worin ich am Ende meiner Laufbahn erkennen kann, was ich als Dichter und Schriftsteller geleistet habe und was ich hätte leisten sollen. Hier sey geschlossen, damit wir uns nicht in die Fluth wagen, die uns zu verschlingen droht (24. XII. I82 I an W. v. Humboldt). Nach Ausweis der Tagebücher beschäftigte sich Goethe bis I 823 mit dem Humboldtschen Werke. III. 8. I43. 25 Das vergleichende Sprachstudium v. Humboldts ... Abends Prof. Riemer... sodann von Humboldts Sprachwerk gelesen und dabey Bemerkungen gemacht (7. XII. 182 1). III. 9. I41. 23 Von Humboldt über das vergleichende Sprachstudium, Vorlesung in der Academie (7. XI. I823). Ohne den Kernfragen der Studie näher zu treten, entnimmt er ihr das ihm Naheliegende, die Auseinandersetzung über den bei allen Mängeln bestehenden Reichtum der Sprache. Selbstredend wird, wie schon eingangs angedeutet, Humboldts Darlegung seine Anschauungen von der Unzulänglichkeit des Sprachmaterials beeinflußt haben. Für die Übersendung einer Sprachstudie über das Indische wird IV. 4I. 204. 8 gedankt: Nun aber muss ich versichern, dass mir und Riemern das übersendete Programm recht zu Gunsten gekommen und über Sprache und Philosophie zu verhandeln gar löblichen Anlass gegeben. Abgeneigt bin ich dem Indischen keineswegs, aber ich fürchte mich davor, denn es zieht meine Einbildungskraft ins Formlose und Difforme (22. X. I826). 
Bis an sein Ende bleibt Goethe mit W. v. Humboldt und seinen Arbeiten in Fühlung. Humboldt 294 (auch Riemer I72): Im Besondern darf ich wohl sagen, dass ich Ihnen oft näher geführt werde als Sie wol denken, indem die Unterhaltungen mit Riemer gar oft aufs Wort, dessen etymologische Bedeutung, Bildung und Umbildung und Fremdheit hingeführt werden (I. XII. I83I an W. v. Humboldt). Über diese Unterhaltungen geben außer den schon angemerkten allgemeinen Angaben einige wenige Notizen genauere Auskunft: G. II. I98. ,war die Rede... über

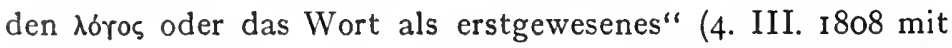
Riemer). - III. 9. 307. 24: Wir [G. und Riemer] besprachen besonders auch die eigentlichen Entwicklungen der Sprache aus sich selbst und die grossen dabey obwaltenden Schwierigkeiten, woher die Differenzen der verschiedenen Meynungen und Unmöglichkeit sie zu vereinigen entspringt (14. XII. I824). - III. I3. 30. 3: Riemer. Uber Spracheigenheiten und Sprachgeheimnisse. Die fortdauernden Veränderungen in der Sprache. Neue Regeln, Recht und Unrecht abgeleitet... wenn man bey'm Auflösen der Probleme es den Menschen leicht macht, so hat man die Menge vor sich, und da zeigt sich denn allgemeine Überzeugung. Es ist den Männern von Fach nicht übel zu nehmen, wenn sie sich's bequem machen. Wenn man statt des Problems ein anderes hinsetzt, so denkt die gleichgültige Menge schon, es wäre ihr geholfen. Feder sucht sich in seinem Fach zu sichern und lässt den andern auch $z u$, sich mit den ihrigen zu befestigen. So habe ich mit Verwunderung in ihrem Fache sehr consequente, ver. ständige, vortreffliche Männer gesehen, wie sie in anderen Fächern das Absurdeste zugaben und nur sorgten, dass man ihre Kreise nicht störe. Auch in den Wissenschaften ist alles ethisch, die Bchandlung hangt vom Charakter $a b$ (15. II. I83I). Die Bezichung dieser Auslassung mit ihrem Ausfall gegen die Fachgelchrten ist dunkel. Wir sehen aus allem, Goethe war dabei nur empfangend. Wie leicht andere Interessen das für sprachliche Fragen ablenkten und aufzehrten, beweist eine Bcmerkung aus den Annalen von 1820, die sprachlich beginnt 
und auf die geliebte Geologie überspringt: I. 36. I73. I3: Eine Bemerkung konnte mir nicht entgehen, dass die spracherfindenden Urvölker, bei Benamung der Naturerscheinungen und deren Verehrung als ... Gottheiten mehr durch das Furchtbare als durch das Erfreuliche derselben aufgeregt werden ... Mir schienen ... die neusten geologischen Theoristen von eben dem Schlage, die ohne feuerspeiende Berge, Erdbeben ... keine Welt zu schaffen wissen. (Tag- u. Jahreshefte I820.)

Die ganz vereinzelte Darlegung über Sprachübung und Sprachunterricht aus den Wanderjahren, die an ihrem Teil auch von der Hochschätzung der Sprache zeugt, mache den Schluß:

I. 25 I. 3. 22: Und so war ihm [Wilhelm] denn sehr lieb zu vernehmen, dass gerade mit dieser gewaltsam und rauh scheinenden Bestimmung [Pferdezucht] die zarteste von der Welt verknüpft sei: Sprachübung und Sprachbildung ... „Zu jenen Sprachübungen, fuhr der Aufsehende fort, wurden wir dadurch bestimmt, dass aus allen Weltgegenden Fünglinge sich hier befinden. Um nun zu verhüten, dass sich nicht, wie in der Fremde zu geschehen pflegt, die Landsleute vereinigen, und von den übrigen Nationen abgesondert, Parteien bilden, so suchen wir durch freie Sprachmitteilung sie einander zu nähern. Am notwendigsten aber wird eine allgemeine Sprachübung, weil bei diesem Festmarkte [bei dem Wilhelm den Aufseher trifft] jeder Fremde in seinen eignen Tönen und Ausdrücken genugsame Unterhaltung, beim Feilschen und Markten aber alle Bequemlichkeit gern finden mag. Damit jedoch keine babylonische Verwirrung, keine Verderbniss entstehe, so wird das Fahr über monatweise nur eine Sprache im allgemeinen gesprochen, nach dem Grundsatze, dass man nichts lerne ausserhalb des Elements, welches bezwungen werden soll... Zeigt jedoch einer der Unsrigen zu dieser oder jener Sprache besondere Neigung, so ist ... für treuen und gründlichen Unterricht gesorgt." 
Über die pädagogische Berechtigung dieser Grundsätze zu rechten, ist hier nicht der Ort. Wenn auch, wie Harnack ${ }^{\mathbf{1}}$ ) richtig bemerkt, der Sprachunterricht in der pädagogischen Provinz lediglich praktischen Zwecken dienen soll, so darf doch nicht übersehen werden, daß Goethe selbst einleitend Sprachübung als „,zarteste Bestimmung von der Welt" bezeichnet und so über seine Wertschätzung keinen Zweifel läßt. ${ }^{2}$ )

I) Harnack a. a. O. S. 270 .

2) Vgl. Muthesius, K.: Goethe und Pestalozzi (Leipzig 1908), wo im 8. Kapitel der Nachweis erbracht ist, daß G. auch in diesen pädagogischen Ansichten den Urteilen anderer folgt. 


\section{ZWEITER TEIL}

GOETHE UND DIE DEUTSCHE SPRACHE 

Ebenso wie sich Goethe über Sprache als solche nur gelegentlich ausgesprochen hat, lassen sich auch nur aphoristische Bemerkungen und Urteile über die deutsche Sprache nachweisen. Ein paar Verse, eine Buchbesprechung, höchstens ein kleiner Aufsatz. Daß in den täglichen Unterhaltungen, deren allgemein gehaltene Registrierung in den Tagebüchern wir im I. Kapitel nachwiesen, sich manche auch mit der Muttersprache im besonderen beschäftigten, versteht sich von selbst. Besonders als Gesprächsgegenstand genannt ist sie in folgenden Notizen:

III. 3. 281. 19: $Z u$ Durchlaucht dem Herzog: über den von der bayerischen Academie vor kurzem ausgesetzten Preis aut eine deutsche Sprachlehre und sonstiges die Sprache betreffend (3. X. 1807).

III. 4. 209. I8: Abends Germanismen in Vergleich mit den Gallicismen (28. V. I8I I).

III. 4. 349. I8: Alte deutsche Sprache, Sprüchwörter usw. (3. XII. I8I2).

III. 5. 298. I6: Radlofs Sprachen der Germanen (28. XII. 1816).

III. 6. 75. II: von Weimar Reinbecks deutsche Grammatik (9. VII. I 8 I 7). ${ }^{1}$ )

Eine Spielerei mit Wortbildung wird für wichtig genug erachtet, ähnlich dem „etymologischen Spiel" in Rom besonders aufgezeichnet zu werden: III. 3. 274. 5: Vorher und

I) Reinbeck: Deutsche Sprachlehre zum Gebrauch deutscher Schulen. Lübeck I802; II. VII. I 817 wird nach III, 6. 76. 3 eine von Vulpius gemachte Auswahl von drei Sprachlehren der Jenaer Universitätsbibliothek zurückgesandt. (W. A.) 
nachher Augustens und Riemers Spässe mit der Bildung von lauter collectiven Substantivwörtern mit der Vorschlagssylbe ge, als: Geöchs, Gekälb, Gebäuch, Gehühn ectr. (10. IX. I807 im Wagen auf der Rückreise von Karlsbad). Wir erinnern uns dabei, daß Goethes Badeaufenthalt von 1807 reich an sprachlichen Unterhaltungen mit Bergrat Werner war.

Als Goethe am 2I. VIII. I8I6 vom Freiherrn vom Stein der Savignysche Entwurf zur Bildung einer Gesellschaft für deutsche Geschichte zugestellt wird, beschäftigt ihn derselbe nach Ausweis der Tagebücher (III. 5. 237. I4; 265. 26; 266. I. $28 ; 283$. 2I) lebhaft; er zieht von Wilhelm Grimm Erkundigungen über den Paragraphen I4 des Entwurfes ein, der altdeutsche Sprache und Literatur behandelt, hält dem Großherzog Vortrag zur Sache (III. 5. 274) und macht auch berichtliche Vorlage, in der er aber gesteht: da ich mich in diesen Regionen nur als Gast und Wanderer aufhalte. Er gibt sodann die Grimmschen Vorschläge an Stein weiter, und damit scheint die Frage ihr Interesse für Goethe verloren zu haben; die betreffenden Papiere werden erst I820 wieder gefunden (III. 8. I9. II), nachdem sie als verloren gegolten hatten. $\left.{ }^{1}\right)$

Spuren dafür, daß Goethe die Grimmsche deutsche Grammatik, die von I8I9 an erschien, und deren I. Band schon I822 dic 2. Auflage erfuhr, kannte, sind, trotz Steig, nicht mit Sicherheit nachweisbar. Dieser meint nämlich, daß das Buch, auch wenn es von Goethe nicht erwähnt sei, doch ,,in seinen Beobachtungskreis gedrungen" sei. Für mich ist das unwahrscheinlich, da es nicht Goethes Art ist, Bücher, die ihn beschäftigten, nicht wenigstens in Briefen oder Gesprächen lobend oder tadelnd zu nennen. Wenn er Jakob Grimm einen "Sprachgewaltigen" nennt, so setzt dieses Lob doch nicht dic Kenntnis der Grammatik voraus. ${ }^{2}$ )

1) Vgl. die ausführliche Behandlung der Frage bei Steig a. a. O. $129 \pi$. und 154 .

2) Vgl. Steig a. a. O. 219. 
Goethes Beschäftigung mit dem deutschen Altertum erstreckt sich, wie schon $\mathrm{Große}^{1}$ ) nachweist, nahezu ausschließlich auf Kunst und Literatur. Mit altdeutscher Sprache hat er sich nie um ihrer selbst willen abgegeben. Wenn er ins Mhd. so weit eindrang, daß er den Weimarer Damen die Nibelungen und anderes aus dem Urtext vorlesen und übersetzen konnte (Annalen I 807 und I 809), so sind damit kaum Sprachstudien verbunden. ${ }^{2}$ ) Auch fällt bei den vielen Erwähnungen ahd. und mhd. Sprachquellen und bei den zahlreichen Urteilen über geschichtliche, literarische Beziehungen derselben nicht eines über ihre Sprache. ${ }^{3}$ ) Die Minnesänger werden sogar ausdrücklich zum Teil ihrer Sprache wegen, die man erst hätte studieren müssen, abgelehnt. $\left.{ }^{4}\right)$ Vielleicht liegt ein ähnlicher Grund dafür vor, daß eine "treue reproducierende Darstellung der Nibelungen", zu der die Vorarbeiten schon im Gang waren, liegen blieb. (IV. 3I. 409. Konzept an Schubarth v. 2I.VIII. I819.) Mit der Etymologie Nibelungen $=$ Nebelvölker ${ }^{5}$ ), die aber jedenfalls übernommen ist, trifft er das Richtige. Auch scheint er nach dem Zeugnis der Frau v. Stein: „Ohne seine Erklärung hätten wir's alle nicht verstanden" ${ }^{\text {(6) }}$, das Mhd, immerhin so weit beherrscht zu haben, daß er das Nibelungenlied seinen Damen nicht nur übersetzen, sondern auch wohl sprachlich einigermaßen interpretieren konnte.

Die Bemühungen um die Entzifferung der sogenannten Heilsberger Inschrift (I. 42 I. 75; Briefwechsel mit Sprachforschern wie Gg. F. Grotefend und v. Hammer-Purgstall IV. 3 I : 104. I26. I45; IV. $32: 32$.38) entspringen nicht sprach-

I) Grosse, H.: Goethe und das deutsche Altertum. Göttinger Dissertation. Dramburg 1875 .

2) Vgl. auch Kap. 7 Seite 104.

3) Vgl. die eingehende Untersuchung von E. Jenny: Goethes alt. deutsche Lektüre. Baseler Dissertation I900; auch Steig a. a. O. 46-47.

4) Jenny a. a. O. 37 .

5) Düntzer, H.: Charlotte v. Stein II, 301.

6) Morris: Goethestudien I, 163. 
lichem, sondern in erster Linie geschichtlichem Interesse. Nach den in der zweiten Hälfte des 42. Bandes der W. A. veröffentlichten Fragmenten zur Literatur hat Goethe sich auch einmal mit der Studentensprache befaßt. Es hat sich ein „Studenten-Comment" überschriebenes, I5 Ausdrücke enthaltendes Verzeichnis studentischer Wörter mit Erklärung gefunden (I. 42II. 516: Pech - Unglück, Treffer - Glück, Dämmerfürst - Phlegmaticus, in Verschiß thun - in Bann thun u. s. w.).

\section{FÜNFTES KAPITEL.}

\section{TADEL UND LOB DER MUTTERSPRACHE.}

Von der Seite aus, die Goethe nationale Gesinnung absprechen will, werden mit Vorliebe auch Worte angeführt, die den Dichter in feindlichem Verhältnis zu seiner Muttersprache zeigen. Es gehört nicht hierher, eine Lanze für Goethes Deutschtum zu brechen. Nur so viel sei gesagt: obgleich er Sohn des von kosmopolitischer Begeisterung erfüllten I8. Jahrhunderts ist, hat er sich stets als Deutscher gefühlt, wenn es seinem Wesen auch widersprach, mit seiner Vaterlandsliebe an die breite Öffentlichkeit zu treten, und wenn sie auch durch sein sonstiges Denken und Empfinden manche Einschränkung erfuhr. Über seine Stellung zu nationalen Fragen haben sich namentlich $\mathrm{H}$. Grimm und neuerdings ausführlicher $B^{1} e^{1}$ ) ausgesprochen. Erinnern wir uns weiterhin, daß im Kampf zwischen Begriff und Wort gar manche harte Äußcrung gegen dic Sprache fällt, dic mit nationalen Anschauungen nichts zu tun hat, bedenken wir endlich, daß die deutsche Sprache des 18. Jahrhunderts für einen Dichter wenig Lobenswertes hatte, so darf es nicht wundernehmen, daß wir eine Reihe abfälliger Urteile über sie zu verzeichnen haben, die zu beschönigen und zu mildern keine Ursache vorliegt, da

1) Grimm a. a. O. II, 254 fr.; Bode: Stunden mit Goethe III, 13 ff. 
sie wohl verständlich sind, und da es auch an gegenteiligen $\mathrm{Be}$ legen keineswegs fehlt. Diejenigen Aussprüche, die der deutschen Sprache eine fremde lobend entgegenstellen, werden wir zumeist im dritten Hauptteil behandeln, weil wir dort die Gründe für dieses Hervorheben anderer Sprachen es ist namentlich das Italienische - eingehender würdigen können. Nur einer sei hier aufgenommen: IV. 4. 283. 24: Dann las ich zur Abwaschung und Reinigung einiges griechische, davon geb ich Ihnen in einer unmelodischern und unausdrückendern Sprache, wenigstens durch meinen Mund und Feder, auch Ihr Theil (7. IX. I780 an Frau v. Stein). „Unausdrückender" wird das Deutsche getadelt. Hört man diesem Wort nicht den Zwang an, mit dem es gebildet ist? Vielleicht führt uns gerade das dem Verständnis der viel beredeten und zerklärten Venetianischen Epigramme näher, in denen Goethe mit der Muttersprache abrechnet:

I. 1. 3I4. V. I37:

Vieles hab' ich versucht, gezeichnet, in Kupfer gestochen, Öl gemalt, in Thon hab' ich auch manches gedruckt, Unbeständig jedoch, und nichts gelernt und geleistet; Nur ein einzig Talent bracht' ich der Meisterschaft nah: Deutsch zu schreiben. Und so verderb' ich unglücklicher Dichter In dem schlechtesten Stoff leider nun Leben und Kunst.

(Ven. Epigr. 29. I790.)

I. I. 325. V. 349:

Was mit mir das Schicksal gewollt? Es wäre verwegen, Das zu fragen - denn meist will es mit vielen nicht viel! Einen Dichter meint es zu bilden, es wär' ihm gelungen, Hätte die Sprache sich nicht unüberwindbar gezeigt.

(Ven. Epigr. 76. 1790.)

Kluge will ${ }^{1}$ ) das zweite Epigramm im Gegensatz zur italienischen Sprache aufgefaßt wissen, also die „Unüberwindlich-

I) Kluge a.a. O. 37 . 
keit" auf das Unmelodische des Deutschen bezogen wissen. Er verweist auf Briefstellen, die wir unten wiedergeben. Die klangvolle, vom Dichter stets geliebte, ihn bei Abfassung des Epigramms umtönende Sprache Italiens mag bei dem Urteil mitgewirkt haben, allein bestimmt hat sie es meines Erachtens nicht. Riegel will die unüberwindlichen Hindernisse in den prosodischen Schwierigkeiten ${ }^{1}$ ) der deutschen Sprache finden, von denen Goethe in der italienischen Reise berichtet. Knauth $^{2}$ ) verweist darauf, daß Goethe keinen bestimmten Stil hatte, sondern sich je nach Zeit und Werk die entsprechende Weise des Ausdruckes schuf und errang. „In der Empfindungen überströmender Fülle und raschem Wechsel, die naturgemäß nach immer neuem, mannigfaltigem Ausdruck drängten", hat die Klage über die unüberwindliche Sprache ihren Grund. Sie richtet sich also nicht gegen die deutsche Sprache, sondern gegen die Sprache überhaupt als Ausdrucksmittel für des Dichters Reichtum an Gefühlen und Empfindungen. $\mathrm{DaB}$ auch andere sprachgewaltige Geister ihren Mißmut über die Sprödigkeit des Sprachstoffes auslassen, bestätigt Knauths Auffassung. Waetzoldt ${ }^{3}$ ) belegt ähnliche Äußerungen für Luther und Lessing; für Schiller und J. Möser haben wir die Nachweisungen schon oben gebracht.

Was das erste Epigramm anlangt, so ist die Goethephilologie sich heute darüber einig, daß unter dem ,,schlechtesten Stoff" nicht, wie man früher vielfach annahm, der frivole Inhalt der Epigramme gemeint ist, sondern die deutsche Sprache. ${ }^{4}$ ) Schon Klopstocks Entgegnung wurde dadurch

1) Vgl. darüber Kapitel 1o Metrik.

2) Knauth, Paul: Goethes Sprache und Stil im Alter. Leipzig 1898. S. 27.

3) Waetzoldt, St.: Die Jugendsprache Goethes. Zeitschr. d. allg. deutsch. Sprachver. I, Nr. 17 (1887), S. 265.

4) Vgl. Mauthner a. a. O. I29ff.; Riegel, H.: Einige Äußerungen Goethes und Schillers über die deutsche Sprache. Zeitschr. d. allg. deutsch. Sprachver. 1893. Nr. 1 u. 2. S. 7 ; Waetzoldt a. a. O. 265; Biedermann: Goetheforschungen II. Lcipzig 1886. S. 362; Hempel (Löper) I, 444; Heinemann I, 211. 
hervorgerufen, der die geschmähte Sprache sich also verteidigen läßt:

„Goethe, du dauerst dich, daß du mich schriebst;

Wenn du mich kenntest, wär dies dir nicht Gram.

Goethe, du dauerst mich auch."

Aber „Gerade dem nach Vervollkommnung Ringenden, dem um das dichterische Dasein Kämpfenden dürften derartige Stoßseufzer gestattet sein, trotz Klopstock" (Löper). Die deutsche Sprache des 18. Jahrhunderts, die ein Patriot wie der Herzog Karl August in einem Briefe an Schiller mit Hagel vergleicht, der an die Fenster schlägt ${ }^{\mathbf{1}}$ ), deren Ausdrucksmittel spröde und beschränkt waren und die erst durch Goethe auf die Höhe ihrer heutigen Vollkommenheit gehoben wurde, diese deutsche Sprache konnte sehr wohl der Dichter einen schlechten Stoff nennen, zumal in mißmutiger Stunde, zumal in Venedig, wo ihn das Italienische mit seinem Wohllaut, seiner Klangfülle schmeichelnd umtönte. Das Deutsche ist unausdrückender, unüberwindbar, ein schlechter Stoff: nicht die Muttersprache an sich soll damit verworfen werden, sondern nur das Unfügsame, Spröde der damaligen deutschen Sprache beklagt werden; und zudem gesteht der unmutige Dichter ja selbst, $\mathrm{da} ß$ er es im Deutschschreiben trotz der Widerstände zur Meisterschaft gebracht, den Stoff also doch sich willig gemacht habe.

Weitere abfällige Äußerungen über die Muttersprache sind verhältnismäßig so selten, daß sie sehr wohl als spontane Ergüsse des Mißmuts und schlechter Laune gelten können; einmal heißt sie einsilbig, dann wunderlich, ohne Geschmack:

IV. 10. 22. 17: Ew. Durchl. wird bekannt seyn, dass die Sprache der Batterien noch einsilbiger ist als die deutsche Sprache. (22. VI. I793 an Herzogin Amalie von der Belagerung v. Mainz.)

1) Riegel a. a. O. 8. 
IV. I0. 348. 6: Von den Anmerkungen [Schillers] zu den Elegien wollen wir, so viel die Zeit erlaubt, Gebrauch machen. In so einer wunderlichen Sprache wie die deutsche ist, bleibt freylich immer etwas zu wünschen übrig. (I5. XII. I795 an Schiller.)

G. III. 95 (Riemer 348): Geschmack ist ein Euphemismus. Deutsche haben keinen Geschmack weil sie keinen Euphemismus haben und zu derb sind. Es kann keine Sprache euphemistisch seyn und werden als die, in der man diplomatisirt. (26. X. 18I3.) Vgl. dazu I. 42 II. 244. 19: Man spricht soviel von Geschmack: der Geschmack besteht in Euphemismen. Diese sind Schonungen des Ohres mit Aufregung der Sinne. Eng mit der Gesprächsstelle berührt sich das Paralipomenon aus dem Nachlaß: I. $42^{\text {II. } 392 . ~ N r . ~} 9$ u. IO: Geschmack= Euphemism. Cultur der Sprache und Styl besteht in Ausbildung des Euphemismus. Deutsche Derbheit diesem entgegen. Nothwendig diplomatische und Weltausbildung. - Euphemismus: die erste Figur das harte zart zu sagen. Figuren der Steigerung - der Milderung.

Wenn Goethe I 8 I 6 zwei Engländern gegenüber deren Muttersprache wegen ihrer Lebendigkeit preist und dem Deutschen eine öffentliche Beredsamkeit abspricht, sowie abfällig über Kanzel- und Kathedersprache urteilt, so muß dieses Urteil $z u$ Recht bestehen. Der englische Parlamentarismus hat dort frühzeitig auf die öffentliche Beredsamkeit günstig eingewirkt, für Deutschland ist sie erst in der Mitte des 19. Jahrhunderts geboren worden. Zudem mögen die Höflichkeit des Hofmanns Goethe und der Nationalstolz der Briten bei Aussprache und Wiedergabe des Urte ls mitgewirkt haben: G. IV. 271: "Once his genius kindled and in spite of himself he grew almost fervent, as he deplored the want of extemporay eloquence in Germany, and said what I never heard beforce, but which is eminently true, that the English is kept a much more living language by its influence. 'Here' he said, 'we have no eloquence - our preaching is a monotonous, middling declamation public debate we have not at all, and if a litte inspiration 
sometimes comes to out of place for eloquence does not teach'." (25. X. 1816 mit Gg. Ticknor und Ed. Everett.) ${ }^{1}$ )

Der $\mathrm{HaB}$ Goethes gegen hohles Phrasentum und tote Wortherrschaft ging so weit, daß er es für das kleinere Übel hielt, in einer fremden Sprache oder mit fremden Worten zu dichten, um seine eigenen Gedanken zum Ausdruck zu bringen, als sich leerer, von anderen geschaffener und benutzter Phrasen in der Muttersprache zu bedienen. Das ist der ziemlich versteckt liegende Sinn des „Phrasendichtung“ überschriebenen Absatzes des Aufsatzes „Deutsche Sprache“, der einzigen größeren Arbeit über Sprachliches, auf dessen andere für uns sehr wichtige Teile wir zurückkommen werden. Voraus geht die Erörterung, daß die lateinisch schreibenden deutschen Dichter des 16. - 17. Jahrhunderts den Beweis erbringen, daß Deutsche sich auch in fremder Sprache treu bleiben:

I. 4I I. I13. 16: Leider bedenkt man nicht, dass man in seiner Muttersprache oft ebenso dichtet, als wenn es eine fremde wäre. Dieses ist aber also zu verstehen: Wenn eine gewisse Epoche hindurch in einer Sprache viel geschrieben und in derselben von vorzüglichen Talenten der lebendig vorhandene Kreis lebendiger Gefühle und Schicksale durchgearbeitet worden, so ist der Zeitgehalt erschöpft und die Sprache zugleich, so dass nun jedes mässige Talent sich der vorliegenden Ausdrücke als gegebener Phrasen mit Bequemlichkeit bedienen kann. (K. u. A. III. I8I7.)

Bouke $^{2}$ ) bemerkt zur Stelle sehr richtig, daß in der ersten Hälfte des I8. Jahrhunderts durch die Sprachgelehrten vom

I) „Einmal brauste er auf und wurde gegen seinen Willen beinahe heftig, als er den Mangel an aus dem Stegreif vorgebrachter Beredsamkeit beklagte und sagte, was ich nie zuvor hörte, was aber in hohem Grade wahr ist, daß das Englische durch seinen Einfluß eine viel lebendigere Sprache bleibt. Hier, sagte er, haben wir keine Beredsamkeit, unser Predigen ist eine eintönige, mittelmäßige Rede, öffentliche Erörterung haben wir überhaupt nicht, und wenn eine schwache Begeisterung manchmal über uns in unseren Hörsälen kommt, dann ist sie am unrechten Ort, denn Beredsamkeit lehrt nicht." Auch Bode: G. Ged. I, 442.

2) Bouke a. a. O. 276.

Rausch, Goethe u. die deutsche Sprache. 
Schlage der Gottsched und Adelung die Sprache in tote grammatische Formen gepreßt und alle Sprachbereicherung aus den Mundarten verbannt werden sollte. Daran wird Goethe gedacht haben; einer solchen Sprache war dann freilich das weite, freie Feld der Fremdsprachen vorzuziehen.

Weniger auf die deutsche Sprache als auf den nationalen Charakter beziehen sich die folgenden abfälligen Äußerungen:

IV. 26. 258. 5: Ew. Wohlgeboren würde nicht einmahl rathen, wenn das... Blättchen einen fremden beträfe, solches [in die Literatur-Zeitung] aufzunehmen, weil es durchaus unschicklich ist . . . Dass doch die lieben kostbaren Deutschen nicht lernen etwas mit Manier zu sagen! (I2. II. I816 an Eichstädt.)

IV. 34. 2 I I. 4: Geschieht es mit Ihrer Genehmigung, so werden auch diese Blätter gedruckt: denn es geht doch mit uns Deutschen auf so eine nationale Rederey hinaus; gesprochen mu $\beta$ werden, herüber, hinüber; was geschieht, bleibt dem Zufall unterworfen. (29. IV. I82I an Schultz.)

I. I5. I. 98 :

Meph.: Du weißt wohl nicht, mein Freund, wie grob du bist. Baccal.: Im Deutschen lügt man, wenn man höflich ist.

(Faust II. 2. v. 6700.)

Nur indirekten Bezug auf die deutsche Sprache haben auch die beiden nächsten Belege, mit denen wir die Reihe der Urteile und Äußcrungen cröffnen, aus denen uns das Lob der Muttersprache entgegenklingt. Wir stellen sie an die Spitze, weil sie glänzend Zeugnis ablegen für des Dichters ihm so oft abgesprochenes nationales Empfinden.

IV. 27. 224. 4: Wir Deutsche stehen sehr hoch und haben gar nicht Ursache uns vom Winde hin- und hertreiben zu lassen. (7. XI. 1816 an Zelter.)

G. VII. 238: Ich selbst habe immer nur mein Deutschland vor Augen gehabt. (6. III. $1830 \mathrm{zu}$ Sorct.) ${ }^{1}$ )

1) Dicses schönc Bekenntnis dürfte in Bodes Sammelwerk, das doch so vicle zum Teil cinseitige Äußerungen über Politik aufnahm, nicht fehlen. 
Dieselbe Gesinnung läßt sich in einer ganzen Reihe von Belegen nachweisen, in denen sich Goethe voll und ganz als Deutscher bekennt und mit Stolz und rückhaltlosem Lob von seiner Muttersprache redet. Am bekanntesten von allen derartigen Aussprüchen ist das Gedicht "Sprache" aus dem Jahre 1773, dessen Sinn freilich näherer Erklärung bedarf:

I. 2. 256. I. Was reich und arm! Was stark und schwach!

Ist reich vergrabner Urne Bauch?

Ist stark das Schwert im Arsenal?

Greif milde drein, und freundlich Glück

Fließt, Gottheit, von dir aus!

Faß an zum Siege, Macht, das Schwert

Und über Nachbarn Ruhm. ${ }^{1}$ )

Die Verse wollen sagen: nicht auf den Reichtum einer Sprache an sich kommt es an, sondern auf den lebendigen Gebrauch, der von dem Sprachschatz gemacht wird. Das Gedicht fordert nach Herders Beispiel dazu auf, „das Innere unserer Sprache hervorzugraben ... Deutsche in der Sprache zu sein, in deren Schoß noch unendlich viel unbekannte Schätze ruhen", den „vergrabenen Schatz", wie Herder an anderer Stelle die Sprache nennt, zu heben, das Schwert, das unnütz im Arsenal rostet, hervorzuholen und zum Siege gegen die Nachbarn zu schwingen. Der Dichter, der seine Muttersprache eine Gottheit und Macht nennt und ihr den Sieg über die anderen Sprachen prophetisch verkündet, der ist von ihrem Reichtum und ihrer Schönheit innerlich tief überzeugt. Dieser Reichtum aber darf nicht nach Art eines Klopstock (Epigramm: Unsere Sprache) nur überschwenglich gepriesen werden, sondern er will der Sprache in schwerem Ringen abgestritten sein. Und dieses Ringen hat keiner gewaltiger ausgeführt

I) Zur Erklärung vgl. Hempel (Löper) II, 199. 465; Heinemann II, 65.432; Riegel a. a. O. 3; Waetzoldt a.a. O. 279; Kluge a.a.O. 39; Düsel: Zeitschr. d. allg. deutsch. Sprachver. XIV. S. I64; Minor = Sauer: Goethestudien 47.85 . 
als Goethe. Und wenn es ihm gar zu schwer und schier erfolglos zu sein schien, dann fallen die mißmutigen Äußerungen gegen die Sprache, die, aus diesem Zusammenhang gerissen, Goethe in so falschem Verhältnis zu seiner geliebten Muttersprache zeigen können.

Zwei weitere warme Zeugnisse sprechen ohne Erläuterung für sich:

I. I4. 62 Faust:

Mich drängt's den Grundtext aufzuschlagen, Mit redlichem Gefühl einmal

Das heilige Original

In mein geliebtes Deutsch zu übertragen.

(Faust I. Studierzimmer I. v. I220.)

Heinemann XIV. 75: Die vier ersten Bände meiner Schriften bei Göschen waren angekommen und das Prachtexemplar sogleich in die Hände Angelikas gegeben, die daran ihre Muttersprache aufs neue zu beloben Ursach' zu finden glaubte.

(Ital. Reise II. Rom. Septbr. I787.)

Auch der sehnsüchtige Gruß, den Pylades in der Fremde der Muttersprache zusendet, darf hierher gestellt werden, denn es ist doch das Deutsche, das in dem Drama als Sprache der Personen zu gelten hat.

I. I 0.35 . v. 803 :

O süße Stimme! Vielwillkommner Ton

Der Muttersprach' in einem fremden Land!

Des väterlichen Hafens blaue Berge

Seh ich Gefangner neu willkommen wieder

Vor meinen Augen.

(Iphig. II. 2. Pylades zu Iphigenic; 1787.)

Teilweise $z u$ Unrecht dagegen ist meines Erachtens eine fran\%ösische Bricfstelle an lrau v. Stein für dic deutsche Sprache in Anspruch genommen worden. Von einem Besuche am Braunschweiger Hofe, an dem das Französische herrscht, 
schreibt Goethe: IV. 6. 337. 20: Voiant ces caracteres barbares etrangers a mon coeur ce fut un tout nouveau sentiment pour moi, ces Vous me faisoit trembler et je tournai vite la feuille pour $V$ oir s'il ny avoit pas un mot de la langue cherie, qui m'est devenue tous les jours plus chere par les expressions du veritable sentiment d'ont $t u$ l'enrichis. O ma chere il m'est presque impossible de poursuivre ce jeu, ma plume n'obeit qu'a regret, et ce n'est qu'avec peine que je traduis, que je travestis les sentiments originaux de mon coeur. Fe ne sens mon existence que par to $i, t u m^{\prime}$ as appris a aimer moi meme, $t u$ m'as donné une patrie, une langue, une stile et je finirois par t'ecrire des phrases. (I8. VIII. 1784 an Frau v. Stein.)

Ringel ${ }^{1}$ ) übersetzt frei: ,Er nennt das Deutsche die ihm alle Tage teurer gewordene, geliebte Muttersprache, die ihm ein Vaterland, eine Sprache, einen Stil gegeben habe." Nicht an die Sprache jedoch richtet sich der Dankesgruß - daß diese ihm eine Sprache gegeben habe, wäre ja zudem wenig sinnvoll -, sondern Frau v. Stein ist die Spenderin. Er haßt die fremde Sprache, weil sie seinem Herzen fern steht; die deutsche wird ihm, dem Liebenden, täglich teurer, weil die geliebte Frau sich ihrer bedient, sie durch die Ausdrücke ihres wahren Gefühls bereichert. Es widerstrebt ihm, den verabredeten französischen Briefwechsel fortzusetzen, seine Gefühle zu „,travestiren“, weil auch er seine Gefühle nur in der Muttersprache ausdrücken will. „Ich fühle mein Dasein nur durch dich (d. i. Frau v. Stein), du hast mich mich selbst lieben gelehrt, du hast mir ein Vaterland, eine Sprache, einen Stil gegeben und ich hörte durch dich auf, Phrasen zu schreiben." Auch in dieser Übersetzung bilden die Worte immerhin einen Beleg für die Wertschätzung des Deutschen, wenn sie auch in erster Linie ein Kompliment an die Adresse der Frau v. Stein sind.

Wie weit Goethe davon entfernt war, eine Vernachlässigung der Muttersprache einer fremden gegenüber gutzuheißen,

I) Riegel a. a. O. 18. 
belegt eine Auslassung in den Aufsätzen über Winckelmann: I. 46. 86. I : Er [W.] vernachlässigte darüber [über den altklassischen Sprachen]... fast alle Übung in der Muttersprache d. i. in dem modischen Deutsch oder Undeutsch vor A. I740. So weit war damals noch die Pädagogik zurück, dergleichen Unheil geschehen zu lassen; obwohl schon einige zu Stendal, vermutlich die Gelehrten des Orts, die Abneigung des jungen Menschen strafbar fanden. (Winckelmann II. I805.)

Der Spruch I. 2. 242. v. 416:

\section{Im Vaterlande}

Schreibe, was dir gefällt,

Da sind Liebesbande

Da ist deine Welt

(Sprüchwörtlich I8I2-I8I4.)

bezieht sich meines Erachtens mehr auf den Inhalt als auf die Form des Geschriebenen. Daß Goethe, wie Kluge ${ }^{1}$ ) glaubt, mit ihm das angeblich harte Urteil der Venet. Epigramme zurücknimmt, ist kaum zu begründen. Eher dürfte ein von Löper ${ }^{2}$ ) als Parallele beigebrachter Ausspruch Platens dem Sinn nahe kommen: „Ein Dichter wird am besten tun, niemanden als seine Landsleute zu konsultieren, für die allein cr schreibt."

Selbst in der Unglückszeit 1806-1807, in der so mancher Patriot verzagte, hat Goethe weder an der deutschen Sache noch an der sicgreichen Zukunft der deutschen Sprache gezwcifclt. Frau Christine Reinhard schreibt am I. VI. I807 an ihre Mutter: „Vorgestern wurde in meinem Salon die Frage bchandelt, ob Deutschland und die deutsche Sprache zu völligem Verschwinden bestimmt scien. Das glaube ich nimmermehr, sagte jemand, dic Deutschen wie die Fuden lassen sich wohl unterdrücken, aber nicht vertilgen. Sie lassen sich nicht entmutigen und wïrden stark geeint bleiben, selbst wenn

1) Kluge a. a. O. 38.

2) I.öper: IIempel 1H, 67. 
es ihnen beschieden sein sollte, kein Vaterland mehr zu besitzen. Der das sprach, war Goethe." Einen ähnlichen Ausspruch berichtet Riemer vom I5. III. I808. Deutsche gehen nicht zugrunde, so wenig wie die Fuden, weil es Individuen sind. ${ }^{1}$ )

Ganz verschiedene Auffassung hat das Gedicht Nativität aus dem Jahre 1818 gefunden:

I. 3. $14 \mathrm{I}$ :

Der Deutsche ist gelehrt, Wenn er sein Deutsch versteht;

Doch bleib ihm unverwehrt, Wenn er nach außen geht.

Er komme dann zurück, Gewi $\beta$ um viel gelehrter. Doch ist's ein großes Glück, Wenn nicht um viel verkehrter.

Mich. Bernays hält die Verse für ein unpatriotisches, abfälliges Urteil über die deutsche Sprache, „mißtönend jedem patriotischen Ohr", das billigerweise das Ärgernis jedes edelsinnigen Vaterlandsfreundes erregen müßte. ${ }^{2}$ ) Riegel bezeichnet sie als einen Beweis der Unsicherheit des Dichters der Sprache gegenüber. Rud. Hildebrand sagt: „Als Gegen. satz und Abschluß der wiederholten Versuche, sich die antike, philologische Bildung voll anzueignen, erkannte Goethe den Bildungswert der Muttersprache", und an anderer Stelle bezieht er das Gedicht auf den Fremdwörterunfug, der vom Deutschen Gelehrsamkeit zur Deutung verlange. Lyon führt es als Beweis für Goethes Wertschätzung des Deutschen an, Heinemann nennt es eine Prophezeiung für einen Deutschen, der das Ausländische höher schätze als die Muttersprache

I) Vgl. Bode: Goethes Gedanken I, 428, und Bode, Stunden mit Goethe III, 35 .

2) Barnays, M.: Schriften zur Kritik und Literatur-Gesch. II, 2 I 7 ; Riegel a. a. O. 7; Hildebrand a. a. O. 77. 131. I69; Heinemann II, I66. 452; Kluge: Unser Deutsch 73 . 
und will die Verse nicht ironisch aufgefaßt wissen. Kluge endlich bezieht sie auf die namentlich dem Sprachforscher bewußte Vielseitigkeit des deutschen Sprachlebens, auf die heute noch vielfach schlummernden Schätze im Schoße der deutschen Sprache und auf die auch von Luther und Leibniz betonte Schwierigkeit, diesen verborgenen Schätzen nachzuspüren. Wir möchten unter teilweiser Anlehnung an Hildebrand das Gedicht als ein warmes Zeugnis für die Muttersprache in Anspruch nehmen: der Deutsche findet Bildung in ihr, es bedarf dazu nicht fremder Sprachen, die wohl seine Kenntnisse zu bereichern fähig sind, aber auch seine deutschen Gesinnungen verkehren.

Die Verse sind übrigens, wie Bernays nachweist, Nachbildung und Umgestaltung eines Originals von Canitz. Unsere Auffassung wird gestützt durch eine Äußerung aus gleicher Zeit:

I. 4II. II 5. 23: Wir geben gerne zu, das jeder Deutsche seine vollkommene Ausbildung innerhalb unserer Sprache ohne irgend eine fremde Beihülfe hinreichend gewinnen könne... Diese Personen sämmtlich [Bewohner kleiner Städte - Mittelstand] können ihr Lebens- und Lehrbedürfniss innerhalb der Muttersprache befriedigen. Die Förderung dagegen, die in weiteren und höheren Regionen an uns auch in Absicht einer aus. gebreiteten Sprachfertigkeit gemacht wird, kann niemand verborgen bleiben, der sich nur einigermassen in der Welt bewegt. Also ohne den Wert fremdsprachlicher Bildung zu verkennen, hält er eine allgemeine Bildung auf der Grundlage der Muttersprache für weite Kreise der Bevölkerung für möglich. (Deutsche Spr. 1817. K. u. A. I. 3.)

Goethe ist - für dic älteren Jahre ergeben das die Belege mit Sicherheit - voll Stolz von der hohen Entwickelung des Deutschen überzeugt und stellt sie bedingungslos neben, ja über seine fremden Schwestern. Das beweist zunächst der Briefwechsel mit einem Studenten Blumenthal, der, angeregt durch Goethes schon crwähnte Hinweise in seinem Aufsatz 
„Deutsche Sprache“, lateinische Gedichte deutscher Dichter des I6. - I7. Jahrhunderts übersetzen wollte: Goethe schreibt ihm: IV. 31. I59. I8: Möge doch an Ihrer Hand lateinische und deutsche Poesie zu Anfang des neunzehnten Fahrhunderts abermals sich begegnen, wobei erhellen wird, wie sehr in drei. hundert Fahren unsere Sprache sich ausgebildet, um auf ihre Weise auszudrücken, was wir bei den Alten so höchlich bewun. dern (28. V. I819).

Einen Lobeshymnus singt der Dichter seiner Sprache bei der Besprechung übersetzter serbischer Volkslieder: I. 4I II. 151. 25: Die deutsche Sprache ist hiezu besonders geeignet; sie schließt sich an die Idiome sämmtlich mit Leichtigkeit an, sie entsagt allem Eigensinn und fürchtet nicht, dass man ihr Ungewöhnliches, Unzulässiges vorwerfe; sie weiss sich in Worte, Wortbildungen, Wortfügungen, Redewendungen und was alles zur Grammatik und Rhetorik gehören mag, so wohl zu finden, dass, wenn man auch ihren Autoren bei selbsteignen Produc. tionen irgend eine seltsamliche Kühnheit vorwerfen möchte, man ihr doch vorgeben wird, sie dürfe sich bei Übersetzung dem Original in jedem Sinne nahe halten. Und es ist keine Kleinig. keit, wenn eine Sprache diess von sich rühmen darf: denn müssen wir es zwar höchst dankenswerth achten, wenn fremde Völker. schaften dasjenige nach ihrer Art sich aneignen, was wir selbst innerhalb unseres Kreises Originelles hervorgebracht, so ist es doch nicht von geringerer Bedeutung, wenn Fremde auch das Ausheimische bei uns zu suchen haben. Wenn uns eine solche Annäherung ohne Affectation wie bisher nach mehreren Seiten hin gelingt, so wird der Ausheimische in kurzer Zeit bei uns zu Markte gehen müssen und die Waaren, die er aus der ersten Hand zu nehmen beschwerlich fände, durch unsere Vermittelung empfangen. (Serbische Licder. K. u. A. V. 2. I 825.)

Wiegt dieses eine Urteil nicht alle oben zusammengestellten tadelnden glänzend auf? Dabei wollen wir nicht einmal verkennen, daß es nicht die deutsche Sprache an sich ist, die 
Goethe zu diesem Lob begeistert, sondern in erster Linie ihre Fähigkeit, Erzeugnissen fremder Literaturen vollgiltigen Ausdruck zu verleihen. Es war ein Lieblingsgedanke des alten Goethe, auf den wir zurückkommen werden, das Deutsche im Mittelpunkt einer Weltliteratur zu sehen und die Erkenntnis, daß es in der Tat fähig sei, durch mustergiltige Übersetzungen den Geist der fremden Sprache in sich aufzunehmen, erfüllte ihn mit Stolz und Freude, und aufrichtiges Lob der Muttersprache kommt noch an anderen Stellen uneingeschränkt zum Ausdruck. So I 825 einem Engländer gegenüber: G. V. I23: Ihre jungen Landsleute thun wohl, dass sie jetzt zu uns kommen und auch unsere Sprache lernen; denn nicht allein, dass unsere eigene Literatur es an sich verdient, sondern es ist auch nicht zu leugnen, dass, wenn einer jetzt das Deutsche gut versteht, er viele andere Sprachen entbehren kann. Von der Französischen rede ich nicht, sie ist die Sprache des Umgangs und ganz besonders auf Reisen unentbehrlich, weil sie jeder versteht und man sich in allen Ländern mit ihr statt eines guten Dolmetschers aushelfen kann. Was aber das Griechische, Lateinische, Italienische und Spanische betrifft, so können wir die vorzïglichsten Werke dieser Nationen in so guten deutschen Übersetzungen lesen, dass wir ohne ganz besondere Zwecke nicht Ursache haben, auf die mühsame Erlernung jener Sprachen viele Zeit zu verwenden. Es liegt in der deutschen Natur, alles Ausländische in seiner Art zu würdigen und sich fremder Eigen. thümlichkeit zu bequemen. Dieses und die grosse Fügsamkeit unserer Sprache macht denn die deutschen Ubersetzungen durch. aus treu und vollkommen (10. I. I 825).

In der Besprechung von Carlyles German Romance finden wir eine sehr anklingende Stelle: I. 4I IL 306. 23: Zu einer solchen Vermittelung und wechselseitigen Anerkennung [der Völker unter sich] tragen dic Deutschen scit langer Zeit schon bci. Wer die deutsche Sprache versteht und studiert, bcfindet sich aut dom Marlite, wo alle Nationen ihre Waaren anbicten, or spielt den Dolmetscher, indem er sich selbst be. 
reichert (auch IV. 42. 270. 10). Bodes neuer Sammlung "Goethes Gedanken" verdanken wir den folgenden, im gleichen Gedankengang liegenden Beleg: ... Ganz abgesehen von unsern eignen Produktionen, stehen wir schon durch das Aufnehmen und völlige Aneignen des Fremden auf einer sehr hohen Stufe der Bildung. Die anderen Nationen werden bald schon deshalb deutsch lernen, weil sie inne werden müssen, dass sie sich damit das Lernen fast aller andern Sprachen gewissermassen ersparen können; denn von welcher besitzen wir nicht die gediegensten Werke in vortrefflichen deutschen Über. setzungen? Die alten Klassiker, die Meisterwerke des neweren Europas, indische und morgenländische Literatur - hat sie nicht alle der Reichtum und die Vielseitigkeit der deutschen Sprache wie der treue Fleiss und tief in sie eindringende Genius besser wiedergegeben, als es in andern Sprachen der Fall ist? Frankreich hat gar viel seines einstigen Übergewichts in der Literatur dem Umstande zu verdanken gehabt, dass es am frühesten aus dem Griechischen und Lateinischen leidliche Übersetzungen lieferte; aber wie vollständig hat Deutschland es seitdem übertroffen! (I4. IX. $1826 \mathrm{zu}$ Hermann Fürst v. Pückler.) ${ }^{1}$ )

Eine aus dem Nachlaß herausgegebene ,Wohlgemeinte Erwiderung" richtet sich ja allerdings halb ironisch an die vielen berufenen und unberufenen Dichter, die dem Altmeister die Kinder ihrer Muse zur Beurteilung einsandten, das ernste Lob, das aber darin der Muttersprache gespendet wird, gehört hierher: I. 4III. 375. I4: Die deutsche Sprache ist auf einen so hohen Grad der Ausbildung gelangt, dass einem jeden in die Hand gegeben ist, sowohl in Prosa als in Rhythmen und Reimen sich dem Gegenstande wie der Empfindung gemäss nach seinem Vermögen glücklich auszudrucken. (K. u. A. VI. 3. I832.)

Zwei poetische Blumen aus Faust und Divan seien zum Schluß diesem Ehrenkranze deutscher Sprache eingeflochten:

I) Bode: Goethes Gedanken II, 337 aus „Briefen eines Verstorbenen von Hermann Fürst v. Pückler،, 
I. 6. 265. I: Und so möcht' ich alle Freunde, Fung und alt, in eins versammeln, Gar zu gern in deutscher Sprache Paradieses Worte stammeln.

(Divan. Buch d. Paradieses. I8I9.)

I. I5 1. 214: Helena:

Vielfache Wunder seh' ich, hör' ich an, Erstaunen trift mich, fragen möcht ich viel. Doch wïnscht' ich Unterricht, warum die Rede Des Mannes mir seltsam klang, seltsam und freundlich Ein Ton scheint sich dem andern zu bequemen. Und hat das Wort zum Ohre sich gesellt, Ein andres kommt, dem ersten liebzukosen.

Faust: Gefällt dir schon die Sprechart unsrer Völker, $O$, so gewi $\beta$ entzückt auch der Gesang, Befriedigt Ohr und Sinn im tiefsten Grunde.

(Faust II. 3. Akt. V. 9365 ff. 1830.)

So überstrahlt das Licht in Goethes allgemeinen Äußerungen über die Sprache in vollen, hellen Strahlen die vereinzelten Schatten. Der Dichter ist voll überzeugt von der Schönheit, der Kraft und dem Reichtum seiner Muttersprache.

\section{SECHSTES KAPITEL.}

\section{SCHRIFT, ORTHOGRAPHIE, INTERPUNKTION.}

Wir gchen nunmehr dazu über, Goethes Stellung zu sprachlichen Einzelfragen zu behandeln, und beginnen mit den Außenseiten der schriftlichen Aufzeichnung, der äußeren Form, der sogenannten Rechtschreibung, d. h. Schreibung nach als maßgebend festgesetzten Regeln und der Setzung von Satzzeichen als Hilfen für das Lesen. Wenn nach den Ergebnissen der bisherigen Untersuchung selbst für dic wichtigen allgemein-sprachlichen Gebiete nur gelegentliche Urteile

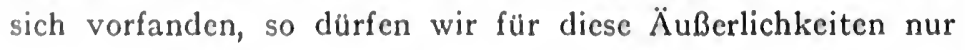


mit ganz bescheidener Ausbeute rechnen. Dem großen Geist waren diese Dinge tatsächlich gleichgiltig, da es ihm in erster Linie auf den inneren Gehalt des Geschriebenen ankam. Seine Mißachtung, die er diesem, wie wir sahen, überhaupt entgegenbrachte, wirkt zudem mit, ebenso die Tatsache, daß er in späteren Jahren verhältnismäßig wenig mit eigener Hand schrieb, sondern sich auf das Diktat beschränkte. Da Goethe jedoch den verschiedenen Ausgaben seiner Werke eine bis in die Einzelheit gehende Sorgfalt widmete, ergeben sich aus den Verhandlungen mit den Redaktoren und Verlegern doch manche Äußerungen über unsere Fragen, mit denen er sich bei der Gelegenheit wohl oder übel abgeben mußte. Die über Schrift entspringen nicht gelehrten, historischen oder nationalen Gründen, sondern ästhetischen und auch der ganz prosaischen Rücksicht auf das liebe Publikum. So schreibt er an W. v. Humboldt:

IV. I2. 122. 3: Zur zweyten Ausgabe [von Hermann und Dorothea] würde ich die lateinische Schrift wählen, da sie heiterer aussieht, und da auch wir nun schon einen deutschen Druck haben, ich glaube denn doch zu bemerken, dass der gebildete Theil des Publikums sich durchaus zu lateinischen Lettern hinneigt (14. V. 1797). Auch I826 vor der Ausgabe letzter Hand werden Verhandlungen über die Schrift gepflogen (IV. 4I. I85. I). Wie sein Schönheitsgefühl den Dichter zur Beobachtung scheinbar ganz bedeutungsloser Kleinigkeiten im Druck führte, belegen Mitteilungen an den Buchdrucker Wesselhöft: IV. 34. 236. 9: Ich wünschte zu wissen: ob Sie, wenn man griechische Namen mit deutschen Lettern, z. B. Chry. seis, drucken wollte, unter Ihrer deutschen Schrift das doppelt punctirte $\ddot{i}$ besitzen, damit man sich darnach richten könnte (I6. V. I82I). Auf die verneinende Antwort erging die Anweisung: IV. 34. 253. I2: Sodann vermelde, dass bey den griechischen Namen welche einen doppelten Punct über dem $i$ ver. langten, wir es bei dem einfachen wollen bewenden lassen, weil mir der lateinische Buchstabe zwischen den deutschen sehr wider. 
lich erscheint und ich immer nicht habe begreifen können, wie man einen so leicht $z$ u hebenden Missstand nicht eiligst abgeschafft hat. Doch es mag auch diess seine Gründe haben. So sieht z. B. Boifjerée und $\mathfrak{A b}$ é wunderlich aus (22. V. I82I). Auch sein schon oben (S. 48/49) berührter Eifer im Sammeln fremder Handschriften erklärt sich zum Teil aus ästhetischen Gründen: er sah, wie er selbst in den Annalen gesteht, in einer schönen Schrift ein kunstvolles Gebilde. ${ }^{1}$ ) Ganz vereinzelt steht die Äußerung in der Gedächtnisrede auf Wieland, daß die eigenhändigen, sorgfältigen und schönen Niederschriften dieses Dichters auf ,das Zarte und Zierliche, Fassliche, das natürlich Elegante" seiner Produktionen von Einfluß gewesen ist. Das wäre die Umkehrung des graphologischen Satzes, daß der Charakter sich in der Handschrift ausprägt.

Was des Dichters eigene Schrift anlangt, so belegt Tewes ${ }^{2}$ ) aus einer Mitteilung Eckermanns (vom I4. VII. I853), daß er persönlich die lateinischen Schriftzüge für die Aufzeichnung von Gedichten bevorzugte, daß aber die Fausthandschriften (I. und II. Teil) deutsche Schrift zeigen; das gleiche gilt für die Jugendwerke. Weitere Beobachtungen sind mir nicht bekannt geworden. Da Goethe namentlich in späteren Jahren ja nur wenig selbst schrieb, ist die Frage ja auch von keiner größeren Wichtigkeit. Immerhin wäre man den an den Quellen des Goethearchivs sitzenden Gelehrten für eine $\mathrm{Zu}$ sammenstellung aus den Handschriften dankbar.

Die Durchsicht seiner in die Druckerei wandernden Werke auf Orthographie und Interpunktion übertrug Goethe in der späteren Weimarer Zeit Riemer, Eckermann sowie dem Jenaer Professor Göttling. Der Dichter macht kein Hehl daraus, daß ihm diese „Künste" fern licgen, wacht aber sorgsam darüber, daß dic Druckereien nicht aus eigener Machtvollkommenheit an dem durch die Redaktoren durchgesehenen

1) Vgl.Isabella v. Ungern-Stermberg in Bode: Stunden mit Goethe III, 51 .

2) 1'ewes: Aus Goethes Lebenskreise: J. P. Eckermanns Nachlab I. Herlin 1905. S. 307. 
Text noch ändern. Verschiedene Notizen und Briefstellen werfen Streiflichter auf die Verhandlungen.

IV. I2. I28. I: Es ist mir sehr angenehm zu hören, dass Sie mit der Interpunction des Gedichts [Hermann und Dorothea] zufrieden sind und wir haben Ursache dem Freunde dankbar zu seyn, der uns diesen Dienst leistet, es ist eine Kunst, die ich nie habe lernen können (26. V. I797 an Böttiger).

IV. 19. 65. I0: Haben Sie ja die Güte, einem sorgfältigen Mann die Revision [der Gesamtausgabe der Werke] höchlich anzuemptehlen, wobey ich ausdrücklich wünsche, dass man das übersandte Exemplar genau abdrucke, nichts in der Rechtschreibung, Interpunction und sonst verändere, ja sogar, wenn noch ein Fehler stehn geblieben wäre, denselben lieber mit abzudrucken (30. IX. I805 an Cotta). Ähnlich IV. I9. 76. 23 (25. XI. I8I5 an denselben).

IV. 37. 282. 8: Rechtschreibung, Interpunction und, was mehr ist, Klarheit und Übereinstimmung des Ausdrucks wird hierdurch [Riemers Tätigkeit] gesichert (I2. XII. I823 an S. Boisserée; vgl, auch III. 12. 267).

IV. 39. I 6. 7: Ew. Wohlgeboren ... gebe . . völlige Macht und Gewalt fernerhin nach Ihrer Überzeugung zu handeln: a) die Rechtschreibung betreffend; b) die Flexion; c) Schreiben der aus fremden Sprachen entlehnten Wörter; d) Interpunction (I2. III. I825 an Göttling).

Für die Schreibung des y erhält der Korrektor der sorgfältigst vorbereiteten Ausgabe letzter Hand eine jedenfalls von Göttling besorgte besondere Aufstellung (IV. 4I. 37I. I826). Demselben wird für die Verbesserung der Orthographie der Ortsnamen ,die früher mehr nach dem Gehör als nach der eigentlichen Rechtschreibung aufgezeichnet waren" gedankt (IV. 46. 2. I I. - I829).

Von einem Zuviel in der Interpunktion wollte der Dichter nichts wissen. Mit Recht hielt er dafür, daß gehäufte Zeichen den freien Vortrag des Geschriebenen störten. Seine Erfah- 
rungen an der Bühne bestätigten ihm diese Ansicht. Die neuzeitlichen Bestrebungen, die Zeichen auf das Notwendigste zu beschränken, finden also in Goethe einen Vorkämpfer.

IV. 27.45. 23: Die Interpunction betreffend äussere folgendes. Es hat sich in der deutschen Schrift dadurch, dass man mehr liest als hört, die Gewohnheit eingeschlichen viel zu viel Commata zu machen. Wie schädlich dies dem lebendigen Vortrag sey, hab ich seit dreyssig Fahren nur allzusehr bemerken können, indem ich mir die Mühe gab Schauspieler auszubilden. Z. B. Glaubst du denn, dass sie dich liebt! - Hab ich dir nicht gesagt, dass ich nicht kommen kann? Diese hier roth gezeichneten Commata sind es die ich [in der neuen Ausgabe] möglichst weggestrichen habe, weil sie den Schauspieler, den Vorleser zu einem gehackten Vortrag verführen. Denn wenn es gleich Fälle giebt, dass man an einer solchen Stelle etwas anhält, so entspringt doch eine solche Pause aus dem Gefühl, nicht aus dem Sinn, welcher allein durch die Interpunction zu bezeichnen ist, wie denn ja in Versen die Cäsur nicht immer einen Sinnesabschnitt macht. Doch bin ich hier nicht pedantisch und lasse dem Herrn Corrector die völlige Freyheit in gewissen Fällen nach eignem Urtheil ein Comma herzustellen (9. V. I8I6 an Cotta).

IV. 38. I82.23: Eben so wäre die Interpunction [bei der Neuausgabe der Werke] mit Milde zu behandeln, und allenfalls nur die überflïssigen Unterscheidungszeichen, die zu jener Zeit in Schwung waren auszulöschen. (28. VI. I824 an Schultz.)

IV. 39. 76. I 8: zu beachten wäre. . dass etwa eine, in früherer Zeit gewöhnliche, allzuhäufige Interpunction und Commatisirung ausgelöscht und dadurch ein reinerer Fluss des Vortrags bewirkt werde. (IO. I. I 825 an Göttling; ähnlich IV. 42. 35.7 an denselben.)

Goethe gesteht freimütig scine Mängel in der Rechtschreibung und Zeichensetzung und führt sic selbst auf die Bevorzugung des Diktats zurúck: G. IV. 20I: Das Gespräch .. . kam dann auch auf die jetzige deutsche Orthographic: „Lasst ihr mich mit euern Schreiblehlern gehen, sagte Goethe, ich 
mache in jedem Brief Schreibfehler und keine Comma. Ich dictire meistens und sehe nicht nach. (26. VIII. I822 mit Grüner, Eger.)

IV. 36. 280. 5:- Wenn ich denken müsste, dass ein Freund, an den ich einen Brief dictiere, ïber Wortgebrauch und Stellung, ja wohl gar über Interpunction, die ich dem Schreibenden überlasse, sich formalisiere; so bin ich augenblicklich paralysirt und keine Freiheit kann stattfinden. (I8. I. I822 an Zelter.)

G. VIII. 23I: Mir, der ich selten selbst geschrieben, was ich zum Druck beförderte, und weil ich dictirte, mich dazu verschiedener Hände bedienen musste, war die consequente Rechtschreibung immer ziemlich gleichgültig. Wie dieses oder jenes Wort geschrieben wird, darauf kommt es doch eigentlich nicht an, sondern darauf, dass die Leser verstehen, was man damit sagen wollte. Und das haben die lieben Deutschen bei mir doch manchmal gethan. (1827/31. mit v. Holtei.)

Den mancherlei Bestrebungen seiner Zeit, eine Vereinfachung der Rechtschreibung herbeizuführen, konnte Goethe demgemäß kein Interesse entgegenbringen; sie forderten höchstens als lächerliche Nichtigkeiten seinen heiteren Spott heraus, den sich selbst der gute Klopstock gefallen lassen mußte, als er sich in seinen alten Tagen ins Neuland der orthographischen Reform begab:

I. 5. 37 9: Er und sein Name.

Ach der Gute, hat leider endlich altshändischer Ahndung

Böse Schuld bezahlt! Aus seinen Höhen und Tiefen

Sich in das Stein- und Gebeinreich der Lettern und Sylben begeben.

Mit dem eignen Sinne, der grossen Dingen geziemte, Heftet er sich ans Kleinste, und so klopstockt er die Sprache. $\left.(\mathrm{I} 780 \text { ?.) })^{\mathbf{1}}\right)$

Ähnlichen Versuchen gilt das Epigramm Dem Buchstabensparer: I. 5. I8I :

1) Vgl. Heinemann III, I32, altshändisch-schrullenhaft. (?)

Rausch, Goethe u. die deutsche Sprache. 
So soll die orthographische Nacht

Doch endlich auch ihren Tag erfahren.

Der Freund, der so viel Worte macht,

Er will es an den Buchstaben sparen. (I812.)

$\mathrm{Da}$ es auf Jean Paul gemünzt ist und sich gegen dessen Versuche, das $\mathrm{s}$ in Zusammensetzungen zu sparen, richtet, möchten wir mit Löper nicht annehmen, da diese Neuerung doch grammatischer, nicht orthographischer Art war; vielmehr schließen wir uns Heinemann an, der die Verse auf Chr. H. Wolke bezieht, welcher ,, mit vielen Worten darzutun suchte, wie man durch Vereinfachung der Orthographie Zeit sparen könne“.1) Ob das Xenion Nr. 287 „Preisfrage an die Akademie nützlicher Wissenschaften"

I. 5. 246. Wie auf dem u fortan der teure Schnörkel zu sparen?

Auf die Antwort sind dreißig Dukaten gesetzt,

nach Suphan-Schmidt (Xenien. G. G. 8.) sich auf lächerliche orthographische Reformversuche einer ,Akademie nützlicher Wissenschaften" in Erfurt bezieht, oder nach Bellermann (Schillers Werke IX. I59) nur allgemein ,gegen kleinliche und nutzlose Aufgaben mancher Akademien gerichtet" ist, lassen wir dahingestellt. Auf die Kreise, die mit alberner Wichtigtuerei für die unhistorische Schreibung ,teutsch" eintraten, zielen die Verse "An die T. . . und D. . ."

I. 5. 144: Verfluchtes Volk! kaum bist du frei,

So brichst du dich in dir selbst entzwei.

War nicht der Not, des Glücks genug?

Deutsch oder Teutsch, du wirst nicht klug.

(Zahme Xenien IX. 3. II. 1814.)

1) I.öper (Hempel) III, 334; Heincmann III, 211. Die Schrift Wolkes, in der neben dem gegeiBelten Vorschlag noch manche ähnliche uemacht werden, trägt den schönen Titel: Anleit zur deutschen Gesamtsprache oder zur baldigen Frkennung und Berichtigung von wenigstens 20000 Sprachfehlern und zur Abwendung eines großen \%eit - und Geld. verlustem. (1812.) 
Für Goethe ist die Beschäftigung mit derartigen Nichtigkeiten Zeitvergeudung. Er verzichtet darauf, die Richtig. keit der einen oder anderen Schreibung zu prüfen. Mag er deutsch, mag Teutsch sich schreiben, wie es im Divan heißt, die Sache berührt das nicht. Vgl. auch die kurze schroffe Abweisung, die ein gewisser Olivier erfährt, als er an den Dichter mit seinen orthographischen Reformplänen herantrat (IV. 40. 102 u. 3I3).

So ist es auch verständlich, daß nach Ausweis der Tagebücher fast nie Fragen erörtert werden, die sich auf Rechtschreibung beziehen. Zum Jahre I8I9 finden wir den Vermerk III. 7. 107. 24: Abbreviaturen in den diplomatischen Schriften (30. X. I8I9) und III. 7. I09. 4: Betrachtungen über Abbreviaturen Styl $u$. d. g. (2. XI. I8I9). Jedenfalls hat ein eingereichtes Buch $\mathrm{zu}$ diesen Unterhaltungen Anlaß gegeben.

Wenn Goethe am 24. II. I806 an seinen Verleger Cotta schreibt: Ferner bitte, meinen Namen Goethe, und nicht Göthe drucken zu lassen (IV I9. I06. IO), so ist es ihm dabei weniger um die Rechtschreibung des Wortes als um die Unantastbarkeit des Eigennamens zu tun, die er ja auch den Spielereien und Spöttereien Herders gegenüber verteidigt (vgl. S. 59).

Trotz der beinahe erhabenen Ferne, in der sich Goethe die Rechtschreibe-,,Kunst“ hält, verschmäht er es aber doch nicht bei Adelungs tonangebender „Orthographie" sich Rats zu holen; er scheint sogar - ein Beweis der Unentbehrlichkeit - mehrere Exemplare des Werkes besessen zu haben, wie folgende Briefstellen an Göschen erschließen lassen: IV. I8. 32. 26: Senden Sie mir doch Adelungs Schrift, deren Titel hier beyliegt (9. X. I788). IV. 9. 49.7: Das Geld ist wohl angekommen. Auch Adelungs Orthographie. Senden Sie mir doch baldigst von Adelungs Wörterbuch den letzten Band. Die vier ersten besitze ich (6. XI. I788). IV. I8. 35. I 5 : Senden Sie mir doch auch noch zwey Exemplare von Adelungs vollständiger Anweisung zur deutschen Orthographie (15. XII. 1788). Wir haben es wohl dabei auch mit Handexemplaren für die Schreiber und Redaktoren zu tun. 


\section{SIEBENTES KAPITEL. GRAMMATIK UND STIL.}

Der Name Johann Christoph Adelungs, des bedeutendsten und angesehensten Sprachforschers der zweiten Hälfte des I8. Jahrhunderts, führt uns auf Goethes Stellung zu grammatischen Fragen und solchen der Nachbargebiete. Das „Grammatisch kritische Wörterbuch der hochdeutschen Mundarten" und das „Umständliche Lehrgebäude der deutschen Sprache“ waren bis auf die Grimmsche Grammatik die tonangebenden Wegweiser in Sprachgebrauch und Sprachrichtigkeit. Darüber, ob sich Goethe den Sprüchen des „Orakels", wie Schiller spöttelnd den Sprachdiktator nennt, unterwarf, fehlen Belege außer zwei gelegentlichen Erwähnungen IV. 17.8.6: Adelungs Wörterbuch werden sie erhalten haben [zur Rezension in der Liter. Ztg.]. (II. I. I 804 an Eichstädt), und IV. I7. 34. 5: Hier schicke ich meinen Adelung; verzeihen Sie, dass ich den Ihrigen wohl eingepackt an Vo $\beta$ geschickt habe, der dessen $\approx u$ einer Rezension von Klopstocks grammatischen Gesprächen höchst nöthig bedurfte. (26. I. 1804 an Schiller.)

Schon dem Knaben Goethe war die Grammatik mit ihren vielen Regeln und Ausnahmen, wie er in Dichtung und Wahrheit gesteht, verhaßt.

I. 26. 46. 2: Die Grammalik mißfiel mir, weil ich sie nur als ein willkïrliches Geselz ansah; die Regeln schienen mir lächerlich, weil sie durch so viele Ausnahmen aufgehoben wurden, die ich alle wieder besonders lernen sollte. (D. W. I. I811.)

Da ihm dieser $\mathrm{HaB}$ mit manchem unserer geplagten sprach. beflissenen Gymnasiasten gemein ist, dürfte dem Geständnis aus der Jugend kein allzu großer Wert beizulegen sein; mehr schon dem aus späteren Jahren an Wilhelm v. Humboldt: IV. 13. 217. 18: Da sie denn doch einmal ein erklärter Deutscher sind, so wiinschte ich, dass Sie noch mit Brinkmann eine Prosodie unserer Sprache zu Stande brächlen, die sich auch von 
Paris her datirte, es wäre kein geringes Verdienst, besonders um Poeten von meiner Natur, die nun einmal keine gramma. tische Ader in sich fühlen (16. VII. 1798).

Wenn wir auch Bouke darin beipflichten, daß ,,äußere Korrektheit der Diktion mehr angeborene Gabe als gewissenhaft zu erstrebendes Ziel" war'), so steht Goethe der gram. matischen Regel doch keineswegs so ablehnend und gleich. gültig gegenüber, wie denen der Rechtschreibung und Zeichensetzung. Aus den im vorigen Kapitel zitierten Anweisungen an Göttling geht ja hervor, daß sich dessen bessernde Hand auch mit „Flexion" beschäftigen sollte. Eine ausführliche, sich auf Grammatik und Stil beziehende Anleitung ergeht an Riemer bei Übersendung des 11.-12. Buches von Dichtung und Wahrheit zur Revision. IV. 23.368. I3: Es sey also, mein Werthester, Ihnen die völlige Gewalt übertragen, nach gram. matischen, syntaktischen und rhetorischen Überzeugungen zu verfahren. Ohnvorgreiflich einige Bemerkungen. Die Enthy. meme scheinen sich zu häufen. Phrasen wiederholen sich, weil man doch in dem engen Kreise von ähnlichen Gesinnungen und Beschäftigungen, vorzüglich auch in dem einen subjektiven Wesen verweilt. Z. B. Es zog mich an, Es hielt mich fest. Um so mehr. Um so weniger. - Rediten, Wiederholungen derselben Sache habe ich zu tilgen gesucht; doch kommt eine Sache öfters, einigemal mit Fleiss, von verschiedenen Seiten, vor. - Wendungen wiederholen sich. Besonders verdriessen mich die unglücklichen Auxiliaren aller Art. Vielleicht gelingt Ihnen hie und da die Umwandlung in die Participial-Construction, die ich scheue, weil sie mir nicht gerathen will. Euphonische Zwischenwörter, wie gerade, eben können auch wohl hie und da gelöscht werden. Ausländische Worte zu verdeutschen sey Ihnen ganz überlassen $u$. s. w. (20. VI. I8I3 an Riemer.) Es wäre dankbar, nach den Lesarten der Weimarer Ausgabe, soweit möglich, festzustellen, welcher Gebrauch von derartigen

I) Bouke a. a. 0.267 . 
Vollmachten gemacht wurde, ob sich die Revision nur auf die Ausmerzung kleiner Versehen, Schreibfehler u. dgl. beschränkte oder sich auch auf Satzbau, Wortstellung erstreckte. Uns scheint das erstere der Fall zu sein. Denn Goethe läßt, wie auch Biedermann ${ }^{1}$ ) bemerkt und wie wir bei Behandlung des Fremdworts weiter beobachten werden, den Revisoren keineswegs die ,,völlige Gewalt", die er Riemer anträgt, sondern verteidigt seine Schreibweise im Bewußtsein ihrer Richtigkeit. So bricht er Göttling gegenüber eine Lanze für den schwach deklinierten Genitiv des Adjektivs ohne Artikel: IV. 39. 203. 5: Einer Idiosynkrasie werden Sie aber gefällig nachsehen: ich kann mich der Flexion „köstlichen Sinnes" nicht entschlagen, sie ist so in mein Wesen verwebt, dass ich sie, i'o nicht für recht, doch mir gemäss achten muss. Ich habe mich besonnen, wie dieser Eindruck in der frühsten Zeit bei mir entstanden sein möchte, und mir sind Lessings Briefe antiquarischen Inhalts eingefallen, auch noch verschiedene andere Beispiele, und ich darf also desto eher einige Nachsicht hoffen. (28. V. I825 an Göttling.)

Die Antwort des Philologen ist leider nicht erhalten. Biedermann tadelt mit Recht, daß Kuno Fischer, der Herausgeber des Briefwechscls, sich nicht der Mühe unterzog, die Stellen zu ermitteln, auf die sich die Auslassungen beziehen. Wie Knauth und Lehmann ${ }^{2}$ ) feststellen, gebraucht Goethe in der Iphigenie und in Tasso noch häufig die starken Formen; in llermann und Dorothea, der Achilleis, Pandora herrscht die schwache vor, im 2. Teil des Faust ist sie fast durchgängig in Gebrauch. Nach Lyon und Weise ${ }^{3}$ ) waren Luther, Klopstock und Voß nur dic starken Formen bekannt, während Les-

1) Biedermann: Goetheforsch. II, 237.

2) Knauth a. a. O. 51; I.chmann, O. 1..: Goethes Sprache und ihr (icist. Berlin 1852 . S. 343 .

3) L,yon, O.: Handbuch der deutschen Sprache. 9. Auf. Jeipzig 1905. 1,27 Anm.; Weisc, ().: Ästhetik der dentschen Sprnche. Leipzig 1903. S. 25. 
sing, Wieland und Schiller beide kennen, jedoch bereits mit Überwiegen der schwachen. Von Wichtigkeit ist, daß sich Goethe zur Verteidigung seines Sprachgebrauchs auf das Vorbild Lessings beruft, also das für sprachrichtig hält, was sich durch den Sprachgebrauch anerkannter Schriftsteller belegen läßt. Daß heute, abgesehen von einzelnen erstarrten Formen, die schwache Form fast zur Regel geworden ist trotz des zum Teil immer noch ablehnenden Standpunkts der Schulgrammatik ${ }^{1}$ ) - , ist in erster Linie auf Goethes Sprachgebrauch zurückzuführen. Offenbar zur Verteidigung der "Idiosynkrasie" ließ Goethe von Riemer eine Sammlung ähn. licher Bildungen veranstalten (IV. 39. 353).

Seine Achtung vor den Lehren und Regeln der Grammatik bezeugt Goethe vielleicht im Zusammenhang mit der ungrammatischen Vorliebe für die schwache Adjektivform dem Professor zwei Monate später: IV. 39. 230. 10: Ew. Wohlgeboren halten sich überzeugt, dass ich das Geschäft des Grammatikers in seinem ganzen Umfang zu schätzen weiss und dass ich mir gern von ihm die Erlaubnis erbitte als Poet mich einiger Freiheiten bedienen zu dürfen. (18. VI. 1825 an Göttling.)

Seine lebhafte Anteilnahme an grammatischen Fragen bezeugen auch die zahlreichen sich darauf beziehenden Aufzeichnungen in den Tagebüchern, wenn wir auch immer wieder betonen müssen, daß Riemer die Unterhaltungen dieser Art wird angeregt haben. Wir finden verzeichnet:

III. 4. 349 Grammatica und critica (1812).

III. 5. 98. 4 Grammatica (I8I4).

III. 5. I58. Io Periodenbau (I815).

III. 5. 212.26 Sprache. Etymologie (1816); ähnlich:

1) Auch Andresen: Sprachgebrauch und Sprachrichtigkeit. 7. Aufl. Leipzig 1892. S. 53, und Wustmann: Allerhand Sprachdummheiten. 4. Aufl. Lcipzig 1908. S. 25, verteidigen unter Verkcnnung des Sprachgebrauchs der besten Schriftsteller die historische Form auf es. Dagegen kommt Sitterlin (Die deutsche Sprache der Gegenwart. 1907. S. 330) zu dem Schlub: ,heute ist sozusagen nur noch die schwache im Gebrauch.“ 
III. 8. I4. IO (I821). III. 9. 247. 2 I (I824). III. IO. I8. 25; 24. 25 (1825) desgl.

III. 10. 54. 6 Gottscheds Grammatik. Gram. und rhetorische Probleme (1825).

III. I0. 66. I7 Unterhaltung über Declination durch Suffixe von Ortsbestimmungen (1825).

Ferner: III. 10. 123. I5; 212. 19; 279. 6, III. II. I72. 22; I 54. I8 (I828-29); III. I2. 205. I6; 325. 5 (I830);

III. 13.39.6 Allgemeine Sprach- und grammatische Gespräche... Ich bewunderte seine [Riemers] Umsicht und tief eindringende Sprachkenntnis (1831).

Hätte sich aber Goethe nicht lebhaft und angeregt an den von Riemer aufgeworfenen Fragen beteiligt, dann würden sie sicher nicht so oft den Unterhaltungsstoff geboten haben und der Festlegung in den Tagebüchern für wert erachtet worden sein. Die Grammatik der älteren deutschen Sprache aber lag ihm fern. Seine schon oben berührte Nibelungenlektüre nimmt auf sie keinerlei Rücksicht: I. 36. 28. 17: Ich wendete mich an die Nibelungen wovon wohl manches zu sagen wäre. . Unmittelbar ergriff ich das Original und arbeitele mich bald dermassen hinein, dass ich den Text vor mir habend, Zeile für Zeile eine verständliche Übersetzung vorlesen konnte. Es blieb der Ton der Gang und vom Inhalt ging auch nichts verloren... Ich verfertigte mir ein Verzeichnis der Perscnen und Charaktere, flüchtige Aufsätze über Localität, Geschichtliches, Sitten und Leidenschaften, Harmonie und Incongruitäten, und entwarf zugleich zum ersten Theile eine hypothetische Karte. Hierdurch gewann ich viel fïr den Augenblick, mehr für die Folge, indım ich nachher die ernsten anhallenden Bemühungen deutscher Sprach- und Alterthums-Freunde besser zu beurtheilen, zu geniessen und zu benutzen zerusste. (Tag-u. Jahreshefte 1807.)

So mannigfach die altgermanische und altdeutsche Lektüre :uch ist - Ulfilas, Edda, Otfrid, König Rother, Armer Heinrich, Tristan, Jierabras U. a. m. werden außer dem Nibelungenlied 
genannt -, nirgends finden wir einen Niederschlag der Beschäftigung mit der Sprache der Denkmäler. II. 42 II. 437 ff. sind neuerdings aus dem Nachlaß die spärlichen Zeugnisse seiner Beschäftigung mit mhd. Literatur veröffentlicht. Es sind aus dem Nibelungenlied wenige Wörter, Namen und zwei Kartenskizzen sowie ein Namenverzeichnis ("Christen und Haiden“) aus Fierabras. Dem ersten Besuch Wilhelm Grimms in Weimar von 1809 und der Bekanntschaft mit des Knaben Wunderhorn schreibt Goethe allerdings Einfluß auf sprachliche Fragen zu: I. 36. 45. 19: . . . zugleich war nichts natürlicher als dass man deutsche Sprachalterthümer hervorhub und immer mehr schätzen lernte, wozu Grimms Aufenthalt unter uns mitwirkte, indess ein gründlich grammatischer Ernst durch des Knaben Wunderhorn lieblich aufgefrischt wurde. (Tag- u. Jahreshefte I809). Spuren davon sind aber nicht nachzuweisen, über Gespräche ist es offenbar nicht hinausgekommen. I824 wird in den Tagebüchern angemerkt: III. 9. 293. 12: Riemer. Später über Anmassung der Grammatiker. Modestyl und darauf gegründete Kritik (7. XI). III. 9. 296. 23: Riemer. Gespräch über grammatisches Interesse (I6. XI.). Daraus ergibt sich das vom Dichter beanspruchte Recht, sich von der Zunft der Sprachgelehrten keine Regeln über Sprachrichtigkeit vorschreiben zu lassen, sondern guten Mustern und dem eigenen Sprachgefühl zu folgen. In diesem Zusammenhang versteht sich auch wohl die Warnung vor den Grammatikern, die Goethe dem Grafen Uwarow gegenüber ausspricht: Strehike II. 334: Fe vous prie très-instamment el au besoin j'exige la promesse de ne confier à aucun allemand ce que vous nommez la revision grammaticale de vos manuscrits. A coup sûr il ôtera de votre style ce qui en fait le prix à mes yeux, en $y$ mettant une foule de belles choses dont je ne me soucie guère. Profitez en paix de l'immense avantage, que vous avez de ne pas savoir la grammaire allemande; il y a trente ans que je travaille à l'oublier. Stil und Grammatik sind hier, wie öfters, zusammengefaßt: der gute Schriftsteller schafft sich seinen 
Sprachgebrauch selbst. Eine ungeschickte Durchsicht seiner Schriften hat die Gefahr, grammatischen Kleinigkeiten zuliebe das persönliche Gepräge des Stiles zu zerstören. Goethe selbst beugte dem dadurch vor, daß er, wie wir sahen, über der Tätigkeit seiner Revisoren sorgfältig wachte.

In grammatischen Streitfragen der Zeit hat Goethe nur einmal das Wort ergriffen und das in dem Gedichte: Kein Vergleich: I. 3. 157 .

I. Befrei uns Gott vor s und ung,

Wir können sie entbehren;

Doch wollen wir durch Musterung

Nicht uns noch andre scheren.

2. Es schreibt mir einer: den Vergleich

Von Deutschen und Franzosen,

Und jeder Patriot sogleich

Wird heftig sich erbosen.

3. Kein Christenmensche hört ihm zu;

Ist denn der Kerl bei Sinnen?

Vergleichung aber läßt man $z u$,

Da mïssen wir gewinnen.

Nach Löper und Heinemann ${ }^{1}$ ) bezichen sich die Verse auf Jean Pauls Bestrebungen, die unhistorischen Binde-s und die Substantivendung ung zu beseitigen. Für Goethe ist die Frage zu einem Wortscherze gerade gut genug. Dic neuerdings viel erörterte s-Frage aufzurollen, ist hier nicht der Ort, zumal Goethe ja auf den Kern der Sache nicht weiter eingeht. ${ }^{2}$ ) Übrigens verspottet auch Jakob Grimm Jean Pauls Versuche. ${ }^{3}$ ) Ähnlich ergießt der Dichter seinen Hohn

1) Löper III, 228 und 508; Heinemann II, 173 und 453.

2) Vgl. Behaglael: Deutsche Sprache. 3. Aufl. S. 261 ; Zcitschr. f. d. allg. deutsch. Sprachver., Beiheft 1.2. 3. 4. 19; Wilmanns Deutsche Grammatik. Straßburg 1896. II, 516 und 524; Wustmann a. a. O. 4. Auf. S. 77: Andergen a. a. O. 97: Süterlin a. a. O. S. 119.

3) Steig a. a. O. 197. 
über die etymologischen Spielereien und Künsteleien, die Ursprung und Verwandtschaft der Wörter nach ihrem Klang - lucus a non lucendo - zu erklären suchten: I. 5. 47. I.:

Ars, Ares wird der Kriegesgott genannt, Ars heißt die Kunst und $A$. . . ist auch bekannt.

Welch ein Geheimnis liegt in diesen Wundertönen!

Die Sprache bleibt ein reiner Himmelshauch, Emptunden nur von stillen Erdensöhnen, Fest liegt der Grund, bequem ist der Gebrauch, Und wo man wohnt, da muß man sich gewöhnen. Wer fühlend spricht, beschwätzt nur sich allein; Wie anders, wenn der Glocke Bimbam bammelt, Drängt alles zur Versammlung sich hinein!

Von Können kommt die Kunst, die Schönheit kommt vom Schein,

So wird erst nach und nach die Sprache festgerammelt, Und was ein Volk zusammen sich gestammelt Muß ewiges Gesetz für Herz und Seele sein.

(Etymologie. Paralip. zu Faust. Druck I836.)

Auch das Wortspiel Greis - Greif im Faust ist gleicherweise als Spott auf die Etymologie oben gekennzeichneter Art zu erklären: I. I5. I. I 3 :

Meph.: Glück zu! den schönen Fraun, den klugen Greisen.

Greif: Nicht Greisen! Greifen. - Niemand hört es gern, Daß man ihn Greis nennt. Fedem Worte klingt

Der Ursprung nach, wo es sich her bedingt:

Grau, grämlich, griesgram, greulich, Gräber, grimmig, Etymologisch gleicherweise stimmig,

Verstimmen uns.

Meph.: Und doch, nicht abzuschweifen, Gefällt das Grei im Ehrentitel Greifen.

Greif: Natürtich die Verwandtschaft ist erprobt. Zwar oft gescholten mehr jedoch gelobt; 


\section{Man greife nur nach Mädchen, Kronen, Gold, Dem Greifenden ist meist Fortuna hold.}

(Faust II. 2. Klass. Walpurgisnacht. V. 7092.)

Es ist nicht ersichtlich, warum man mit Heinemann') hier etymologisch im Sinne von alliterierend verstehen soll. Darin liegt unseres Erachtens der Spott, daß das Wort Greis abgejehnt wird, weil es der Bedeutung der anderen mit gr anlautenden durch den Klang nahekommt.

Obwohl Riemer als Verfasser einer griechischen Etymologie oft dieses Gesprächsthema aufgeworfen haben wird, konnte Goethe doch, wie er mehrmals andeutet, diesem Zweig der Sprachwissenschaft nichts abgewinnen. Lässt man sich in historische und etymologische Untersuchungen ein, so gelangt man meistens immerfort ins Ungewissere, erklärt er am 20. XI. I829 Zelter (IV. 46. 157). Er war berechtigt zu dieser Ablehnung. Denn die Art, wie vor dem Entstehen der wissenschaftlichen Etymologie am Anfang des 19. Jahrhunderts cine lächerliche Methode beim Suchen nach der Grundbedeutung und dem Ursprung der Worte die sonderbarsten und willkürlichsten Erklärungen zeitigte, mußte den Spott herausfordern.

Eine Sammlung des gesamten Wortschatzes der deutschen Sprache hat Goethe 1804 beschäftigt. Nachdem er schon im Februar mit Bezug auf einen im Merkur erschienenen Aufsatz von Macard (Rückblick einiger Neuerungen in der deutschen Sprache) an Eichstädt geschrieben hatte: IV. 17. 84. 25: Es ist sonderbar und gut, dass von allen Seiten das deutsche Sprachwesen zur Sprache kommt (29. II. 1804), läßt er sich im März in einem viclleicht an C. G. Voigt gerichteten Bricfentwurf über seinen großzügigen Plan ausführlich aus:

IV. 17 (L.esarten 305/306): Fïr die deutsche Sprache scheint mir ein glücklicher Zeitpunct cinzutrelen. Die Recension der grammatischen Gespräche [Klopstocks in der Jen. Lit. Ztg. ?]

1) Heinemann V, 559 . 
legt einen fürtrefflichen Grund. Die kurzen sich auf Sprache beziehenden Bemerkungen im Intelligenzblatt machen die allgemeine Aufmerksamkeit rege. Durch ein sonderbares Zusammentreffen zeigt sich Macard im deutschen Mercur im gleichen Fache, dessen Vorbringen ich auch unter dem Strich geprüft wünschte, und nun sollte man suchen die Deutschen allgemeiner dafür zu interessiren. Hiezu wünschte ich, dass sich im Stillen eine kleine Societät zusammenthäte, nicht zu einem Kleyensondern wo möglich Waizen-Verein. Unser Voss müßte präsidiren, die Herren Eichstädt, Fernow, Voss der Sohn würden sich anschliessen, und Schiller und ich nach unserer Weise nicht unwirksam bleiben. Man vereinigte sich leicht über den schon ausgesprochenen Hauptzweck, e in wahrhaft allgemeines deutsches Wörterbuch zusammen zu bringen, wozu ja unser Voss so vortrefflich vorgearbeitet hat, dass er auch ganz allein das Werk zu vollbringen im Stande wäre. Man vereinigte sich sodann über einen zu erlassenden Aufruf wegen der Idiotiken; diesem wäre freylich schon die möglichste Bedeutsamkeit zu geben. Man theilte Deutschland in Provinzen ein, je nachdem sie sich verschiedener Dialecte bedienen, man zeigte an, von welchen Gegenden Idiotiken vorhanden sind, bezeichnete ihren Wert und zöge die nöthigen Linien zur Anleitung für künftige Sammler. Man forderte diejenigen auf, die sich bisher im Stillen mit diesem Geschäft abgegeben, mit in Verbindung zu treten und so sähe man, in wie fern sich nach und nach eine Masse von Liebhabern sammle, welche den Stoff herbeyzuführen geneigt wäre...V Vielleicht interessirte man in der Folge einige Regierungen (III. I804).

Es ist sehr zu bedauern, daß Goethe diesen Plan nicht weiter verfolgte. Ein großes deutsches Wörterbuch auf der Grundlage des lebendigen Wortschatzes der Mundarten, zusammengestellt von einem Stabe von Gelehrten unter tätiger Mithilfe der hervorragendsten Dichter, unter dem Schutz und der finanziellen Beihilfe der Regierungen - es wäre ein Werk geworden, das noch heute der stille Wunsch nicht nur 
der Germanisten, sondern aller Freunde der Muttersprache ist. Selbst die neuzeitlichen Pläne eines Reichsamts für die deutsche Sprache hätten hier bei Goethes hervorragender Dienststellung und seinen weitverzweigten Verbindungen sich in gewisser Hinsicht der Verwirklichung genähert. ${ }^{1}$ )

In eigenartiger Weise beschäftigt, was in diesem Zusammenhang angefügt sei, Goethe vom IO. bis 2I. Oktober I8I2 (III. 4. 330-332) infolge einer französischen Anregung eine Frage des Wortschatzes, indem er aus Grimm und Diderot: Correspondance litteraire die tadelnden und lobenden Ausdrücke sammelt. Er schreibt darüber an Freund Knebel: IV. 23. I 14. 4: Ich habe mir den Spass gemacht, alle Worte auszuziehen wodurch Menschen sowohl als literarische und sociale Gegenstände verkleinert, gescholten oder gar vernichtet werden, und ich denke daraus ein dictionnaire détractif zu bilden, welches dem $d$. des négations des Herrn Pougens zum Supplement dienen mag. Geisterhebendes findet sich wenig (17. X. I8I2). Aus dem Dictionaire détractif wird aber nur ein Aufsätzchen in Kunst und Altertum I. 4II I44: Urtheilsworte französischer Kritiker. Reichliche des Tadels: abandonée, absurde, arrogance ...viellerie, voluminaux. Karge Zeugnisse des Lobes: animé, applaudie ... spirituel, verve. (K. u. A. II. 2. 1820.) Schon in einem früheren Hefte seiner Zeitschrift hatte er kurz auf die Sammlung hingewiesen (K. u. A. I. 3. I8I7. - I. 4II. I2I). Die zusammengestellte Liste weist 142 tadelnden Ausdrücken gegenüber nur 24 des Lobes auf, ein Ergebnis, das sich Goethe wie folgt erklärt: Hempel 19. I28: Das Wahre, Gute und Vortreffliche ist einfach und sich immor gleich, wie es auch erscheine. Das Irren aber, das den Tadel hervorruft, ist höchst mannichfaltig, in sich selbst verschieden und nicht allein gegen das Gute und Wahre, sondern auch gegen sich selbst kämplend,

1) Fin sich auf das geplante deutsche Wörterbuch bezichender Aufsatz von 1. Geiger im zweiten Morgenblatl der Frankfurter \%eitung vom 17. Deyember 1896 ist mir leider weder durch den Verfasser noch durch die Redaktion der \%eitung zughinglich geworden. 
mit sich selbst im Widerspruch. Daher müssen die Ausdrücke des Tadels die Worte des Lobes in jeder Literatur überwiegen. (Sprüche in Prosa. Nachlaß.)

$\mathrm{Ob}$ das untersuchte Werk jedoch richtig gewählt war und ob Goethe berechtigt ist, von der einen Probe derart verallgemeinernde Schlüsse auf alle Sprachen zu ziehen, scheint uns recht zweifelhaft. Bouke ${ }^{1}$ ) stellt z. B. fest, daß Goethe selbst eine Ausnahme von seiner eigenen Regel macht, da in seinem Sprachschatz die Ausdrücke des Tadels an Zahl hinter den lobenden weit zurückbleiben.

Eine ähnliche Arbeit hat ihn nach Ausweis der Tagebücher 1814 beschäftigt. III. 5. 90. 3: Ernst und Scherz Reden aller Sprachen und Art sortirt (I. I. I8I4). An die Öffentlichkeit ist aber von dieser Sammlung nichts gelangt. ${ }^{2}$ )

Goethe verdanken wir unseren heutigen Stil; er hat, um mit Hermann Grimm zu reden, ,,die deutsche Sprache so weit erhoben, daß in ihr die feineren Wendungen der Gedanken Ausdruck finden können". Das nachzuweisen, ist hier, wo Goethes Äußerungen über Stil zur Behandlung stehen, nicht der Platz, es sei aber vorausgeschickt, um diesen als Grundlage zu dienen. Denn es ist bezeichnend für den Meister der Sprache, daß ihm Äußerlichkeiten wie Schrift, Schreibung, Zeichensetzung gleichgültig waren, daß ihn die Grammatik in ihrem Bestreben, die Sprache in starre Regeln zu pressen, wenig anzog, daß er aber für den Stil, als die dem Schreibenden eigentümliche Schreibart, in einer ganzen Reihe wichtiger Äußerungen eintrat. Ein Kampf für das Recht am Stil und ein Kampf gegen die hohle Phrase ist es, den wir von 1774 bis in die letzten Jahre verfolgen können. Der Stil der Geniezeit wird im Werther verteidigt: I. I9. 9I. 18: Ich arbeite gern leicht weg, und wie es steht, so steht es: da ist er

1) Bouke a. a. O. 206.

2) Im Anhang S. 262 ist eine kleine Reihe von Worterklärungen, Etymologien und grammatischen Bemerkungen zusammengestellt, die ganze Ausbeute, die Goethes Schriften auf diesem Gebiete lieferten. 
[der Gesandte] im stande, mir einen Aufsatz zurückzugeben und zu sagen: „Er ist gut, aber sehen Sie ihn durch, man findet immer ein besseres Wort, eine reinere Partikel." Da möchte ich des Teujels werden. Kein Und, kein Bindewörtchen darf aussen bleiben, und von allen Inversionen, die mir manchmal entfahren, ist er ein Todfeind; wenn man seinen Perioden nicht nach der hergebrachten Melodie heraborgelt, so versteht er gar nichts drin. Das ist ein Leiden, mit so einem Menschen zu thun zu haben. (Werthers Leiden. II. I774.)

Von einem ruhigeren Standpunkte freilich beurteilt der Greis ein halbes Jahrhundert später die allzu große Ungebundenheit des Jugendstils: I. 29. 146: Damals manifestirte sichs [das Genie] nur, indem es die vorhandenen Gesetze überschritt, die eingeführten Regeln umwarf und sich für gränzenlos erklärte. Daher war es leicht genialisch zu sein und nichts natürlicher als dass der Missbrauch in Wort und That alle geregelten Menschen aufrief, sich einem solchen Unwesen zu widersetzen. (D. W. I9. I830.) - Die hohle Phrase, das bedeutungslose Flickwort verfolgte der Dichter mit einem $\mathrm{Haß}$, der vor den kräftigsten Äußerungen nicht zurückscheut, ja die Grenzen der Berechtigung bisweilen überschreitet. Schon 1773 werden die Fluch- und Bcteuerungswörter mit dem Bann belegt. IV. 2. 67. 15: Nun aber die Art von Beteurungsflüchen möcht ich vom Theater ganz verbannen. Im gemeinen Leben sind sie schon lästig und zeugen von einer leeren Seele, wie alle Gewohnheitsworte, und im Drama mag es gar leicht für einen Mangel der dialogischen Verbindungsfähigkeit angesehen werden. Auch hat der Über. setzer [von Plautus' Komödien] sie oft hingestellt, wo Plautus gar nichts hat. Und das hercle kann ich für nichts als unser wahrhaftig nehmen. Sie werden diese Anmerkungen sehr wunderlich finden, wenn Sie in meinem Berlichingen auf manchen Schimpf und Fluch treffen werden, davon ich jetst nicht Rechenschaft geben kann. Vielleicht auch werden Sie mir um desto cher recht geben, da Sie sehen, es ist nicht edles Ge/ühl, sondern 
nur relative Besorgnis $\imath m$ Aufnahme dieser Stücke. (6. III. I773 an Salzmann.)

Wie ein Bekenntnis klingt ein Notschrei, den ihm die Übersetzung von Benvenuto Cellini auspreßt: I. 35. I58. 9: $D a$ ich mich in meinem Leben vor nichts so sehr als vor leeren Worten gehütet, und mir eine Phrase, wobei nichts gedacht oder emp. funden war, an andern unerträglich, an mir unmöglich schien, so litt ich bei der Übersetzung des Cellini, wozu durchaus unmittelbare Ansicht gefordert wird, wirklich Pein. (Tag- u. Jahreshefte 1803. Kein Wunder, daß bei solch ehrlichem Phrasenhaß das Zeitungsdeutsch schlecht abschneidet. Als Sulpiz Boisserée von Goethe eine Empfehlung seines Domplanes in den Tagesblättern erbittet, ergeht folgende Absage: IV. 22. 120. 22: Mit Tages-, Wochen- und Monats-Blättern bin ich ausser aller Verbindung, und diese haben die böse Art, dass sie sehr oft die höchsten Worte, mit denen nur das Beste bezeichnet werden soll, als Phrasen anwenden, um das Mittelmässige oder wohl gar Geringe zu maskiren. In solcher Gesellschaft thut ein bestimmtes, vernünftiges Wort nicht seine rechte Wirkung. (26. VI. I8II.)

Besondere Fehde war den sogenannten Flickwörtern geschworen, die nichts bedeuten und Gedankenarmut bemänteln. Eine ganze Blütenlese der verhaßten Wörter $-5 \mathrm{I}$ an der Zahl - werden infolge des Verkehrs mit Fichte, der der. gleichen bedingende Phrasen aus mündlichem und schriftlichem Verkehr ebenfalls verbannt wissen wollte, in Kunst und Altertum dem öffentlichen Spott preisgegeben. I. 4II. II 8-I20: Redensarten, welche der Schriftsteller vermeidet, sie jedoch dem Leser beliebig einzuschalten überlässt: aber, gewissermassen, einigermassen, beinahe, ungefähr, kaum, fast, unmassgeblich, wenigstens, ich glaube, mich deucht, ich läugne nicht, wahr. scheinlich vielleicht, nach meiner Einsicht, wenn man will, so viel mir bewusst . . . mit Ausnahme, ohne Zweifel, irgend, damals, sonst... zugegeben . . geradezu. Verzeihung dem Ausdruck. So war es eine Zeit, wo er [Fichte] dem Worte, ge. 
wissermassen" einen heftigen Krieg machte. Diess gab Gelegenheit, näher zu bedenken, woher diese höflichen, vorbittenden, allen Widerspruch des Hörers und Lesers sogleich beseitigenden Schmeichelworte ihre Herkunft zählen. Möge diese Art Euphemismus für die Zukunft aufbewahrt sein, weil in der gegenwärtigen Zeit jeder Schriftsteller zu sehr von seiner Meinung überzeugt ist, als dass er von solchen demütigen Phrasen Gebrauch machen sollte. (K. u. A. I. 3. I8I7.) Andere werden an anderen Stellen gebrandmarkt: II. 13. 116. 4: Auf diesem Wege hilft man sich durch ein ,beinahe, à peu près, semblable", und es ist auffallend, welch ungewisses Schwanken sich des Wissens hiedurch bemächtigt. (Morphol. II. Paralip. zu II. 7.)

I. 40. 254. 2 I (IV. I7. 9. 23): So wird das Wort ein [in Reichardts Briefen aus Paris] so oft wiederholt, dass es seine Bedeutung am Ende selbst aufzehrt. Das Wort "letat" liesse sich gleichfalls öfter entbehren oder durch neulich, letztens, letzthin ersetzen und variiren. (Jen. Allg. Lit. Ztg. I804.)

Seines besonderen Hasses aber scheint sich der Ausdruck „, nichts anders als" erfreut zu haben. Kanzler v. Müller berichtet uns darüber: G. V. 90: „Ich führte an, dass irgend ein Schriftsteller gesagt habe, der Humor sei nichts anders als der Witz des Herzens. Goethe ergrimmte aufs Heftigste über die Redensart "Nichts anders". So, schrie er, sagt einst Cicero: Die Freundschaft ist nichts anderes als: 0 , du Esel, du einfältiger Bursche, du heilloser Kerl, der nach Griechenland läuft, um Weisheit zu holen und nichts Klïgeres als jene unsinnige Phrase herausbringt. Nichts anderes! Lauter Negation, lauter Herabsetzung! Ich werde gleich wiithend, wenn ich dergleichen höre. Nie konnte ich vor Matthisson Achtung haben wegen des absurden Liedes: Namen ich nenne dich nicht. $\left.{ }^{1}\right)$ - Und ,Witz des Herwens" welcher Unsinn! Ich weiss nicht, was Herz ist und will ihm Witz beilegen! Dergleichen Phrasen streifon an meinem Ohr voriiber wic serplatate Luftblasen; der Verstand

1) Nach einer Anmerkung der W. A. zur Stelle ist das Lied ,Namen nennen dich niclst" von Ueltzen gemeint. 
findet absolut nichts darin; das ist hohles Zeug. Es dauerte lange, ehe er sich beruhigte." (6. VI. 1824.) Ja, ein eigenes Aufsätzchen über die Negation hat sich im Nachlaß gefunden. I. 42 II 49: Nichts anders als. Fe mehr von Fugend auf das Gefühl bei mir wuchs, dass man schweigen solle, wenn man nichts zu sagen hat, und dagegen das Wohlgedachte auch gut und ohne Stottern hervorgeben solle, desto mehr bemerkt ich, dass man aus natürlicher Fahrlässigkeit immer noch gewisse Flick- und Schaltwörter behaglich einschiebt, um eine sonst tüchtige und wirksame Rede, man weiss nicht warum, zu erlängen. Indessen mag es wohl aus der mündlichen Rede hergekommen sein, welche, um sich zu fassen und Zeit zu nehmen, allenfalls eine solche Interjektion gebraucht... Eine Redensart aber, die sich durch die würdigsten Vorgänger in Ansehen setat, den gemeinen Menschensinn einschläfert, damit er das Absurdeste ertragen möge, ist die, wovon dieser Aufsatz den Titel führt. (Nachgel. Werke IX. Bd. I833, entstanden I 82 I.)

An einem Gedichte Byrons wird ausdrücklich das Fehlen der Flickwörter lobend hervorgehoben. G. VII. I08: „Lord Byron was the subject of his praise. He said: Es sind keine Flickwörter im Gedichte ... And he compared the brilliancy and clearness of his style to a metal wire drawn trough to a steal plate." (Aug. I829 mit Robinson.) ${ }^{1}$ )

Wie soll nun ein mustergiltiger Stil nach Goethe beschaffen sein? Einem neugierigen Frager, der wissen wollte, ,, wie es Seine Exzellenz nur angefangen habe, einen so schönen Stil zu schreiben", erteilt der Altmeister die einfache Antwort: Bode II. 87: Das will ich Ihnen sagen, mein Lieber. Ich habe die Gegenstände ruhig auf mich einwirken lassen und den bezeichnendsten Ausdruck dafür gesucht (nach 1827 zu G. Stickel). Das stimmt mit früheren Äußerungen zu Luden und Riemer

I) "Lord Byron war der Gegenstand seines Lobes. ... Und er verglich den Glanz und die Klarheit seines Stils mit einem durch eine Stahlplatte gezogenen Metalldraht." 
überein, in denen ein klarer, einfacher, sinnlicher, ,,repräsentativer" Stil gefordert wird.

G. II. 102: In Ihrer Darstellung aber machen Sie sich frei von jedem Vorbilde und geben Sie namentlich jede Hämmerung und Verrenkung auf ... Schreiben Sie vielmehr klar und einfach, ohne Scheu vor einem poetischen Anflug und ziehen Sie eine bequeme Entwicklung der geschraubten Kürze vor, die man schlagend zu nennen und hoch zu bewundern pflegt. (19. VIII. 1806 mit Luden.)

G. II. 347: $D a$ die Rede die Sinne und das innere Vorstellungsvermögen vertreten muss, so muss sie auch zu diesen reden und der Ausdruck muss sinnlich und repräsentativ sein. (24. XII. I8Io mit Riemer.)

Also nirgends Hinweis auf Stilmuster, Anempfehlung von Stilregeln, sondern jeder hat sich seinen Stil unabhängig von anderen und dem jeweilig darzustellenden entsprechend $z u$ gestalten. So hatte ja auch er selbst keinen ausgeprägten Stil, sondern für jedes Werk und jede Zeit einen eigenen. „Wem,“ sagt Ulrich v. Wilamowitz-Moellendorff ${ }^{1}$ ), , die Rede unmittelbar aus der Seele kommt, die Kunst Natur ist, der wird anders reden, wenn er anders geworden ist, sein Stil wird mit ihm altern, weil er mit ihm jung war. So ist es bei Goethe und bei Platon." Das geflügelte Wort Le style c'est l'homme war von Buffon geprägt worden und wird von Goethe bezeichnend variiert. II. 3. 12. 12: Wenn man behauptet hat: schon der Stil eines Schriftstellers sei der ganze Mann, wie vielmehr sollte nicht der ganze Mensch den ganzen Schriftsteller enthalten. (Histor. Farbenl. Einltg. 1810.) Oder zu Eckermann: Im ganzen ist der Stil eines Schriftstellers ein treuer Abdruck seines Innern: will jemand einen klaren Stil schreiben, so sei es ihm zuvor klar in seiner Seele; und will jemand einen großartigen Stil schreiben, so habe er einen großartigen Charakter. (G. V. 64; - 14. IV. I824.)

1) In Hinneberg: Dic Kultur der Gegenwart. I. Teil. Abt. 8. Dic gricchische und lateinische Jiteratur. Leipzig 1905. S. 77. 
Vor diesen Forderungen konnte am wenigsten der philosophische und überhaupt gelehrte Stil der Zeit bestehen. Mehrmals läßt Goethe seinen Unmut darüber aus. Bode I. I47: Den Verstandesphilosophen begegnets und muss es begegnen, dass sie undeutlich aus gar zu grosser Liebe zur Deutlichkeit schreiben. Indem sie für jede Enunziation die Quelle oder ihr Acheminement nachweisen wollen von dem Orte an, wo sie ins Raisonnement eingreift, bis zu ihrem Ursprung, auf welchem Weg wieder anderes acheminiert und einläuft, geht es ihnen wie dem, der einen Fluss von seiner Mündung an aufwärts verfolgt und so immer auf einfallende Bäche und Flüsschen stösst, die sich wieder verzweigen, so dass er am Ende ganz vom Wege abkommt und in Deverticulis logiert. Beispiele geben Kant und Hegel. Aristoteles ist noch mässig mit seinen denns und rás. Sie weben eigentlich nicht den Teppich sondern sie dröseln ihn auf und ziehen Fäden aus. (Nov. 1806 mit Riemer.)

G. II. 242: Es herrscht bei uns der Gebrauch, dass man die Wissenschaften . . auf den Kathedern förmlich zersetzt, so das uns Deutschen nur zwischen einer seichten Popularphilosophie und einem unverständlichen Gallimathias transcendentaler Redensarten gleichsam die Wahl gelassen wird. (28. II. I 809 mit F. Falk.)

IV. 24. 3I. 9: Kaum schreiben unsere Mädchen und Füng. linge, unsere Hausfrauen und Geschäftsmänner einen natürlichen Styl und wissen sich allgemein verständlich und angenehm auszudrücken, so treten junge Männer auf, um etwas ganz fremdes, ungehöriges, unverständliches und abgeschmacktes geltend zu machen. (I3. XI. I8I3 an Knebel.) Die Auslassung bezieht sich auf eine Übersetzung aus Thukydides, die auch Knebels Beifall nicht fand, der sie ,steif, holbricht und unverständlicher als selbst das Griechische" nannte. Aus derselben Zeit stammt ein ähnliches Urteil: IV. 24. I5I. 23: Diese Eigenart [der Deutschen, sich einander im Weg zu stehen] ist um so weniger abzulegen, als sie auf einem Vorzug beruht, den die Nation besitzt. . ., dass nämlich vielleicht in keiner andern 
so viel vorzügliche Individuen geboren werden und neben ein. ander existieren. Weil nun aber jeder bedeutende Einzelne Not genug hat, bis er sich selbst ausbildet, und jeder Füngere die Bildungsart von seiner Zeit nimmt . . . so entspringen, da der Deutsche... in steter Verwandlung begriffen ist. . . eine solche Reihe von Bildungsverschiedenheiten . . . dass der gründlichste Etymolog nicht dem Ursprung unseres babylonischen Idioms ... nachkommen könnte.

(I4. II. I8I4 an Fr. B. v. Bucholtz.)

Bei der Lektüre des Buches des Philosophen Hinrichs „,Das Wesen der antiken Tragödie" kommt es Eckermann gegenüber $z u$ einer grundsätzlichen Aussprache über den Philosophenstil: G. VI. 68: Wenn ich aber ehrlich sagen soll, so thut es mir leid, dass ein ohne Zweifel kräftig geborener Mensch von der norddeutschen Seeküste wie Hinrichs durch die Hegelsche Philo. sophie so zugerichtet worden, dass ein unbefangenes, natürliches Anschauen und Denken bei ihm ausgetrieben und eine kïnstliche und schwerfällige Art und Weise sowohl des Denkens wie des Ausdrucks ihm nach und nach angebildet worden, so dass wir in seinem Buch auf Stellen gerathen, wo unser Ver. stand durchaus stillsteht und man nicht mehr weiss, was man liest... Es gibt in seinem Buche nicht wenige Stellen, bei denen der Gedanke nicht rückt und fortschreitet und wobei sich die dunkle Sprache immer auf demselbigen Fleck und in demselbigen Kreise bewegt völlig so wie das Einmaleins der Hexe in meinem Faust... [nach Vorlcsung einer besonders dunklen Stellc)... Was sollen erst die Engländer und Franzosen von der Sprache unserer Philosophen denken, wenn wir Deutschen sie selber nicht verstehen. (28. III. 1827.) ${ }^{1}$ )

1) Wir finden den Beleg auch in einer kleinen Zusammenstellung von "Gedanken Goethes über die deutsche Sprache“ in Nr. 394 des „Berliner Tageblatts" (6. August 1907) von M. Stadler. Da dic Aussprüche nur aufgezahle werden - neun an der Zahl -, bedarf es cines weiteren Einfehens auf den Artikel nicht. Ich verdanke ihn der gef. Vermittelung der Schriftieitung der Zeitschr. d, allg, deutsch. Sprachvereins. 
Schon 1824 hatte eine Unterhaltung über den philosophischen Stil Goethe Gelegenheit gegeben, sich über den deutschen Stil überhaupt und sein Verhältnis zu dem der Engländer und Franzosen auszusprechen. G. V. 64: Den Deutschen ist im ganzen die philosophische Speculation hinderlich, die in ihren Stil oft ein unsinnliches unfassliches, breites und aufdröselndes Wesen hineinbringt. Fe näher sie sich gewissen philosophischen Schulen hingeben desto schlechter schreiben sie. Diejenigen Deutschen aber, die als Geschäfts- und Lebemenschen blos aufs Praktische gehen, schreiben am besten. So ist Schillers Stil am prächtigsten und wirksamsten, sobald er nicht philosophirt, wie ich noch heute an seinen höchst bedeu. tenden Briefen gesehen, mit denen ich mich gerade beschäftige. Gleicherweise giebt es unter deutschen Frauenzimmern geniale Wesen, die einen ganz vortrefflichen Stil schreiben, so dass sie sogar manche unserer gepriesenen Schriftsteller darin über. treffen. Die Engländer schreiben in der Regel alle gut, als geborene Redner und als praktische auf das Reale gerichtete Menschen. Die Franzosen verleugnen ihren allgemeinen Charakter auch in ihrem Stil nicht. Sie sind geselliger Natur und vergessen als solche nie das Publicum, zu dem sie reden; sie bemühen sich klar zu sein um ihren Leser zu überzeugen, und anmuthig, um ihm zu gefallen. Im ganzen ist der Stil eines Schriftstellers ein treuer Abdruck seines Innern usw. (vgl. oben; I4. IV. 1824 zu Eckermann).

Die Verdienste seiner großen Zeitgenossen Wieland und Schiller um die Bildung des deutschen Stiles und seinen eigenen werden voll anerkannt. G. V. I35: Wielanden verdankt das ganze obere Deutschland seinen Stil. Es hat viel von ihm gelernt, und die Fähigkeit, sich gehörig auszudrücken, ist nicht das geringste. (I8. I. I825 mit Eckermann.)

II. II. 53. 3: Und so [durch den Verkehr mit Schiller und die Beschäftigung mit dessen philosophischen und ästhetischen Schriften] gewöhnte ich mich nach und nach an eine Sprache, die mir völlig fremd gewesen und in die ich mich um so leichter 
finden konnte, als ich durch die höhere Vorstellung von Kuns und Wissenschaft, welche sie begünstigte, mir selbst vornehmer und reicher dünken mochte, da wir andern vorher uns von den Popular-Philosophen . . . gar unwürdig mussten behandeln lassen. Weitere Fortschritte verdank' ich besonders Niethammern, der mit freundlicher Beharrlichkeit mir... die einzelnen Be. griffe und Ausdrücke zu entwickeln und zu erklären trachtete. (Zur Naturwiss. Neuere Philosophie.) Auch Freund Zelters Stil wird lobend erwähnt, wobei es ohne einen Seitenhieb auf den deutschen Briefstil freilich nicht abgeht. Burkhardt 43. 30: Ich habe von ihm eine grosse Anzahl Briefe so voll Geist und Lebhaftigkeit wie dieser, und das ist gewiss beachtenswerth in einer Sprache, die dem Briefstil so wenig günstig ist wie die unsere. (3. VI. I 824 mit Soret.)

$\mathrm{Ob}$ die folgende Bemerkung über den Wandel des deutschen Stils im Anfang des 19. Jahrhunderts stichhaltig ist, dürfte fraglich erscheinen. G. II. I I9: Wir Deutsche waren im Bewusstsein unserer Tugenden früherhin im Ausdruck freier und loser, da wir jetzt bei ungebundenen Sitten zu einer Decenz des Ausdrucks streben müssen. (8. XII. I 806 mit Ricmer.)

Sehr wenig $\mathrm{zu}$ Goethes stets vertretener Forderung des persönlichen, individuellen Stiles will uns eine Auslassung aus dem vorletzten Lebensjahr passen: G. VIII. 50: Ich lasse darin [in der Metamorphose] einige Stellen von bedeu. tenden jungen Naturforschern eintreten, wobei es erfreulich ist zu sehen, dass sich jetzt in Deutschland unter den Bessern ein so guter Stil gebildet hat, dass man nicht mehr weiss, ob der eine redet oder der andere. (18. III. I83 I mit Eckermann.) Wie vereint es sich mit dem Ausspruch, daß der Stil ein treuer Abdruck des Charakters cines Schriftstellers ist, wenn hier behauptet wird, daB die nicht zu unterscheidende Schreibweise mehrerer das Zeichen eines guten Stiles sei? Erklärt es sich vielleicht daraus, daß der Naturforscher Goethe in der sich allmählich angleichenden Kunstsprache der jüngeren Zunftgenossen, die das gegenseitige Verständnis förderte, 
ein erfreuliches Zeichen für die Entwickelung der Wissenschaft und das endliche Durchdringen seiner eigenen Ideen sah? Wir erinnern uns aus dem ersten Kapitel, wie er gerade in der wissenschaftlichen Terminologie ein schweres Hindernis für neue Lehren sah. Wir hätten also auch hier bei dem Gelehrten eine Anschauung zu konstatieren, von der der Dichter nichts weiß, ebenso wie es zu einem Teil bei der von der Unzulänglichkeit der Sprache der Fall ist.

Wie gewissenhaft und ernst es Goethe mit Fragen des Stiles nahm, mögen zum Schluß noch zwei Bemerkungen dartun. Als er von Berlin aus um eine passende Inschrift für das dort $\mathrm{zu}$ errichtende Blücherdenkmal angegangen wird, sinnt er längere Zeit darüber nach und schreibt IV. 27. 39. 18: Inschriften in deutscher Sprache sind schwierige Aufgaben; scheint mir etwas zu gelingen, so sende solches zur Beurtheilung. (2. VI. 18 I6 an A. C. v. Preen.) Schließlich schlägt er "In Harren und Krieg" vor. Und der Kanzler v. Müller berichtet: G. IV. 86: „Alle Geistliche, die nicht wahre Rationalisten seien, betrügen sich selbst oder andere (sagte Goethe). Das Wort Betrug wollte ich nicht zugestehen; er gab es endlich preis, ohne jedoch den Sinn desselben aufzugeben und ich fühlte abermals, wie schwer es halte, mit ihm bei der Schärfe und vollendeten Klarheit aller seiner Begriffe und Redewendungen zu disputiren." (8. VI. I82I.)

Davon, daß sich Goethe um schulmäßige Lehrbücher des Stiles gekümmert hätte, finden wir seinen Anschauungen entsprechend nur eine schwache Spur in den Tagebüchern. III. 10. 240. 3: Wilhelm Mejers von Clausthal praktisches Handbuch des Stils der deutschen Prosa. (7. IX. 1826.) Irgendwelchen Niederschlag hat die jedenfalls nur vorübergehende und flüchtige Vornahme dieses Buches nicht hinterlassen. Auch in einem Briefe an Soret vom II. VI. I829 (IV. 45. 287) wird es nur erwähnt, ohne daß ein Urteil darüber abgegeben würde. 


\section{ACHTES KAPITEL.}

\section{SCHRIFTSPRACHE UND MUNDART.}

Adelung, auf den wir auch hier wieder zurückgreifen müssen, vertrat die Anschauung, daß das „Meißener Deutsch“ die allein maßgebende Norm für die Schriftsprache sei, daß die Mundarten im übrigen roh und ungeschlacht seien und die Übernahme von Sprachstoff aus ihrem Wortschatz deshalb unwürdig der Schriftsprache sei, ,die in den obersten Klassen der kultivirtesten Provinz entstanden ist." $\left.{ }^{\prime 1}\right)$ Mit dem ersten Teile dieser Behauptung ist $\mathrm{zu}$ Goethes Zeit insofern aufgeräumt, als man sich zu der Auffassung bekehrt hatte, „daß, wie Socin es formulirt, das Gutdeutsche überhaupt an keinem Ort und in keinem Gau zu Hause, sondern eine allgemeine von allen Stämmen gleichmäßig zu pflegende Mundart ist, die jeder mit Schönheit sprechen kann." Die Oberherrschaft des Obersächsischen war damit gebrochen, und in Dichtung und Wahrheit spricht Goethe von ihr als von etwas, das der Vergangenheit angehört. I. 27. 56: Fede Provinz liebt ihren Dialect denn es ist doch eigentlich das Element, in welchem die Seele ihren Atem schöptt. Mit welchem Eigensinn aber die meissnische Mundart die übrigen zu beherrschen, ja eine Zeitlang auszuschließen gewusst hat, ist jedermann bekannt. Wir haben viele Fahre unter diesem pedantischem Regimente gelitten und nur durch vielfachen Widerstreit haben sich die sämmtlichen Provinzen in ihre alten Rechte wieder eingesetzt. (D. u. W. 6. I8II.) Noch 1803 aber steht er im Bann der alten Ansicht, wenn er in seincn "Regeln für Schauspicler" sagt: I. 40. 139: auf der Bühne herrsche nur die reine deutsche Mundart, unter dieser wird jene Oberdeutsche, durch den sächsischen Dialect gemilderte und durch Geschmack, Kïnste und Wissen. schaften ausgebildete und verfeinerte Mundart verstanden. Schon

1) Vgl. über dic Frage: Socin, Schriftsprache und Dialekte im Deutschen. Heilbronn 1888. S. $403 \mathrm{fr}$. 
in den Xenien aber werden Adelungs Ansichten von den Dichtern verspottet, wenn sie vor dem „,Dresdener Wassermann" warnen, für den das nicht in Meißen gesprochene Deutsche „Kauderwälsch“ ist:

\section{5. 217:}

Übrigens haltet euch $j a$ von dem Dr . . r Wassermann ferne, Daß er nicht über euch hergieße den Elbestrom aus.

$$
\text { (Xen. Nr. 86. - I796.) }
$$

I. 5. 220: Elbe.

All ihr andern, ihr sprecht nur ein Kauderwälsch. Unter den Flüssen

Deutschlands rede nur ich, und auch in Meißen nur, Deutsch. (Xen. Nr. I05 von Schiller.)

War also der Streit über die Heimat der Schriftsprache für die Klassiker in der Hauptsache abgeschlossen, so war die bei weitem wichtigere Frage nach der Berechtigung der Aufnahme mundartlichen Sprachstoffes in die Schriftsprache oder gar der Verwendung der Mundart als Literatursprache noch weit von einer dieser günstigen Lösung entfernt. Gottscheds und Adelungs ablehnender Standpunkt ist auch von den Klassikern noch keineswegs verlassen trotz Herders Begeisterung für die „Idiotismen“, welche er "Schönheiten“ nennt, „die uns kein Nachbar durch Übersetzung entwinden kann." Die Mundart ist auch Goethe in seinen ersten Äußerungen zur Sache noch die schlechtere, unreine Sprache der Schriftsprache gegenüber. Er weicht hierin aber nicht, wie Michel annimmt, von Schiller $a b$, sondern scheint diesen vielmehr späterhin günstig für die Mundart beeinflußt zu haben. Stolz ablehnend oder gar feindselig hat der Frankfurter niemals der angestammten Mundart und dem Recht auf sie überhaupt entgegengestanden. Das beweist die warme und verständnisvolle Verteidigung, die er ihr in seiner Lebens. geschichte widmet bei der Schilderung seines Eintritts in die 
Leipziger Kreise, die an seiner Sprache Anstoß nahmen: 1. 27. 57. 21: Ich war nämlich in dem oberdeutschen Dialect geboren und erzogen, und obgleich mein Vater sich stets einer gewissen Reinheit der Sprache befliss, und uns Kinder auf das, was man wirklich Mängel jenes Idioms nennen kann, von Fugend an aufmerksam gemacht und zu einem besseren Sprechen vorbereitet hatte, so blieben mir doch gar manche tieferliegende Eigenheiten, die ich, weil sie mir ihrer Naivetät wegen gefielen, mit Behagen hervorhob und mir dadurch von meinen neuen Mitbürgern jedesmal einen strengen Verweis zuzog. Der Ober. deutsche nämlich, und vielleicht vorzüglich derjenige, welcher dem Rhein und Main anwohnt (denn grosse Flüsse haben wie das Meeresufer immer etwas Belebendes) drückt sich viel in Gleichnissen und Anspielungen aus und bei einer inneren menschenverständigen Tüchtigkeit bedient er sich sprichwört. licher Redensarten. In beiden Fällen ist er öfters derb, doch wenn man auf den Zweck des Ausdrucks sieht, immer gehörig; nur mag freilich manchmal etwas mit unterlaufen, was gegen ein zarteres Ohr sich anstössig erweist. Fede Provinz liebt ihren Dialect (s.o.) . . . Was ein junger lebhafter Mensch unter diesem beständigen Hofmeistern ausgestanden habe, wird der. jenige leicht ermessen, der bedenkt, dass nun mit der Aussprache, in deren Veränderung man sich endlich wohl ergäbe, zugleich Denkweise, Einbildungskraft, Gefühl, vaterländischer Charakter sollten aufgeopfert werden. (D. W. 6. I8II.)

Betrachten wir nun, wie sich Gocthes Verhältnis zur Mund. art in seiner Stellung zu den Produkten der allmählich hervortretenden Dialcktliteratur kennzeichnet, so werden wir ein zunchmendes Verständnis feststellen können. Als er I798 eine Besprechung der mundartlichen Dichtungen des Nürnbergers J. Konrad Grübel (1736-1809) an Schiller schickte, gab er ihnen folgende Begleitworte mit: IV. 13. 49. I9: Hier schicke ich eine eigne Erscheinung, eine Ankïndigung, dass cin letater Abkömmling der alten Nürnberger Meistersänger eine Auswahl seiner Gedichte herausgeben will... Er hat 
Sachen gemacht von Humor und Natürlichkeit, die leicht ins reinere Deutsch zu übersetzen wären und deren sich niemand schämen dürfte. (3 I. I. I798.)

Ähnlich schreibt er an Knebel: IV. I3. 80. 8: Wenn seine Sachen einmal heraus sind, wird man sehr leicht Auszüge daraus ins gewöhnliche Deutsch übersetzen und sie dadurch weiter bekannt machen können. (20. II. 1798.) Die Rezension selbst, die zunächst in der Cottaschen Allgemeinen Zeitung (23. XII. 98) erschien, sagt über die Sprache der Gedichte: I. 40. 24. 3. 5 : In Oberdeutschland, wo man mit dieser oder ähnlicher Mundart bekannt ist, wird man ihn mit Vergnügen lesen, aber auch in Sachsen und Niederdeutschland wird er jedem Freunde deutscher Art und Kunst willkommen sein, um so mehr als sich die Gedichte mit geringer Mühe in ein verständliches Deutsch über. tragen lassen, und jeder, der sich übt sie auf eine solche Weise vorzulesen, mit den meisten derselben jede geistreiche und heiter gestimmte Gesellschaft angenehm unterhalten wird... Wären die Arbeiten unsers Dichters in reinem Deutsch geschrieben, so braucht es weiter keiner anzeigenden Emplehlung, da man aber das Gute derselben aus der Schale der wunderlichen Mundart herausklauben muss, so wird es wohlgethan sein, den Leser auf einiges aufmerksam zu machen. Die Mundart ist also Goethe unrein, ungewöhnlich, unverständlich, wunderlich; er denkt an Verhochdeutschung, ist also noch weit entfernt von der richtigen Wertung der Mundart als Literatursprache. Die Gedichte des Nürnbergers gewinnen ihm lediglich ihres poetischen Gehaltes wegen Lob ab, um dessentwillen er auch die ,wunderliche" Sprache mit in den Kauf nimmt. Die gleiche Anschauung spricht auch aus Schillers Antwort vom 2. II. I 798, für den der ,Nürnberger Meistersänger" ein Kuriosum ist. Als aber Goethe nach sieben Jahren den Aufsatz wieder vornimmt, um ihn erneut mit einer Rezension von Hebels alemannischen Gedichten zu veröffentlichen, macht er den bezeichnenden Zusatz: II. 40. 311. 6: Sein Dialect hat zwar etwas Unangenehmes, Breites, ist aber doch seiner 
Dichtart sehr gïnstig. (Jen. Lit. Zeitung v. I3. II. I805.) Er ist also der richtigen Beurteilung der Mundart entschieden näher gekommen. Es wird ihr das Zugeständnis gemacht, daß sie nicht die äußere schlechte Form der Dichtungen, sondern ein Charakteristikum derselben, ein notwendig zu ihnen Gehöriges, nicht beliebig von ihr zu Trennendes ist. Schon im vorhergehenden Jahre hatte Goethe in einer Besprechung von Vossens zum Teil niederdeutschen Gedichten, dem ersten Versuch ,, wahrer Dialektdichtung von literarischem Wert", Worte gefunden, die der Mundart alle Gerechtigkeit widerfahren lassen, wobei freilich dahingestellt bleiben muß, ob die Stelle nicht aus der Feder von Voß dem Jüngeren stammt, der nach den neueren Forschungen Anteil an der Rezension hat. Immerhin würde sie auch dann Goethes Überzeugung zum Ausdruck bringen. Sie lautet: I. 40. 278. 6: $\mathrm{Zu}$ einem liebevollen Studium der Sprache scheint der Nieder. deutsche den eigentlichen Anlass zu finden. Von allem was un. deutsch ist abgesondert, hört er nur un sich her ein santtes behagliches Urdeutsch und seine Nachbarn reden ähnliche Sprachen. Fa wenn er ans Meer tritt, wenn Schiffer des Auslands ankommen, tönen ihm die Grundsylben seiner Mundart entgegen und so empfängt er manches Eigene, das er selbst schon aufgegeben, von fremden Lippen zurück und gewöhnt sich desshalb mehr als der Oberdeutsche, der an Völkerstämme ganz verschiedenen Ursprungs angränzt, im Leben selbst auf die Abstammung der Worte zu merken. (Jen. Lit. Ztg. April I804.)

Das Jahr 1805 bringt Goethe die Bekanntschaft mit Johann Peter Hebels alemannischen Gedichten, die ihn veranlassen, sich ausführlicher über Dialektdichtung zu äußern. Eine von Falk für die Jenacr Lit. Zeitung cingercichte Besprechung der Ge. dichte wurde weder von Voß noch von Gocthe gebilligt. Letzterer schrcibt darüber: IV. 17. 239. I: Der gute Mann ist mit sich selbst und seinen Grundsätaen nicht einig und kommen seine Grundsätze auf wunderliche Weise den Allemannischen Gedichten in die Haare. Das aert sich nun herum, sodass man 
gar nicht weiss, wo man hinsehen soll. Indessen da mich die Gedichte interessiren, will ich sehen, ob ich Ihnen in diesen Tagen eine kurze Rezension darüber aufsetzen kann. Vielleicht nehme ich dann auch die Grübelschen Gedichte vor, welche, wenn ich nicht irre, Falk viel höher schätzt, die ich aber caeteris paribus den allemannischen wohl an die Seite setzen möchte (16. I. 1805 an Eichstädt). Die versprochene Rezension steht in der Lit. Ztg. Febr. 1805.

II. 40. 303. 20: Allen diesen innern guten Eigenschaften kommt die behagliche naive Sprache sehr zu statten. Man findet mehrere sinnlich bedeutende und wohlklingende Worte, theils jenen Gegenden selbst angehörig, theils aus dem Französischen und Italie. nischen herübergenommen, Worte von einem, von zwei Buch. staben, Abbreviationen, Contractionen, viele kurze leichte Sylben, neue Reime, welches, mehr als man glaubt, ein Vortheil für den Dichter ist. Diese Elemente werden durch glückliche Constructionen und lebhafte Formen zu einem Stil zusammengedrängt, der zu diesem Zwecke vor unserer Büchersprache große Vorzüge hat. . . Denn so sehr zu wünschen ist, dass uns der ganze deutsche Sprachschatz durch ein allgemeines Wörter. buch möge vorgelegt werden, so ist doch die praktische Mitteilung durch Gedichte und Schrift sehr viel schneller und lebendig eingreifender. Vielleicht könnte man sogar dem Verfasser zu bedenken geben, dass, wie es für eine Nation ein Hauptschritt der Cultur ist, wenn sie tremde Werke in ihre Sprache übersetzt, es eben so ein Schritt zu Cultur der einzelnen Provinz sein muss, wenn man ihr Werke derselben Nation in ihrem eignen Dialekt zu lesen gibt. Versuche doch der Verfasser aus dem sogenannten Hochdeutschen schickliche Gedichte in seinen oberrheinischen Dialekt zu übersetzen. Haben doch die Italiäner ihren Tasso in mehrere Dialekte übersetzt. Nachdem wir nun die Zufriedenheit . . nicht verbergen können, so wünschen wir nur auch, dass jenes Hinderniss einer für das mittlere und niedere Deutsch. land seltsamen Sprech- und Schreibart einigermassen gehoben werden möge, um der ganzen Nation diesen erfreulichen Genuss 
zu verschaffen. Dazu gibt es verschiedene Mittel, theils durch Vorlesen, theils durch Annäherung an die gewohnte Schreibund Sprechweise, wenn jemand von Geschmack das, was ihm an der Sammlung am besten gefällt, für seinen Kreis um. zuschreiben unternimmt, eine kleine Mühe, die in jeder Sozietät grossen Gewinn bringen wird. (Folgt als Musterstück: Die Sonntagsfrühe.)

Wenn Goethe in den lebendigen Sprachformen der Mundart einen dem Inhalt der Gedichte zugute kommenden Vorzug sieht, so trifft er das Richtige. Wenn er aber anderseits Übertragung beliebiger schriftdeutscher Gedichte in die Mundart und Rückübersetzung der Dialektpoesie ins Hochdeutsche verlangt, so verrät er dadurch doch noch eine verkehrte Auffassung vom Wert und der Bedeutung mundartlicher Dichtung. Darf es uns aber sehr wundernehmen, da man in unseren Tagen sich nicht gescheut hat Reuter zu verhochdeutschen? Von seinen Zeitgenossen hat jedenfalls keiner eine andere Auffassung, Schiller sogar noch eine rückstän. digere. Behaghels Urteil ${ }^{1}$ ) ist also in seinem ersten Teil etwas zu mildern: „Die wahre Bedeutung der Dialektdichtung hat ... vielleicht gerade Goethe am wenigsten erkannt ... Mit völlig bewußter Klarheit hat überhaupt keiner der Zeitgenossen es erkannt und ausgesprochen, worin der eigentümliche Reiz, der eigentümliche Wert mundartlicher Poesie beruht. - In einer Sprache kann nur das mit Leichtigkeit dargestellt werden, wofür sie Ausdrucksmittel besitzt." Socin nennt Goethes Urteil ,cine seltsame Verkennung von Inhalt und Form dicser Dichtungsart". In seiner Ansicht von der Übertragung der Mundart ins Hochdeutsche wurde Goethe von Schiller bestärkt, der dem Freunde nach Kenntnis der Rezension schrieb: ,Sonntagsfrühe möchte ich wohl in einer reinen und hochdeutschen Dichtersprache lesen, wcil dic Mundart, wenigstens beim Lesen immer etwas Störendes hat. Das

1) Bchaghel: Hebels Werke I. Allemannische Gedichte (Kürschner: 1)eutsche National-Literatur, Bd. 142, I). S. XV; auch Socin a. a. O. 447. 
Gedicht ist ganz vortrefflich und von unwiderstehlichem Reiz" (27. II. I805). Wir sehen, Schiller steht noch I805 der Dialektdichtung so gegenüber, wie Goethe 1798. Der aus Goethes Brief von I 798 übernommene Ausdruck, ,reine Sprache“ läßt vermuten, daß Schiller erst durch Goethe Stellung zur Mundart zu nehmen veranlaßt wurde. Während dieser aber den alten Standpunkt, daß die Mundart eine schlechtere Sprache sei, verlassen hat und eine Verhochdeutschung nur der allgemeinen Verständlichkeit wegen fordert, hat ihn Schiller beibehalten; für ihn ist die Mundart noch immer die schlechtere Schwester der Schriftsprache. Die Übertragung der Sonntagsfrühe (Der Samstig hat zum Sunntig gseit) scheint Goethe auf Schillers Anregung hin selbst beabsichtigt zu haben. Wenigstens befindet sich nach I. 40. 459 im Goethe-SchillerArchiv in Weimar ein Verzeichnis von 73 durch Riemer verhochdeutschten Wörtern und Wendungen des Gedichts.

Zehn Jahre später hat sich der Dichter der richtigen Anschauung von der Mundart doch mehr genähert, indem er bei Gmelin in Hebels Gegenwart gerade gegen eine Übersetzung ankämpft und der Mundart volles Recht widerfahren läßt. Gmelin berichtet darüber: (G. III. 252) ,Dieser [Hebel] ward von der Lattrop, einer Niedersächsin, zum Hersagen von einem Gedichte genöthigt. Der freundliche Mann muss endlich nachgeben und übersetzt jeden Vers ins Hochdeutsche. Goethe ward grimmig darüber; man sollte doch dem Dichter die Ehre anthun seine Sprache zu lernen. Die Niedersächsin wird, da sie noch wiederbellt, schön mit ihrem Niedersächsisch und dem Norden geschoren. Goethe lobt das Oberländische, sagt noch etwas sich auf ein Liebchen beziehendes Elsässisches her (4. X. I815). Auch Grübel wird nochmals in Schutz genommen und dabei das Recht der Mundart als Literatursprache anerkannt. IV. 2I. 467 (Lesarten): Ungerne habe ich z. B. in Nr. 242 [der Lit. Ztg.] die höchst ungerechte Recension über Grübel gelesen. Erst hat es Herr Dr. A. E. mit der Nürnberger Mundart zu thun, die doch eben so gut, wie alle andern ein Recht 
hat sich poetisch auszudrücken . . . dann stellt er Forderungen an die Epistel auf, wie man sie im höchsten Sinn der gebildeten Societät machen kann... welche köstlichen Bissen (morceaux) müssten wir entbehren, wenn wir die niedern Klassen aller Zeiten und Völker von der Dichtkunst ausschliessen wollten? (22. XI. I809 Entwurf an Eichstädt.)

$\mathrm{Zu}$ einer gleichberechtigten Anerkennung der mundartlichen Dichtung mit der schriftsprachlichen kann sich Goethe aber nicht aufschwingen, wenn er ihr auch überall da, wo sie ihm begegnet, Aufmerksamkeit und wohlwollende Beurteilung entgegenbringt. Im Vordergrunde seines Interesses bleiben mit Recht Hebels köstliche Dichtungen, die er bei verschiedenen Gelegenheiten lobend erwähnt. So bezeugt Johanna Schopenhauer (G. II. I49): „Zuletzt kam das Gespräch auf die Allemannischen Gedichte... Goethe ist die Sprache fremd, er las aber doch sein Lieblingsstück «Das Gespenst an der Kanderer Strasse», und er las es, wie nur er lesen kann" (vgl. III. 3. 39I. 2I). Auch im II. Buch von Dichtung und Wahrheit wird der unschätzbare Hebel genannt und seine Sonntagsfrühe gelobt, ähnlich IV. 22. 25. 20 in einem Brief an den Fürsten Lichnowsky vom 23. I. I8I I; G. X. 66 endlich wird be. richtet, daß er den Bergmann von Falun sehr hoch schätzte. Äußerungen über die Sprache der Gedichte finden wir aber nicht mehr, so daß diese Lobsprüche wohl in erster Linie dem poetischen Gehalt, der ja freilich von der Sprache kaum $z u$ trennen ist, gelten.

Neben den Hebelschen Gedichten werden III. 4. 93. 12 solche in Wiener und Berliner Mundart genannt (26. I. I810); 1820 treten die niederdeutschen von Dietrich Gg. Babst (I74 I bis 1800 ) in Goethes Gesichtskreis: G. IV. 66 „,Es wurde über Hebels allemannische Gedichte gesprochen, die von Goethe sehr belobt wurden, dann über plattdeutsche Gedichte und über die plattdeutsche Sprache übcrhaupt, für die Goethe sich $\%$ interessiren schien" (24. VIII. 1820). Frau v. Both, die uns dieses berichtet, vermittelte Goethe die Dichtungen, die 
nach Tagebuchnotizen (III. 7. 243) vom 3I. X. bis 3. XI. seine nächtliche Lektüre bilden. Daß ihn aber dabei lediglich literarisches, nicht sprachliches Interesse leitete, beweisen zwei Aufzeichnungen:

I. 36. 182.25: Von Both und Gemahlin aus Rostock ... brachten mir eines Natur- und Nationaldichters D. G. Babsts Productionen, welche sich neben den Arbeiten seiner gleichbürtigen gar wohl und löblich ausnehmen. Höchst schätzbar sind seine Gelegenheitsgedichte, die uns einen altherkömmlichen Zustand in festlichen Augenblicken neu belebt wieder darstellen. (Tagu. Jahreshefte I820.)

IV. 34. 7. 6: Erfreulicher kann ich sprechen von den plattdeutschen Gedichten des guten Babst. Sie interessiren mich sehr, indem ich für solche lebendige Idiotikons höchst eingenommen bin, und sie, wie sie sich vorfinden, benutze und bekannt mache . . . Er [Babst] giebt mir Gelegenheit auszusprechen, was ich längs im Sinne habe, und er wird dabey nicht übel fahren, nur müsste der Sohn und Herausgeber sich entschliessen, ein paar Bogen Wort-Erklärungen anzufügen. Mich lassen die drey Abende her die ich mich damit beschäftige, sämmtliche niederdeutsche Idiotiken im Stich, die ich um mich versammeln konnte. Ich wollte recht gern andeuten, dass nicht zu wenig und nicht zu viel geschähe und, wenn dies Hinderniss gehoben wäre, müsste das Heft durch ganz Deutschland durchdringen. (3. XI. I820 an C. Fr. v. Both.)

Über die Ansicht, daß die Sprache den Gedichten ein Hindernis ist, das ihr Verständnis stört, kommt Goethe nicht hinaus.

Ausführliche Bemerkungen macht er im gleichen und nächsten Jahre zu Arnolds in Straßburger Mundart geschriebenem Lustspiel Pfingstmontag.

I. 4I I. I46. 4: Das grosse Verdienst dieses Kunstwerkes um die deutsche Sprache, jenen bedeutenden Strassburger Dialect und nebenher die verwandten oberdeutschen lebhaft und ausführlich dargestellt zu haben, ist wohl eben die Ursache, dass es nicht nach seinem eigentlichen Werthe allgemein beachtet werden 
kann, denn indem es jenen Kreis vollkommen austüllt, verschließt es sich vor dem übrigen Vaterlande....,In jeder Volksmundart, sagt der Verfasser, spricht sich ein eigenes inneres Leben aus, welches in feinen Abstufungen eine besondere Nationalcharakteristik darbietet". Dabei drängte sich uns folgende Betrachtung auf: Wenn man auch keineswegs den Nutzen abläugnen darf, der uns durch so manche Idiotiken geworden ist, so kann man doch abläugnen, dass jene soeben berührten in einer lebendigen, lebhaft gebrauchten Sprache unendlich mannichfaltigen Abstufungen unter der Form eines alphabetischen Lexikons nicht bezeichnet werden können, weil wir nicht erfahren, wer sich dieses oder jenes Ausdrucks bedient und bei wetcher Gelegenheit? Desswegen wir auch in solchen Wörterbïchern hie und da die nützliche Bemerkung finden: dass z. B. ein oder das andere Wort von gemeinem und gemeinstem Volke, wohl auch nur von Kindern und Ammen gebraucht werde. (Dieser Unzulänglichkeit der Wörterbücher hilft der Verfasser ab, indem er uns Angehörige der verschiedensten Stände in der ihrem Beruf eigentümlichen Sprache in seinem Lustspiel vorführt.) (K. u. A II. 2. 1820.) Im nächsten Hefte seiner Zeitschrift kommt er auf das Lustspiel zurück. I. 4I I. 243. 23: In Mitteldeutschland machen sich Gesellschaften gebildeter Personen, obgleich mit einiger Mühe, das Geschäft diesem Werke sein Verdienst abzugewinnen, gefördert durch Hebels Gedichte, welche man längst gern und schon mit Leichtigkeit aufnimmt. Und hiermit wïrde denn der Weg zu einer wahrhaften, einzig möglichen Sprachverbindung der Dentschen gebahnt. Hörten wir doch dagegen vor einigen Fahren, wo man zu so viel Wunderlichem [Sprachreinigung] schweigen musste, gar unbedachte Reden; es hiess: die Deutschen sollten ihre verschiedenen Zungen durcheinander mischen, um zu einer wahren Volkseinheit ai gelangcn. Wahrlich die seltsamste Sprachmengerei! zu Verderbnis des guten sondernden Geschmackes nicht allein, sondern auch zum innerlichsten Zerstören des eigentlichen Charakters der Nation; denn was sol' aus ihr zeerden, wenn man das Be- 
deutende der einzelnen Stämme ausgleichen und neutralisiren will? - Alle Sprachverschiedenheit ruht auf der Mannichfaltigkeit der Organe . . lassen wir also gesondert, was in grossen Fernen auf dem Erdboden auseinandersteht, ohne den Charakter des Einzelnen zu schwächen in Geist und Liebe. (K. U. A. III. I. I82 I.)

Nicht das Lustspiel als mundartliche Dichtung an sich ist es, was Goethe Interesse abgewinnt, sondern der Umstand, $\mathrm{da} B$ es $\mathrm{ihm}$ den mundartlichen Sprachschatz verschiedener Berufsklassen treuer und lebendiger darbot, als ein Wörterbuch dies vermochte; „ein lebendiges Idiotikon" nennt er es deshalb zu verschiedenen Malen. Daß die Sammlung des gesamten deutschen Sprachschatzes ihm in dieser Zeit anlag, sahen wir ja schon. Auch diesem hervorragenden Produkte der mundartlichen Literatur gegenüber ist er also von der Erkenntnis ihres wahren Wertes weit entfernt. Nur als Gefäß für die ihm interessanten mundartlichen Sprachformen ist ihm das Lustspiel - abgesehen von seiner literarischen Bedeutung - wert. Die Mundart selbst wird gewürdigt, nicht aber die Dichtung im Kleide der Mundart. In der Forderung, den Sprachschatz einzelner Stände festgelegt zu sehen, eilt Goethe seiner Zeit voraus. Erst die letzten Jahre haben uns wissenschaftliche Behandlungen der Standes- und Berufssprachen gebracht. Die Ablehnung des absurden Vorschlages einer Mischung der deutschen Mundarten zu einer Einheitssprache zeigt Goethes gesundes Urteil in sprachlichen Dingen und scine Anerkennung der Mundart als eines bodenständigen Charakteristikums der deutschen Landschaften, das mit seinem Heimatboden verwachsen ist und nicht mit andersartigen Elementen vermischt werden kann und darf. Noch einige Schritte weiter auf dicsem Wege und Goethe wäre wohl auch zu der richtigen Beurteilung der Dialektpoesie gekommen.

Die Aufmerksamkeit Erscheinungen der mundartlichen Literatur gegenüber hält auch in späteren Jahren an, ohne daß es jedoch nochmals zu ausführlicheren Äußerungen darüber 
kommt. So werden nach III. 8. 59. I6 Sebastian Sailers I8I9 von Bachmann herausgegebene ,,Schriften im schwäbischen Dialekt" gelesen; ebenso ein Jahrzehnt später J. F. Castellis Gedichte in niederösterreichischer Mundart, die in Kunst und Altertum VI. 2. (I828) kurz angezeigt werden, und Holteis schlesische Gedichte (III. I2. 238. 4 vom 6. V. I830).

Mundartliche Studien hat Goethe nie gemacht. Es muß auffallen, da $\beta$ er in den Beschreibungen seiner Reisen, die ihn durch vicle deutsche Gaue führten, so selten auf Sprachliches zu reden kommt. Kunst und Naturwissenschaft stehen ja im Vordergrund seiner Beobachtungen, aber er schenkt doch auch allenthalben der Geschichte, den sozialen Verhältnissen, der Landwirtschaft, dem Bergbau, der Industrie seine Aufmerksamkeit; ganz vereinzelt nur begegnen wir dem spärlichen Niederschlag sprachlicher, also mundartlicher Beobachtungen. Wir lassen die Belege zeitlich geordnet im Anhang folgen (S. 263).

In seinen eigenen Dichtungen hat Goethe - vereinzelte Worte und Wendungen abgerechnet - von der Mundart nur in dem Gedichtchen:

Uf'm Bergli bin $i$ gesässe

Ha de Vögle zugeschaut;

Hänt gesunge, hänt gesprunge,

Hänts Nestli gebaut usf.

Gebrauch gemacht ${ }^{\mathbf{1}}$ ), und für dieses ist neuerdings die Anlehnung an eine wenn auch nicht schweizerische, so doch mundartliche Vorlage wahrscheinlich gemacht worden.

Was schließlich Gocthes cigene Sprache in bezug auf mund. artliche Färbung anlangt, so entspricht es seiner jederzeit wohlwollenden Stellung der Mundart gegenüber, daß er seine angeborene Frankfurter Sprechweise nie verleugnete, wenn sie auch jedenfalls nicht so stark hervortrat, wie bei Schiller die schwäbische. Wir haben gesehen, daß er seinen, ,ober-

1) Vgl. Martin: Focthe über Weltliteratur und Dialektpoesic. Straß. burger fiocthevorträge 1899. S. 21. 
deutschen Dialekt" den Leipzigern gegenüber in Schutz nimmt. Daß er die Verwendung der Mundart oder doch mundartlicher Anklänge in der Verkehrssprache für sein gutes Recht hält, bestätigt er mit Bezug auf die Leipziger Spöttereien an einer anderen Stelle der Biographie bei Erwähnung der Schwierigkeiten, die er in Straßburg mit seiner französischen Aussprache hatte: I. 28. 53. I: Abermals ging es mir also hier wie vordem in Leipzig, nur dass ich mich diessmal nicht auf das Recht meiner Vatergegend, so gut als andere Provinzen idiotisch zu sprechen, zurückziehen konnte.

(D. W. II. I8I3.)

Kein Geringerer als Wilhelm Grimm bestätigt uns, daß Goethe mit vollem Bewußtsein von der Mundart in seiner Rede Gebrauch machte. G. IX. 2. I I : ,Goethe hat mit dem richtigsten Gefühl, wie der Augenblick drängte, die ihm angeborene Mundart benutzt und mehr daraus in die Höhe gehoben als irgend ein anderer. Auch seine Aussprache, zumal in vertraulicher Rede, war noch danach gefärbt, und als sich jemand beklagte, daß man ihm den Anflug seiner südlichen Mundart in Norddeutschland zum Vorwurf gemacht habe, hörte ich ihn scherzhaft erwidern: Man soll sich sein Recht nicht nehmen lassen, der Bär brummt nach der Höhle, in der er geboren ist." (I809). Frankfurter Anklänge in seiner Sprache bezeugen des weiteren Riemer und W. Zahn: G. VIII. I 85: Da wurde denn hinterher eine solche Person [Eingebildete] mit einem Frankfurter Provinzialismus ein Schnudelput\% genannt. (Riemer I804-I8I2.) G. VI. 201: Er ... fragte mit seiner ausdrucksvollen, volltönenden Stimme, die jedoch zuweilen den Frankfurter Dialekt anklingen liess... „Freut mich! Höre das gern", sagte Goethe, der eine gedrungene Redeweise liebte und gern die Pronomina wegliess. (W. Zahn 8. IX. I 827.)

Dasselbe bezeugt Heine ${ }^{1}$ ): „Was wir in Norddeutschland Mauscheln nennen, ist nichts anders als die eigentliche Frank-

I) Heines Werke, herausgeg. von Elster VII, 30; herausgeg. von Lachmann III, 445 . 
furter Landessprache, und sie wird von der unbeschnittenen Population ebenso vortrefflich gesprochen, wie von der beschnittenen. Börne sprach diesen Jargon sehr schlecht, obgleich er ebenso wie Goethe den heimatlichen Dialekt nie ganz verleugnen konnte." (Über Ludw. Börne I 840.) Heine hatte im Jahre I 824 Goethe in Weimar besucht. Die Gleichstellung der Frankfurter Mundart mit dem jüdischen Mauscheln ist natürlich pro domo geredet und hinfällig.

Die Verwendung von Idiotismen in der geschriebenen Sprache ist nach Burdach in den Briefen Goethes aus den früheren Jahren nicht selten, tritt aber später immer mehr zurück. ${ }^{1}$ )

\section{NEUNTES KAPITEL. \\ SPRACHREINIGUNG UND SPRACHBEREICHERUNG.}

Goethes Stellung zur Sprachreinigung und Sprachreinheit, zum Purismus des I8. Jahrhunderts, ist schon des öfteren, wenn auch nirgends zusammenhängend, untersucht worden.

Der junge Goethe, der an den Briefen seiner Schwester das Sprachmeisteramt übt, steht entschieden auf der Seite der Sprachreiniger. „Deutsch geschrieben!" ist seine entschiedene Forderung. Daß die Verdeutschungen von fremdem Sprachgut freilich zum Teil in einem französisch geschriebenen Briefe anverlangt werden, läßt den jungen Verteidiger der Muttersprache in einer ausgesetzten Stellung sehen. Wir setzen die ganze Critik über deinen Brief hierher: IV. I. 22. 16: "denn ich sehe" dieses hängt nicht mil dem nachfolgenden "so" zusammen. "Abzwecken" ist kein Briefwort. Sagst du es im gremeinen Leben?" "Weil du an viel hohe Dinge denckst" wäre natürlich; ,weitläufiger werdenden": das Participium ist nicht gut angebracht. Setze lieber: die bald weitläufiger werden wird.

8) Vgl. Socin a. a. O. \$. 127 Anm. (Burdach: Dic Sprache des jungen riscthe. S. 166.) Kluge", lir.: Unser Deutsch. Leipzig 1907. S. 39. 
„Zu Ohren bringen": wenn der Ausdruck auch gebräuchlich wäre, so wäre der Gedancke doch nicht richtig. ",Verlauten will" ist curial. "Als" ist nicht besser. „Durchleben" ist poetisch. „Und giebt man sich Mühe": es wäre besser: Man giebt sich Mühe; subsistieren ist nicht deutsch; "Herbst" setze lieber Weinlese; Exequiendeutsch geschrie. ben!1) Castrum doloris besser Trauer Ge. r üs te; „beschauen" ist nicht gewöhnlich; „Dass dir bald" $p$. warum lässest du die verba auxiliaria fort: hätte; ",mit der Zeit hinwissen", besser: weil ihnen die Zeit lange wird. "Alschon" ist curial. "Veranstaltung" ist nicht gut; ,,gesonnen ist": besser will; ,zu Ende gebracht": besser geendigt; ,angewandelt": setze angekommen. (7. XII. I765 an Cornelie.) Und einige Wochen später: IV. I. 36. 6: Prends garde... de ne te servir des mots etrangers. Au lieu Figure Charge, dis plustot Aufsehen, Amt (18. I. 1766). So wenig wie wir uns mit der Zurückweisung poetischer und volkstümlicher Worte oder der Verwerfung von „Veranstaltung, gesonnen sein, zu Ende bringen" einverstanden erklären können, so sehr müssen wir dem sechzehnjährigen Studenten in der Ablehnung fremder und der Kanzlei angehöriger Worte beipflichten. ${ }^{2}$ )

Mitten in den Kampf um das Fremdwort werden wir in den Xenien geführt. In Betracht kommen zunächst die Distichen Nr. I52, 87, I4I und I5I.

\section{5. 227. Nr. I 52. Der Purist.}

Sinnreich bist $d u$, die Sprache von fremden Wörtern $\approx u$ säubern,

Nun, so sage doch, Freund, wie man Pedant uns verdeutscht!

I) Die Aufforderung könnte sich freilich auch auf die Anwendung deutscher Buchstaben beziehen, zumal man es in der Zeit liebte, fremde Worte lateinisch zu schreiben.

2) Das bekannte Gedicht an den Kuchenbäcker Händel (I, 37. 58), in dem geläufige Fremdwörter der Zeit auf die Kuchenbäckerei angewendet werden, richtet sich in seiner Satire nicht gegen die Fremdwörter als solche, sondern gegen die bombastische Dichtungsart des Leipzigers Clodius. 


\section{5. $217 . \quad$ Nr. 87. Eridanus. ${ }^{1}$ )}

An des Eridanus Ufern umgeht mir die furchtbare Waschfrau, Welche die Sprache des Teut säubert mit Lauge und Sand.

I. 5. 225. Nr. I4I. Der Sprachforscher.

Anatomieren magst du die Sprache, doch nur ihr Kadaver; Geist und Leben entschlüpft flüchtig dem groben Skalpell. ${ }^{2}$ )

I. 5. 226. Nr. I5I. Gesellschaft von Sprachfreunden.

$O$ wie schätz ich Euch hoch! Ihr bürstet sorglich die Kleider Unsrer Autoren, und wem fliegt nicht ein Federchen an?

Wenig von Belang ist es für uns, welchem der beiden Dichter die Verse zuzuschreiben sind. Da es hier auf den Inhalt und nicht auf die Form ankommt, genügt es festzustellen, daß in den Xenien der Standpunkt beider Dichter vertreten ist. Übrigens wird das erste von allen Herausgebern außer Löper sicher Goethe zugeschrieben; die anderen scheinen auf Schillers Rechnung zu kommen. Die Adresse der Ausfälle ist Joachim Heinrich Campe in Braunschweig (1746-I8I8), der in seinen löblichen, nationalen Bestrebungen, die deutsche Sprache von Fremdwörtern zu säubern, sich in seinen ,,Beiträgen zur weiteren Ausbildung der deutschen Sprache, von einer

1) „Der Eridanus der Alten, den man in den verschiedensten Flüssen hatte finden wollen, wird hier scherzhaft auf die Ocker bei Braunschweig übertragen." Bellermann: Schillers Werke IX, I35 Anm. 7. Unter dem "Puristen" im IValpurgisnachttraum, dem (Faust I. 4279) die Worte in den Mund gelegt sind:

Ach mein Unglieck fiilht mich her:

Wie wird nicht hier geludert!

Und won dem ganzen Hexenher

Sind sweic mir sepudert

ist "kein Sprachreiniger (Campe) und kein Formkorrektor (W. Schlegel), sondern ein altmodisch zopfiger und prüder . . Kunstakademiker" «u verstehen. (E. Schunidt. Goethes Werke. Cotta. XiII. S. 337.)

2) Skalpell = chirurgisches Messer. 
Gesellschaft von Sprachfreunden" auch ungeschickt an den Schriften der Klassiker vergangen hatte. Schon die eine Tatsache, daß sich die Xeniendichter in Nr. I40 bei dem Angegriffenen gleichsam entschuldigen, führt uns der richtigen Auffassung der Epigramme zu: Mit Erlaubnis.

Nimms nicht übel, daß nun auch deiner gedacht wird! Verlangst $d u$

Das Vergnügen umsonst, daß man den Nachbar vexiert? ${ }^{1}$ )

Nur als Abwehr, nicht als Angriff sind die Verse aufzufassen. Nur der Übereifer des Puristen, der mit plumper Hand auch in die Sprache der Iphigenie, dieses herrlichen Kunstwerkes, zergliedernd und schlimmbessernd hineingegriffen hatte ${ }^{2}$ ), fordert ihren Spott und ihre berechtigte Verwahrung heraus. Campes Replik auf das erste Distichon:

Gib auf meine Gefahr, ihm deinen eignen Namen;

Trifft er nicht jegliche Art, cin e trifft er gewiß mit Boas und Schmidt-Suphan als besonders gelungen ,,schlagfertig" zu bezeichnen, müssen wir mit Bellermann (Schillers Werke IX. 459) ablehnen: „Denn gerade die Verfasser der Xenien „Pedanten“ $\mathrm{zu}$ nennen, etwas Sinnloseres könnte auch die trübste Phantasie nicht erdenken."

Die lächerliche Teutschtümelei, die übertriebene Wichtigtuerei eines Campe und seines Kreises soll getroffen werden, nicht die von ihm vertretene Sache an sich. Denn dieser stand Goethe ganz entschieden sympathisch gegenüber. Daß er die Anschauung vertrat, ein Fremdwort, für das sich nach Form und Inhalt vollgiltiger Ersatz bot, gehöre nicht in die deutsche Sprache, beweist sein von Dehnike und Matthias ${ }^{3}$ ) nach.

1) Das Xenion ist nach Boas: Schiller und Goethe im Xenienkampf. (Stuttgart 185I.) I, I02, auf Campe gemünzt. Nr. 139 richtet sich gegen Eschenburg, der auch in Braunschweig lebte.

2) In den „Beiträgen“ 1796 und 1797

3) Dehnike, O.: Goethe und die Fremdwörter. Progr. d. Johanneums zu Lüneburg 1892. Matthias, Zeitschr. d. allg. deutsch. Sprachver. XVII, Nr. 3, mit Zusätzen von Neste cbda. Nr. 9. 
gewiesenes Bestreben, solche überflüssigen Fremdlinge aus seinen Werken zu entfernen. Herders Einfluß ist hier nicht zu verkennen. Im Götz von $\mathrm{I} 773$ sind 6 Fremdausdrücke der Ausgabe von I77I durch deutsche ersetzt (dagegen freilich auch umgekehrt 3 deutsche durch fremde); die Ausgabe von I 787 weist sogar an I 8 Stellen Verdeutschungen von Fremdwörtern derjenigen von 1773 auf; und die letzte von 1804 endlich solche an 5 weiteren Stellen. Doch gewiß ein schlagender Beweis für Goethes fortlaufende Arbeit im Sinne der Sprachreinheit. In der Stella bleiben nach Abzug der in der Zeit üblichen Standes- und Fachausdrücke überhaupt nur 18 Fremdwörter übrig, die zudem zumeist der vornehm tuenden Postmeisterin in den Mund gelegt sind. Auch die Verhöhnung des Olearius im Götz, der wegen der Latinisierung seines deutschen Namens von Liebetraut der Lächerlichkeit preisgegeben wird, darf wohl in diesem Zusammenhang genannt werden. Und bedürfte es noch eines weiteren Beweises, so sei auf sein Zeugnis in Dichtung und Wahrheit hingewiesen, wo er den Fremdwortunfug scharf verurteilt und die Reinheit der Muttersprache warm verteidigt:

I. 27. 72. 5: Deutschland, so lange von auswärtigen Völkern überschwemmt, von andern Nationen durchdrungen, in gelehrten und diplomatischen Verhandlungen an fremde Sprachen gewiesen, konnle seine eigne unmöglich ausbilden. Es drangen sich ihr, zu so manchen neuen Begriffen, auch unzählige fremde Wörter nöthiger und unnöthiger Weise mit auf, und auch für schon bekannte Gegenstände zeard man veranlasst, sich ausländischer Ausdrïcke und Wendungen su bedionen. Der Deutsche, seit beinahe zuei Fahrhunderten in einem unglücklichen, tumultuarischen Zusiand verwildert, begab sich bei den Franiosen in die Schule, um lebensartig au werden, und bei den Römern, um sich zoürdig auszudrïcken. Dies sollte aber auch in der Mullersprache geschehen; da denn die unmittelbare Ane'endung jener Idiome und deren Halbverdeutschung sowohl den Weltals Geschäfts.Stil lächerlich machte. Uberdies fasste man die 
Gleichnissreden der südlichen Sprachen unmässig auf und bediente sich derselben höchst übertrieben... Wie aber schon in dieser Epoche genialische Werke entsprangen, so regte sich auch hier der deutsche Frei- und Frohsinn. Dieser begleitet von einem aufrichtigen Ernste, drang darauf, dass rein und natürlich, ohne Einmischung fremder Worte, und wie es der gemeine verständige Sinn gab, geschrieben würde. Durch diese löblichen Bemühungen ward jedoch der vaterländischen breiten Plattheit Thür und Thor geöffnet, ja der Damm durchstochen, durch welchen das grosse Gewässer zunächst eindringen sollte. Indessen hielt ein steifer Pedantismus in allen vier Facultäten lange stand, bis er sich endlich viel später aus einer in die andere flüchtete. Gute Köpfe frei aufblickende Naturkinder hatten daher zwei Gegens:ände, an denen sie sich üben, gegen die sie wirken und, da die Sache von keiner grossen Bedeutung war, ihren Mutwillen auslassen konnten; diese waren eine durch tremde Worte, Wortbildungen und Wendungen verunsierte Sprache, und sodann die Werthlosigkeit solcher Schriften, die sich von jenem Fehler frei zu erhalten besorgt waren; wobei niemandem einfiel, dass indem man ein Übel bekämpfte, das andere zu Hülfe gerufen ward. (D. W. VII. - I $8 \mathrm{II}$.)

Goethe kennt also die Geschichte des Fremdworts und unterschätzt das Unheil, das es in der Muttersprache angerichtet, keineswegs; er tritt kraftvoll für seine Bekämpfung ein, verkennt aber auch die Fehler, zu denen Übereifer und einseitige Rücksicht auf die Form geführt, in keiner Weise. So geißelt er auch mit vollem Recht an zwei Stellen der Lehrjahre eine der oben angedeuteten Plattheiten, die überschwengliche Deutschtümelei in der Forderung altdeutscher Namengebung: 1. 21. I98. 13: Federmann [der Schauspielergesellschaft] war [beim Lesen deutscher Ritterstücke] von dem Feuer des edelsten Nationalgeistes entzündet . . . Feder Schauspieler sah nun, wie er seine Deutschheit vor dem Publico produciren werde. Feder wollte sich sogleich einen Namen aus dem Stück oder aus der deutschen Geschichte zueignen und Madame Melina 
beteuerte, Sohn oder Tochter... nicht anders als Adelbert oder Mathilde taufen zu lassen. (W. M. L. II. IO.)

1. 22. 59. 6: Er [Laertes] erzählte verschiedene lächerliche Züge von der Gesellschaft [der Schauspieler nach dem Überfall], besonders gab er Frau Melina schuld, sie beweine den Verlust ihrer [totgeborenen] Tochter nur deswegen, weil sie nicht das altdeutsche Vergnügen haben könne, eine Mechtilde taufen zu lassen. (W. M. L. IV. IO. 1795/96.)

Denn das muß ihm zugegeben werden: so sehr es eine nationale Ehrenpflicht ist, unsere schönen deutschen Vornamen den fremden gegenüber wieder zu Ansehen zu bringen, so sehr mußte die Überspannung des Gedankens, wie ihn die Puristen und Romantiker am Ende des 18. Jahrhunderts zum Ausdruck brachten, zum Spott herausfordern, zumal man hinsichtlich der Bedeutung der deutschen Namen noch vielfach im Dunkeln tappte.

Einer maßvollen, vernünftigen Sprachreinigung hat Goethe stets, auch in späteren Jahren, das Wort geredet; das muß von vornherein festgestellt und soll bewiesen werden denen gegenüber, die als Verteidiger des Fremdworts Gocthe gern auf ihre Seite zichen und als Kronzeugen für ihre Sache benutzen möchten. Daß er sich für Sprachreinigung besonders begeistert oder mit eigenen Auslassungen für sie ins Feld tritt, wird niemand erwarten, der weiß, wie spärlich er sich überhaupt in sprachlichen Fragen äußert, wie verhältnismäßig gleichgültig ihn dic formellen Außenseiten der Sprache lassen, wie er als Gelehrter im Ringen mit dem Wort den dem Begriff adäquaten Ausdruck freudig und dankbar da nimmt, wo er sich ihm am besten bietet, und endlich wie er in alten Tagen von der deutschen Sprache als Trägerin ciner Weltliteratur träumt.

Die Beschäftigung mit der Fremdwortfrage beweisen zwei lagebuchnotizen aus der Wende der Jahrhunderte: III. 2. 264. 20 Abends bey Schiller über Einfïhrung fremder Worte in die tragische Sprache (9. X. 1799); III. 3. 361. 20 Ver. wechshung ausländischer Worte. Aus der Zeit, da man so viel 
französische Worte in die deutsche Sprache mischte, welche von denen nachgesprochen wurden die kein französch kannten. Macarone, Macedone, Amazone (I6 VII. I808) Daß die Fremdheit des Wortes in den Unterhaltungen mit Riemer "gar oft" den Stoff bildet, bezeugt er uns ja ausdrücklich in dem schon oben zitierten Briefe an Humboldt vom I. XII. I83I. Dasselbe erhärtet Reinbeck von den Gesprächen bei Johanna Schopenhauer: G. II. 153: Oft betraf auch die Unterredung die Sprache und ich erinnere mich noch des Aufwandes von Scharfsinn, für aufgegebene Fremdwörter echt deutsche zu suchen. So schuf Goethe für Balanciren: in der Schwebe, und ich glaube, der Ausdruck, der in den meisten Fällen so treffend ist, trat an diesem Abend zuerst hervor. (Winter I806/07.)

Nach Dehnike gehen übrigens noch folgende Neubildungen auf Goethe zurück: ausweiten - elongieren, Besuchskarte Visitenkarte, bewegter Boden - kupiertes Terrain, Selbstlernerei - Autodidaktentum, ausgesprochen - prononciert, Mächler - faiseur, Zweigesang - Duett. ${ }^{1}$ ) In den Lehrjahren hat er eigenhändig an 19 , in Dichtung und Wahrheit sogar an 50 Stellen das Fremdwort ersetzt. Die Riemer und jedenfalls auch den anderen Redaktoren erteilte Vollmacht erstreckte sich, wie wir oben sahen, auch darauf, ausländische Worte zu verdeutschen (Brief an Riemer v. 20. VI. I813; IV. 23. 368. I3). Keineswegs werden aber alle Verdeutschungen des Philologen angenommen ${ }^{2}$ ); die Ersetzung von idiotisch

1) M. Hecker erweitert, G. G. XXI., S. 373, die Liste um: Tagschrift Journal, Tagesblattler - Journalist, Tagblatt - Portefeuille, Aufstürzung Refoulement. Gerade glücklich kann man diese Verdeutschungen freilich nicht nennen.

2) Von 13 vorgeschlagenen deutschen Ersetzungen finden nur drei Gnade vor Goethes scharf abwägender Kritik. Zurückgewiesen werden:

Nachtherberge, Herberge für Nachtquartier.

Lebensordnung, Lebensgewohnheit, -art, Kost für Diät.

Landkutsche für Diligence.

Versender für Spediteur. 
z. B. durch eigentümlich weist Goethe mit Recht zurück, da an der betr. Stelle (vgl. oben: das Recht so gut als andere Provincen idiotisch zu sprechen) „mundartlich" die richtige Eindeutschung gewesen wäre. Nur soweit das deutsche Wort sich mit dem Begriffsinhalt und -umfang des fremden deckt, wird es als Ersatz verwendet; ein Grundsatz, der ja auch heute als der maßgebende für vernünftige Sprachreinigung gilt.

In seiner eigenen Unterhaltungssprache liebte Goethe nach Riemers Zeugnis mannigfaches aus fremden Sprachen entlehntes Gut: G. VIII. I7 I : ,, Goethe brauchte im gewöhnlichen Gespräch und unter Freunden viel aus fremden Sprachen entlehnte und angewöhnte Worte und Wendungen theils in den Grundsprachen, theils in Nachbildungen." Es folgen in längerer Reihe Beispiele aus dem Italienischen (dice bene, a conto torniren precipizio, spregiudicato, periano noi periano anche, i bicchieri), dem Französischen (c'est une mer à boire, cc sont les suites inévitables de la guerre) und Lateinischen (difficilia quae pulchra, ars est de difficili et bono, sustine et abstine, decet imperatorem stantem mori, der Mensch ist brevis aevi amici fures temporis; ,eine der häufigsten Anwendungen erfuhr das Basedowsche Witzwort ergo bibamus, ja es ward zu einem terminus technicus gestempelt und als ein Substantiv gebraucht nicht nur für Gelegenheit, Anlaß, Grund

Gclass für Lokal; (eigentümlich für idiotisch).

Haupttugend für Cardinaltugend.

lebten und westen für existirten und vegetirten.

Erfriscliung für Collation.

Kleinstädter für Provinzler.

Angenommen werden nur:

folgerechter für consęuenter.

das sich aufzeigen liess fiir producibles.

ohne Umschweif für direct.

Dic Girinde der Ableknung werden bei einigen jedenfalls gernde so berechtigt sein, wic für eigentüulich; sic licgen für Goethe in dem Inhalt, nicht in der Form der Worte; bei dem zurückgewiesenen "Gelass" macht er die Bemerkung: ein schönes Wort. 
zu Lust und Vergnügen, sondern auch zur Persiflage einer seltsamen Folgerung" (Riemer I804-I8I2). Wenn der Haus. freund auch hier nicht Fremdwörter im eigentlichen Sinn aufzählt, sondern Zitate, geflügelte Worte, durch deren Gebrauch ein gereifter, sprachkundiger Mann sich weniger an der Muttersprache versündigt, so soll doch keineswegs geleugnet werden, daß auch die eigentlichen Fremdwörter zahlreich gebraucht wurden. Denn so weit ging seine Parteinahme für die Sprachreiniger nicht, daß er sich im ungezwungenen mündlichen Verkehr den Zwang auferlegte, die überkommenen fremden Worte durch ungeläufige deutsche $z u$ ersetzen. Wir müssen uns hüten, ungerechterweise von unserem heutigen Standpunkt zu urteilen. Die Sprachreinigung war eine noch junge Bewegung, und die Fremdwörter saßen viel fester in dem Sprachgebrauch als heute, wo ihre Stellung doch durch fortgesetzte Angriffe erschüttert und das jeweilige Ersatzwort viel näher gelegt ist.

$\mathrm{Zu}$ einer grundsätzlichen Aussprache über Sprachreinigung und Sprachbereicherung kommt Goethe in den Jahren I812/I3. - Allem nur Negativen war der Dichter abhold. Das sahen wir schon aus seinem ehrlichen $H a ß$ negierenden Partikeln wie ,nichts anders als" gegenüber. Dieselbe Abneigung bringt er der Seite der Sprachreinigung entgegen, die nur beseitigen, nur einreißen, nicht aber für Ersatz und Zuwachs sorgen wollte. Ihm steht die Sprachbereicherung als das Positive über diesem „,negativen Purismus". Das fremde Sprachgut darf nicht einfach beseitigt werden, sondern es soll uns veranlassen, aus ihm deutsche Neuschöpfungen herauszuarbeiten, damit die Sprache keinen Verlust erleidet. Und ehe ein solcher eintritt, soll man getrost auch das Fremde beibehalten, solange die Muttersprache versagt. Sprachen, namentlich verwandte Sprachen sind Schwestern, die sich mit ihrem Reichtum sehr wohl gegenseitig aushelfen können, wenn ein Mangel im Wortschatz nicht mit eigenem Sprachgut gedeckt werden kann. Diesen Gedanken gibt Goethe schon 1806 dem däni- 
schen Dichter Oehlenschläger gegenüber Ausdruck. Dieser berichtet (G. II. 28): Ich mußte ihm [Goethe] ... deutsch vorlesen. Da machte ich mich denn vieler Dänismen schuldig; er verwarf sie aber nicht alle; er meinte, die beiden verwandten Sprachen, aus einer Wurzel entsprungen, könnten einander mitunter mit guten Worten schwesterliche Geschenke machen. „,Hm! das ist hübsch", sagte er mitunter, wenn ich etwas vorlas. „Sagen Sie denn das so deutsch?" frug ich. „Nein, wir sagen es nicht, könnten es aber sagen." - „Soll ich denn ein andres Wort brauchen?" - ,Nein, thun Sie das nicht." Einen Mann, der mich in Berlin gekannt hatte und nach Weimar kam, fragte Goethe: „Kennen Sie etwas von Oehlenschläger?“ - „Nein", war die Antwort, ,, aufrichtig, ich mag die deutsche Sprache nicht radebrechen hören." - ,Und ich", antwortete Goethe mit imposantem Gefühl, „mag die deutsche Sprache sehr gern in einem poetischen Gemüthe entstehen sehen. (Mai-Juni 1806.) Dasselbe bezeugt Steffens; nach seinem Bericht sagte Goethe: Die uns verwandten Dänen könnten wohl unsere Sprache bereichern und was wir, von der einseitigen Ausbildung ergriffen, nur zu tadeln geneigt sind, verdiente wohl nicht selten unsere Aufmerksamkeit. (Mai-Juni 1806.)

Diese seine zum herrschenden Purismus im Gegensatz stehenden Ansichten von Sprachreinigung und Sprachbereicherung beabsichtigte Goethe offenbar zusammenhängend zu veröffentlichen. Leider ist es über im Nachlaß aufgefundene, jedenfalls I8I2 entstandene Leitsätze nicht hinausgekommen.

I. 42It. 238. I3: Die Gewalt einer Sprache ist nicht, dass sie das Fremde abweist, sondern dass sie es verschlingt. - Der pedantische Purismus ist ein absurdes Ablehnen weiterer Aus. breitung des Sinnes und Geistes (z. B. Das engl. Wort Grief.)') - Ich verfluche allen negativen Purismus, dass man ein Wort nicht brauchen soll, in welchem eine andere Sprache vieles oder zarteres gefasst hat. - Meine Sache ist der affirmative Purismus,

1) Englisch grief in Vergleich zu deutsch Kummer. 
der productiv ist und nur davon ausgeht: Wo müssen wir umschreiben und der Nachbar hat ein entscheidendes Wort? $\left.{ }^{1}\right)$ ebda. 523. 19 Vorschlag $z u$ einem polemischen Purism. in Schulen.

Wie Goethe dieses „etymologisiren und formiren“ meint, werden uns die Beispiele bepaalt - bepfählt und percher stängeln unten zeigen.

In einem jedenfalls zum 7. Buch von Dichtung und Wahrheit gehörenden Fragment drückt er den Gang der Entwickelung so aus: I. 27. 293: Erst Tüchtigkeit der deutschen Sprache. Dann Verwirrung und fremder Einfluss. Dann Purismus und Wässrigkeit. - Neue Stoffe, neue Ausdrücke. D. h. die ursprünglich reine deutsche Sprache wird von Fremdwörtern durchsetzt. Der nur beseitigende Puri mus versagt, denn es gilt für neu an uns herantretende Stoffe entsprechende Bezeichnungen $\mathrm{zu}$ finden.

Die Fremdwörter sind ein Übel, aber ein geschichtlich gewordenes, das sich nicht nach der Weise der radikalen Puristen des 18. Jahrhunderts beseitigen läßt. Die neuen dem menschlichen Geist sich aufdrängenden Stoffe erheischen eine sprachliche Ausdrucksform; die muß geschaffen werden auf die Weise, die der Sache am reinsten entspricht. Goethe klebt nicht am fremden Wort, weil es ihm schöner oder gar vornehmer dünkt; nein, er hält es nur dann, und manchmal freilich auch hartnäckig, wenn es ihm den Begriff voller wiederzugeben scheint als das deutsche; er gibt es aber gern auf, wenn dieses den Dienst gerade so gut als der Fremdling leistet; er bemüht sich, wie wir sahen, zu jeder Zeit sogar redlich darum Ersetzungen zu suchen. Ausführlicher als in den Leitsätzen äußert sich Goethe zur Sache in einem Briefe an Riemer, der als Antwort zu gelten hat für

1) Lesart: Nicht fremde Worte zu vermeiden. Daran ist gar nicht gelegen. Aber zu finden, wo wir umschreiben miissen und der Fremde hat das Wort, dass wir es heraus etymologisiren und formiren. 
dessen zu weit gehende Verdeutschungen. Wir lassen die Stelle unverkürzt folgen. ${ }^{1}$ )

IV. 23. 374. I: Bey meiner letaten Sendung, werthester Freund, habe ich Ihnen abermals völlige Macht und Gewalt gegeben, die fremden Worte aus der Handschrift zu tilgen, insofern es möglich und rätlich sey, wie wir auch schon früher gethan haben. Ich bin, wie Sie wissen, in diesem Puncte weder eigensinnig noch allzu leicht gesinnt, allein das muss ich Ihnen gegenwärtig ver. trauen, ... dass es eigentlich geistlose Menschen sind, welche auf die Sprachreinigung mit so grossem Eifer dringen: denn da sie den Werth eines Ausdrucks nicht zu schätzen wissen, so finden sie leicht ein Surrogat, welches ihnen ebenso bedeutend scheint, und in Absicht auf Urtheil haben sie doch etwas zu erwähnen, und an den vorzüglichsten Schriftstellern etwas auszusetzen, wie es Halbkenner vor gebildeten Kunstwerken zu thun pflegen, die irgend eine Verzeichnung, einen Fehler der Per. spective mit Recht oder Unrecht rügen, ob sie gleich von den $V$ erdiensten des Werkes nicht das geringste anzugeben wissen... Eine fremde Sprache ist hauptsächlich dann zu beneiden, wenn sie mit Einem Worte ausdrucken kann, was die andere umschreiben muss, und hierin steht jede Sprache im Vortheil und Nachtheil gegen die andere, wie man alsobald sehen kann, wenn man die gegenseitigen Wörterbücher durchläuft. Mir aber kommt vor, man könne gar manches Wort auf diesem Wege gewinnen, wenn man nachsieht, woher es in jener Sprache stammt, und alsdann versucht, ob man aus denselben etiimologischen Grïnden durch ähnliche Ableitung zu demselben Wort gelangen könnte. So haben zum Beispiel die Franzosen das Wort perche Stange, davon das Verbum percher. Sie bezeugen dadurch, dass die Ilühner, die Vögcl sich auf eine Stange, einen Zweig setzen. Im Deutschen haben wir das Wort stängeln. Man sagt ich stängle die Bohnen, das heisst, ich gebe den Bohnen Stangen, cben so gut kann man sagen dic Bolmen stängeln, sie winden

1) Teilweise bei Kluge 43, Kiegel 2, Bouke 286. 
sich an den Stangen hinaut, und warum sollten wir uns nicht des Ausdrucks bedienen: die Hühner stängeln, sie setzen sich auf die Stangen? Es wird Ihnen leicht seyn, mehrere Beyspiele dieser Art anzuführen, zu finden oder zu erfinden, mir kommt sie viel vorzüglicher vor, als wenn man entweder durch Vorsetzung der kleinen Partikeln oder durch Zusammensetzung Worte bildet. Wo aber solche Ausdrücke besonders zu finden sind, will ich noch kürzlich bemerken, da wir schon öfters, jedoch in anderm Zusammenhang, darüber gesprochen haben.

Man trifft sie häufig an in den eigenthümlichen Sprachen der Gewerbe und Handwerke, weil die natürlichen Menschen, die auf einem gewissen Grade der Cultur stehen, bey lebhaftem sinnlichen Anschauen an einem Gegenstande viele Eigenschaften auf einmal entdecken, und da sie kaum in einem Begriff zusammenzufassen sind, welches überhaupt auch dieser Menschenklasse Art nicht ist, so gewinnen sie dem ganzen etwas bildliches ab und das Wort wird meistenstheils metaphorisch und also auch fruchtbar, so dass man, mit einigem Geschick, gar wohl andere Redetheile davon ableiten kann, die sich alsdann gar wohl, besonders durch humoristische Schriften, einführen liessen (30. VI. I 8I3).

Reißt man einzelne Stellen dieser Ausführungen aus dem Zusammenhang heraus, wie etwa die von den geistlosen Menschen, so kann wohl ein Gegner der Sprachreinigung Kapital daraus schlagen. Tatsächlich aber kann sie noch heute jeder Anhänger einer vernünftigen, maßvollen Sprachreinigung Wort für Wort unterschreiben: Einseitige Betonung des puristischen Standpunkts bei Kritik von Literaturprodukten ist zu verwerfen; bei der Verdeutschung ist mit der größten Sorgfalt vorzugehen; ein fremder prägnanter Ausdruck ist einer deutschen Umschreibung vorzuziehen; Sprachbereicherung durch Eindeutschung des fremden Sprachgutes fördert die Muttersprache; die lebendigen Standes- und Berufssprachen sind eine reiche Quelle für die Vermehrung der Schriftsprache. Sind das nicht alles Leitsätze, die ohne Einschränkung auch 
für uns geltend sein müssen? Wenn die Sache der Sprachreinigung mehr solcher Verteidiger gehabt hätte, wäre sie vor mancher Übertreibung bewahrt geblieben. Der Hinweis auf die Berufssprachen allein sichert Goethe einen ehrenvollen Platz in den Reihen der Kämpfer für Reinheit und Bereicherung der Muttersprache.

Seine Neuschöpfung stängeln führt er nach Bouke auch selbst in die Sprache ein. Im Divan heißt es I. 6. 22 I. I :

Einer sitzt auch wohl gestängelt Auf den Ästen der Cypresse.

(Sommernacht I8I4.)

In ähnlicher Weise hat er dem Holländischen das Adjektiv bepaalt als bepfählt im Sinne von bestimmt entnommen:

II. II. I33. I 8: Gleich muss etwas bestimmt sein (bepaalt sagt der Holländer) und nun glaubt man eine Weile den unbekannten Raum zu besitzen, bis ein anderer die Pfähle wieder ausreisst und sogleich enger oder weiter abermals wieder bepfählt. (Zur Naturwiss.)

Daß diese Sprachbereicherungen sich keine dauernde Stätte im Wortschatz errungen haben, ist kein Beweis gegen sie; sie teilen dieses Schicksal mit den meisten Verdeutschungen Campes.

Dem Dichter, der einen so vernünftigen Standpunkt vertritt, Gegnerschaft nachzureden, ist hinfällig. Wir wiederholen: er haßt den negativen, übertreibenden, lächerlichen Purismus. Seine abfälligen Urteile treffen nur die Auswüchse der Bewegung. So IV. 24. I77: das über Arndt Gesagte [finde ich] so freundlich als gründlich. Etwas Ahnliches möchte ich wohl über das neue Bestreben vernehmen, durch welches die aus einer Knechtschaft kaum entronnenen Deutschen sich schnell wieder in die Fesseln ihrer eignen Sprache wu schmieden gedenken. Indem ich diesen Dingen nun ausehen kann, so ist mir nichts angenchmer als von anderen wu hören, was ich gern 
selbst sagen möchte. (23. II. I8I4 an Achim v. Arnim.) In dem Romantiker fand er nun freilich keinen Bundesgenossen. ${ }^{1}$ )

Das nette Gedichtchen an die Gräfin Fritsch aus demselben Jahre zeigt uns ihn wieder auf den Bahnen richtiger Sprachreinigung durch Sprachbereicherung:

I. 4. 244. 9: Die deutsche Sprache wird nun rein, Pensée darf künftig nicht mehr gelten; Doch wenn man sagt: Gedenke mein! So hoff' ich soll uns niemand schelten.

(Bei Übersendung eines Pensée-Bouquets. 27. II. 18I4.) Ausdrücklich betont er seinen Standpunkt, daß er die Sache an sich lobt, aber jede Übertreibung verurteilt, dem Germanisten und Puristen Radlof gegenüber. IV. 24. 203. 8: Ew. Wohlgeboren danke mit Vergnügen, dass Sie mir Gelegenheit geben, Ihnen zu versichern, dass Ihre Bemühungen um unsere werthe Muttersprache schon bisher von mir und meinen Freunden anerkannt und benutzt worden. Auch der letzte Aufsatz [Frankreichs Sprach- und Geistestyrannei über Europa] zeugt von Ihrem biedern Sinn und festen Willen. Sehr verdienstlich ist es, solche Stellen beizubringen, woraus erhellt, wie der Deutsche, der seiner Natur nach das Ausland nicht entbehren kann, sich dem Charakter nach immer dagegen gewehrt hat (20. III. I8I4).

Im Entwurf zu dem Briefe findet sich der in die Reinschrift nicht übergegangene Zusatz: IV. 24. 372: In dem 3. Bande meines biographischen Versuches finden Sie die Ursachen und Umstände, warum und wie ich mich sobald von der französischen Sprache zur deutschen gervendet und mich dieser praktisch allein hingegeben, indem ich studien- und versuchsweise das Fremde zu ergreifen nicht verschmähte. Fahren Sie fort in der jetzigen Epoche von Ihrer Seite kräftig mitzuwirken. Auf Goethes Verhältnis zum Französischen werden wir im 3. Teil zurückkommen. Deutlicher werden Radlofs Bestrebungen Eichstädt gegenüber kritisiert. IV. 24. 194. 4: Herrn Radlofs Schrift

1) Vgl. G. G. XIV, 344 . 
verdient ja wohl einer ehrenvollen Erwähnung [in der Lit. Ztg.], wenn die guten, lieben Männer nur Maass und Ziel zu finden wüssten (12. III. 18I4). ${ }^{1}$ )

Der hier ausgesprochene Grundsatz, daß die Übertreibung der Sache der Sprachreinigung zum Schaden gereiche, ist es auch, der, wie schon Pentshorn ${ }^{2}$ ) bemerkt, ihn für den I8I6 in Ludens Zeitschrift Nemesis erschienenen Aufsatz von Karl Ruckstuhl: ,Von der Ausbildung der Teutschen Sprache in Beziehung auf neue dafür angestellte Bemühungen" völlig einnimmt. ${ }^{3}$ ) Im Mai und nochmals im Dezember des Erscheinungsjahres widmet ihm Goethe nach III. 5. 232 u. 296 seine Aufmerksamkeit und ist von der Arbeit geradezu entzückt, so daß er sie an Sulpiz Boisserée, Knebel und Rochlitz mit Lobeserhebungen empfiehlt:

IV. 27. 285. 25: Beyliegende Bogen sind vielleicht schon mit der Nemesis zu Ihnen gekommen. Die Erscheinung ist mir aber gar zu lieb und werth, als dass ich sie nicht mittheilen sollte. Sie verdient wiederholt gelesen und beherzigt zu werden. Das ist auch einmal wieder ein junger Mann der einen über die alten Narren, Pedanten und Schelme tröstet. (24. XII. I8I6 an Boisserée.)

IV. 28. 23. 15: Den Aujsatz von Ruckstuhl hast du wohl schon in der Nemesis gelesen ... man kann sich nicht genug daran erfreuen und ihn genugsam besonders jungen Leuten emplehlen. (17. III. I8I7 an Kncbel.)

IV. 28. I10. 10: Wie erfreulich ist mir der reine freie Ausdruck Ihres Briejes, auch nur als Sprachäusserung betrachtet, und zu welchen ekelhaften befremdenden Neuheiten wollen uns die

1) Konzept dazu IV. 24. 369: Auch der gute Radlof verdicnt Wïrdigung und chrenvolle Erviahnung, sugleich aber freylich auch Begrö̈zung, denu das ist's, was unsere zuerthen deutschen Männer sich am wenigsten selbst geben können.

2) \%eitschr. d. allg. deutsch. Sprachver. I (1886). S. 22.

3) Neudruck: Gocthe-Ruckstuhl: Vonder Ausbildung der deutschen Sprachc. Gicßen 1890. 
deutschen Männer zwingen! Auch gegen die werden wir auftreten und welche wackere junge Theilnehmende wir für unsere Überzeugung hoffen können, davon zeugt beyliegendes Heftchen [Ruckstuhls Aufsatz]. - Kennen Sie schon den Aufsatz, so ist es Ihnen wohl angenehm ihn zu besitzen und Freunden mitzutheilen. Man muss jetzt auch Partei machen, das Vernünftige zu erhalten, da die Unvernunft so kräftig zu Werke geht. (I. VI. I817 an Rochlitz.) Auch an andere Freunde scheinen Abzüge des Aufsatzes gegangen zu sein. Die Kampfstimmung, in die ihn die unverhoffte Bundesgenossenschaft versetzt, spricht auch aus einer Briefstelle an J. H. Meyer: IV. 28. 45. I: Haben Sie noch einige Ruckstuhls? so schicken Sie mir solche, es bleibt in unserer Zeit nichts übrig als offensiv vor zu gehen. Worauf ich mich ganz einrichte (3I. III. I8I7).

Er tritt in briefliche Beziehungen zum Verfasser und ist über die günstige Beurteilung des Rochusfestes sowie seiner gesamten ,schriftstellerischen Arbeiten“ durch Ruckstuhl beglückt, wie er am I. VIII. I8I7 Boisserée gesteht (IV. 28. 157. I2). In seiner Zeitschrift Kunst und Altertum widmet er der Arbeit eine Besprechung, würdigt den Autor sogar eines Lebensabrisses und bekennt sich rückhaltlos zu seinen Ansichten. Dasselbe bezeugt endlich Meyer, der den Aufsatz an Goethe vermittelte, in einem Brief an Ruckstuhl: G. X. 77: Goethe hat Ihre Schrift mit vielem Vergnügen und Lobeserhebungen gelesen ... er sagte, der Beifall, welchen er Ihrer Schrift gebe, sei freilich ein wenig parteiisch, indem er über deutsche Sprachverbesserung gerade ebenso denke, wie Sie (I8. V. I8I6).

Sehen wir uns daraufhin zunächst den Aufsatz, in dem Goethe mit wahrer Begeisterung Ansichten niedergelegt fand, die sich mit seiner Überzeugung deckten, genauer an. ${ }^{1}$ ) Er beschäftigt sich keineswegs mit dem Purismus allein, sondern in seinem ersten Teile auch mit anderen sprachlichen Fragen, die also

I) Vgl. L. Hirzel: Karl Ruckstuhl. Quellen und Forschungen. Heft 17. Straßburg 1876 . 
von Goethe gleichermaßen gebilligt werden. Er begrüßt es, daß die Alleinherrschaft des Obersächsischen gefallen, wendet sich aber gegen eine Vermischung von Sprachstoff aus verschiedenen Mundarten; es soll vielmehr neben den „Volksdialekten" eine allgemeine Sprache der Gebildeten bestehen, die aber aus den Mundarten ,poetischen Schwung und neue Lebenskraft" schöpfen soll. Wir erinnern uns, daß Goethe in der Besprechung von Arnolds Pfingstmontag I82I dieselben Ansichten vertrat, wobei auch ein Seitenhieb auf den Purismus - so viel Wunderliches - fiel. Ruckstuhls Einfluß ist da unverkennbar.

Weiterhin wendet sich der Verfasser gegen die übertriebene Sprachbereicherung durch Archaismen. „Es ist freilich großes Verdienst des Kenners und Forschers Provinzialismen und veraltete Wörter ans Licht zu ziehen, aber er soll dabei behutsam, bedächtig und mit Rücksicht auf die besonderen Umstände verfahren, so daß er nur das Unübliche in Übung bringt, was durch eigentümlichen Vorzug sich empfiehlt, oder was besonders zu Erweiterung des Ideenkreises, oder um irgend einem Sprachmangel abzuhelfen, dient." Also auch hier nur Auflehnung gegen die Übertreibung, nicht Ablehnung überhaupt. Nicht die Archaismen und Provinzialismen an sich werden wie von Gottsched und Adelung verworfen, sondern nur ihr wahlloser, manierierter Gebrauch, wie er bei den Romantikern und allen Teutschtümelnden damals auf dem Programm stand. Nachdem dann Ruckstuhl noch cine Lanze für Erhaltung und Pflege der Eigennamen besonders Ortsnamen - gebrochen hat und dabei auf den kulturgeschichtlichen Wert derselben hingewiesen, jedoch vor dem überhitzigen Erklären, dem verfrühten Forschen „,nach Wurzeln und Quellen, nach Verästungen und Verzweigungen“" gewarnt hat, das den Sprachforscher zu haltlosen Hypothesen verführt, tritt er dem „Purismus" entgegen.

Schon die einleitenden Worte sind bezeichnend: „Noch wurde von uns die vorzüglichste Richtung unbeachtet gelassen, 
welche die Bemühungen für die Muttersprache genommen haben, und nach welcher sie sich als Sprachreinigung behaupten wollen. Um sie in diesem Bezug als eine ganz eigentümliche Art von Tun und Treiben zu bezeichnen, gebraucht man dafür wohl auch den Namen Purismus und die dafür zusammen. haltenden Männer werden Puristen geheißen. Der Begriff des Reinigens, Fegens, Wegschaffens läßt uns kein rechtes Vertrauen fassen. Denn es läßt sich hier nicht so absondern und verwerfen, etwa wie der Metzger ein Stück Fleisch ab. schneidet und es den Hunden vorwirft." Von vornherein wird demnach nur die Seite der Bewegung als verwerflich bezeichnet, die Goethe den negativen Purismus nennt.

Ruckstuhl bekämpft die Ansicht, daß solche Fremd. wörter, die nicht ersetzbar seien, eine undeutsche und deshalb verwerfliche Sache bezeichneten, und weist darauf hin, daß gerade unserem Wesen innigst verwandte Begriffe bisweilen nicht deutsch ausgedrückt werden könnten, wie z. B. Schiller für naiv keine Verdeutschung fand Wenn jemand dagegenhält, daß, wenn auch nicht ein einzelnes, so doch für die verschiedenen Seiten der $\mathrm{Be}$ deutung mehrere deutsche Worte den Begriff des fremden völlig deckend wiedergeben, so müssen wir zur Verteidigung Ruckstuhls darauf hinweisen, daß derartige Verdeutschungen erst eine Errungenschaft unserer Tage sind, dem damaligen Purismus aber, seinen Freunden und Gegnern, ablagen, so daß Ruckstuhl die Berechtigung zu seinem Einwurf nicht abzusprechen ist. Der Zusammenhang unserer Kultur, so fährt Ruckstuhl fort, mit der griechischen, römischen und derjenigen der modernen Völker, mache die Übernahme fremden Sprachgutes natürlich. Die neuen Ideen der Wissenschaft und Kunst ferner heischen nach Ausdruck. Diese aber werden am besten mit fremden Worten getauft, weil die deutschen ihrer Bedeutung nach vergeben sind und sich dem neuen Inhalt nicht anzupassen vermögen. $\mathrm{Zu}$ völligen Neubildungen aber haben selbst Leute wie Herder nicht gegriffen, der z. B. 
das Fremdwort Humanität einer Neubildung vorzog. Auch um diesen Ausführungen gerecht zu werden, müssen wir uns ins 18. Jahrhundert zurückversetzen. Wir verfügen heute dank der rastlosen Arbeit der Sprachreiniger, dank der Mithilfe der führenden Geister der Nation über so manche Verdeutschungen, die unmöglich schienen. Sie haben sich eingebürgert, weil sie erst nach eingehender fachmännischer Prüfung des Inhalts, Umfangs und der Form vorgeschlagen oder durch das Beispiel mustergiltiger Autoren empfohlen wurden. Im I8. Jahrhundert war es umgekehrt. Leute wie Campe, die weder als Fachgelehrte, noch als Schriftsteller hervorragten, bildeten Unmassen von Verdeutschungen und muteten einem Goethe $z u$, diese unbesehen $z u$ verwenden, wagten sich mit ihrer Kritik lediglich vom puristischen Standpunkte aus an seine Werke. Sind da die scharfen Worte des Unmuts, ist da die fast überschwengliche Freude über gefundenen Beistand gegen solche Vergewaltigung nicht verständlich? Namentlich in seiner wissenschaftlichen Arbeit mußte er sich durch das plumpe Dreinfahren der Puristen empfindlich gestört sehen. Ausdrücke, die ihren festumgrenzten Begriffsinhalt hatten, wurden ihrer Fremdheit wegen kurzerhand beseitigt und durch deutsche ersetzt, die eine anders gefärbte Bedeutung mitbrachten. Wer Goethes Kampf mit Wort und Begriff kennt, versteht, wie heftig ihn das Verfahren der Puristen erbittern mußte.

Hören wir Ruckstuhl weiter: Durch die pedantische Splitterrichterci schädigen dic Puristen den freicn Meinungsaustausch und rufen cine Vernachlässigung der Sache durch einseitige Berücksichtigung der Form hervor. Fremdwörter wie Adicu "gelten dem Gemüte als cin Schatz", auch hat das Wort in der Form Ade „, durch zarte, dem Volke werte Lieder eine höhere Weihe erhalten". Dic Antastung und Verdrängung fremder Familiennamen ist ein Bruch altgeheiligter Licbesbande. „Dic Verbannung aller fremden Wörter ist ein gar trockennüchternes Benchmen" und wird auch von den ersten Schrift. 
stellern Herder, Schiller, Goethe abgelehnt. „, Ja, Goethe scheint gar gegen die Puristen einigermaßen ironisch sich $z u$ benehmen, indem er fast desto häufiger fremde Worte zuläßt, je heftiger sie von jenen Eiferern befehdet werden. (Der Nach. weis dieser Annahme dürfte freilich schwer zu erbringen sein.) Die Verbannung alles Ausländischen ... erweckt keine gute Meinung von der Selbständigkeit unseres Geistes." Wir müssen mit dem Fremden fertig werden, es verarbeiten, nicht nur abweisen.

Und endlich führt Ruckstuhl gegen den radikalen Purismus einen Grund ins Feld, der von Goethe mit besonderem Beifall begrüßt worden sein wird: „Gleichwie Teutschland in der Mitte der anderen Länder liegt, so soll auch sein Volk im Verein der Europäischen Staaten die Stelle des Herzens vertreten, von welchem alle Adern ausströmen, in welches sie zurückfliessen." Auch nach Goethes Wunsch sollte ja, wie wir unten weiter ausführen werden, Deutschland und seine Sprache der Mittelpunkt einer Weltliteratur werden, zu welchem Beruf es des Fremden nicht entraten konnte.

Zum Schluß wendet sich der Verfasser gegen die übertriebene Neubildung von Sprachstoff, die nur dem Dichter zusteht, der vom Volksgeist durchdrungen ist, nicht aber den nüchternen „Zionswächtern der Sprachreinigkeit". „Die Worte wollen bewußtlos erschaffen sein wie Gottes Geschöpfe!“

Das sind die Thesen, auf denen Karl Ruckstuhl, der junge Berliner Gelehrte, seinen von Goethe so bewunderten Aufsatz aufbaut. Noch manches andere von warmer Vaterlandsliebe, von eingehender Kenntnis der Muttersprache zeugende Wort könnten wir anführen. Und nicht leugnen wollen wir, daß auch hier und da zu weit gegangen, zu kosmopolitisch gedacht wird.

Aber fassen wir zusammen: Wenn man dem Zeitgeist Rechnung trägt, wenn man der vielen Mißgriffe der Puristen gedenkt, wenn man Goethes wissenschaftliche Tätigkeit in Betracht zieht, die der fremden Nomenklaturen nicht ent- 
behren konnte, dann müssen wir seinen Beifall als völlig berechtigt anerkennen. Seine Besprechung im I. Band von Kunst und Altertum gipfelt in folgenden Sätzen: I. 4II. IO9ff.: ... damit man nicht etwa in 20 Fahren uns noch über den Lethe hinüber Vorwürfe nachschicke, so entschlossen wir uns über deutsche Sprache und über den Fug und Unfug, welchen sie sich jetzt muss gefallen lassen, ein Wort mitzusprechen. Glücklicher Weise fiel uns ein Aufsatz in die Hände, den wir unseren sämmtlichen Lesern bekannt wïnschen, damit durch fremden Mund ausgesprochen werde wie wir ungefähr selbst denken. [Anzeige.] Wir sind dem Verfasser vielen Dank schuldig, dass er uns der Pflicht entledigt über diese Angelegenheit unsere Gedanken zu eröfnen. Er warnt, wie wir auch würden gethan haben, vor dem unersetzlichen Schaden, der einer Nation zugefïgt werden kann, wenn man ihr selbst mit redlicher Über. zeugung und aus bester Absicht, eine falsche Richtung giebt, wie es jetzt bei uns mit der Sprache geschehen soll. Da wir nun alles, was und wie er es gesagt, unterschreiben, so enthalten wir uns alles Weiteren und sagen nur soviel von ihm selbst, dass er nicht etwa ein Undentscher, ein Entfremdeter sey, sondern ächt und brav. [Lebensabriß.] ... Er wird viel Gutes stiften, besonders da er nicht eigentlich als Gegner der vorzüglichen Männer auftritt, die in diesem Fache wirken, sondern wie er es selbst ausspricht, neben ihnen hergeht. Die sich anschließenden Betrachtungen beziehen sich nicht direkt auf die Sprachreinigung, sondern auf lateinische Gedichte deutscher Verfasser, die beweisen sollen, daß der Deutsche sich auch in fremder Zunge treu bleibt, während anderseits in der Muttersprache oft so gedichtet wird, als wenn es eine fremde wäre. $\left.{ }^{1}\right)$ Des weiteren weist er darauf hin, wie durch Anleihen bei Italienern und Franzosen unsere Oper und unser Schauspiel neu belebt wurden. Doch hiervon ist gegenwärtig su schweigen besser, die Zeit wird kommen, wo der Deutsche wieder frägt, auf welchen Wegen es seinen Vorfahren wohl gelungen die Sprache auf

1) Vgl. Kap. 5, S. 81 . 
den hohen Grad von Selbständigkeit zu bringen, dessen sie sich jetzt erfreut.

Der nächste Abschnitt, den wir ebenfalls schon oben (S. 88) berührt haben, behandelt die Notwendigkeit fremder Sprachkenntnisse für die höheren Regionen der Bevölkerung. Mit dem letzten kommt er dann wieder auf den Purismus zurück und setzt ähnlich wie im bekannten Brief an Riemer vom 30. VI. I 8 I 3 auseinander, was er unter Sprachreinigung versteht: $D i e$ Muttersprache zugleich reinigen und bereichern ist das Geschäft der besten Köpfe; Reinigung ohne Bereicherung erweist sich öfters geistlos: denn es ist nichts bequemer als von Inhalt absehen und auf den Ausdruck passen. Der geistreiche Mensch knetet seinen Wortstoff, ohne sich zu kümmern aus was für Elementen er bestehe; der geistlose hat gut rein sprechen, da er nichts zu sagen hat. Wie sollte er fühlen, welches kümmerliche Surrogat er an der Stelle eines bedeutenden Wortes gelten lässt, da ihm jenes Wort nie lebendig war, weil er nichts dabei dachte. Es gibt gar viele Arten von Reinigung und Bereicherung, die eigentlich alle zusammengreifen müssen, wenn die Sprache lebendig wachsen soll. Poesie und leidenschattliche Rede sind die einzigen Quellen aus denen dieses Leben hervordringt und sollten sie in ihrer Heftigkeit auch etwas Bergschutt mitführen, er setzt sich zu Boden und die reine Welle fliesst darüber her. (Deutsche Sprache. K. u. A. I. 3. I8I7.)

Wir halten diese Stelle für die bedeutsamste und gewichtigste Äußerung zur Sache überhaupt. Wir unterschreiben sie noch heute Wort für Wort und wohl jeder vernünftige Sprachreiniger mit uns. Der Bergschutt, den der Quell der poetischen Rede mitführt, sind die zufällig mitunterlaufenden Fremdwörter, die unschädlich sind, wenn die Quellen der Sprachbereicherung rein fließen und die notwendig sind, solange kein den Begriff deckendes deutsches Wort da ist. ${ }^{1}$ )

1) Diese Erklärung nach Dehnike a. a. O. 5; Knauth, der offenbar den Zusammenhang nicht beachtet, will a. a. O. 145 unter dem Lerg. schutt allgemein die Eigenarten des Altersstils verstanden haben. Vgl. 
Auch während der Abfassung seines Aufsatzes beschäftigte sich Goethe mit Schaffung passender Verdeutschungen; das beweisen die Lesarten I. 4II. 465: Schuztitel, Vortitel; Stängeln, perche, Leibgefecht, Duel, Zweykampf zum Manuskript desselben.

Aus der gleichen Zeit treffen wir zahlreiche Äußerungen zur Sprachreinigung. Nicht nur Ruckstuhls Arbeit wird der Grund dazu sein, sondern wohl auch die Tatsache, daß in der I8I5 zu Berlin von Wolke gegründeten „Gesellschaft für die Reinigung der deutschen Sprache" der Purismus wieder Auswüchse lächerlichster Art trieb. Wir erwähnen zunächst das Gedicht: Neologen:

I. 2. 206. I :

Ich begegnet einem jungen Mann, Ich fragt' ihn um sein Gewerbe; Er sagt': „Ich sorge wie ich kann, Dass ich mir, eh' ich sterbe, Ein Bauerngütchen erwerbe.

Ich sagte: Das ist sehr wohlgedacht; Und wünschte, er hätt' es so weit gebracht. $D a$ hör' ich er habe vom lieben Papa Und ebenso von der Frau Mama Die allerschönsten Rittergüter.

Das nenn' ich doch originale Gemüther.

Das Bauerngütchen sind die Neologismen, dic neugebildeten Worte und Redensarten, das Rittergut ist der ererbte Sprachschatz. Mit Löper das Gedicht allgemeiner als Vorwurf gegen den Fehler der Deutschen, immer von vorn anzufangen, aufzufassen, ist wohl wegen der Überschrift nicht angängig. ${ }^{1}$ )

auch Riegel a. a. O. 2 und Riegel: Ein Hauptstück von unserer Muttersprache. 1883. S. 55.

1) Vgl. Heinemann II, 31. Hempel II, 175. 443. 
Kein Geringerer übrigens als Wilhelm Grimm steht hier auf Goethes Seite. Obgleich er wie dieser gegen den Fremdwortunfug eifert, spottet er über die Neubildung des unaussprechlichen Jetztzeit und über selbstredend. ${ }^{1}$ ) Auch Jakob Grimm, der mit seinem Bruder wider Willen zum Mitglied jener Berliner Gesellschaft gemacht worden war, will von ihren Bestrebungen nichts wissen und stellt sich offen auf Goethes Seite. „Die Meinung ist gut, schreibt er, aber die Kraft und Art dieser Sprachreinigung will mir nicht in den Kopf, ich halte sie für unerlaubt ... wie unendlich höher steht das heilige, innere Wesen unserer Sprache selbst. Goethe (der aus halbem Gegensatz jetzt über die Gebühr fremde Wörter braucht) schreibt dieser Flecken ungeachtet grunddeutscher als alle Wolke und Heinsius." Und in der Vorrede zum Wörterbuch werden die Fremdwörter als ein notwendiges Zeitübel bezeichnet, dessen Verschwinden der Zeit zu überlassen und nicht einmal völlig zu wünschen sei. ${ }^{2}$ ) Ausdrücklich als ,,recht schön" werden Goethes Ausführungen gegen die Puristen in der Vorrede zur deutschen Grammatik von Jakob Grimm I818 anerkannt. Bedarf es noch einwandfreierer Kronzeugen für die Richtigkeit von Goethes Standpunkt in seiner Zeit als die beiden Grimm? Offen an die Adresse der Puristen in Berlin wendet sich der entrüstete Dichter in den Zahmen Xenien.

I. 5. I43. v. 826: Die Sprachreiniger:

Gott Dank! Dass uns so wohl geschah, Der Tyrann sitzt auf Helena!

Doch liess sich nar der eine bannen, Wir haben jetzo hundert Tyrannen.

Die schmieden uns gar unbequem,

Ein neues Continental-System.

Teutschland soll rein sich isolieren,

I) Kluge: Zeitschr.d.allg. deutsch.Sprachver. 1894 . Nr. 10/I I. Sp. 2 I0.

2) Steig a.a.O.196; Socin a. a. O. 464.

Rausch, Goethe u. die deutsche Sprache. 


\section{Ein Pest-Cordon um die Gränze führen,} Dass sie nicht einschleiche fort und fort Kopf, Körper und Schwanz von fremdem Wort. Wir sollen auf unsern Lorbeern ruhen, Nichts weiter denken als was wir thun. $\left.(1816 / 17)^{1}\right)$

Nicht bekennen möchten wir uns zu der Auffassung Harnacks, der meint ,,die Verse richten sich zunächst zwar gegen den pedantischen Purismus der Sprache, eröffnen aber in ihrer allgemeinen Ausdrucksweise noch einen viel weiteren Horizont", d. h. auf die Kleinstaaterei. Diese Interpretation erscheint durch nichts gerechtfertigt. ${ }^{2}$ )

Gegen die (übrigens auch in Goethes Sinn von Ruckstuhl behandelte) Verbannung fremder Namen aus der deutschen Literatur wendet sich das Xenion Nr. 283, die Frage in den Reichsanzeiger, W. Meister betreffend. I. 5. 246:

$Z u$ was Ende die wälschen Namen für deutsche Personen? Raubt es nicht allen Genuss an dem vortrefflichen Werk?

Dadurch, daß die Frage nämlich als für den von Zacharias Becker herausgegebenen Berliner Reichsanzeiger bestimmt bezeichnet wird, will sic der Dichter als besonders töricht kennzeichnen, was die Verfasser der Xenien auch anderwärts taten. Wenn wir in dieser Frage heute über Goethe hinausgekommen sind, so ist immer wieder darauf hinzuweisen, daß wir auf den Höhepunkt in der Sprachreinigung stehen, Goethe aber nur die Anfänge erlebt hat; zweifelsohne wären Goethe und auch Ruckstuhl den Bahnen der vernünftigen Sprachreinigung bis zu ihrem heutigen Stande gefolgt. Gegen eine Verdeutschung cler wissenschaftlichen

1) Dat Ruckstuhl (S. 67 des Neudrucks) den Ausdruck Pest-Cordon, ohne sich auf froethe zu beziehen, anwendet, hat ihn dieser wohl von jenem ïbernommen, und das erstmalig 1833 veröffentlichte Gedicht dürfte also $1816 / 1817$ entstanden sein.

2) Harnack a. a. O.256. Anm. 2; vgl. Heinemann III, 192. Kluge a. ล. (). 34 . 
Terminologie wendet sich eine Tagebuchnotiz von I8I6: III. 5. 235. 2I: Mit Bergrath Voigt um den Graben. Forderung der Studenten vom Professor, dass er die wissenschaftliche Terminologie deutsch geben soll. Seltsamer Einfuss dieser Grille auf Wissenschaft und Praxis (27. V. I8I6). Wie ich Bodes „Stunden mit Goethe“ (V. I07) entnehme, bezicht sich das Gespräch auf das Verfahren des Jenaer Professors Oken, der eine deutsche Terminologie für Botanik mit Hunderten von sonderbaren Namen (Wurzler, Schore, Pölen, Kunze, Lüche, Reische usf.) gebildet hatte. Also auch hier wieder ist es eine Übertreibung, eine Überspannung des Purismus, der Goethes Opposition und Spott aufruft.

Zwei weitere Äußerungen Goethes zur Sache aus dem Jahre I 8 I 6 müssen wir im Zusammenhang behandeln, weil sie Bern: hard Suphan benutzt, um Goethe als Gegner der Sprachreinigung hinzustellen. ${ }^{1}$ Es sind zwei Briefstellen an Schultz (Konzept) und W. v. Humboldt.

IV. 27. 372: (Lesarten) Meinen sämmtlichen chromatischen Apparat habe nach Fena herübergebracht und secretire ihn in einem Beyzimmer unserer Museen. Wie schwer es ist ohne fremde Worte zu reden, sehen Sie hieraus, ich ver he i m. liche ihn nicht, weil jedermann wissen kann dass er da ist, er bleibt aber doch in secreto, im Abgesonderten, weil sich niemand darum bekümmert, ja weil manche dagegen Apprehension haben. Dieses würde umschrieben in ächter deutscher Sprache heissen, er widert ihnen, ist unbequem, ist verdriesslich, ist lästig; furchtbar und gehässig. In solchen Umschweifen nöthigt uns die Sprachreinigkeit, der wir uns doch auf alle Weise zu fïgen haben. (25. V. I816 an Schultz.)

IV. 27. 158. 7: Was Sie in Ihrer Einleitung [zur Äschylos. übersetzung] über Synonymik sagen ist köstlich, möchten doch

1) In einem uns leider nicht mehr zugänglichen Aufsatz in der ,Frankfurter Zeitung “ vom Dezember 1902. Wir sind auf die Besprechung Streichers, Zeitschr. d. allg. deutsch. Sprachver. XVIII (I903). Nr. 4. Sp. 106, angewiesen. 
unsere Sprachreiniger davon durchdrungen seyn! Doch in so hohe Angelegenheiten wollen wir die traurigen Missgriffe nicht mischen, durch welche die deutsche Nation ihre Sprache von Grund aus verdirbt; ein Unheil, das man erst in dreyssig Fahren einsehen wird. (I. IX. I8I6 an W. v. Humboldt.)

Lassen wir zunächst Humboldt in seinem Vorwort zum Agamemnon reden ${ }^{1}$ ): „Man hat schon öfter bemerkt, und die Untersuchung sowohl als die Erfahrung bestätigen es, daß, sowie man von den Ausdrücken absieht, die blos körperliche Gegenstände bezeichnen, kein Wort einer Sprache vollkommen einem in einer andren gleich ist. Verschiedene Sprachen sind in dieser Hinsicht nur eben so viel Synonymieen, jede drückt den Begriff etwas anders, mit dieser oder jener Nebenbestimmung, eine Stufe höher oder tiefer auf der Leiter der Empfindungen aus. Eine solche Synonymik der hauptsächlichsten Sprachen, auch nur (was gerade vorzüglich dankbar wäre) des Griechischen, Lateinischen, Deutschen, ist noch nicht versucht worden, . . . aber bei geistvoller Behandlung müßte sie zu einem der anzichendsten Werke werden. Ein Wort ist so wenig ein Zeichen eines Begriffs, daß ja der Begriff ohne dasselbe nicht entstehen, geschweige denn festgehalten werden kann. Das unbestimmte Wirken der Denkkraft zicht sich in ein Wort zusammen, wic leichte Gewölke am heitren Himmel entstehen .. Alle Sprachformen sind Symbole, nicht die Dinge selbst, nicht verabredete Zeichen sondern Laute, welche mit den Dingen und Begriffen, die sie darstellen, durch den Geist, in dem sie entstanden sind und immerfort entstehen, sich in wirklichem, wenn man es so nennen will, mystischem Zusammenhang befinden."

Was der berühmte Sprachforscher hier darlegt und Goethe billigt, ist auch heute nicht abzulehnen. Dadurch wird eben der Ersatz vicler nicht dem Sprachschatz des alltäglichen L.ebens, sondern namentlich der Wissenschaft angehörigen

1) Humboldt, Agamemnon (Reclams Univ.-Biblioth.), Einleitung S. Io. 
Fremdworte so schwer oder gar unmöglich, daß sich im Deutschen kein Äquivalent findet, das den betreffenden Begriff genau so bis in die feinste Nuance wiedergibt. In diesem $\mathrm{Zu}$ sammenhang ist Goethe berechtigt, von traurigen Mißgriffen zu reden, denn der unzulängliche oder gar falsche Ersatz eines Fremdworts ist eben ein Mißgriff und eine Schädigung der Muttersprache. Nur wenn die Briefstelle nicht mit Humboldts Ausführungen zusammengehalten wird, kann man Kapital für das Fremdwort daraus schlagen. Dem Dichter und Gelehrten, für den sich mit jedem, ob fremdem, ob heimischem Wort ein oft schwer erkämpfter Begriffsinhalt verband, mußte das Verfahren des radikalen Purismus, der alle Fremdworte ohne Rücksicht auf die Zulänglichkeit oder überhaupt das Vorhandensein eines Ersatzes hinwegfegen wollte, ein Raub an der Muttersprache bedeuten. Und die andere Briefstelle an Schultz? Müssen wir mit Streicher zu dem Notbehelf greifen, daß es sich um einen Ausfluß augenblicklicher Gereiztheit handelt? oder um Hohn, wie Ruckstuhl und Grimm andeuten? Brauchen wir darauf hinzuweisen, daß Goethe die Stelle unterdrückte, also selbst bei ruhiger Betrachtung sie als ungerechte Aufwallung ablehnte? Wir meinen, was ein Goethe schrieb, muß er auch verantworten. Zwei Fremdwörter laufen ihm in die Feder, für die er keine passende Verdeutschung bei allem guten Willen findet. Im Unmut über den Mißerfolg seiner Studien zur Farbenlehre ärgert er sich auch über den Purismus, der jedem fremden Wort auf die Finger sieht und dem daran Gewöhnten unbequem wird. Das ist alles. - Bis in seine letzten Lebensjahre, keineswegs nur bis zum Jahre I8I8, wie Dehnike meint, lassen sich $\ddot{u}$ ß̉erungen über den Purismus verfolgen. Die, welche sich in den bekannten Bahnen, Ablehnung des radikalen, negativen Purismus, bewegen, lassen wir ohne weitere Erläuterung folgen:

I. 4III. 133. 8: Pietät, ein im Deutschen bis jetzt jungfräulich keusches Wort, da es unsere Reiniger abgelehnt und als ein fremdes 
glïcklicherweise bei Seite gebracht haben. (K. u. A. V. I Salvandy: Don Alonzo 1824.) - I. 4III. 320. 23: Sehen wir doch den Purismus, der eine durch Mengsal entstellte Sprache wieder herzustellen bemüht ist, so streng und zudringlich verfahren, wie sollten diejenigen [die griechische Geistlichkeit], welche ein reines Alt-Herkömmliches [das Altgriechische] zu bewachen haben, nicht das Gleiche zu üben berechtigt sein [d. h. streng an dem Altgriechischen der Volkssprache gegenüber festzuhalten]. (K. u. A. VI. 2 Nationelle Dichtkunst, I 828.)

I. 36. 241. 8: Pater Küchenmeister:

Die Plätze sind alle mit Wasser verschlemmt

Und noch nicht peigniert.

Pater Orator:

Sag er doch ge $k \ddot{a} m m t$ !

Daß er doch sein Frankreich, wo die Küch' er studiert, Noch immer und exig im Munde führt.

(D. u. W. Fragment. Luisenfest. I830.)

Die Verse entstammen cinem von Seckendorff zu dem Weimarer Fest 1778 verfaßten Dramolet. Es wird also auch hier die kritiklose wörtliche Übersetzung eines Fremdworts (peigner $=$ kämmen) verspottet, denn peignieren ist hier als tcrm. techn. in der Bedeutung von ,säubern" gebraucht.

II. I. 246. I: Priorität. Anticipation. Präoccupation. Plagiat. Possess. Usurpation. Den lateinischen Ursprung vorstehender Wörtcr wird man ihnen nicht verargen, indem sie Verhältnisse bezeichnen, die gewöhnlich nur unter Gelehrlen stattinden. (Zur Naturwiss., Meteore des Himmels.)

Zwei Zcugnisse, die auch dem strengsten Sprachreiniger Frude machen, seien angereiht: in dem einen lehnt Goethe fremde Fachausdrücke für deutsche Minerale $\mathrm{ab}$, im anderen stellt er dem Deutschen das Ehrenzeugnis aus, daß es den höchsten Anforderungen einer Sprache genüge und „das Innere des Volkes" zum Ausdruck bringe. IV. 28. 296. I3: 
ich... will nur soviel hinzufïgen, dass ich mich in diesem Falle [neue Minerale] wie in mehreren über die disparate Nomenclatur betrübt habe, im eigentlichen Sinne, weil dies der Wissen. schaft, die auf dem Anschauen ruht, von unglaublichem Schaden ist, wenn nahverwandte Gegenstände mit himmelweit entfernten, aus fremden Sprachen entlehnten disparaten Klängen und Tönen benannt werden. (29. X. I8I7 an A. C. Preen.)

Hempel 29. 697: Wie aber die militärisch-physische Kraft einer Nation sich aus ihrer inneren Einheit entwickelt, so muss auch die sittlich-aesthetische aus einer ähnlichen Übereinstimmung nach und nach hervorgehen. Ich sehe soviele Fahre als ein Mitarbeitender zurück und beobachte, wie sich, wo nicht aus widerstreitenden, doch heterogenen Elementen eine deutsche Literatur zusammenstellt, die eigentlich nur dadurch eins wird, dass sie in einer Sprache verfasst ist, welche aus ganz verschiedenen Anlagen und Talenten, Sinnen und Thun, Urtheilen und Beginnen nach und nach das Innere des Volkes zu Tage fördert (I82I). ${ }^{1}$ )

Mit dieser Anerkennung der hohen Entwickelung der deutschen Muttersprache berührt sich ein, wie wir schon verschiedene Male andeuteten, von Goethe in seinen alten Tagen gern gepflegter Gedankengang, der auch seine Stellung zur Sprachreinigung beeinflußte. Es ist die Idee von einer Weltliteratur, deren Mittelpunkt das Deutsche als Weltsprache werden sollte. Die Muttersprache steht auf einer so hohen Stufe der Ausbildung, daß sie ihm fähig erscheint, alles Fremde aufzunehmen, wiederzugeben und $z u$ vermitteln. Diesem weltumfassenden Beruf des Deutschen arbeitet nach des Dichters Ansicht der Purismus entgegen, wenn er der Sprache das fremde Material, dessen eine Weltsprache bedarf, unbedacht wieder zu entwinden sucht. Goethes literarische Tätigkeit in seinen letzten Lebensjahren, seine Beschäftigung mit griechischer, römischer, italienischer, fran-

I) Vgl. Hildebrand, R.: Vom deutschen Sprachunterricht 9. Aufl. S. I3r. Anm. 
zösischer, neugriechischer, slawischer, chinesischer Poesie, steht unter dem Einfluß dieses Lieblingsgedankens. Wir werden im 3. Teil darauf zurückkommen; hier kommt nur in Betracht, was sich gleichzeitig auf den Purismus bezieht. I. 4 I I. I26. II: Der wirkl. russisch. kaiserliche Staatsrath Uwarow gedenkt. . . unserer in Ehren also: „Die Wiedergeburt der Altertumswissenschaft gehört den Deutschen an . . Aus diesem Grunde lasien sich auch geroisse neue Ansichten kaum in einer anderen neuern Sprache ausdrücken; und desswegen habe ich Deutsch geschrieben... Es ist Zeit, dass ein jeder, unbekümmert um das Werkzeug, immer die Sprache wähle, die am nächsten dem Ideenkreise liegt, den er zu betreten im Begriff ist." Hier hört man nun doch einmal einen fähigen Mann, der über die kümmerliche Beschränkung eines erkältenden Sprachpatriotismus weit erhoben, gleich einem Meister der Tonkunst jedes. mal die Register zieht, welche Sinn und Getühl des Augenblicks ausdrücken. Möchten doch alle gebildeten Deutschen diese zugleich ehrenvollen und belehrenden Worte sich dankbar einprägen und geistreiche Fïnglinge dadurch angefeuert werden, sich mehrever Sprachen als beliebiger Lebenswerkzenge zu bemächtigen. (K. u. A. 1817. Urtheilsworte französ. Kritiker I.) Deutlicher kommt der Gedanke IO Jahre später zum Ausdruck. I. 42I. 251: Die [deutsche] Sprache gewinnt immer mehr Biegsamkeit sich andern Ausdrucksweisen zu fügen; die Nation gewöhnt sich immer mehr Fremdartiges aufzunehmen sowohl in Wort als Bildung und Wendung . . . Anlockung für Fremde, Deutsch zu lernen, nicht allein der Verdienste unsrer eignen Literatur [wegen] sondern dass die deutsche Sprache immer mehr Vermittlerin werden wird, dass alle Literaturen sich vereinigen. Und so können wir sie ohne Dünkel empfehlen. Man missgönnt der französischen Sprache nicht ihre Conversations. und diplomatische Allgemeinheit; in dem oben angedeuteten Sinne muss die deutsche sich nach und nach zur Weltsprache erheben. (K. U. A. VI. 1. Paralip. zu Serbische Gedichte 1827.) 
IV. 36. 233. I3: Sprachstudium und Anerkennung des Nachbarlichen ist zu befördern, damit Eine Heerde unter Einem Hirten versammelt sey. (I4. XII. I822 an Knebel.) ${ }^{1}$ ) Ähnlich schon 1820: Denn es ist einmal die Bestimmung des Deutschen, sich zum Repräsentanten der sämmtlichen Weltbürger zu erheben. (IV. 33. 67. I7 an L. Büchler I4. VI. I 820.) Dagegen erfährt der Gedanke eine Ablenkung vom Kosmopolitischen zum Nationalen in zwei Aussprüchen aus Makariens Tagebuch, die neuerdings ans Licht getreten sind:

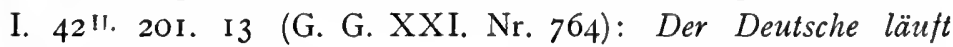
keine grössere Gefahr, als sich mit und an seinen Nachbarn zu steigern. Es ist vielleicht keine Nation geeigneter, sich aus sich selbst zu entwickeln; desswegen es ihr zum grössten Vortheil gereichte, dass die Aussenwelt von ihr so spät Notiz nahm. - Ebenda 202. 3 (Nr. 767): Fetzt da sich eine Weltliteratur einleitet, hat, genau besehen, der Deutsche am meisten zu verlieren; er wird wohl thun, dieser Warnung nachzudenken. (W. M. W. I829.) Nun noch eins: Wie bei Goethe überhaupt vor dem inneren Gehalt die äußere Form zurücktritt, so kommt es ihm bei der Sprache weniger auf das Wie? als auf das Was? an. Auch in fremder Sprache (also auch mit entliehenen fremden Worten) verleugnet sich der deutsche Charakter des Schreibenden nicht; er kann vielmehr unter Umständen besser hervortreten als in der Muttersprache. Das ist der schon oben ${ }^{2}$ ) skizzierte Inhalt eines Abschnittes seines bekannten Aufsatzes „, Deutsche Sprache" vom Jahre 18I7: I. 4II. I 4: Einer freieren Weltansicht, die der Deutsche sich [durch übertriebenen Purismus] zu verkümmern auf dem Wege ist, würde ferner sehr zu statten kommen, wenn ein junger geistreicher Gelehrter das wahrhaft poetische Verdienst zu würdigen unternähme, welches deutsche Dichter in der lateinischen Sprache seit drey Fahrhunderten

I) An Staatsrat Schultz dasselbe Citat mit der Abweichung: damit eine Heerde auch ohne Hirte versammelt sey. Ohne Datum; zu S. 263, Nr. 79 der Ausgabe von Düntzer.

2) Vgl, oben S. 158 . 
an den Tag gegeben. Es würde daraus hervorgehen, dass der Deutsche sich treu bleibt und wenn er auch in fremden Zungen spricht... Zugleich wïrde er beachten, wie auch andere gebildete Nationen zur Zeit, als lateinisch die Weltsprache war, in illr gedichtet und sich auf eine Weise unter einander verständigt, die uns jetzo verloren geht. (K. u. A. I. 3.) Als dadurch angeregt ein junger Breslauer Student sich an das Studium der lateinisch dichtenden Deutschen früherer Jahrhunderte machte und von Goethe Material erbat, antwortete dieser: IV. 3I. I I9. 7: Fahren Sie in der löblichen Arbeit fort, deren Resultat kein anderes seyn wird, als dass der Deutsche auch in fremden Formen und Sprachen sich selbst gleich bleibt, seinem Charakter und Talent überall Ehre macht. (IO. IV. I8I9 an A. O. Blumenthal.) Sonderbarerweise denkt schon cinen Monat später Goethe anders in der Sache zugunsten der Muttersprache und äußert sich auch über den Purismus unter Ablehnung der Übertreibung mit Anerkennung des guten Kernes der Bewegung.

IV. 3I. I59. 24: Nun noch ein Wort von der neueren Teutschthümlichkeit. Die Menschen in Masse werden von jeher nur verbunden durch Vorurtheile, und aufgeregt durch Leidenschaften; selbst der beste Zweck wird somit immer getrïbt und oft ver. schoben; aber demohngeachtet wird das Trefflichste gewirkt, wenn auch nicht im Augenblick, doch in der Folge, wenn nicht unmittelbar, doch veranlasst. Und so werden Sie erleben, dass Werthe und Wïrde unserer Ahnherrn rein und schön aus der eignen Sprache hervortreten; denn es ist wahr, was Gott im Koran sagt; Wir haben keinem Volk einen Propheten geschickt als in seiner Sprache! Und so sind denn die Deutschen erst ein Volk durch Luthern geworden. Lassen Sie sich aber durch alles dies in Ihrem eigensten Geschäfte nicht irren, denn man kennt die Eigenthïmlichkeit einer Nation erst alsdann, wenn man sicht, wie sie sich auswärts beträgt. (28. V. I8I9 an Blumenthal.)

Das Ergebnis unserer Untersuchung ist also in kurzen Worten dieses: Gocthe hat die Berechtigung und Notwendig- 
keit einer Sprachreinigung niemals verkannt, sich aber stets gegen den negativen, radikalen Purismus mit aller Deutlichkeit und Schärfe ausgesprochen. Die Forderung einer dem Begriffsinhalt möglichst entsprechenden Wortform, die gelehrten Interessen, der Gedanke an eine deutsche Weltliteratur, die geringe Anziehungskraft sprachlicher Fragen an sich, die plumpen Angriffe der Puristen, ihre Einseitigkeit und Pedanterie, alles das hat seine Stellung zur Frage ungünstig, aber niemals ungerecht beeinflußt. Für eine vernünftige Sprachreinigung war Goethe aus Licbe zur Muttersprache stets zu haben.

Rembrandts Wort: An meinen Bildern müßt ihr nicht schnüffeln, die Farben sind ungesund, führte auch Goethe im Munde. ${ }^{1}$ ) Haften an Äußerlichkeiten, Kleinigkeiten und Kleinlichkeiten war ihm verhaßt, und die puristische Bewegung war ihm Schnüffelei an der Sprache. „Märkische Rübchen schmecken gut, am besten gemischt mit Kastanien. Und diese beiden edlen Früchte wachsen weit auseinander. Erlaubt uns in unsern vermischten Schriften doch neben den abend- und nordländischen Formen auch die morgen- und südländischen." (Aphor.) $\left.)^{2}\right)^{3}$ )

I) G. G. XXI. Nr. II23.

2) Bode: Groethes Ästhetik. S. 262/263 (teilweise auch I, 421I. 255. 1). Das Wort bezieht sich in dem Zusammenhang der Stelle der Hauptsache nach auf dic metrischen Entlehnungen, bezeichnet aber auch treffend Goethes Standpunkt der Sprachreinigung gegenüber.

3) In den Grenzboten, Bd. 64 (1905), S. 566, ist ein für das Chaos (die von Ottilie v. Goethe und ihrem stark mit Ausländern versetzten Kreis herausgegebene private Zeitschrift) bestimmtes Gedicht hervorgetreten, das z. B. in der Goetheausgabe von Boas I846. Bd. I. 27, Aufnahme gefunden hat, in der Weimarer Ausgabe aber nicht erschienen ist. Es wendet sich mit beißendem Spott gegen die Ausländerei, gehört aber nach Ton und Inhalt u, E, nicht Goethe zu. Wir setzen es aber immerhin hierher:

I. Brittisch, Gallisch und Italisch, Daran scheint es nicht zu fehlen; Wüsst ich etwas kamtschadalisch, 


\section{ZEHNTES KAPITEL.}

\section{METRIK UND PHONETIK.}

Wie der Sprachgewaltige sich nirgends zusammenhängend über Sprachrichtigkeit ausgelassen hat, so hat der Dichter nur ganz vereinzelt sich über Versbau geäußert. Selbst die Tagebücher schweigen fast völlig; vgl. nur III. 9. 287. 5: Inter essantes Gespräch [mit Riemer] über Sprache, Sylbenmaas (24. X. 1824). Die Unsicherheit in der deutschen Verslehre, die durch Herübernahme fremder Gebilde, Anlehnung an die prosodischen Regeln der Alten, durch Schwanken zwischen Silbenmessung und Silbenzählung, Behandlung der unbetonten Silben und anderes mehr hervorgerufen wurde, gibt vornehmlich

Möcht ich wirksam mich empfehlen,

Ach ich freute mich zu Tode,

Könnt' ich türkisch radebrechen;

Aber Deutsch ist aus der Mode,

Und ich weiss nur Deutsch zu sprechen.

2. Geduld! Verlass dich auf mein Wort,

Gar vieles ändert sich auf Erden;

Und gehts nur so ein Weilchen fort,

Wird bald das Deutsche hier am Ort

Als fremde Sprache Mode werden.

3. Vom Baume fällt das letzte Blatt,

Die Flur deckt hohen Schnees Lage;

Die Schlitten klingeln durch die Stadt;

Man sieht, es nahn die Weihnachtstage.

Doch trittst du zum Salon herein,

Und hörst beim Thee und süssen Wein

Zehn Sprachen durcheinander schrein,

So zweifelst du nicht im Geringsten,

Wie draussen Weihnacht, ist hier Pfingsten.

4. Manches lässt die Zeit uns sehen,

Was uns cinst gedünkt als Fabel.

Sonst hiess Weimar Deutsch-Athen,

Jetzo heisst's das Deutsche Babel. 
dem Dichter Anlaß zur Klage. Das Schwanken in den Regeln und Vorschriften scheint ihm viel Schwierigkeiten bereitet zu haben; Riegel nimmt ja sogar an, daß dies die „,unüberwindlichen" Hindernisse seien, von denen Goethe im oben besprochenen venetianischen Epigramm redet. Die prosodischen Studien von K. Ph. Moritz und dessen I786 erschienener „Versuch einer deutschen Prosodie" kamen ihm in Italien bei der Umarbeitung der Iphigenie sehr zustatten. Das erkennt er dankbar an. I. 30.248. 7 : Denn wenn ich die Prosa seit mehreren Fahren bei meinen Arbeiten vorzog, daran war doch eigentlich schuld, dass unsere Prosodie in der grössten Unsicherheit schwebt, wie den meine einsichtigen, gelehrten, mitarbeitenden Freunde die Entscheidung mancher Fragen dem Gefühl, dem Geschmack anheim gaben, wodurch man denn doch aller Richtschnur ermangelte. Iphigenia in Famben zu übersetzen, hätte ich nie gewagt, wäre mir in Moritzens Prosodie nicht ein Leitstern erschienen. Der Umgang mit dem Verfasser, besonders während seines Krankenlagers [in Rom Armbruch] hat mich noch mehr darüber aufgeklärt und ich ersuche die Freunde [Herder] darüber mit Wohlwollen nachzudenken. Es ist auffallend, das wir in unserer Sprache nur wenige Silben finden, die entschieden kurz oder lang sind. Mit den andern verfährt man nach Geschmack oder Willkür. Nun hat Moritz ausgeklügelt, dass es eine gewisse Rangordnung der Silben gebe, und dass die dem Sinn nach bedeutendere, gegen eine wenig bedeutendere lang sey und diese kurz mache, dagegen auch wieder kurz werden könne, wenn sie in die Nähe von einer anderen geräth, welche mehr Geistesgewicht hat. Hier ist denn doch ein Anhalten und wenn auch damit nicht alles gethan wäre, so hat man doch indessen einen Leitfaden, an dem man sich hinschlingen kann. Ich habe diese Maxime öfters zu Rathe gezogen und sie mit meiner Empfindung übereinstimmend gefunden. (Ital. Reise. I0. I. 1787.) Wir sehen, Goethe operiert noch mit den Begriffen lang und kurz, die Silbenbetonung liegt noch im Widerstreit mit der antiken Silbenmessung. Die neben- 
tonigen Silben machen Schwierigkeiten; Wortakzent und Satzakzent werden wohl empfunden, aber nichr klar er. kannt.

Gleich dankbar ist übrigens Schiller für das Buch: „Man sieht eine schöne Ordnung in die Anarchie der Sprache kommen" schreibt er am 23. VIII. I794 darüber an Goethe. In Dichtung und Wahrheit berichtet dieser über diese Zeit der Unsicherheit: I. 27. 89. 28: Die Rhythmik lag damals noch in der Wiege, und niemand wusste ein Mittel ihre Kindheit zu verkürzen. Die poetische Prosa nahm überhand. Geßner und Klopstock erregten manche Nachahmer; andere wieder forderten doch ein Sylbenmass und übersetzten diese Prose in fassliche Rhythmen. (D. W. 7. I8I I.) Über dieselbe Sache äußert er sich am Beginn des 18 . Buches ausführlicher: I. 29. 213: Die Deutschen waren von den älteren Zeiten her an den Reim gewöhnt, er brachte den Vorteil, dass man auf eine sehr naive Weise verfahren und fast nur die Silben zählen durfte. Achtete man bei fortschreitender Bildung mehr oder weniger instinktmässig auch auf Sinn und Bedeutung der Silben, so verdiente man das Lob, welches sich manche Dichter anzueignen wussten. Der Reim zeigte den Abschluss des.poetischen Satzes, bei kürzeren Zeilen waren sogar die kleineren Einschnitte merklich, und ein natülich wohlgebildetes Ohr sorgte für Abwechs. lung und Anmut. Nun aber nahm man auf einmal den Reim weg, ohne zu bedenken, dass ïber den Silbenwert noch nicht entschieden, ja schwer zu entscheiden war. Klopstock ging voran. Wie sehr er sich bemïht und, was er geleistet, ist bekannt. Federmann fïhlte die Unsicherheit der Sache, man wollte sich nicht gerne wagen, und, aufgefordert durch jene Naturtendenz, griff man nach einer poetischen Prosa. Geßners höchst liebliche Idyllen öfneten eine unendliche Bahn. Klopstock schrieb den Dialog von Hermanns Schlacht in Prosa sowie den "Tod Adams". Durch die bïrgerlichen Trauerspiele sowic durch die Dramen bemächtigte sich ein empfindungsvoller höherer Stil des Theaters, und umgelehrt aog dor fïnflüssige Jambus, der sich durch Ein. 
fuss der Engländer bei uns verbreitete, die Poesie zur Prosa herunter. Allein die Forderungen an Rhythmus und Reim konnte man im allgemeinen nicht aufgeben . . . Am besten aber gelang es denen, die sich des herkömmlichen Reimes mit einer gewissen Beobachtung des Silbenwertes bedienten, und, durch natürlichen Geschmack geleitet, unausgesprochene und unentschiedene Gesetze beobachteten, z. B. Wieland. . . Unsicher aber blieb die Ausübung auf jeden Fall, und es war keiner, auch der Besten, der nicht augenblicklich irre geworden wäre. (D. W. I8.)

In einem Schema zu diesem Buche von Dichtung und Wahrheit faßt er diese Verwirrung in der Metrik und Rhythmik in der Geniezeit folgendermaßen zusammen: I. 29. 225 (Lesarten): I. Die Ungewissheit der Rhythmik deutscher Sprache macht eine bedeutende Hinderniss, dass die besten Köpfe nicht vorwärts kommen. Reim als Nachhilfe des Sylbenmaasses. Reimlose Verse. Poetische Prosa. Trennung des Dichters vom Grammatiker. Lessing lässt seine Verse durch Ramler revidieren. Überhaupt Neigung zur Prosa. Mehr Unmittelbarkeit des Ausdrucks und Wahrheit. Losse Versarten . . . II. Unsicherheit der deutschen Poesie besonders im rhythmischen.

Aber trotz Moritz, trotz Einführung des jambischen Fünffüßlers hörte die Unsicherheit nicht auf. Neue erhob sich bei der Frage nach Beschaffenheit des deutschen Hexameters, die für Goethe brennend wurde, als er sich I792 entschloß, den Reineke Fuchs in diesem Versmaß zu übersetzen. „Klopstock und noch mehr Johann Heinrich Voß waren bestrebt, den deutschen Hexameter so viel als möglich nach dem Muster des antiken zu bauen. Ohne sich darüber klar zu sein, daß im Deutschen der Wortakzent zu gelten habe, schuf Voß gegen den Geist der Sprache künstlich Spondeen und Daktylen und bestimmte willkürlich Kürze und Länge der Silben; der große Philolog Friedrich August Wolf brachte sogar das Kunststück fertig, hundert Homerverse so zu übersetzen, daß in der Übersetzung und dem Original jeder Versfuß sich 
entsprach."1) Goethe, der mit Voß und Wolf befreundet war und namentlich letzteren hochschätzte, geriet zunächst in Abhängigkeit von ihren prosodischen Lehren: I. 35. 22. II: Auch darf ich zu bemerken nicht vergessen, dass ich sie [die Übersetzung des Reineke] zugleich als Übung im Hexameter vornahm, den wir freilich damals nur dem Gehör nachbildeten. $V o \beta$, der die Sache verstand, wollte solange Klopstock lebte, aus Pietät dem guten alten Herrn nicht ins Gesicht sagen, dass seine Hexameter schlecht seien. Das mussten wir jüngeren aber biissen, die wir von Fugend auf uns in jene Rythmik eingeleiert hatten. Vo $\beta$ verläugnete selbst seine Übersetzung der Odyssee ... und so zoussten wir nicht, welchem Heiligen wir uns widmen sollten. (Tag- u. Jahreshefte I 793.) Voß ging nämlich über Klopstock in der Festhaltung der Zäsur und anderem noch weit hinaus. In der Rezension von Voß' Gedichten in der LiteraturZeitung von 1804 werden seine Verdienste hoch hervorgehoben, wobei aber zu berücksichtigen ist, daß die betreffenden Stellen nicht aus Goethes Feder stammen, sondern aus der von Heinrich Voß d. Jüngeren, seinem Freunde und damaligen Hausgenossen. ${ }^{2}$ ) Immerhin stellen sie Gocthes damalige Überzeugung dar: I. 40. 279. 21 : Und hier erkennen wir sein unsterbliches Verdienst um die deutsche Rhythmik, die er aus so manchen schwankenden Versuchen einer für den Künstler so erwïnschten Gewißheit und Festigkeit entgegen hebt. Aufmerksam horchte derselbe den Klängen des griechischen Alterthums und ihnen fïgte sich die deutsche Sprache zu gleichem Wohllaute. So enthüllte sich ihm das Geheimniss der Sylbenmasse, so fand er die innigste Vereinigung zwischen

1) Heinemann, K.: Gocthe. Lcipzig 1895. II, 83.

2) Goethe und Schiller in Briefen von Heinrich VoB d. J., herausgeg. von H. G. Girä (Reclams Univ.-13ibl.), S. 33: Einige Stellen (der Rezension) habe ich $(\mathrm{V} O B)$ ausgearbeitet, nämlich ... den letzten Teil ïber Sprache, Rhythmik und Mythologic. (April 1804.) Nach diesen Zeugnis hätte auch M. Hecker in der Weimarer Ausgabe Vossens Autorschaft nicht in dubio lassen dirfen, zumal sie schon von Biedernann (Hempel) und Witkowski (Kürschner) anerkannt war. 
Poesie und Musik. Des alten Voß Verdienste um die deutsche Metrik sollen übrigens ungeschmälert bleiben. Denn wenn auch seine strengen rhythmischen Forderungen und die Übertragung der antiken prosodischen Grundsätze auf das Deutsche überholt wurden, so sind seine Lehren von der Zäsur des deutschen Hexameters doch im allgemeinen in Geltung geblieben. ${ }^{1}$ ) Goethe war von den neuen Lehren anfänglich so eingenommen, da $B$ er, offenbar weil er selbst sich nicht recht mit ihnen zurechtfand, I805 den jungen Voß nach dessen Zeugnis Hermann und Dorothea in ,bessere Hexameter" überarbeiten ließ; ,,ich darf ändern, so berichtet Voß, der Sohn stolz, wo und wie ich will“. $\left.{ }^{2}\right)$ Nach den Nachweisungen Ludwig Geigers $^{3}$ ) bessern auch W. v. Humboldt und W. Schlegel an dem Epos und in gleicher Weise Voß, Riemer und Göttling von $\mathrm{I} 808 \mathrm{ab}$ an der Achilleis. Daß er dieser ,,Versrichter und Metrumswächter" bedurfte, beweist das Gefühl der Unsicherheit, das ihn den vielen Vorschriften und Regeln gegenüber beherrschte.

Später denkt Goethe über Voß und seine Lehre ganz anders: I. 35. I 84. 25: Die deutsche Prosodie, insofern sie die alten Sylbenmasse nachbildete ward anstatt sich zu regeln immer problematischer; die anerkannten Meister solcher Künste und Künstlichkeiten lagen bis zur Feindschaft im Widerstreite. Hierdurch ward das Zweifelhafte oft noch ungewisser; mir aber, wenn ich etwas vorhatte, war es unmöglich über die Mittel erst zu denken, wodurch der Zweck zu erreichen wäre; jene mussten mir schon bei der Hand sein, wenn ich diesen nicht alsobald aufgeben sollte. (Tag- u. Jahreshefte I804; entstanden I817/26.) Zum Glück hatte er sich in seiner „Unkenntnis aller künstlichen Gesetze, und ohne sich vom Metrum einengen zu lassen", den freien deutschen Hexameter so geschaffen, wie er der deutschen

I) Paul, H.: Deutsche Metrik (Pauls Grundriß der germ. Philologie) 1893. I I, I. S. 990.

2) Vgl. Gräf a. a. O. 81 und 95 .

3) Geiger: Goethes Leben und Werke. Leipzig (Hesse). S. I28. I 32.

Rausch, Goethe u. die deutsche Sprache. 
Sprache allein entsprach, wenn er damit auch den Beifall weder des alten Voß noch des strengen Fr. A. Wolf errang. ${ }^{1}$ ) Goethe vergalt übrigens bald Gleiches mit Gleichem, ging über die Forderungen eines Voß zur Tagesordnung über und ließ es in späteren Jahren an scharfem Spott nicht fehlen. Schon I806 beginnt die Abwendung:

IV. 19. I19. 6: wenn man überlegt, dass in Deutschland sich noch manche tausend befinden, die mit dem bisherigen Hexameter noch ganz wohl zufrieden sind, so kann man sich um desto eher beruhigen, wenn eine neue Schule, oder vielmehr Familie [Voß!] nach selbst gegebenen Gesetzen, gar wunderliche Forderungen auch an andere macht; wobei wir Gedichte der vollkommensten Technik erleben, welche völlig ungeniessbar sind. (28. III. I 806 an N. Meyer.) Im nächsten Jahr schreibt er mit Bezug auf des alten Voß Homerübersetzung: IV. I9. 283: In zehn Fahren wird der Dünkel, womit die Rhythmiker von der strengen Observanz sich jetzt vernehmen lassen, höchst lächerlich sein, und doch leisteten sie nicht, was sie leisten, wenn sie sich nicht so viel darauf einbildeten (I4. III. I807 an Knebel). Wieder ein Jahr darauf lesen wir: IV. 20. 85. 6: Für lauter Prosodie ist ihm die Poesie ganz entschwunden. (22. VI. I 808 an Zelter.)

Die Umarbeitung von Hermann und Dorothea durch den jüngeren $V_{O} B$ blieb bezeichnenderweise liegen und kam für die Ausgabe der Werke nicht in Betracht.2) Goethe scheint vielmehr je länger um so mehr die undeutsche Tendenz der Voßschen Metrik, die Unterdrückung des deutschen Wortakzents zugunsten des antiken Hexameters erkannt zu haben. Zum ehrlichen Zorn gesteigert gibt sich die Abwendung von Voß, nachdem übrigens auch persönliche Entfremdung durch Ubersiedlung der Familic von Jena nach Heidelberg eingetreten war, 1818 kund: IV. 29. 90. 9: Von den Ioo Hexametern (Wolfs s. o.) mag ich ebensowenig wissen, als von den

1) Heinemann: Foethe II, 84 .

2) Schreyer: Gocthe-Jahrbuch X. S. 138. 
hundert Tagen der letzten Bonapartischen Regierung. Gott behüte mich vor deutscher Rhythmik wie vor französischem Thronwechsel. Dein mitternächtiger Sechsachtel Tact erschöptt alles. Solche Quantitäten und Qualitäten der Töne, solche Mannigfaltigkeit der Bewegung, der Pausen, Atemzüge. Dieses immer Gleiche, immer Wechselnde! Da sollen die Herren lange mit Balken und Hütchen - w. sich unter einander verständigen, dergleichen bringen sie doch nicht heraus. Nun vergessen sie immer, dass sie uns früher bis zur langen Weile, versicherten, ein Poet sey kein Grammatiker! Homer, Homeriden, Rhapsoden und alle das confuse Geschlecht haben so hinsaalbadert wie Gott gewollt, bis sie endlich so glücklich gewesen, dass man ihr dummes Zeug aufgeschrieben, da denn die Grammatiker sich ihrer erbarmt und es nach zweytausendjährigem Renken und Rücken endlich so weit gebracht, dass ausser den Priestern dieser Mysterien niemand mehr von der Sache wisse noch wissen könne. Neulich versicherte mich jemand, Xenophon habe eben so schlechte Prosa geschrieben als ich, welches mir denn zu einigem Troste dienen sollte. (19. III. I818 an Zelter.) So scheint die Musik ein gut Teil dazu beigetragen zu haben, Goethe nach längerem Schwanken, in dem er bald dem Sprachgefühl bald den Forderungen der „Grammatiker", d. h. hier der gelehrten Metriker folgte, die Augen zu öffnen. ${ }^{1}$ ) Auch zwei Zahme Xenien richten sich an die Adresse von Voß und Wolf:

I. 3. 320. v. I257:

Noch bin ich gleich won euch entfernt Hass' euch Cyklopen und Sylbentresser!

Ich habe nichts von euch gelernt,

Ihr wusstet's immer besser.

I. 3. 338. v. 1447 :

Allerlieblichste Trochäen

Aus der Zeile zu vertreiben,

I) Vgl. zur ganzen Hexameterfrage auch Biedermann: Goetheforschungen $4 \mathrm{II}$; Neue Folge 358 . 


\section{Und schwerfälligste Spondeen}

An die Stelle zu verleiben,

Bis zuletzt ein Vers entsteht

Wird mich immerfort verdriessen.

Lass die Reime lieblich fiessen,

Lass mich des Gesangs geniessen

Und des Blicks, der mich versteht.

(1827/30.)

Nach diesen schlechten Erfahrungen mit metrischen Theorien, nachdem er sehen mußte, daß sowohl Moritz mit seinem Versuche, ,durch Schaffung geistiger Längen und Kürzen die antike Metrik aufs Deutsche zu übertragen“"1), als auch Voß und seine Schule die Verwirrung nur vergrößert hatten, ließ er sich in seinen älteren Jahren nicht mehr durch Regeln und Vorschriften irren und folgte allein seinem Gefühl für Rhythmus. Wenn er auch den Theorien ihren „bessernden Einfluß auf die poetische Form" zugestand und „die Gewalt der Form" anerkannte, so ,, lehnte er sich doch gegen jede Gesetzgebung auf und war bereit, jeden Verstoß gegen die bisher heiligen poetischen Regeln zu billigen, wenn ein dichterisches Genie ihn aus innerem Bedürfnis begehen mußte".9) Er huldigte dem Gefühl des echten Dichters, daß das poetische Werk ohne verstandesgemäßc Arbeit aus dem Inneren schallen müsse. Das Metrum muß ,,magisch" mit dem ganzen Gedicht entstehen. Schon 1797 schreibt er: IV. I2. 143: Es ist wirklich beinahe magisch dass etreas, was in dem einen Sylbenmasse noch ganz gut und charakleristisch ist, in einem andern leer und unerträglich erscheint. (6. VI. 1797 an Meyer.) Von ihm gilt, was er seinen Wilhelm Meister sagen läßt: „Mir ist zwar von der Natur eine glückliche Stimme versagt, aber innerlich scheint mir oft ein geheimer Genius etwas Rhythmisches cinzuflustern, so daß ich mich beim Wandern jedesmal im Takt bewege und zugleich leise Töne zu vernehmen glaube,

1) Grimm, H.: Vorlesungen über Groethe II, 129.

2) Bode: Foethes Ästhetik \$. 195. 206. 
wodurch dann irgend ein Lied begleitet wird, das ich mir auf die eine oder andere Weise vergegenwärtige."1) „Wir sprachen über Rhythmus", berichtet Eckermann G. VII. 56, ,im allgemeinen und kamen darin überein, daß sich über solche Dinge nicht denken lasse. Der Takt, sagte Goethe, kommt aus der poetischen Stimmung wie unberusst. Wollte man darüber denken, wenn man ein Gedicht macht, man würde verrückt und brächte nichts Gescheidtes zu stande" (6. IV. 1829). Noch 183 I spricht er sich bei der Lektüre von Voß' Luise gegen die übertrieben strengen metrischen Forderungen aus. G. VIII. 36: Überhaupt geht jetzt alles aufs Technische aus, und die Herren Kritiker fangen an zu quängeln, ob in einem Reim ein $s$ auch wieder auf ein s komme, und nicht ein $\beta$ auf ein s. Wäre $i c h$ noch jung und verwegen genug, so würde ich absichtlich gegen alle solche technische Grillen verstoßen und würde Alliterationen, Assonanzen und falsche Reime, alles gebrauchen, wie es mir käme und bequem wäre; aber ich würde auf die Hauptsache losgehen und so gute Dinge zu sagen suchen, dass jeder gereizt werden sollte, es zu lesen und auswendig zu lernen. (9. II. I83 I zu Eckermann.) Biedermann, der nachweisen will, daß Goethe dem Versbau die größte Wichtigkeit beigelegt und ihn von eingehender Bedeutung für die Dichtung gehalten habe ${ }^{2}$ ), sucht diese unbequeme Stelle abzuschwächen als ,,im scherzhaften Mutwillen geredet". Seine Beweisgründe scheinen uns aber wenig stichhaltig. Wenn ja freilich nicht abzuleugnen ist, daß er metrischen Fragen Aufmerksamkeit schenkte, so ,huldigte er, um mit $\mathrm{Harnack}^{3}$ ) zu reden, doch keiner strengen Technik in dieser Hinsicht. Wie seine eigenen Hexameter große Freiheit im Rhythmus, seine Reimgedichte äußerst of t unreine Reime zeigen ${ }^{4}$ ), so stand er auch den Bestrebungen

I) Geiger a. a. O. S. 7I.

2) Biedermann: Goetheforsch. Neue Folge 361. 377.

3) Harnack a. a. O. 219.

4) Nach Biedermann Goetheforsch. I, 4 I I sind unreine Reime freilich der deutschen Sprache gemäß. 
anderer, hierin strengere Regeln einzuführen, feindlich gegenüber." Der gleichen Anschauung ist Ludw. Geiger ${ }^{1}$ ): „Das Große an ihm ist weder die Geschicklichkeit der Versbehandlung, noch die Verschiedenheit der Reime, vielmehr sind letztere gelegentlich unrein; in Gesetzmäßigkeit des Silbenmaßes, in Verschiedenartigkeit des Strophenbaus, in kunstvoller Behandlung ausländischer Metren sind ihm Zeitgenossen und Nachfolger überlegen." Und eben weil er den technischen Fragen der Metrik, Rhythmik und Prosodie so wenig Gewicht beilegte, hat er sich auch so verhältnismäßig selten zu ihnen geäußert. ${ }^{2}$ ) Die äußere Form ist für Goethe auch auf metrischem Gebiet nur das Gefäß, in das jeder von Gehalt hineinlegen kann, was er vermag. (22. VI. 1808 an Zelter s. o.) Vgl. auch den schon im I. Kapitel (S. 20) gegebenen Beleg, der von prosodisch untadelhaften doch nonsensikalischen Versen spricht.

Wäre Goethe nicht Leiter des Weimarer Theaters gewesen, und hätte er sich als solcher nicht eingehend mit der Ausbildung seiner Schauspieler beschäftigt, so wäre wohl kaum eine Äußerung über Phonetik zu verzeichnen. Denn die vereinzelten Aussprüche, die sich nachweisen lassen, hängen mit den praktischen Zwecken der Bühne zusammen. Einmal nur scheint sich ein Gespräch mit der Entstehung der Sprachlaute befaßt zu haben. Die Tagebücher verzeichnen III. 5.98. I : Riemer. Entstehung der Vokale und Consonanten (25. II. I8I4). So haben auch die I803 erlassenen "Regeln für Schauspieler" nur praktischen, nicht wissenschaftlichen Wert. Wir lassen

1) Geiger a. a. O. S. 70 .

2) Nachträglich finde ich bei Bode, Gocthes Gedanken II, 177, eine Auslassung gegen den jumbischen SechsfuB. Man wird sich in Deutsch. land schwerlich dariber [Vers der Tragödic] vereinigen. Jeder machts, wie er cben will und wie es dem Gegenstande cinigermassen gemäss ist. Der sechsfïssige Jambus wäre freilich am wïrdigsten, allein er ist foir uns Deutsche su lang; wir sind wegen der mangelnden Beiwortcr greaühnlich schon mit fïnf Fïssen fertig. Die Engländer reichen wegen ihrer viclen einsilbigen Worter noch weniger. (21. X. $1823 \%$ Fickermann.) 
sie - auch die nicht rein phonetischen - im Auszuge folgen. I. 40. I $39 \mathrm{ff.}$ : I . . Kein Provinzialismus taugt auf die Bühne! Dort herrsche nur die reine deutsche Mundart . . . 2. lieber übertriebenes Hochdeutsch in der Bühnenaussprache als Mundart. 3. reine und vollständige Aussprache jeden einzelnen Wortes. 4. Kein Buchstabe ist zu unterdrücken. 5. Der Zuschauer muß den Sinn jedes Wortes leicht erfassen. 6. Falsche Aussprache stört oft den Sinn einer ganzen Stelle. 7. folgen $d$ e $m$ nicht folgend'm. 8. leben nicht lewen. 9. ebenso sind $\mathrm{p}$ und $\mathrm{b}$, $\mathrm{t}$ und $\mathrm{d}$ scharf, lieber zu scharf, zu unterscheiden als zu vermengen. IO. deutliche Pause zwischen gleichlautenden Konsonanten zweier Worter blühend/den. II. Alle Endsilben und Endbuchstaben sind deutlich auszusprechen, besonders $\mathrm{m}, \mathrm{n}, \mathrm{s}$, weil diese Buchstaben die Endungen bezeichnen, welche das Hauptwort regieren. I2. Hauptwörter, Eigennamen und Bindewörter rein und deutlich aussprechen. 13. Auf die Eigennamen muss im Allgemeinen ein stärkerer Ausdruck in der Aussprache gelegt werden als gewöhnlich, weil so ein Name dem Zuhörer besonders auffallen soll . . . I4. Der Anfänger soll langsam sprechen. (Es folgen weitere Vorschriften über Rezitation und Deklamation) (1803). Mit Ausnahme des oben im Anfang von Kapitel 8 erwähnten und deshalb hier gestrichenen Zusatzes zu $\S$ I über die obersächsische Mundart dürfte noch heute jeder Bühnenleiter, namentlich in Mitteldeutschland, diese Anweisungen gutheißen, nicht aber einige Vorschriften über Aussprache einzelner Worte. So fordert er (I. 40. 425), daß blutiger $=$ blutger, boten $=$ botn, freut $=$ freuit gesprochen, da $\beta$ zwischen das und $d a \beta$ unterschieden und sogar da $\beta$ eu in griechischen Eigennamen mit ei (also Eimenide) wiedergegeben werde. Nur seine eigne Aussprache, nicht aber wissenschaftliche Gründe können ihn zur Aufstellung solcher Regeln, die übrigens nicht von ihm veröffentlicht, sondern nur zum Unterricht zweier jungen Schauspieler niedergeschrieben wurden, veranlaßt haben. Dazu will schlecht stimmen, daß wie oben so auch anderwärts 
mundartliche Aussprache verdammt wird. G. I. 219: „Besonders warnte er vor allem Dialekt (in der Bühnensprache), wobei er die dem Sachsen eigene offene Aussprache des e, wie geben, leben (in Sachsen oft wie gäben, läben) als ihm besonders gehässig bezeichnete". (1801 zu Heinr. Schmidt.)

Ebensowenig kann, wie auch Bouke bemerkt, der kleine Aufsatz „Hör-, Schreib- und Druckfehler" als Phonetik in wissenschaftlichem Sinn Anspruch machen. Es sind gelegentliche Beobachtungen, die er im Laufe der Zeit namentlich bei der Durchsicht der Diktate und Druckbogen seiner Werke machte. Er gibt lediglich ein Verzeichnis von 30 derartigen Fehlern, deren Entstehung er z. T. auf Mißverständnis durch ungebildete Schreiber und undeutliche Aussprache des Diktierenden, z. T. auf Assimilation des Fremdartigen an Bekanntes, z. T. endlich auf Nachlässigkeit der Druckereien zurückführt. Der Grund zur Veröffentlichung der eigenartigen Sammlung ist auch nur der, die Druckereien dadurch zu größerer Aufmerksamkeit zu zwingen. Wir haben es also mehr mit einer Auslassung pro domo des in den Forderungen an die Drucklegung seiner Werke peinlich genauen Dichters zu tun als um ein Kapitel zur Phonetik. Einige Beispiele: I. 4II. I83 Hörfehler: anstatt beritten lies Pyriten, Residenz lies Evidenz, sehr dum lies Irrthum. Druck-und Schreibfehler aus Unachtsamkeit: geschlungenen - geschwoungenen; Unform - Uniform; Furchtbarkeit - Fruchtbarkeit. ... Verwandlung französischer Worte im Ohr und Sinn der deutschen Menge: Rückruthen - Recruten, Inspectrum - Inspector; Verwandlung eines deutschen Worts durch französische akademische Fugend: Verjus - Verruf $\left.(V \operatorname{crschi} \beta)^{1}\right)$ (K. u. A. II. 2. 1820). 1824 crwähnt Goethe außerdem den scherzhaften Hörfehler die "Seepost" für „dieses Epos". (I. 4II. 479.)

Gelegentlich werden der akademische Vortrag und Aussprachfehler mit Bemerkungen bedacht. III. 5. 233. 25: Es ward

1) Im nächsten Heft von K. u. A. will übrigens umgekchrt ein Einsender das deutsche Wort als Fintlehnung aus dem Französischen erkliiren! 
über academischen Vortrag, deutliche Rede, Kraft der Stimme usw. gesprochen (23. V. 1816). Hempel 19. 54: Die Verwechslung eines Konsonanten mit dem andern möchte wol aus Unfähigkeit des Organs, die Verwandlung der Vokale in Diphthongen aus einem eingebildeten Pathos entstehen. (Sprüche in Prosa. 1823.)

Ein längeres Gespräch über Aussprache, das sich vielfach an die Schauspielerregeln anschließt, berichtet Eckermann aus dem Jahre I824:

G. V.76: Die Aussprache der Norddeutschen (von Goethe unterrichteten Schauspieler) liess im ganzen wenig zu wünschen übrig; sie ist rein und kann in mancher Hinsicht als musterhaft gelten. Dagegen habe ich mit geborenen Schwaben, Öster. reichern und Sachsen oft meine Not gehabt. Auch Eingeborene unserer lieben Stadt Weimar haben mir viel zu schaffen gemacht. Bei diesen entstehen die lächerlichsten Missgriffe daraus, dass sie in den hiesigen Schulen nicht angehalten werden, das $B$ vom $P$ und das $D$ vom $T$ durch eine markirte Aussprache stark zu unterscheiden. Man sollte kaum glauben, da $\beta$ sie $B_{\text {, }}$ $P, D$ und $T$ überhaupt für vier verschiedene Buchstaben halten, denn sie sprechen nur immer von einem weichen und einem harten $B$ und von einem weichen und einem harten $D$ und scheinen dadurch stillschweigend anzudeuten, dass $P$ und $T$ gar nicht existiren. Aus einem solchen Munde klingt denn Pein wie Bein, Paß wie Baß und Teckel wie Deckel . . . Gleicherweise . . . wird hier das $\dot{U}$ hä ufig wie I ausgesprochen, wodurch nicht weniger die schändlichsten Missverständnisse veranlasst werden. So habe ich nicht selten statt Küstenbewohner - Kistenbewohner, statt Thürstück - Thierstück, statt gründlich - grindlich, statt Trübe - Triebe und statt Ihr müsst - Ihr misst vernehmen müssen, nicht ohne Anwandlung von einigem Lachen ... So auch ... wird hier das $G$ und $K$ häufig miteinander verwechselt, und statt $G-K$ und statt $K-G$ gesprochen, wahrscheinlich abermals aus der Ungewissheit, ob ein Buchstabe weich oder hart sei, eine Folge der hier so beliebten Lehre. Sie werden im hiesigen Theater wahrscheinlich sehr oft Kartenhaus für Garten- 
haus, Kasse für Gasse, klauben für glauben, bekränzen für begrenzen, Kunst für Gunst bereits gehört haben oder doch künftig hören... Dergleichen Verwechslungen von $G, K$. . hören wir übrigens nicht blos von Schauspielern sondern wohl auch von sehrgelehrten Theologen... (Es folgt die bekannte Erzählung von dem stud. theol., der zum Archidiakonus Koethe wollte und zu Goethe kam) (5. V. I824). Besonders tiefgehend sind diese Beobachtungen freilich nicht. Einer der Schwestern Levetzow wird IV. 37. 2 I4. 7 der Rat erteilt: möge sie beym Vorlesen... den Perioden, wo es sich schickt, tief anfangen, um hernach den Ausdruck in die Höhe steigern zu können. (9. IX. I823 an Car. v. Levetzow.)

Eine letzte hierher gehörige Äußerung ist eine der letzten Goethes überhaupt. Als ihm Freund Zelter Anfang Mărrz I832 eine Reihe seiner Unterrichtsmaximen für seine Musikschüler mitteilte, die auf wirklich wissenschaftlicher Grundlage beruhen, und also auch Goethes Interesse für reine Akustik und Phonetik voraussetzen, antwortet dieser (Zelter VI. 420): Nun bitte ich aber fahre fort wie $D u$ in Deinem letaten Briefe gethan, die alten ewigen Naturmaximen, wornach der Mensch dem Menschen durch die Sprache verständlich wird, aphoristisch auszusprechen, damit in der Folge auch wohl einmal erfïllt werde was geschrieben steht. Es ist wundersam Engländer, Franzosen, und nun auch Deutsche erfreuen sich unverständlich zu sprechen, so wie auch Andere, das Unverständliche zu hören. Ich wünsche nur, dass manchmal ein Italiener hereinträte und seine emphatische Sprache hören liesse (II. III. I832). Empfänglich bis zum letzten Atemzug für wissenschaftliche Anregungen greift er des Freundes Anregungen auf, „daß die Zunge der Lenker der Rede sey und einen geschickten Steuerer erfordere, daß der Vokal sich zum Consonanten verhalte wie die Glocke zum Klöppel..., da $B$ der innere Bau des menschlichen Mundes der Wissenschaft der Akustik die erste Richtung gebe, daß der Gebrauch des Odems sein Verhältniss zum Periodenbau habe". Ein weiterer Gedankenaustausch, dem der Tod ein Ziel setzte, hätte wohl noch manchen fruchtbaren Gedanken zur Frage gezeitigt. 


\section{DRITTER TEIL}

GOETHE UND DIE FREMDEN SPRACHEN 



\section{ELFTES KAPITEL. \\ GOETHES SPRACHKENNTNISSE.}

Goethe hat, abgesehen von einem mißglückten Versuche während des Umbaues des väterlichen Hauses, keinen öffentlichen, regelmäßigen Schulunterricht genossen, sondern ist vom Vater und Privatlehrern für die Hochschule vorgebildet worden. Rat Goethe legte den Schwerpunkt dieser Erziehung in die Erlernung fremder Sprachen. Lateinisch, Französisch, Italienisch, Englisch, Griechisch und Hebräisch wurden dem Jungen nahegebracht und ihm so frühzeitig eine reiche Sprachkenntnis vermittelt, die ihm später die größten Vorteile bieten sollte. Er berichtet selbst: II. 6. 98. I2: In einer ansehnlichen Stadt geboren und erzogen gewann ich meine erste Bildung in der Bemühung um alte und neue Sprachen, woran sich früh rhetorische und poetische Übungen anschlossen (Zur Morphol. I). „Ist er später, so urteilt Morsch ${ }^{1}$ ), für die Deutschen ein Vermittler und Wiedererwecker alter wie neuer Literaturen geworden, ist er als Dichter ebenso sehr durch die neuere Literatur wie durch die antike beeinflußt, so ist dies nur möglich durch jene mannigfachen Sprachkenntnisse, welche er bis zu einem gewissen Grade sich schon als Knabe erwarb." Die Unterrichtsmethode legte keinen Wert auf die Erlernung der Grammatik, sondern nur auf den Gebrauch der Sprache als Verständigungsmittel. Goethe bestätigt das selbst: I. 27. 408: So hatte ich denn das Lateinische gelernt wie das Deutsche, das Französische, das Englische nur aus dem Gebrauch, ohne Regel und ohne Begriff. Wer den damaligen Zustand des Schulunterrichts kennt, wird nicht seltsam finden, dass ich die Grammatik übersprang, sowie die Redekunst; mir schien alles natürlich $z u$ zugehen, ich behielt die Worte, ihre Bildungen und Umbildungen

I) Morsch, H.: Goethe und die griechischen Bühnendichter. Progr. d. Kgl. Realschule zu Berlin. I888. S. 3 . 
in Ohr und Sinn und bediente mich der Sprache mit Leichtigkeit zum Schreiben und Schwätzen. (D. W.6. I811.) Die oben (Kap. 7 S. IOO) zitierte Klage über die vielen zu lernenden Regeln und Ausnahmen ist also übertrieben. Das Lernen fremder Sprachen ohne Grammatik war schon von den Philanthropen und Neuhumanisten und dann von Herder und Wolf vertreten worden. Mit den Regeln anzufangen, nannte der letztere eine "lumpige Methode“. ${ }^{1}$ )

Bekannt ist ja, daß der junge Goethe, und auch das ergibt sich aus der Ablehnung des grammatischen Verfahrens, einen Roman schreiben wollte, in dem sechs Brüder sich in sechs Sprachen brieflich unterhalten, gewiß ein Beweis der früh erworbenen Sprachfertigkeit. I. 26. 195. I I: In Gefolg diesem (englischen Sprachkurse) hegte mein Vater eine neue Sorgfalt, dass auch das Englische hübsch in der Reihe der übrigen Sprachbeschäftigungen bliebe. Nun bekenne ich, dass es mir immer lästiger wurde, bald aus dieser bald aus jener Grammatik oder Beispielsammlung, bald aus diesem oder jenem Autor den Anlass zu meinen Arbeiten zu nehmen... Ich kam daher auf den Ge. danken alles mit einmal abzuthun und ich erfand einen Roman von sechs bis sieben Geschwistern, die. . . sich wechselseitig Nachricht von ihren Zuständen und Empfindungen mitteilen. (I. Bruder Deutsch, ebenso eine Schwester, aber Romanstil, 2. Bruder als Theolog Lateinisch und Griechisch; 3. Bruder als Kaufmann Englisch; 4. Bruder in Marseille Französisch; 5. Bruder, Musiker, Italienisch; 6. Bruder Judendeutsch). (D. W. 4. I8II.) Seine geringe Hochachtung vor der Grammatik in späteren Jahren mag mit seinc Ursache in dieser Art Unterricht haben. Auch dic Ausbildung ciner Gcheinsprache, in der er sich nach dem Bericht von D. u. W. mit der Schwester verständigte, sei hier erwähnt, wenn sie auch nicht höher als die in Jugendkreisen auch heute allgemein beliebte Spiclerei zu werten ist. Da dic Geschwister es zur

1) Vg\}. Zeitschr. f. franz. u. engl. Unterricht VIII. (1909.) S. 117. 
Fertigkeit in ihr gebracht zu haben scheinen, so zeugt auch das immerhin von Begabung für sprachliche Dinge. ${ }^{1}$ ?

Daß der nach Leipzig ziehende Student die im Vaterhause betriebenen Fremdsprachen völlig beherrschte, ist kaum anzunehmen; die Grundlagen waren aber solche, daß er auf ihnen ohne große Schwierigkeiten weiter bauen konnte; Werke in französischer, lateinischer und italienischer Sprache lesen und auch mündlich und schriftlich wenigstens dieser drei Sprachen zu Unterhaltung und Briefwechsel sich bedienen konnte.

Seine griechischen Kenntnisse waren offenbar bei der Ankunft in Leipzig nicht bedeutend, die Aussprache machte ihm nach seinem eignen Geständnis dort Schwierigkeit. I. 27. 379 (Lesart): I. Sprache Deutsch Dialeckt. Griechische Aussprache. 2. Griechische Sprache Verwirrung wegen der Aussprache. Bekanntschaft mit einem Neugriechen. Annahme des neuen Dialects. Umlernen der Worte, die man sich anders eingeprägt. Verwirrung und Unmut deshalb. Zweytes Hinderniss. Widerstreit der Quantität und der Accente. 3. Hinderniss an Erlernung des Griechischen. Widerstreit der Aussprache. Widerstreit der Quantität und Accente (D. W. Schemata zu Buch 6. 1811). - I. 27. 382: Er (Horn) war kein sonderlicher Grieche, ich auch nicht (Fragment zu D. W. 6). Dagegen scheint ihm das Lateinische in Schrift und Wort geläufig gewesen zu sein. Von der Abfassung seiner Dissertation berichtet er: I. 28. 42. 22: Da ich diese Arbeit ganz aus mir selbst schöpfte und das Latein geläufig sprach und schrieb, so verfloss mir die Zeit, die ich auf die Abhandlung verwendete, sehr angenehm (D. W. 11. 1813). Einem Zeugnis aus späteren Jahren nach war er im Gebrauch der Sprache nicht mehr so fest. G. X. 76 : „Goethe hört ihn (Gmelin, der in lateinischer Sprache eine Muschel erklärte) behaglich an ... deutete auf eine andere Muschel und pries deren noch anschaulichere Ähnlichkeiten

I) Kluge, Fr.: Unser Deutsch. S. 88. 
ebenfalls lateinisch, mit heiterer Emphase, wobei er freilich hin und wieder den rechten Ausdruck erst suchen mußte (4. X. I8I5 v. Biedenfeld). - In Weimar werden die griechischen Sprachstudien wieder aufgenommen. IV. 9. 16I. I: Das Griechische wird eifrig getrieben und ich habe gute Hoffnung. (5. XI. I789 an Karl August.) Aus dieser Zeit, nach Suphans Datierung I787, stammt auch ein jetzt I. 42 II. 8 ff. (früher Goethe-Jahrbuch I90I) veröffentlichter „Versuch, eine homerische dunkle Stelle zu erklären". Da die Handschrift eigen. händig ist, ist Mitwirkung eines Philologen nicht anzunehmen. Die Stelle, Odyss. K 8I, wird von Goethe im Gegensatz zu

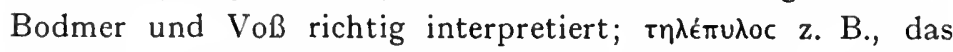
der erstere mit ,türmend“, Voß gar als Nom. propr. wiedergab, wird von Goethe mit ,Stadt mit doppelten, von einander abstehenden Toren" übersetzt. Die Bekanntschaft mit Fr. A. Wolf, den beiden Voß, Riemer und anderen Philologen erhielt das Interesse für und die Beschäftigung mit den altklassischen Sprachen bei Goethe sein ganzes Leben hindurch wach. ${ }^{1}$ )

Die abendlichen Unterhaltungen mit Riemer haben sehr oft die griechische Grammatik und Etymologie zum Gegenstand, wobei freilich zu berücksichtigen ist, daß der Professor diese Gebiete als Spezialfächer bearbeitete. III. 4. 65. 6: Abends griechische Etymologie bey Gelegenheit des kleinen griechischen Wörterbuchs von Niz (25. IX. 1809). - 104: bey Tisch griechische Stammzeörter und abgeleitete (24. III. 1810); III. 7. I35. 17: [Riemer] erklärte seine Tabelle der uranfänglichen Bildung griechischer Worte (7. II. 1820); III. 8. I70. 8: [R.] Griechische Wortformen und deren Ableitung (23. II. I822); - 177. I5: Nach Tische Prołessor Riemer, wurden Graeca besprochen (20. III. 1822); - I78. 18: Griechisch und Lateinisch, Etymologie und Styl durchgesprochen (22. III. 1822); III.9. 26.13:

1) IV. 19. 53.9: können Sic mir die neulich ervuähnte griechische Grammatit mit schicken, so geschicht mir cin besonderer Gefallen. (30. VIII. $180 ;$ an $1 * \Lambda$. Wolf.) 
Umständliche Unterhaltung [mit Fromann] über Riemers griechisches Lexikon (2 I. III. I823); - 38. 23: [R.] über griechische Sprachbildung und Etymologie gehandelt (I7. IV. I823); Ähnliche Bemerkungen auch III. 6. 22I. 4 (23. VI. I8I8); III. 8. 70. I3 (20. VI. I 82 I); III. 9. 53. I (23. VI. I823). I8I3 beschäftigt die beiden längere Zeit Ernestis Lexicon technologiae Graecorum rhetoricae (III. 5. 30-53; III. 5. 279), 1826 der Thesaurus Graecae linguae ab H. Stephano constructus (III. IO. I58 f. und nochmals I83 I: III. I 3. I45).

Verschiedene Auslassungen und Zeugnisse beweisen, daß er es im Griechischen nicht zur Meisterschaft gebracht hatte: Ein im Nachlaß vorgefundenes Bruchstück zu einer Rezension fordert in längerer Ausführung, griechische Zitate mit deutscher Übersetzung zu geben. I. 42II. 477. I6: Bedenke man doch, dass man von einem Studierenden, der sein summus Aristoteles, Plato et Euripides im Liede feyert, nicht erwarten darf, dass er den Sinn, den sie in ihre Sprache gelegt, sogleich entziffern werde, und hätte er auch mit Nutzen seine Schulstudien vollendet. Noch viel weniger kann man dies von einem Laien, von einem andern erwarten, dessen Thun und Treiben aufs Practische gerichtet seyn mu $\beta$. Im weiteren wird von den, verschleyerten Geheimnissen" der griechischen Sprache und von ihr als ,einem weniger bekannten Idiom" gesprochen (1827-28).

I 822 bedankt Goethe sich für eine Übersetzung des Sophokleischen Philoktet mit den Worten IV. 36. 24. 20: Nun aber lässt mich Ihre Vermittlung ihn [S.] auf einmal wieder in vaterländischer Sprache, ohne Ansto $\beta$, fasslich und geniessbar vernehmen. (20. IV. I 822 an A. O. Gersdorff.)

Voß, der Jüngere, der mit Goethe I807 Sophokles liest, bekundet: „Goethe eröffnet mir den wahren Sinn für klassische Literatur immer mehr, obgleich er selbst nur ein sehr dürftiger Philolog ist und kaum den Sophokles im Original lesen kann." Er übersetzt ihm die schönsten Chöre der Antigone, und Goethe liest das griechische Original nach. $\left.{ }^{1}\right)$ Dem-

I) Gräf a. a. O. 4 I u. 5 I.

Rausch, Goethe u. die deutsche Sprache. 
ohngeachtet gehört aber Sophokles mit Homer und Horaz zu seiner Lieblingslektüre; den Lukrezstudien Knebels bringt er jederzeit sprachliches Verständnis entgegen. Zahlreiche Zitate vieler lateinischer Schriftsteller aller Zeiten beweisen seine Vertrautheit mit ihrer Sprache.

Das $\mathrm{He} \mathrm{brä} \mathrm{is} \mathrm{ch} \mathrm{e} \mathrm{lernte} \mathrm{der} \mathrm{junge} \mathrm{Goethe,} \mathrm{nachdem}$ der Vater das im Briefroman zutage getretene Interesse für das Judendeutsch ${ }^{1}$ ) beobachtet hatte, bei dem Rektor des Frankfurter Gymnasiums Albrecht. Von späterer Beschäftigung mit der Sprache zeugen nur zwei Tagebuchnotizen von I81I: III. 4. 224. 19: Büchelchen des Pater Sacchi über die hebräische Sprache und besonders den Ursprung der Puncte... Über Sprache und was dahin gehört. Kleine Schrift des Sacchi (31. VII.). - 225. 4: hebräische Sprache (2. VIII.). ${ }^{2}$ )

Von modernen Sprachen hat Goethe offenbar das F r a n zösische am besten beherrscht. Der Unterricht durch einen gelegentlich der langen französischen Einquartierung von Rat Goethe angenommenen Sprachmeister sowie der Verkehr mit den französischen Schauspielern in dieser Zeit hat den jungen Goethe sehr in der Sprache gefördert. I. 26. 141. 16: Auch hier kam mir die angeborene Gabe zu statten, daß ich leicht den Schall und Klang einer Sprache, ihre Bewegung, ihren Accent, den Ton und was sonst von äusseren Eigenthümlichkeiten fassen konnte (D. W. 3). Schon von Leipzig aus wechselt er mit der Schwester, mit Gg. Schlosser und anderen lange französische Briefe. Wie ihm in Straßburg scine Vorliebe für die Sprache vergällt wird und eine

1) Auch die vor 1768 entstandene Judenpredigt, dic jetzt allgemein Goethe zugeschrieben wird, ist im Judendeutsch abgefaßt, in dem Goethe übrigens förmlich Unterricht erhiclt. Vgl. Heinemann XXI, 75. Aus dem Nachla ist der Ausspruch bekannt geworden: I, 42II. 523. 15: Judensprache hat etwas Pathetisches, wodurch die bis ins Alter wach geblicbene Vorliebe belegt wird.

2) Nach Ausweis der Weimarer Ausgabe handelt es sich um Giovenale Sacchi: Dell' antica lezione degli Ebrei 1776. 
bewußte Abkehr zum Deutschen stattfindet, schildert er selbst I. 28. 50. 54: Die französische Sprache war mir von Fugend auf lieb; ich hatte sie in einem bewegten Leben und ein bewegtes Leben durch sie kennen gelernt. Sie war mir ohne Grammatik. und Unterricht, durch Umgang und Übung wie eine zweite Muttersprache zu eigen geworden. Nun wünschte ich mich derselben mit größerer Leichtigkeit zu bedienen und zog deswegen Straßburg... anderen hohen Schulen vor; aber leider sollte ich dort gerade das Umgekehrte von meinen Hoffnungen erfahren und von dieser Sprache, diesen Sitten eher ab-als ihnen zugewendet werden. - Die Franzosen . . sind gegen Fremde, die ihre Sprache zu reden anfangen, nachsichtig, sie werden niemanden über irgend einen Fehler auslachen, oder ihn deshalb ohne Umschweif tadeln. Da sie jedoch nicht wohl ertragen mögen, dass in ihrer Sprache gesündigt wird, so haben sie die Art, eben dasselbe, was man gesagt hat, mit einer anderen Wendung zu wiederholen und gleichsam höflich zu bekräftigen, sich dabei aber des eigentlichen Ausdrucks, den man hätte gebrauchen sollen, zu bedienen und auf diese Weise den Verständigen und Aufmerksamen auf das Rechte und Gehörige zu führen. Diese vielen Korrekturen und Ausstellungen und die gewonnene Überzeugung, daß ein Ausländer es überhaupt zu keiner Vollendung bringen könne, ließen ihn an einem Erfolg seiner Bemühungen verzweifeln, besonders weil mein Französisch viel buntscheckiger war, als das irgend eines anderen Fremden. Von Bedienten, Kammerdienern, Schildwachen, jungen und alten Schauspielern, theatralischen Liebhabern, Bauern und Helden, hatte ich mir die Redensarten sowie die Accentuationen gemerkt, und dieses babylonische Idiom sollte sich durch ein wunderliches Ingrediens noch mehr verwirren, indem ich den französischen reformierten Geistlichen gern zuhörte. Dazu kam die Lektüre von Montaigne, Amyot, Rabelais, Marot . . . Alle diese verschiedenen Elemente bewegten sich nun in meiner Rede chaotisch durcheinander, so . . . dass ein gebildeter Franzose mich nicht mehr höflich zurechtweisen sondern geradezu 
tadeln und schulmeistern musste. ...Wir fassen daher den Entschluß, die französische Sprache gänzlich abzulehnen und uns mehr als bisher der Muttersprache zu widmen. Auch hiezu fanden wir im Leben Gelegenheit und Teilnahme. Elsass war noch nicht lange genug mit Frankreich verbunden, als dass nicht noch bei alt und jung eine liebevolle Anhänglichkeit an alte... . Sprache sollte ïbrig geblieben sein. (D. W. 11. 1813.) Es ist also nicht in erster Linie der nationale Standpunkt, der die Abwendung bedingt; er hat zweifelsohne bei Goethe und mehr noch bei seinen Tischgenossen mitgewirkt, aber ausschlaggebend waren die geschilderten Schwierigkeiten. Sie hielt übrigens bei Goethes universaler Geistesrichtung nicht vor. Französische Briefc und Lektüre französischer Werke sind in allen Lebenszeiten nachzuweisen. Nur nach der Rückkehr von Straßburg blieb er bei seinen Grundsätzen. I. 28. 94. 19: Er [Gg. Schlosser] schrieb, wie vormals, gern in allen Sprachen, regte mich aber dadurch nicht weiter an, da ich, mich dem Deutschen ausschliesslich widmend, die übrigen nur insoweit kultivierte, dass ich die besten Autoren im Original einigermassen zu lesen imstande war (D. W. 12. 1813). - Aus dem Jahre I 8 I I verzeichnen die Tagebücher ein Gespräch mit dem Sohne über französische Sprache (III. 4. 193. I9 v. 25. III. I8II), und im gleichen Jahre gesteht er das Verkehrte der Abkehr ein: IV. 22. 186. 8: Das Französische soll nach Ihrer Aufmunterung lebhafter betrieben werden. Meine Fugendgeschichte seugt freilich gegen mich, und ich gestehe, dass ich es in dieser Sprache hätte weiter bringen sollen. (26. X. I8I I an F. v. Rcinhard.) 1817 treibt er altfranzösische Studien an der Hand von Raynouards Eléments de la Grammaire de la lange Romane avant l'an 1000 (III. 6. 4 I und 17. 9; April 1817, März 18I8, sowic I. 36. 129. 14, Annalen 1817) - 1818 wird eine Unterhaltung mit dem Franzosen Lavés über seine Muttersprache erwähnt (III. 6.172. 8. V. 15. II. I 818), und I 827 endlich hat der Vater mit dem Sohnc ein angenchmes Gespräch über dessen Art, das I'ranzősische zu betreiben (III. II. 156. 19. v. 31. XII. 
1827). Französische Briefe sind bis in die letzten Jahre geschrieben worden, so auch z. B. I829 zwei an Italiener (IV. 46. $33-36)$, woraus doch wohl geschlossen werden darf, daß ihm in alten Tagen das Französische geläufiger war als das Italienische. Andererseits bittet Goethe Anfangs 1830 den französischen Bildhauer David um Entschuldigung wegen des Gebrauchs der Muttersprache: da ich mich in der Ihrigen nicht so bequem auszudrücken fähig bin (IV. 46. 26I. 14), und dem Grafen Reinhard gegenüber entschuldigt er in den gleichen Tagen Briefschulden mit den Worten: und dann kam noch die Forderung der französischen Sprache hinzu, vor der ich, wenn vom Schreiben die Rede ist, immer zurückweiche (IV. 46. 269. 14). Und endlich in einem Briefkonzept an die Vikomtesse de Ségur vom 28. XII. 1829 heißt es vom Französischen ausgehend und mit Bezug auf die übrigen Fremdsprachen: Gegenwärtiges ist geschrieben in der Sprache, in der ich allein tähig bin meine eigenen Empfindungen und Gedanken mitzutheilen, der fremden Idiome mehr oder weniger mächtig, vermag ich doch nichts als das Gesagte zu sagen, will ich auf meine eigne Weise reden, so erscheint oft das Beste und Einzigste, was man mittheilen möchte, als Soloecism (IV. 46. 37I. 10). Mit Besuchern aus Frankreich unterhielt sich der alte Goethe noch gern in deren Sprache (G. IV. 29I vom I4. X. 1823). Über seine Fertigkeit darin haben wir zwei übereinstimmende Zeugnisse aus dem Jahre 1827 von Eckermann und Antoine Ampère, zwei noch günstigere von Andr. Kózmian aus I829 und 1830 . G. VI. 36: Da Herrn Soret, als einem geborenen Genfer, das Deutsche nicht ganz geläufig war, Goethe aber im Französischen sich ziemlich bequem ausdrückte, so ging die Unterhaltung französisch und nur an solchen Stellen deutsch, wo ich mich in das Gespräch mischte. (29. I. I 827 Eckermann.) - G. VI. I 17: Goethe parle français avec un peu de difficulté mais cependant avec correction; on ne s'aperçait de cette difficulté que par intervalle qu'il met entre chaque mot. (April 
-Mai I827. A. Ampère.) - G. X. I76: Er sprach gut, doch drückte er sich langsam aus. (2. X. I829 A. Kózmian.) G. VII. 225: . . erwiderte Goethe auch in französischer Sprache, die er mit Leichtigkeit handhabte. (Februar I830 derselbe.) Mit Ampères Zeugnis deckt sich das von Soret, der als Franzose und mehrjähriger täglicher Gast Goethes wohl in erster Linie zu hören ist: Burkhardt 3. 21 : Er spricht das Französische ziemlich rein, obwohl nicht ohne Schwierigkeiten. Er sucht und wählt seine Ausdrücke; man sieht, wie er Fehler zu vermeiden strebt. Er braucht unverhofft eine deutsche Wendung, spricht dann aber um so fließender, lebhaft und feurig (24. IX. I832). Lefèbres Lob aus dem Jahre I 8 I I ,sa conversation riche et abondante, son expression toujours pittoresque" teilt Goethe selbst am 26. X. I8I I Reinhard mit. Die meisterhaften Übersetzungen Goethes aus dem Französischen beweisen am besten, wie weit er in die Kenntnis der Sprache eingedrungen war.

Bei weitem nicht so reich war Goethes Kenntnis der e $\mathrm{n} g$ lis ch en Sprache. Schon der Umstand, daß der alte Rat mit seinem Sohne gemeinschaftlich englischen Sprachunterricht nahm, wird den Erfolg ungünstig beeinflußt haben. Goethe schreibt zwar von Leipzig auch englische Briefe, worüber er sich selbst ein günstiges Zeugnis ausstellt:

I. 27. 2 10. 10: Sonst konnte ich auch bemerken, dass die französischen und englischen Stellen meiner Briefe, obgleich nicht fehlerlos, doch mit Leichtigkeit und Freiheit geschrieben waren. Diese Sprachen hatte ich auch in meiner Korrespondens mit Gg. Schlosser. . . zu ïben fortgefahren. (D. W. 8. I8I r.) Später aber gesteht er selbst dic lückenhafte Kenntnis zu:

I. 36. 187. 3: Lord Byrons Invective gegen die Edinburger ... fing ich an zu übersetzen, doch nöthigte mich die Unkunde der Particularien bald inne zu halten. (Tag. u. Jahreshefte 1821.) Dazu stimmt auch, daß nirgends eine Äußerung über das Englische in späteren Jahren zu belegen ist, obgleich cr, wie wir unten schen werden, den Wert desselben keines- 
wegs verkannte. 1823 veranlaßt er Eckermann, die Sprache noch nachträglich zu lernen (III. 9. I56. 27 vom I9. XII. I823). Daß die Kenntnisse aber völlig hinreichend waren, englische Lektüre mühelos zu pflegen, bezeugen die eingehende Beschäftigung mit den Werken Shakespeares, Scotts, Byrons und anderer englischer Dichter, sowie die engen Beziehungen zu Männern der englischen Wissenschaft.

Wie das Französische dem Dichter am geläufigsten, so war ihm das I t a li e $\mathrm{n}$ is ch e am liebsten. Nach seinem Bericht hat es der Knabe gelegentlich gelernt.

I. 26. 46. 24: Mein Vater lehrte die Schwester in demselben Zimmer Italiänisch, wo ich den Cellarius auswendig zu lernen hatte. Indem ich nun mit meinem Pensum bald fertig war und doch still sitzen sollte, horchte ich über das Buch weg und fasste das Italiänische, das mir als eine lustige Abweichung des Lateinischen auffiel, sehr behende. (D. W. I. I8I I.) Auf der Reise in die Schweiz mit den beiden Stolberg hatte er zum erstenmal Gelegenheit die Sprache anzuwenden.

I. 19. 304. 22: Er [der Pater im Gotthard-Hospiz] sprach nichts als Italiänisch und wir fanden hier Gelegenheit von den Übungen, die wir uns das Frühjahr in dieser Sprache gegeben, Gebrauch zu machen. (Briefe a. d. Schweiz I779.) $\mathrm{Zu}$ den mannigfachen Vorbereitungen für die italienische Reise gehören auch Sprachstudien. Der lange Aufenthalt in Italien selbst wird den Dichter in der Landessprache sehr vervollkommnet haben, wenn auch der Kreis, in dem er verkehrte, zumeist aus deutschen Künstlern bestand, und er Caroline Herder gegenüber behauptet ,er hätte meist Deutsch gesprochen" (G. I. I06; 6. X. 1788). Mit seinem jungen Freunde Fritz v. Stein wechselt Goethe von Rom aus italienische Briefe; auch in späteren Jahren taucht ab und zu ein solcher auf, wie sich aus einzelnen Aufzeichnungen auch ergibt, daß das Interesse für die schöne Sprache zeitlebens rege blieb:

III. 3. 182. 20: Fernow las über den florentinischen und rö. mischen.Dialect (14. XII. I806). - III. 3. I83. 2: Fernow über 
die italiänischen Dialecte (21. XII. 1806). - III. I I. I55. 25: Tabellarische Übersicht der italiänischen Dialecte in ihren Ab. zieichungen von der Büchersprache, durch Professor Wolf (30. XII. 1827). I8I8 werden mit Hofrat Rehbein italienische Eigennamen behandelt (III. 6. 237. I vom I8. VIII. I818) und I 828 ein altes italienisches Wörterbuch aus dem 17 . Jahrhundert von Kramer „näher betrachtet" (III. I I. 267. 23 vom 23. VIII. I828). Manzonis Werken wird 1827-1828 lebhafte Aufmerksamkeit geschenkt und die davon entstehenden Übersetzungen mit den Originalen unter Riemers Beihilfe verglichen. Die Übersetzung des Benvenuto Cellini, die eingehende Beschäftigung mit italienischer Kunst, der Verkehr mit jtalienischen Kunsthändlern haben ihm die Sprache Italiens allezeit in vertrauter Nähe gehalten, wenn sie ihm auch im Alter zu mündlichem Gebrauch weniger geläufig blieb, wie Alessandro Poerio bezeugt. G. V. 27I: ,Non vuol parlare Italiano, dice: non mi seducete! Ė lungo lempo che non ho parlato questa lingua." (12. II, I826.)

Von anderen nicht in der Jugend erlernten ${ }^{1}$ ) Sprachen scheint Goethe das Spanische und Portugiesische in den Grundzügen beherrscht zu haben, so daß er in diesen Sprachen Geschriebenes sich mit Hilfsmitteln zur Not verdeutschen konnte. IV. 18.7. I: Soeben zeigt sich mir eine wunderbare Er. scheinung: ein neues spanisches Stück, das wir vielleicht auf unserm Theater sehen können. Ich bitle um das spanische Wörterbuch um die Übersetzung an einigen Stellen beurtheilen au können. (1788/1805 an Knebcl?) Vielleicht hängt damit zusammen, daß er sich, wie Fr. G. Welcker 1805 berichtet (G. VIII. 293), aus spanischen Büchern viele Wörter aufzeichnete. Das Ge. ständnis seiner geringen Sprachkenntnis nötigt ihm neben einem begeisterten Urteil über die Sprache die 1821 von Fr. Ch. Perthes zugestellte Floresta de Rimas antiguas Castellanas ordinada par Don Juan Nicolas Pohl de Faber ab.

1) Vkl. über Goethes Sprachbildung: Lorenz, Die Jugendbildung unserer Klassiker. Pïl. Archiv. Band 49 (1907). Heft 9. S. $515 \mathrm{ff}$. 
1. 36. 194. 5: Eine spanische Blumenlese durch Gefäligkeit des Herrn Perthes erhalten, war mir höchst erfreulich; ich eignete mir daraus zu, was ich vermochte, obgleich meine geringe Sprachkenntnis mich dabei manche Hinderung erfahren liess (Tagu. Jahreshefte I82I). IV. 34. 232. 3: Der spanische Lustgarten hat mich aufgeregt, dieser herrlichen Sprache und Literatur wieder einige Stunden zu widmen; hätte der treffliche Sammler . . nur das Doppelte oder Dreyfache an die Fingerzeige für deutsche Leser gewendet, so hätte er mich und alle, die ohngefähr in demselben Verhältniss gegen das Spanische sich finden, sehr gefördert und würde uns ohne Mühe viel Mühe erspart haben. (21. V. I82I an Fr. Chr. Perthes.) - Ähnlich stand es mit dem Portugiesischen. IV. I5. 290. 22: fïr die Portugiesische Schrift danke ich recht vielmals, ich kann damit so ziemlich zurechtkommen. (29. XI. I80 I an W. v. Humboldt.)

Die s la wis che n Sprachen, deren Literaturen ihn, wie wir sehen werden, in der Spätzeit so sehr anzogen, kannte er nach eigenem wiederholten Geständnis nicht. IV. 38. 234. I2: Ich lese so eben Ew. Wohlgeboren Vorrede zu der serbischen Grammatik [von Wuk] wieder und bewnndere die mögliche Klarheit, die Sie über das Gewïhl der Volkswanderung und Volksversetzung so wie über die Wandelbarkeit der Sprache verbreitet. Leider hab' ich auch nicht die geringste Anmuthung zu jenen östlichen Zungen und ist mir deshalb eine geistreich angeschlossene Übertragung [ebenfalls von Grimm] von größtem Werth. (30. VIII. I824 an J. Grimm.) - I. 4I II. 468: Mir aber... mu $\beta$ angelegen seyn, eine Sprache [serbisch], die uns nun durch Grammatik, Lexikon und so viele Mustergedichte zugänglich geworden, dringender zu emplehlen. Nie hab'ich aufgehört mich mit Gedichten aus serbischen Dialecten bekannt zumachen, aus Übersetzungen freylich nur, womit mich Ungarische Freunde versehen. (Lesart $\mathrm{zu}$ Serbische Lieder K. u. A. V. 2 I 825.)

G. VII. II7: „Goethe ... beklagte ... dass er nur wenig von der polnischen Literatur kenne und keine slavische 
Sprache verstehe." (I9. VIII. I829 mit Mickiewicz.) G. VII. 225: Ich bedaure, sagte Goethe, dass der Schatz Ihrer älteren und neuern Literatur für mich unerreichbar ist. (Februar I 830 zu Andr. Kózmian.) Nur in die tschechische Sprache, die ihm auch der mehrfache Aufenthalt in den böhmischen Bädern lebendig näher brachte, scheint er versucht zu haben, durch grammatische Studien einzudringen. Im Marienbader Tagebuch von 182I finden wir verzeichnet III. 8. 95. I2 (auch IV. 35. 60): Unterhaltung mit Richter über böhmische Namen... Böhmische Sprache, Ortschaftennamen übersetzt. Sogar eine böhmische Grammatik wird angeschafft und in Eger vom 30. VIII. bis 5. IX. in ihr nachts studiert. (Böhmische Sprachlehre u. ä. IV. 35. 68-70, IV. 38. 220. 19 und III. 8. 104-107.) Im Nachlaß des Dichters fanden sich tschechische Schreibübungen, Alphabet, Vokabeln (vgl. I. 42 I. 396). In Kunst und Altertum VI. I von I 827 wünscht er die Veröffentlichung von böhmischen Originalliedern: I. 4III. 289: Diess würde die slavische Sprachkunde auch in die deutsche Literatur hereinzuführen, befördern und erfüllen helfen.

Die ersten Jahrzehnte des 19. Jahrhunderts führten Goethe zu den modernen orient a $\mathrm{l}$ is che $\mathrm{n}$ Sprachen. Die deutsche Romantik, Schellings Philosophie, die Entdeckung des Sanskrit, Schlegels „Über die Sprache und Weisheit der Indier“ und andere Werke der jungen indogermanischen Sprachwissenschaft wiesen den Weg. Er führte zur arabischen und persischen Sprache, zu Hafis und zum Westöstlichen Divan. ${ }^{1}$ ) Während des Heidelberger Aufenthalts I $_{5}{ }_{5}$ beginnen die Studien. Wilh. Grimm, der dort mit ihm zusammentraf, berichtet G. III. 244 ,Goethe . . gibt sich mit persischen Sachen ab... liest und erklärt (die chinesische Erzählung) Haoh Kiöh Tschwen und lernt bei Paulus arabisch." (September 1815.) \%u Hause werden sie fortgesetzt. (III. 5. 184-2I3 vom 26. XI. 1815 bis 10. III. 1816.) Er äußert sich

1) Vgl. Burdach: Goethes Westöstlicher Divan. G. J. 17 (1896). S. roff., und K rüger, G. J. 26 (1905). S. 272. 
selbst in seinen Briefen und Annalen darüber. IV. 25. I63. I3: Wenig fehlt, dass ich noch arabisch lerne, wenigstens soviel will ich mich in den Schreibzügen üben, dass ich die Amulette, Talismane, Abraxas und Siegel in der Urschrift nachbilden kann. In keiner Sprache ist vielleicht Geist, Wort und Schrift so urantänglich zusammengekörpert. (23. I. I8I5 an C. $\mathrm{H}$. Schlosser.) - IV. 26. I52.21: Das weite Feld des orientalischen Studiums gibt mir sehr frohe Aussichten, leider fehlt mir die Kenntnis der Sprachen, an welche seit meiner Fugend kaum mehr denken können. (I5. XI. I8I 5 an H. F. v. Diez.) Ähnlich IV. 26. I7 I. I5 an v. Uwarow. (2. XII. I8I5.) - I. 36. 9 I 2 I : Nicht ganz fremd mit den Eigenthümlichkeiten des Ostens wandt' ich mich zur Sprache, in so fern es unerlässlich war, jene Luft zu athmen, sogar zur Schrift mit ihren Eigenheiten und Verzierungen. (Tag- u. Jahreshefte I8I5.)

I. 36. I25.2 I : Um des Divan willen setzte ich meine Studien orientalischer Eigenschaften immer fort und wendete viele Zeit darauf; da aber die Handschrift im Orient von so großer Bedeutung ist, so wird man es kaum seltsam finden, dass ich mich ohne sonderliches Sprachstudium doch dem Schönschreiben mit Eifer widmete, und zu Scherz und Ernst orientalische mir vorliegende Manuscripte so nett als möglich ja mit mancherlei herkömmlichen Zierrathen nachzubilden suchte. Dem aufmerksamen Leser wird die Einwirkung dieser geistig technischen Bemühungen bei näherer Betrachtung der Gedichte nicht entgehen. (Tag- u. Jahreshefte 1817.) - I. 36. 136. 5: Alles wird herangezogen... Freytags Arabische Grammatik. (Ebenda I8I8.) An den Sohn ergeht am I2. XII. I8I7 von Jena aus die Anfrage nach dem Lexikon des Meninsky Türkisch, Arabisch, Persisch, Wien I780. (IV. 28. 326. 25.)

Nach den Mitteilungen von Krüger brachte es Goethe im Arabischen tatsächlich so weit, daß er mit Hilfe des Wörterbuchs Übersetzungen fertigen konnte; im Persischen kam er aber über die ersten Anfänge, nämlich ziemlich unbehülfliche, „die fremden Schriftzeichen mechanisch nachbildende Schreib. 
übungen", nicht hinaus. Er selbst übrigens schätzt sich nicht hoch ein. G. IV. 272: „Bei der ungeheuren Schwierigkeit des Erlernens dieser arabischen Sprache habe er seine Kenntnis von ihr mehr erobert durch Überfall, als regelmäßig erworben." (24. IX. I823 zu Kanzler Müller.) - G. V. 218: Ich kann eben so wenig serbisch als persisch. (I3. VI. I8I5 zu demselb.) 1827 wird über das arabische Element in der Sprache auf Malta verhandelt. G. VI. I76: ,Die Mischung der Sprache aus italienischen und arabischen Elementen .. . das alles wurde mit größtem Bedachte, aber in der eingehendsten Weise besprochen." (25. III. I 827 mit G. Parthey.) Und Stickel berichtet noch aus dem Jahre I83I, G. VIII. 59: „Er (Goethe) erzählte, daß er sich in seiner Jugend mit dem Hebräischen und ein wenig mit Arabisch beschäftigt habe (22. III. I831). Möglicherweise liegt hier ein Gedächtnisfehler des Greises vor, in Dichtung und Wahrheit und sonstigen biographischen Aufzeichnungen wird von Arabisch nichts erwähnt vor 1815 .

Auch das Sanskrit zog Goethe in den Bereich seiner Aufmerksamkeit. III. 7. I8I. 5: Sanscrit Sylbenmaas (3. VI. 1820). - III. 9. 260. 22: Nachher beachteten wir [Riemer] das Sylbenmass der Sanscrit Gedichte (25. III. 1824).

Bei allen diesen Sprachstudien genoß er dankbar der Beihilfe des Jenaer Orientalisten Kosegarten, der des öfteren in den Tagebüchern und Briefen erwähnt wird. - Was die von Wilh. Grimm erwähnte Bcschäftigung mit einem $\mathrm{c}$ h i n e s is ch c n Roman anlangt, so hatte Goethe keinerlei Sprachkenntnisse. Sowohl dieser Roman als später übersetzte chinesische Gedichte (Chinesisch-deutsche Tageszeiten) werden ihm, wic Biedermann nachgewiesen hat, durch englische (nicht, wie früher angenommen wurde, französische) Übersetzungen vermittelt. Unterhaltungen über chinesische Sprache werden mit Riemer 1824 bei Gelegenheit des für den Staat geplanten Ankaufs chinesischer Manuskripte gepflogen. (III. 9. 27 I bis 273 ; vgl. auch IV. 38. 253. 6 ff.) 
Im Zusammenhang mit den uns schon bekannten Weltliteraturplänen beschäftigte sich Goethe im Alter mit Literaturen der mannigfachsten Völker, deren Sprachen ihm aber außer den genannten nicht bekannt wurden. Nur ganz vorübergehend ist die Beschäftigung mit dem Tamulischen, einem Zweig der Drawidasprache, der ein aus dem Sanskrit abgeleitetes Alphabet und eine bis ins zehnte vorchristliche Jahrhundert zurückreichende Literatur besitzt: III. 9. 36. I: Tamulische Sprache (12. IV. 1823), in gleicher Weise wird flüchtig ein gälisches (irisches) Wörterbuch erwähnt. (III. 13. 82 vom 30./31. V. I831.) Übrigens verspricht er schon 177I Herder, ihm für seine Volksliedersammlungen „Celtische und Galische Sachen" zu senden (IV. 2. 2. 4). An Originallieder ist aber dabei ebensowenig zu denken, wie bei der Betrachtung lettischer (1820), finnischer (1823) und faröer Lieder (I824), wenn auch für die erstgenannten wieder zu berücksichtigen ist, daß er nach den Ephemeriden I770 Steuders Lettische Grammatik studiert.

\section{ZWÖLFTES KAPITEL.}

\section{FREMDE SPRACHEN. ALTE SPRACHEN.}

In den Venetianischen Epigrammen verlangt Goethe von den Göttern außer den ,natürlichen Dingen“, Wohnung, Essen, Trinken, Kleidung, Freunde, Liebchen an erster Stelle: I. I. 315. I65: (1790.)

Gebt mir ferner dazu Sprachen, die alten und neu'n, Dass ich der Völker Gewerb' und ihre Geschichten vernehme.

Schon die vielseitige, tiefgehende, andauernde, stets geliebte Beschäftigung mit alten und neuen Sprachen ist ja Beweis für die Wertschätzung, die er Sprachkenntnissen schenkt. Unter den Sprüchen finden wir das gewichtige Werturteil I. 42 II. II8. 3 (G. G. 2 I Nr. 9I): Wer fremde Sprachen nicht kennt, weiss nichts von seiner eignen. Stets hat er einem 
ausgedehnten Gebrauch fremder Sprachschätze das Wort geredet und sich im Bewußtsein ihres großen Wertes in absichtlichen Gegensatz zu der exklusiven Deutschtümelei seiner Zeit gestellt, die in ihrer Einseitigkeit so weit ging, in der Beschäftigung mit fremden Sprachen einen Mangel an Nationalbewußtsein zu sehen. I. 42 II. 238. Io (G. G. 2 I Nr. 978): Der Deutsche soll alle Sprachen lernen, damit ihm zu Hause kein Fremder unbequem, er aber in der Fremde überall zu Hause sei. (1818.) Höhere Bildung ist ohne Sprachkenntnisse seiner Überzeugung nach unmöglich. I. 4I I. 466: Will man aber andere weite Weltverhältnisse miss. kennen, ein ausschliessendes Gesetz aufstellen, fremde Sprachen, deren Übung und Benutzung verbieten, so muss jeder echte Vaterlandsfreund dagegen wirken. Der Gelehrte bedarf die alten, der Welt-, Staats- und Handelsmann die neuen. Für den Mittelstand bietet die deutsche Sprache freilich vollgültigen Ersatz. ${ }^{1}$ ) (Deutsche Sprache I8I7.) Deshalb haben auch die im Kreise seiner Schwiegertochter gepflogenen sprachlichen Studien seinen Beifall: IV.40.291.4: Die junge Welt, von der ich täglich Kenntniss nehme, ist immerfort beschäftigt, sich in fremden Sprachen umzuthun, und da sie fast überall einigen Anfang haben, so muss ich ihnen das Zeugniss geben, das es ernst ist, im Grammatischen, besonders der Rechtschreibung und sonst Erforderlichem zuzunehmen. (7. II. I826 an Karl August.) Hierher gehört auch, daß er sich nach Sorets Zeugnis (September I829) gegen das Eingehen des Chaos, der eigenartigen dreisprachigen Zeitschrift dieses Kreises, aussprach (Burkhardt 63. 9), wenn er auch ,immer mit ein bischen Bosheit" davon sprach (cbenda 94. 26); er hebt an ihr lobend hervor: man würde schwerlich anderswo eine so gleichmäßige und vollständige Vercinigung dreier Sprachen finden. (5. IV. 1830; ebenda II 3. 5.)

Sein jet\%t schon mehrfach erwähnter Wunsch, das Deutsche als 'Träger einer Weltliteratur zu sehen, setzt ja auf der einen

1) Vgl, Kap. 5 S. 88. 
Seite die höchste Wertschätzung der Muttersprache voraus, die in ihrer Vollkommenheit Übersetzungen jeder fremden Sprache bieten und diese also in einem gewissen Sinne entbehrlich machen kann ${ }^{1}$ ), auf der anderen sind umfassende Sprachkenntnisse die Vorbedingung seiner Verwirklichung: I. 36. 41. 20: . . alles fremde Literarische muss gebracht ja aufgedrungen werden, es muss wohlfeil, mit weniger Bemühung zu haben sein, wenn wir darnach greifen sollen, um es bequem zu geniessen. So sehen wir im östlichen Deutschland das Italiänische [?], im westlichen das Französische, im nördlichen das Englische wegen seiner nachbarlichen oder sonstigen Einwirkung vorwalten. (Tag- u. Jahreshefte I808.) Bei der Betrachtung von Goethes Anschauungen über Übersetzung sowie seines Verhältnisses zu den einzelnen Fremdsprachen werden wir auf die Frage zurückkommen. Sie beschäftigt ihn bis ans Ende. Noch I83I verzeichnen im Zusammenhange damit die Tagebücher die Behandlung eines Darmstädter Programms über leichtere Erlernung fremder Sprachen. (III. I3. I77. 2 I vom 25. XI. 183I.)

Ein weiterer Grund für seine Vorliebe für fremde Sprachen ist die Eigenart, daß ihn Bekanntes, ja seine eigenen Werke mit dem "Reiz der Neuheit" anzogen und ihm besser gefielen als im deutschen Gewand. Er gesteht das von Werther in italienischer, Hermann und Dorothea in lateinischer, vom Faust und den Gedichten in französischer Sprache. ${ }^{2}$ ) Das letzte kleidet er in folgende Verse: I. 4. 15I: Ein Gleichnis.

Füngst pflückt ich einen Wiesenstrauss,

Trug ihn gedankenvoll nach Haus,

Da hatten von der warmen Hand

Die Kronen sich alle zur Erde gewandt.

Ich setzte sie in frisches Glas,

Und welch' ein Wunder war mir das!

1) Vgl. Kap. 5 S. 90.

2) Vgl. u. S. 215 ; Kap. 13 S. 220. 
Die Köpfchen hoben sich empor.

Die Blätterstengel im grünen Flor,

Und allzusammen so gesund, Als stünden sie noch auf Muttergrund.

So war mirs, als ich wundersam Mein Lied in fremder Sprache vernahm. ${ }^{1}$ )

(I 828.)

II. II. I07. 3 (G. G. 2I Nr. 1272): Wenn wir das, was wir wissen, nach anderer Methode oder wohl gar in fremder Sprache dargelegt finden, so enthält es einen sonderbaren Reiz der Neu. heit und des frischen Ansehens. (Z. Naturw.) Dasselbe sollte ein unvollendet gebliebener Spruch ausdrücken: G. G. 2 I Nr. 1396: Es war schon bei den Römern, wenn sie was Tüchtiges sagen wollten, sagten sie's griechisch. Warum wir nicht französisch? Wie's kommt, dass eine fremde Sprache uns zum Ausdruck einer seltenen Empfindung mehr... (bricht ab). Die Antwort auf dieses Fragebruchstück finden wir angedeutet IV. 29. 91. 15: Dieses ist ein ganz eigner Spiegel, wenn man sich in einer fremden Sprache wiederblickt (19. III. I8I8 an Zelter). Deutlicher heißt es von einer englischen Übersetzung der von Goethe besprochenen serbischen Volkslieder I. 4I II. 3II: Wie es uns mit schönen geliebten Personen ergeht, die uns immer mit neuem Reiz überraschen, so oft wir sie in einem andern Kleid unvermutet wieder erblicken, so war es auch mir zu Mute, als ich die bekannten und anerkannten serbischen Lieder in englischer Sprache wiederlas. Sie schienen ein neues Verdienst erworben zu haben; es waren dieselbigen Gestalten, aber wie in einem anderen Gewand. Auch der Tasso sowic Schillers Wallenstein wirken in englischer Sprache mit erneutem Reiz auf ihn. Die Übersetzung des Wallenstein, der ihm infolge der früheren eingehenden Beschäftigung gañ trivial, ja widerlich geworden war, vergleicht or mit einem frisch gefirnissten Bild und sucht eine auch in anderem

1) Auch IV. 46.12 .15 als Nachschrift $\%$ einem Bricfe an Carlyle vom 6. Vl. 1829 , sowic Zelter V. 45 vom 21. V. 1828. 
Zusammenhang (vgl. Kap. 5. S. 8I) berührte Erklärung dafür: Carlyle 50: Hier aber tritt eine neue vielleicht kaum ausgesprochene Bemerkung hervor: dass der Übersetzer nicht nur für seine Nation allein arbeitet sondern auch für die, aus deren Sprache er das Werk herübergenommen. Denn der Fall konmt öfter vor, als man denkt, dass eine Nation Saft und Kraft aus einem Werke aussaugt und in ihr eignes inneres Leben dergestalt aufnimmt, dass sie daran keine weitere Freude haben, sich daraus keine Nahrung weiter zueignen kann. Vorzüglich begegnet dies den Deutschen, die gar zu schnell alles, was ihnen geboten wird, verarbeiten, und indem sie es durch mancherlei Wiederholungen umgestalten, es gewissermassen vernichten. Deshalb denn sehr heilsam ist, wenn ihnen das Eigne durch eine wohlgeratene Übersetzung späterhin wieder als frisch belebt erscheint (15. VI. I828). Daß auch rein menschliche Gründe, der Stolz auf die Ausbreitung seiner Werke, die Genugtuung über sein Wirken in die Ferne bei dieser Wertschätzung der Übersetzungen mitwirken, bezeugt eine Briefstelle an Göttling (93): Seiner eignen Nation einigermassen genützt und ihre Aufmerksamkeit verdient zu haben ist schon ein glücklich erreichtes Ziel, aber auch die Wirkungen seiner Thätigkeit auf Auswärtige, Stamm- und Sprachverschiedene ausgedehnt zu sehen, ist als ein unerwartetes Glück zu schätzen. (24. IV. 1830. Vgl. auch IV. 36. 60. 25.)

Trotz seiner stets betonten Liebe für die fremden Sprachen setzt er die Muttersprache nicht zurück; das ergibt sich einerseits aus unseren früheren Darlegungen, anderseits auch daraus, daß gerade im Alter der Gebrauch der Fremdsprachen im Briefwechsel abnimmt, während früher Ausländern öfter in ihrer Muttersprache geantwortet wurde. Mangelnde Beherrschung dieser ist es nicht, denn in Gesprächen bedient sich der Greis als entgegenkommender Wirt noch öfter des Französischen und Englischen. In mehreren Äußerungen rückt der Dichter die Muttersprache den anderen gegenüber in den Vordergrund. IV. 13. 340. 13: Sie verzeihen dass ich 
mich in dieser Antwort meiner Muttersprache und einer fremden Hand bediene, in jener drücke ich mich bequemer aus als in jeder andern und diese liest sich besser als meine eigne. (I2. XII. 1798 an van Marum, der selbst französisch schrieb). IV. I6. 165. 21: So wie mir auch gewiss der Gebrauch einer Sprache verziehen wird, welcher Ew. Durchlaucht Sich so gut wie mancher anderen bedienen und in der ich am besten auszudrïcken glaube, mit welcher Anhänglichkeit und Verehrung ich mich aufrichtig unterzeichnen darf. (I3. I. I803 an Fürst A. Czatoryski.) IV. 16. 358.8: Ich . . bitte um Verzeihung, wenn ich mich meiner Muttersprache bediene als in welcher ich mich am bestimmtesten auszudrücken glaube. (27. XI. I803 an Gr. Severin Potocki in Charkow.) Dagegen finden wir freilich im Dezember desselben Jahres $z$ wei französische Briefe an Frau v. Staël und einen an Lefèbre. ${ }^{1}$ )

Der große Bildungswert der altklassischen Sprachen, namentlich der lateinischen, war nach dem Zeugnis von Dichtung und Wahrheit schon dem die Universität beziehenden Jüngling klar geworden.

I. 27. 39. 10: Eine Hauptüberzengung aber, die sich inmer in mir erneuerte, war die Wichtigkeit der alten Sprachen. Denn soviel drängte sich mir aus dem literarischen Wirmarr immer wieder entgegen, dass in ihnen alle Muster der Redekïnste und zugleich alles andere Wïrdige, was die Welt jemals besessen, aufbewahrt sei. Das Hebräische so wie die biblischen Studien waren in den Hintergrund getreten, das Griechische gleichtalls, da ineine Kenntnisse desselben sich nicht über das Neue Testament hinaus erstreckten. Desto ernstlicher hielt ich mich ans Lateinische dessen Musterwerke uns näher liegen und das uns nebst so herrlichon Originalproductionen, auch den ïbrigen Ernverb aller Zeiten in Übersetzungen und Werken der grössten Gelehrten darbietet. Ich las daher viel in dieser Sprache mit grosser Jeichtigkeit und durfte glauben die Autoren su verstehon,

8) Vhl. dazu anch die im vorigen Kapitel \%u (i's. Sprachkenntnissen beigebrachten Belege. 
weil mir am buchstäblichen Sinne nichts abging. (D. W. 6. I812.) In einer Votivtafel verwahrt er sich gegen die Bezeichnung „,tote" Sprachen, und stellt die der beiden größten Lyriker der Griechen und Römer über das Deutsche, d. h. über das damalige Deutsch als Dichtersprache: I. 5. 3I3:

Todte Sprachen nennt ihr die Sprache des Flaccus und Pindar,

Und von beiden nur kommt, was in der unsrigen lebt.

(Tab. Vot. 62. I797.)

Beim Griechischen ist es hauptsächlich der Klang, der den Dichter anzieht. IV. 8. I3I. I5: Nach verlesnen einigen lateinischen Gedichten traten bey 30 Seminaristen auf und lasen kleine Gedichte jeder in seiner Landessprache. Malabarisch, Epirotisch, Türckisch, Moldauisch, Elennisch, Persisch, Colchisch, Hebräisch, Arabisch, Syrisch, Cophtisch, Saracenisch, Armenisch, Hybernisch, Madagaskarisch, Isländisch, Boisch, Egyptisch, Griechisch, Isaurisch, Aethiopisch pp. und mehrere die ich nicht verstehen konnte... Das Griechische klang, wie ein Stern in der Nacht erscheint. (13. I. I787 aus Rom an die Weimarer Freunde.)

I 799 bezeugt er ausdrücklich sein und seines Landes Festhalten an den alten Sprachen gegenüber anderen Zeitströmungen: IV. 14. 40. I5: In unseren Gegenden ... hat man die Überzeugung, wie nothwendig es sey, alte Sprachen und Literatur fortzubewahren. Bey dem schwankendem, losen Geschmack der Zeit kann man jene Norm nicht sorgfältig genug bewahren. (15. III. I799 an J. J. Hottinger.)

Als Schiller sich von dem Freunde griechische Grammatik und Lexikon ausbittet, um sich die Sprache noch anzueignen, schickt ihm Goethe das Gewünschte mit Worten, die, offenbar einer augenblicklichen Mißstimmung nachgebend, sich gegen das Griechische und die Sprachen überhaupt wenden. IV. 5. 122. 3: Sie werden sich aber wenig daran erbauen. Das Stoffartige jeder Sprache so wie die Verstandesformen stehen so weit von der Production ab, dass man gleich, sobald man nur 
hineinblickt, einen so grossen Umweg vor sich sieht, dass man gern zufrieden ist, wenn man sich wieder herausfinden kann. (28. IX. I800.)

In der Farbenlehre werden die beiden alten Sprachen hinsichtlich ihrer Verwendbarkeit als Ausdrucksmittel der Wissenschaft gegeneinander abgewogen. II. 3. 201. 19: Welch' eine andere wissenschaftliche Ansicht würde die Welt gewonnen haben, wenn die griechische Sprache lebendig geblieben wäre und sich ansiatt der lateinischen verbreitet hätte . . . Das Griechische ist durchaus naiver, zu einem natürlichen, heitern, geistreichen aesthetischen Vortrag glücklicher Naturansichten viel geschickter. Die Art durch Verba, besonders durch Infinitiven und Participien zu sprechen macht jeden Ausdruck lässlich; es wird eigentlich durch das Wort nichts bestimmt, bepfählt und festgesetzt, es ist nur eine Andeutung, um den Gegenstand in der Einbildungskraft hervorzurufen. Die lateinische Sprache dagegen wird durch den Gebrauch der Substantiven entscheidend und befehlshaberisch. Der Begriff ist im Wort fertig aufgestellt, im Wort erstarrt, mit welchem nun als einem wirklichen Wesen verfahren wird. (Histor. Farbenl. IV. Abt.)

Diese Bestimmtheit des Ausdrucks kann der Darstellung in lateinischer Sprache gefährlich werden.

II. 5 I. 388. 19: Wenn er [Telesius] nun ... ganz auf dem rechten Weg ist, die Farben... entstehen zu lassen, so verführt ihn die Derbheit der lateinischen Sprache und indem er seiner Tenuitas die Crassities entgegensetzt und von foedare, impurare spricht, verwirrt er sich und kann sein Werk nicht zu Stande bringen. (Nachtr. z. Farbenl. 1822.)

Im allgemeinen aber bevorzugt er das Lateinische. Das bezeugt Boisserée: G. III. 21 I : ,, Goethes Vorliebe für das Römische wurde später ausgesprochen... Alles Römische ziehe ihn unwillkürlich an. Dieser große Verstand, diese Ordnung in allen Dingen sage ihm zu, das griechische nicht so" (II.VIII. 1875).

Der innere Gehalt und die äußere Form der alten Sprachen sind dem Dichter gleich wertvoll. I. 36. 330. 27 : Denn so wenig 
wir läugnen wollen, dass aus den Fundgruben anderer alten Literaturen mancher Schatz gefördert werden und noch zu fördern ist, so wenig wird man uns widersprechen, wenn wir behaupten, die Sprache der Griechen und Römer habe uns bis auf den heutigen Tag köstliche Gaben überliefert, die an Gehalt dem übrigen Besten gleich, der Form nach allem andern vorzuziehen sind. (Wieland 1813.) Die Form erhält sogar das ehrenvollere Zeugnis. Wir betonen das, weil sowohl von Lyon als neuerdings von Harnack Goethes Vorliebe für die alten Sprachen an sich geleugnet und seine Aussprüche mehr auf den inneren Gehalt des klassischen Altertums bezogen werden. ${ }^{\mathbf{1}}$ ) Lyon behauptet sogar, daß Goethe der Meinung gewesen sei, die Schule könne auf die Kenntnis der alten Sprachen verzichten und sich an Übersetzungen der Schriftsteller genügen lassen. Seine Belege dafür sind aber wenig stichhaltig: Der erste bezieht sich auf das einseitige Studium des Altertums im Hinblick auf Philologen wie Fr. A. Wolf, der zweite auf den Freiheitssinn und die Vaterlandsliebe der Alten, der dritte auf das philosophische System des Empedokles, denn diesem, nicht der Sprache gilt das Epitheton ornans ,,abstruses Zeug“. Allerdings wendet sich Goethe, wie auf jedem Gebiet so auch hier, gegen die Übertreibung, also gegen Stubengelehrsamkeit, Philister- und Pedantentum. Aus keinem der beigebrachten Belege ergibt sich die Empfehlung von Übersetzungen, mit einziger Ausnahme des uns schon bekannten Gesprächs mit dem englischen Ingenieur (10. I. 1825) ${ }^{2}$ ), in dem Nationalstolz und nicht Zurücksetzung der alten Sprachen den Dichter beeinflussen. Die deutsche Sprache soll ja zudem viele andere Sprachen, keineswegs nur die alten in der werdenden Weltliteratur ersetzen. Das Gespräch schließt: G. V. I24: Und dann ist wohl nicht zu leugnen, dass man im allgemeinen mit einer guten Übersetzung sehr weit kommt. Friedrich der Grosse konnte kein Latein, aber er las seinen Cicero in der französischen

I) Lyon, Z. f. d. d. U. V (1891). S. 594; Harnack a. a. O. S. I6I.

2) Vgl. Kap. 5 S. 90. 
Übersetzung ebensogut als wir anderen in der Ursprache. Wohlgemerkt ,im allgemeinen" kommt der, der kein Latein kennt, auch mit einer Übersetzung aus, wie ja auch in dem nun schon zweimal angezogenen Passus aus dem Aufsatz ,Deutsche Sprache" nur die Angehörigen eines "gewissen Mittelstandes" ihr Lebens- und Lehrbedürfnis innerhalb der Muttersprache befriedigen können. Mehr sagt Goethe nicht. Er hat vielmehr zeitlebens die alten Sprachen ebensosehr ihrer Form als ihres Gehaltes wegen sehr hoch geschätzt, wie unsere weiteren Zeugnisse beweisen werden. Ausdrücklich auf die Form beziehen sich die folgenden: IV. 24. I13. 18: Nun ist diess die schönste Gelegenheit... sich der lateinischen Sprache und der römischen Eigenthümlichkeiten zu nähern und die hohe Cultur, wodurch sich jene und die Tüchtigkeit, wodurch sich diese auszeichnet, an sich heran, wo nicht in sich hinein zu bilden. (I9. I. I8I4 an Eichstädt.) - IV. 25. 332. I5: was fand ich! [in den Homilien des Kirchenvaters Chrysostomus] einen Pater Abraham a Sancta Clara, der die ganze hohe griechische Cultur im Rücken hat, in der niederträchtigsten Umgebung lebt und seinem schlechten Publicum mit goldenem Munde das dümmste Zeug vorsagt, um sie durch Erniedrigung zu erbauen. Was man aber griechische Sprache und Bildung auch in diesem widerwärtigen Abglanz bewundert! Nun aber begreife ich erst unsere guten Neuchristen, warum sie diesen so hochschätzen, sie müssen immer dieselben Salbadereyen wiederholen, und jeder fühlt, dass er diesen Vortrag nicht erreichen kann. (17. V. I8I5 an Zelter.) Sogar Äußerlichkeiten wie Aussprachc und Schrift zicht er in den Bereich seiner Kritik. II. 6. 235. 3: Ein ganz ausserordentliches Verdienst hätte sich ausserdem dieser Katalog [der Pflanzen in Belvedere] noch lïr die Wissenschaft erverben können, wenn man die Quantilälen iiber die Namen und hie und da cincn Accent angebracht hätle; denn jetat hört man... eine babylonische nicht Sprachsondern Quantitäts-Verwirmung, welche besonders demjenigen, dem die Ableitung aus dem Gricchischen gegenwärtig ist, mitten 
zwischen den herrlichen Naturprodukten eine verdriessliche Missstimmung erregt. (Z. Morphol. I. 18I7.) - IV. I5. II9. 27: Was die griechischen Buchstaben betrifft, masse ich mir darüber kein Urtheil an, doch würde ich die Art mit verstärkten Strichen vorziehen. (27. IX. I810 an de la Garde.)

Wem doch eine Sprache als solche nicht lieb und wert ist, der bekümmert sich doch gewiß nicht um Aussprache und Schreibart.

Wie oben schon angedeutet, gefällt ihm Hermann und Dorothea in lateinischem Gewand besser als in deutschem. Das Latein ist ihm die ,gebildetere" Sprache - eine Beziehung auf den Gehalt - der ja hier von Goethe stammt - ist dabei unmöglich. IV. 37. 123. 9: Hier sah ich nun mein Sinnen und Dichten, in einer viel gebildeteren Sprache, identisch und verändert, wobei mir vorzüglich auffiel, dass die römische nach dem Begriff strebt, und, was oft im Deutschen sich unschuldig verschleyert, zu einer Art von Sentenz wird, die, wenn sie sich auch vom Gefühl entfernt, dem Geiste doch wohlthut. Ich möchte übrigens nicht weiter darüber nachdenken; denn eine solche Vergleichung führt zu tief in den Text. (8. VII. I823 an Schultz.) - G. V. I34: Hermann und Dorothea, sagt er . . besonders lieb ist es mir in der lateinischen Übersetzung, es kommt mir da vornehmer vor, als wäre es der For $m$ nach, zu seinem $U$ sprunge zurückgekehrt. (I8. I. I $825 \mathrm{zu}$ Eckermann.) Auch hier ist es wie oben dem Griechischen gegenüber, die Fähigkeit des Lateinischen, den auszudrückenden Begriff möglichst genau und bestimmt wiederzugeben, die den Dichter sie bis zur Ungerechtigkeit bevorzugen läßt. Die lateinische Sprache hat eine Art von Imperativus der Autorschaft heißt es in einem Spruch aus dem NachlaB. (I. 42II. 248. I6). Aus dieser rückhaltlosen Wertschätzung der altklassischen Sprachen versteht es sich, daß Goethe ihnen auch eine hervorragende Stellung im höheren Schulunterricht zuwies. IV. 17. 173: Vossen ältester Sohn ist als Professor angestellt, der von seinem Vater diese gründliche Neigung zum Altertum und besonders von der 
Sprachseite geerbt hat, worauf doch alles bei einem Schulmanne ankommt. (30. VII. I 804 an W. v. Humboldt.) I. 42II. I9I. I4: Wenn unser Schulunterricht immer auf das Alterthum hinweist, das Studium der griechischen und lateinischen Sprache fördert, so können wir uns Glück wünschen, dass diese zu einer höheren Kultur so nöthigen Studien niemals rückgängig werden. Denn wenn wir uns dem Alterthum gegenüber stellen und es ernstlich in der Absicht anschauen, uns daran zu bilden, so gewinnen wir die Empfindung, als ob wir erst eigentlich zu Menschen wïrden.

Er redet sogar, so weit ist er von einem Abweisen der Form entfernt, dem Latein als Gelehrtensprache das Wort. I. 42 II. 248. 12: Die Modernen sollen nur Lateinisch schreiben, wenn sie aus nichts etwas zu machen haben. Umgekehrt machen sie ihr weniges etwas immer zu nichts (Nachl.). I. 42II. I9I. 23: Der Schulmann, indem er Lateinisch zu schreiben und zu sprechen versucht, kommt sich höher und vornehmer vor, als er sich in seinem Alltagsleben dünken darf. (Nachl.) Daß einzelne Aussprüche sich mehr auf den inneren Gehalt der alten Sprachen beziehen, wollen wir gerne zugeben; andere können auch ebensogut auf die Form als auf den Gehalt oder auf beides bezogen werden. Z. B. der Spruch: I. 42 II. 20I. 5 (Aus Makariens Archiv): Möge das Studium der griechischen und römischen Literatur immerfort die Basis der höheren Bildung bleiben. Bckannt ist das einem lutherischen Ausspruch nachgebildete Zahme Xenion:

I. $5^{\text {I. }}$ I 17. V. 468 :

Das must du als ein Knabe leiden, Dass dich die Schule tüchtig reckt.

Die alten Sprachen sind die Scheiden, darin das Messer des Geistes steckt. (1814.)

Es gibt dem Gehalt den Vorzug, ohne jedoch die Form als überflüssig zu bezcichnen. Nicht durch Übersetzung also, sondern aus den Originalen sind die Geistesschätze der alten 
Literaturen anzueignen. Wie Harnack gerade von diesem Beleg behaupten kann, daß er sich nur auf den Kulturgehalt des Altertums bezöge, ist kaum einzusehen. Anders steht es mit der Briefstelle an VoB. IV. 35. 25. 5: Fe mehr man durchdrungen ist von dem Wert der Bildung, die wir den alten Schriftstellern verdanken, desto mehr lernt man nach und nach einsehen, dass ein ganzes Leben dazu gehört, sie recht zu verstehen und also gründlich zu nutzen. Vergebens dass man sich ein. bildet, nebenbey zu so wichtiger Einsicht gelangen zu können. Wie hoch haben wir daher den Übersetzer als Vermittler zu ver. ehren, der uns jene Schätze herüber in unsere täglichen Umgebungen bringt, wo wir vor ihnen nicht als fremden, seltsamen Ausgeburten erstaunen, sondern sie als Hausmannskost benutzen und geniessen (22. VII. I82I). - Abgesehen davon, $\mathrm{da} \beta$ es Goethe hier um ein Kompliment an Voß gilt, werden Übersetzungen nur dem empfohlen, der sich die nötige tiefgehende Sprachkenntnis nicht aneignen kann. Nur auf den Gehalt der Sprachen bezieht sich der Ausspruch. IV. 27. 21. 24: Verbleiben Sie in den griechischen Regionen, man hat's nirgends besser; diese Nation hat verstanden aus tausend Rosen ein Fläschchen Rosenöl auszuziehen. (25. V. I816 an Riemer.) Wenn aber noch unter dem 14. Oktober I831 das Tagebuch kurz mitteilt: Griechische Sprache und deren Vorzüge (III. I3. 155.9), so ist das ein letzter Beweis dafür, wie er bis zu seinem Tod die alten Sprachen ihrer Form wegen mindestens so hochgeschätzt hat wie wegen ihres Inhalts und $\mathrm{da} \beta$ es verfehlt ist, Goethe zum Kronzeugen für moderne Unterrichtsbestrebungen aufzurufen.

Der Übertreibung freilich tritt er, wie schon angedeutet, entgegen, sowohl der pedantischen, philologischen Schnüffelei und Akribie als der Überspannung des altsprachlichen Unterrichts: II. 6. 194. 19: Man hat sprachgelehrten Männern oft, und nicht ganz ungerecht, vorgeworfen, dass sie, um wegen der unerfreulichen Trockenheit ihrer Bemühungen sich einigermassen zu entschädigen, gar gerne an verfängliche, leichtfertige 
Stellen alter Autoren mehr Mühe als billig verwendet. (Z. Morphol. I. I8I7.) - II. 9. 398 (Lesarten): Beim Unterricht in den alten Sprachen haben wir schon den Fall, dass man statt Griechisch und Latein für einen tüchtigen Hausgebrauch zu lehren, schon auf Gymnasien Philologen zu bilden trachtet, deren in der Welt sehr wenige nöthig sind, indessen Thatmenschen, welche diese Quellen auf ihre Feldgüter leiten möchten, hierdurch verkürzt werden. (1823. Paralip; Inhaltsangabe von Nose's Kritik d. geolog. Theorie, mit dem Goethe übereinstimmt.)

Auch die Weiterentwicklung der alten Sprachen zum Romanischen bzw. Neugriechischen hat Goethe beschäftigt. IV. 3 I. 158. 9: Denn wie sich die lateinische Sprache durch zufäliges, dann vorsetzliches Pfaffenverderbnis in die romanische verlor und die südwestlichen Völker mit einer solchen Verkindischung sich begnügen mussten; so war nichts natïrlicher als dass begabte freiere Geister von der ausgearbeiteten absurden Tochter wieder zur hohen Mutter zurückkehrten. Ebenso musste sich der Deutsche aus einem Mönchisch barbarischen Druck erst in seine eigne natürliche Liebenswürdigkeit, dann aber mit entschiedenem Geschmacksbedïrfniss gegen die lateinische Sprache wenden. (28. V. I8I9 an Blumenthal.) - I. 4I II. 320. 14: Die hohe (griechische) Geistlichkeit hielt fest an der Würde der altgriechischen durch Schrift überlieferten Sprache und um so fester, als sie ihre Wiirde gegen die betriebsame Menge verwahren musste, die seit geraumer Zeit besonders aber seit dem abendländischen Einfluss unter den Kreuzfahrern, Venetianern und Genuesen sich den stammelnden Kinderdialekt der abendländischen Sprachen und siatt herrlicher geistreicher Formung und Beugung nur Partikeln und Auxiliarien gleichsam stotternd hatte gefallen lassen. (Nation. Dichtk. K. u. A. VI. 2. 1828.) Dic Schätzung der alten Sprachen geht also so weit, daß ihre Weiterentwicklung aus den Mundarten zu modernen Sprachen für Goethe eine Verschlechterung ist. Vom Standpunkt der heutigen Wissenschaft ist zu bemerken, daB ohne absicht- 
liche Einwirkung des Klerus sich die romanischen Sprachen aus dem Vulgärlatein bildeten, und daß im Neugriechischen nicht nur romanischer sondern auch slawischer und türkischer Einschlag zu finden ist. Den Verlust des altklassischen Formenreichtums teilen alle modernen Sprachen mit den romanischen und der neugriechischen. Eine etymologisch-grammatische Darlegung über neugriechisch xápos (Tod) aus altgriechisch xápws in Kunst und Altertum V.3 von 1826 ist wohl auf Riemer, den Etymologen, zurückzuführen, mit dem Goethe nach Ausweis des Tagebuchs am 23. V. I826 griechische Etymologie verhandelte.

\section{DREIZEHNTES KAPITEL.}

\section{FRANZÖSISCH. ITALIENISCH. ENGLISCH.}

Wenn Goethe auch die romanischen Sprachen als Entartungen des klassischen Latein, als minderwertige Töchter der erhabenen Mutter auffaßte, war er doch weit entfernt, sie in ihrer neuzeitlichen Ausgestaltung und als Vermittlerinnen der Kulturschätze moderner Völker zu unterschätzen.

Betrachten wir zunächst seine Stellung zum Franzö$\mathrm{s}$ is ch en: Es stand als Weltsprache, als Sprache der Höfe und Diplomaten, als Sprache des stolzen Hofes von Versailles, nach dem liebäugelnd und nachahmend ganz Europa, vornehmlich das heilige römische Reich deutscher Nation schielte, glänzend und beherrschend da, namentlich dem Deutschen des I8. Jahrhunderts gegenüber. Diese Stellung weiß Goethe voll und ganz zu würdigen, eine ganze Reihe von Zeugnissen belegt das. IV. 22. 22. 3: Übrigens muss man doch gestehen, dass ein Franzose, wenn er einmal vermitteln will, ein sehr bequemes Organ an seiner Sprache findet. Ich habe mich doch an gewissen Stellen [von Degérando: Histoire comparée des systèmes de philosophie] gewundert, wie nahe er an uns Deutsche herantritt, selbst da, wo ihm unsre Denkweise nicht gemäss ist. (22. I. I8 I I an F. v. Reinhard.) - IV. 36. 60. 27 : Indessen 
sich die Deutschen in einer beynahe unverständlich werdenden Sprache Gedanken und Urtheile einander mittheilen, so bedient sich der Franzose herkömmlicher Ausdrücke, weiss sie aber so zu stellen, dass sie wie ein aus Planspiegeln zusammengesetzter Hohlspiegel kräftig auf einen Focus zusammenwirken. (IO. VI. 1822 an Reinhard.) Wie dieses Lob durch die Lektüre einer französischen Übersetzung seiner Dramen hervorgerufen wurde, so nimmt ein zweites auf eine französische Rezension seiner Werke Bezug. IV. 4I. 30. 5: Was auf mich besonders erfreulich wirkt, das ist der gesellige Ton, in dem alles geschrieben ist. Man sieht diese Personen denken und sprechen immerfort in grosser Gesellschaft, wenn man dem besten Deutschen immer die Einsamkeit abmerkt und jederzeit nur eine einzelne Stimme vernimmt. (12. V. I826 an Reinhard.) Strehlke 1. I12: Dieses Alles wird uns nun erst recht eingänglich durch die anmutige, in so hohem Grade gebildete französiche Sprache. (9. X. 1830 an Chézy, den Übersetzer des indischen Dramas Sakuntala.) Auch die beiden französischen Faustübersetzungen von Stapfer und Gérard lösen lobende Äußerungen über diese Sprache aus. I. 4 III. 340: Ist nun jenes Gedicht seiner Natur nach in einem düsteren Element empfangen... so nimmt es sich in der Französischen, alles erheiternden, der Betrachtung, dem Verstande entgegenkommenden Sprache schon um vieles klarer und absichtlicher aus. (Faust traduit par M. Stapfer. K. u. A. VI. 2. 1828.) G. VII. 178: Im Deutschen, sagte Goethe, mag ich den Faust nicht mehr lesen, aber in dieser französischen Ubersetzung (von Gérard] wirkt alles wieder durchaus frisch, neu und geistreich. (3. I. $1830 \mathrm{zu}$ Eckermann.) - Soret I34. (4. III. 1831.): Die tranzösische Sprache eignet sich unvergleichlich zu solchen diplomatischen Äusserungen... Ich will sehen, es glücklich in's Deutsche zu versetzen (betr. Milderung eines Angriffs auf Ferusac im Manuscr. der Metamorphosen). Sorct 135. (7. III. 1831.): Die Übersetwung Ihres schönen Artikels (cben jener bedenklichen Stelle) wird Sie lächeln machen.. um einigermassen höflich zu seyn, hab ich mehr 
Worte (3 Zeilen mehr als Soret) bedurft. Es giebt zu scherzhaften Betrachtungen Anlass. Und endlich II. II. I19. I: Wie man der französischen Sprache niemals den Vorzug streitig machen wird als Hof- und Weltsprache, sich immer mehr ausund fortbildend $z u$ wirken so... (folgt Vergleich mit den Mathematikern) (Zur Naturwiss.). ${ }^{1}$ )

Erkennt also Goethe den geistreichen, lebhaften, biegsamen, eleganten Zug der französischen Sprache gern und voll an, so verschließt er sich doch anderseits ihren Schattenseiten keineswegs. Auch die Nation an sich war Goethe, wenn er auch einzelne hervorragende Vertreter derselben verehrte, nicht sympathisch. Nach den von $B^{2}{ }^{2}$ ) gesammelten Äußerungen sind die Franzosen maßlos, pietätlos, handeln nicht aus reinem Antrieb, ihr Verstand ist ihnen im Weg. In den ,Vögeln" wird der Franzose als Wortemacher gekennzeichnet (I. 17. 98) und in einem Briefe an Knebel vom 17. Oktober 1812 spricht Goethe von ihrem Sprach- und Schreätzübergewicht. Ähnlich macht sich sein Unmut schon 1808 Luft. IV. 20. 19. 6: Die Franzosen, mit denen wir übrigens im Leben auf keine Weise fertig werden, da sie mit dem Maul und mit dem Schwert immer andern voraus sind. (24. II. I808 an Caroline v. Wolzogen.) Diese durch die politischen Verhältnisse mitbedingte Abneigung gegen das Volk überträgt sich auch auf seine Sprache: Verschiedentlich wirft er ihr eine durch Wortschwall hervorgerufene Unbestimmtheit vor. IV. I0. 3I I. 15: Um Ihnen kleine Zurechtweisungen zu ersparen, habe ich ihre [Mde. de Staël] Worte unserm Sinn genähert, und zugleich die französische Unbestimmtheit nach unserer deutschen Art etwas genauer $z u$ deuten gesucht. (6. X. 1795 an Schiller.) - IV. 10. 314. 5: Meinen hiesigen Aufenthalt habe ich gleich benutzt, um Mad. de Stael völlig zu übersetzen und mit unter zu versetzen. Eine weibliche Methode und die Französische Sprache machten mir viel zu schaffen und be-

I) Vgl. auch die günstigen Urteile Kap. 5 S. 90 und Kap. 7 S. II9.

2) Bode: Goethes Gedanken I, 444, 445. II, 63. 
sonders auch die Annäherung ihrer Meynungen an die unsrigen und die Abstände und die vielen Abers. (13. X. I 795 an Schiller.) - IV. 13. 92. 10: Damit Sie sehen, in welcher unmittelbaren Connexion unser liebes Weimar mit Paris steht, übersende ich Ihnen einige französische Blätter. Mir sind dergleichen Saalbaderische Gemeinplätze in der Natur zuwider. Die französische Sprache ist aber auch recht dazu gemacht, um die Erscheinung der Erscheinungen auszudrücken. (14. III. 1798 an Schiller.) Mit dem hier verurteilten Aufsatz über Hermann und Dorothea, der übrigens narh Schillers Empfehlung Goethe besser zusagt, begegnet diesem das Mißgeschick, daß sich nachträglich herausstellt, daß er von einem Deutschen stammte. IV. 42. 20: er (ein ins Französische übersetzter Briefentwurf) will mir aber in dieser Gestalt nicht gefallen, denn die treutn und gründlichen Äusserungen nehmen sich im Französischen einmal allzu naiv und dann wieder amphigurisch aus. (19. I. 1827 an S. Boisserée.)

Die Abneigung gegen das moderne Französisch geht so weit, daß er rät, auf ältere Sprachperioden zurückzugreifen. Cousin berichtet: G. V. I79: Paris . . où on traduisait Schiller et Goethe. Je voulais l'amener à me parler de l'état de la littérature en France... Mais voici tout ce qu'il me dit: ..., Oui, tant de traduction prouvent un désir du mieux, et on ne peut nier, qu'il n'y ait de la bonne volonté en France... On a traduit Faust littéralement? Je le concois pourtant; pour s'améliorer la langue francaise n'a besoin que de reculer de quelque siècles et de revenir à Marot ... Oui, la langue de Marot... Il faut prendre quelques libertés, peu à peu on s'y habitue (28. IV. 1825). Und ähnlich meint er zu Soret (20. VIII. I825): „Seine Werke müßten in altes Französisch übersetzt werden um weniger von ihrem Charakter zu verlieren." (Burkhardt 48. II.) Den Faustüber" setzern, die 1828 und 1830 Lob ernteten, werden 1829 eine ganze Reihe belustigender Übersetzungsfehler nachgewiesen. G. 111. 157: Die neweren und neuesten Ubersetwer des Faust 
sind, was die Unkunde unserer Sprache betrifft, nicht hinter ihrer geistreichen und berühmten Landsmännin, der Frau von Stael zurückgeblieben. (17. X. I829 mit Förster.)

Dieselbe naturwissenschaftliche Schrift ferner, die Mathematiker und Franzosen in schmeichelhaftem Vergleich zeigte (vgl. S. 22 I) stellt sie auch wie folgt zusammen: II. II. 102. 18: Die Mathematiker sind eine Art Franzosen: redet man zu ihnen, so übersetzen sie es in ihre Sprache, und dann ist es ganz etwas Anderes. Es scheinen zwei Überzeugungen in seiner Brust für und gegen das Französische gekämpft, aber die abweisende scheint die Oberhand behalten zu haben. Auch ein Urteil über den französischen Nationalcharakter aus den letzten Tagen spiegelt das wider. III. I3. 86. 25: Die Franzosen bleiben immer wunderlich und merkwürdig, nur muss der Deutsche nicht glauben, dass er irgend etwas gründlich für sie thun könne; sie müssen erst alles, was es auch sey, sich nach ihrer Weise zurecht machen. Ihr unseliger Respect fïr den Calcül bornirt sie in allen artistischen, ästhetischen, litterarischen, philosophischen, historischen, moralischen, religiösen Angelegenheiten, als wenn das alles dem unterworfen seyn müsste. Sie merken gar nicht, dass sie hier auf die niederträchtigste Weise Knechte sind; in allem Übrigen wo sie sich gehen lassen und sich ihrer Vorzüge freudig bedienen, sind sie allerliebst und einzig, man darf sie nicht aus den Augen lassen (7. VI. I83 I). Sogar bis auf das Schreiben erstreckte sich nach seinem eigenen Geständnis die Abneigung. IV. 31. IO. I8: Voerst also will ich mich anklagen dass meine Expedition nach Paris durch allerley Hindernisse verspätet worden, worunter ich freilich die Apprehension zählen muss, die ich habe, eigenhändig zu schreiben, besonders französisch auch nur abzuschreiben! (I6. XI. 18 I 8 an Graf Reinhard.)

Sehr gut in diesen Rahmen paßt das flammende Vernich. tungsurteil, das die in ihrer Liebe betrogene Aurelie in den Lehrjahren über die ,perfide“ Sprache fällt: ,Ich hasse die französische Sprache von ganzer Seele" „Wie kann man einer 
Sprache feind sein, rief Wilhelm, der man den grössten Teil seiner Bildung schuldig ist, und der wir noch viel schuldig werden mïssen, ehe unser Wesen eine Gestalt gewinnen kann?" „Es ist kein Vorurteil, versetzte Aurelie, ein unglücklicher Eindruck, eine verhasste Erinnerung an meinen treulosen Freund hat mir die Lust an dieser schönen und ausgebildeten Sprache geraubt... Zu Reservationen, Halbheiten und Lügen ist es eine treffliche Sprache; sie ist eine perfide Sprache! Ich finde, Gott sei Dank, kein deutsches Wort, um perfid in seinem ganzen Umfange auszudrücken. Unser armseliges treulos ist ein unschuldiges Kind dagegen; Perfid ist treulos mit Genuss, mit Übermut und Schadenfreude. $O$ die Ausbildung einer Nation ist zu beneiden, die so feine Schattierungen in einem Worte auszudrücken weiss! Französisch ist recht die Sprache der Welt, wert die allgemeine Sprache zu sein, damit sie sich nur alle untereinander recht betriegen und belügen können... Er hat mir alle Freude an der ganzen Sprache. . . verdorben. Mich schaudert, wenn ich ein französisches Wort höre!" (W. M. L. V. I6. I795.)

Wenn das Urteil auch mit den übrigen Äußerungen Goethes insofern übereinstimmt, daß das Französische seinen Sprachformen nach gelobt, als Ausdrucksmittel der unsympathischen Nation aber gehaßt wird, so müssen wir gerechterweise (und deshalb haben wir den Beleg ausgesondert) doch mit Ruckstuhl diese Beweisführung ablehnen. Nicht Gocthes Überzeugung kommt zum Ausdruck, sondern wir haben es mit der unlogischen Auslassung ciner Frau zu tun, die die Sprache als treulos haßt, weil der Geliebte in ihr scine Treulosigkeit bekundete. ${ }^{1}$ )

Nicht gegen das Französische allein, sondern gegen den Gebrauch fremder Sprachen überhaupt richtet sich eine Aus-

1) Ins Kapitel über die Fremdwortfrage gehört, daß perfid allerdings kaum durch ein deutsches Wort wielergegeben werden kann, daß aber die verychiedensten deutschen Adjektiva von Fall zu Fall seinen Begrifi völlig decken. (Sarrazin: Beitrïge zur Fremdwortfrage S. 4.) Vgl.darüber aber clas Kap. 9 S. 1.55 über naiv Fesagte. 
lassung in den Briefen aus der Schweiz, die jedenfalls aus der Wertherepoche stammen und später überarbeitet wurden. I. 19. 215. I9: Soll ich französisch reden, eine fremde Sprache, in der man immer albern erscheint, man mag sich stellen, wie man will, weil man immer nur das Gemeine, nur die groben Züge, und noch dazu stockend und stotternd, ausdrücken kann. Denn was unterscheidet den Dummkopf vom geistreichen Menschen, als dass dieser das Zarte, Gehörige der Gegenwart schnell, lebhaft und eigenthümlich ergreift und mit Leichtigkeit ausdrückt, als dass jene, grade wie wir es in einer fremden Sprache thun, sich mit schon gestempelten, hergebrachten Phrasen bei jeder Gelegenheit behelfen müssen (1796-1808). Die Gedanken decken sich z. T. mit denen, die in Straßburg zur Abwendung vom Französischen führten.

Mit Einzelfragen der französischen Sprache hat sich Goethe nur äußerst selten befaßt. Wir verzeichnen (außer den am Schluß der Arbeit zusammengestellten Übersetzungen und Definitionen): I. 45. 216. 24: Es ist merkwürdig zu beobachten, bei welcher Gelegenheit die Franzosen, in ihrer Sprache, statt jener von uns verzeichneten Worte (Tiefe, Genie, Anschauung, Erhabenheit, Gefühl, Talent, Geschmack, Verstand, Anmut usf.) ähnliche oder gleichbedeutende gebrauchen oder in diesem oder jenem Fall anwenden. (Anm. z. Rameaus Neffe I805.) - I. 42 II. I I9. IO: (G. G. 2 I Nr. IO2): Die französischen Worte sind nicht aus geschriebenen lateinischen Worten entstanden sondern aus gesprochenen. Hecker meint, dieser von Ménage übernommene Spruch (Les mots francois ne sont pas nés des mots latins écrits mais des mots latins prononcés) sei ,über den Wortsinn hinaus" zu verstehen als: Nur das gesprochene Wort hat Gehalt und Wert. Wenn auch dieser letzte Gedanke, wie wir sahen, Goethe eignet, so erscheint uns doch hier seine Unterlegung ungerechtfertigt, zumal wir ja schon oben Goethes Interesse für die Entstehung der romanischen Sprachen belegen konnten. 
Für das I t a li e n is ch e hatte Goethe eine vom Vater überkommene Vorliebe von Jugend auf. Alle Äußerungen über diese Sprache bekunden, daß es in erster Linie die Klangfülle, das Melodische ist, das ihr diese Liebe einträgt. ${ }^{\mathbf{1}}$ ) Der früheste Beleg bezieht sich auf die italienische Wertherübersetzung. IV. 5. 240. 6: Ich habe in der italienischen Übersetzung gelesen, sie fängt an mir besser zu gefallen, die Sprache ist gar angenehm und ich habe noch keinen Misverstand gefunden, das viel ist. (13. XII. I78I an Frau v. Stein.)

Mit der immer unbezwinglicher auftretenden Sehnsucht, Italien $\mathrm{zu}$ sehen, sich in seine Kunstschätze $\mathrm{zu}$ versenken, an seiner großen Vergangenheit sich zu erheben, an seinem glücklichen Klima sich zu laben, wuchs auch das Verlangen, die italienische Sprache von Mund zu Mund klingen zu hören und sich an ihrem Wohllaut zu erquicken. Die neben den vorbereitenden italienischen Sprachstudien einherlaufenden Bemühungen, in Gemeinschaft mit dem Komponisten Kayser eine deutsche Oper (die Mystifizierten, später Groß Cophta) zu schaffen, ließen ihm die Unvollkommenheit der damaligen deutschen Sprache und ihren Mangel an Gefügigkeit besonders scharf hervortreten. Die verurteilenden Äußerungen bezichen sich nicht auf das Deutsche überhaupt, sondern nur auf seine geringe Fähigkeit, sich vertonen zu lassen. Wenn man bedenkt, daß die Oper der Zeit überhaupt meist italienische Librettis hatte und daß ja bis auf den heutigen Tag das Italienische als die musikalische Sprache gilt, darf man die folgenden Stellen keineswegs, wie es geschieht, als Beweise für Goethes Mißachtung der Muttersprache werten. Sic sind auf einc Stufe zu stellen mit Hebbels Ausspruch:

Schön erscheint sie mir nicht, die deutsche Sprache, doch schön ist

Auch die französische nicht, nur die italische klingt.

1) Vgl, auch S. 77 f. u. 173 . 
Lassen wir nun Goethes Unmut freien Lauf:

IV. 7. 148. I: könnte ich nur um Ihretwillen, meine Sprache zur Italiänischen umschaffen, damit ich Sie schneller ins grosse Publicum brächte. (23. XII. I785 an Kayser.)

IV. 7. I7I. 12: Hätte ich nur vor zwanzig fahren gewusst, was ich weis. Ich hätte mir wenigstens das Italiänische so zugeeignet, dass ich fürs Lyrische Theater hätte arbeiten können, und ich hätte es gezwungen. Der gute Kayser dauert mich nur, dass er seine Musick an diese barbarische Sprache verschwendet. (26. 1. I786 an Fr. v. Stein.)

IV. 7. 188. 8: Noch eins, wie steht es mit dem Italiänischen. Üben Sie sich fleissig in dieser einzigen Sprache des Musikers. (1. III. I786 an Kayser.)

IV. 7. 2I7. 8: Hätt' ich die italiänische Sprache in meiner Gewalt wie die unglückliche Teutsche, ich lüde Sie gleich zu einer Reise jenseits der Alpen ein und wir wollten gewiss Glück machen. (5. V. 1786 an Kayser.)

IV. 8. 284. 4: Wir [er und Kayser] wollten... vielleicht einen Versuch machen für das Italiänische Theater zu arbeiten. Wenigstens sollen gleich Italiänische Worte unter die vornehm. sten Stücke seiner jetzigen Partitur [von Goethes Oper] gelegt und solche auf diese Weise in Conzerten hier aufgeführt werden. (Rom. 27. X I787 an Bertuch.)

I. 30. 39. I I: Hier bin ich nun in Roveredo, wo die Sprache sich scheidet; oben herein schwankt es noch immer vom Deutschen zum Italiänischen . . Wie froh bin ich, dass nunmehr die geliebte Sprache lebendig, die Sprache des Gebrauchs wird. (Ital. Reise I I. X. I786.)

In Italien selbst tritt hinter der Beschäftigung mit der Kunst, den Altertümern und dem Volksleben, jedes andere Interesse, sogar das für die geliebte Naturwissenschaft völlig zurück; also darf es uns nicht wundern, daß auch für sprachliche Beobachtungen wenig Lust und Zeit bleibt. Einige spärliche Bemerkungen fallen für die Mund. arten $a b$ : 
III. I. 3II. I: Die Bologneser Sprache ist ein abscheulicher Dialect, den ich hier gar nicht gesucht hätte. Rauh und abgebrochen ectr. Ich verstehe kein Wort, wenn sie miteinander reden, das Venezianische ist mittagslicht dagegen. (Bologna 19. X. 1786.) - Heinemann 15. 95. 6: Es ist wohl nichts angenehmer als eine Römerin der Art, die sich in natürlichem Gespräch heiter gehen lässt und . . . eine Theilnahme mit anmutigem Bezug auf sich selbst in der wohlklingenden römischen Sprache schnell doch deutlich vorträgt; und zwar in einer edlen Mundart, die auch die mittlere Klasse über sich selbst erhebt und dem Allernatürlichsten, ja dem Gemeinen einen gewissen Adel verleiht. (Ital. Reise. Oktober 1787.) - I. 30. 263. 10: Ihre [der Neapolitaner] Sprache soll figürlich, ihr Witz lebhaft und beissend sein. (Ital. Reise. Neapel 28. V. 1787.) Diese Ausbeute ist gerade mit Hinsicht auf den letzten Beleg als sehr minimal zu bezeichnen; während das neapolitanische Volksleben bei dem zweimaligen Aufenthalt nach allen Richtungen hin ausführlich geschildert wird, fallen für die Sprache nur diese paar Worte ab. Goethe wurde, das sehen wir immer wieder, von sprachlichen Beobachtungen nicht angezogen, nur gelegentlich fallen Brosamen von seinem reichen Tische dafür ab. So befinden sich auch unter den über 100 Seiten der Weimarer Ausgabe fassenden Kollektaneen für die zweite italienische Reise, die alle nur denkbaren Gebietc umfassen, für die Sprache nur folgende nichtssagenden drei Zeilen. I. $34^{\text {II. }}$ 159: Sprache: Weich; in niedrigen Gegenden Hart. Berghöhen. Venetianer. Bologneser. Saneser. Florentiner. Römer. Neapolitaner (1795/96). - 1804 bemerkt er mit Bezug auf einen Aufsatz im Merkur IV. 17.85. 7: Der Gedanke, die Schicksale der italienischen und deutschen Sprache zu parallelisiren, war sehr glücklich gefasst und ist recht gut ausgeführt. (29. II. I804 an Eichstädt.)

Drei Belege aus späteren Jahren bestätigen unsere oben gemachte Beobachtung, daß im Italienischen Goethe in erster linie der Klang anzog, nicht die Sprache an sich, ihr Bau und ihre Ausdrucksfähigkeit. IV. 23.261.20: Her Abt Bondi 
hat mir gegen das Sonett einen musterhaft schönen Brief geschrieben, wie er vielleicht auch nur in der italiänischen Sprache zu schreiben ist. (22. I. I8I3 an Gräfin O'Donell.

I. 36. 79. 20: Die erneute Gegenwart Brizzis hatte der Oper einen eigenen Schwung gegeben, auch die Aufführung derselben italiänisch möglich gemacht. Keinem Sänger ist diese Sprache ganz fremd, denn er muss sein Talent mehrentheils in selbiger produciren; sie ist überhaupt für den, dem die Natur ein glückliches Ohr gegönnt, leicht zu erlernen. (Tag- u. Jahreshefte I813.) I. 42I. I54: Er (Manzoni) verdiene sich fortan das Glück in einer so ausgebildeten, wohlklingenden Sprache vor einem geistreichen Volke zu sprechen und sprechen zu lassen.

Dem Englischen, das ja auch bei Goethes Sprachstudien wenig hervortritt, schenkt er kaum Aufmerksamkeit, wenn er auch, wie gesagt, großer Verehrer Byrons, Shakespeares, Scotts, Carlyles und anderer ist und zahlreiche poetische und wissenschaftliche englische Werke zu seiner Lektüre zählen. Wir können nur zwei Belege beibringen, von denen sich der eine abfällig über die Aussprache, der zweite beifällig über die Ausbildung des Englischen ausläßt.

G. VIII. I86: „, So scherzte er einmal, als von den Eng. ländern und ihrer undeutlichen, silbenverschluckenden Aussprache die Rede war: sie schienen so hungrig und schwer zu sättigen, dass sie zu den Speisen auch noch Silben verschlingen müßten, wie die Vögel noch Sand und Steinchen, um r der Verdauung nachzuhelfen." (I804-I812 zu Riemer.)

I. 4 II. 247. 24: Der Dichter [Byron] schont die Sprache"so wenig als die Menschen und wie wir näher hinzutreten, so sehen wir freilich, dass die englische Poesie schon eine gebildete komische Sprache hat, welcher wir Deutschen ganz ermangeln. Das Deutsch-komische liegt vorzüglich im Sinn, weniger in der Behandlung. (Byron: Don Juan. K. U. A. III. I. I 82 I.) $)^{1}$ )

1) Über den englischen Stil vgl. Kap. 7 S. 115 ; über den Sprachschatz Kap. 10 S. 182 Anm. und Kap. 15, S. 239. 


\section{VIERZEHNTES KAPITEL.}

\section{SLAWISCHE UND ORIENTALISCHE SPRACHEN.}

Wir sahen, daß im Zusammenhang mit den im Alter gern gehegten Weltliteraturplänen, Goethe eine große Anzahl von Sprachen in den Bereich seiner Aufmerksamkeit zog. Der von Rußland ausgehende Plan einer „Sprachensozietät" wurde von ihm mit Freuden begrüßt. IV. 22. 40. 2 I : Ein junger Mann, Namens Ouwaroff hat mir ein Memoire ïbersendet, welches Vorschläge zu einer asiatischen Societät enthält, welche Sprachen und Literatur der sämmilichen alten und neuen orientalischen Völker zu unsrer Kenntniss fördern soll ... da sich in Wien, ja überall in Deutschland eine gleiche Neigung regt, so kann uns auf diesem Wege wohl doppelt ersetzt werden, was wir von Seiten der Engländer her entbehren müssen. (27. II. I8I I an Knebel.) An den Grafen Uwarof selbst ergeht an demselben Tage begeisterter Dank. IV. 22. 43. I: Mit Bewunderung und Freude habe ich das mir übersendete Memoire gelesen... So viel fïr diessmal zu Begleitung meines aufrichtigen Dankes für die Übersendung eines trefflichen Aufsatzes dem ich den besten Erfolg wiinsche.

Es werden Literaturerzeugnisse der Hebräer, Griechen, Römcr, Engländer, Inder, Perser, Araber, Chinesen in bunter Folge betrachtet, Stichproben zum Teil übersetzt. Hand in Hand damit geht die Beschäftigung mit der Volksdichtung. Nicht nur dic deutschen Volksliedersammlungen und mundartlichen Dichtungen werden herangezogen, sondern auch slawische, italienische, brasilianische, englische, dänische, litauische, wendische, finnische, neugriechische Volkslieder werden untersucht. ${ }^{1}$ ) Sprachliche Studien werden dabei aber in keiner Weise gemacht, wic übcrhaupt Goethe ja der Kenntnis der slawischen und orientalischen Sprachen nach unseren früheren Nachweisen fernstand. Er beschränkt sich

1) Vgl. Biedermann: (i.- l\% N. I. 3 I6. 
vielfach auf den Gebrauch von Übersetzungen. Wenn die Tagebücher in den zwanziger Jahren z. B. finnische und lettische Lieder (III. 9. 97. 2 vom 21. VIII. I823) oder Faröer Lieder, mitgeteilt von Grimm dem Fïngeren (III. 9. 300. I vom 2I. XI. I824) verzeichnen, so sind das lediglich Übersetzungen. Litauische Volkslieder von Resa werden ohne jede Beziehung auf die Sprache von Goethe in K. u. A. VI. 2. I828 angezeigt. (I. 4III. 327.) Sprachliche Beobachtungen gehören zu den Seltenheiten. Wir verzeichnen G. III. 89: „Ich betrachtete mit ihm die Kindheit des Menschengeschlechts in der hebräischen Sprache, deren Fügung und Behelfe in den Mitteln mit Hinsicht auf die falschen Auslegungen seinen Geist nicht wenig befriedigte." (Juli I8I3 mit St. Schütze.)

I. 7. I01. 3: In der arabischen Sprache wird man wenig Stammund Wurzelworte finden, die wo nicht unmittelbar, doch mittelst geringer An- und Umbildung sich nicht auf Kamel, Pferd und Schat bezögen. Diesen allerersten Natur- und Lebensausdruck dürfen wir nicht einmal tropisch nennen. Alles was der Mensch natürlich frei ausspricht, sind Lebensbezüge; nun ist der Araber mit Kamel und Pferd so innig verwandt als Leib mit Seele, ihm kann nichts begegnen, was nicht auch diese Geschöpfe angriffe. Und obgleich Übersetzungen höchst löblich sind, um uns anzulocken, einzuleiten, so ist doch aus allem Vorigen er. sichtlich, dass in dieser Litteratur die Sprache als Sprache die erste Rolle spielt. (Noten zum Divan I8I9.)

III. 9. 273. 20: Der Einfluss chinesischer Literatur auf unsere Studien orientalischer Sprachen ist noch viel zu gering, als dass es dergleichen Hülfsmittel [chinesischer Sprachwerke] bey uns bedürfte. (22. XI. I824.)

Am eingehendsten beschäftigt sich Goethe jedenfalls mit der serbischen Volkspoesie ${ }^{1}$ ); I823 empfahl kein Geringerer als Jakob Grimm den Serben Wuk, der eine serbische Gram. matik und ein Wörterbuch verfaßt hatte und eine Liedersammlung vorbereitete, an Goethe. Im nächsten Jahr über-

I) Vgl. Steig a. a. O. $163 \mathrm{ff}$. 
setzte Grimm die Grammatik, versah sie mit einer Vorrede und sandte sie Goethe, dem unterdessen serbische Volkslieder auch durch die Übersetzerin Therese v. Jakob nahegebracht worden waren. Auf all diese Anregungen hin schrieb Goethe den Aufsatz ,Serbische Lieder" (K. u. A. V. 2. I825), dessen auf die Sprache bezüglichen Auslassungen aber aus Jakob Grimms Vorrede stammen: I. 4III. 147. 1: Die slavische [Sprache] theilt sich in zwei Hauptdialecte, den nördlichen und südlichen. Dem ersten gehört das Russische, Polnische, Böhmische, dem letzten fallen Slovenen, Bulgaren und Serben zu. Die serbische Mundart ist also eine Unterabteilung des südslavischen Dialects, sie lebt noch im Munde von 5 Millionen Menschen und darf unter allen südslavischen für die kräftigste geachtet zerden. (Zwei Sprachparteien: die eine betrachtet eine alte Bibelübersetzung saec. 9 als Sprachgrund und hält die Volkssprache für abgeleitet und verderbt.) Betrachtet man aber diese Sprache des Volkes genauer, so erscheint sie in ursprünglicher Eigenthümlichkeit, von jener im Grunde verschieden und in sich selbst lebendig... Um nun von meinem Verhälniss zu dieser Literatur zu reden, so muss ich vorerst gestehen, dass ich keinen der slavischen Dialecte, unerachtet mehrerer Gelegenheiten, mir jemals eigen gemacht noch studirt und also von aller Originalliteratur dieser grossen Völkerschaften völlig abgeschlossen blieb, ohne jedoch den Werth ihrer Dichtungen, insofern solche zu mir gelangten, jemals zu verkennen. .. Bibliothekar Grimm in Cassel ergriff nit der Gewandtheit eines Sprachgewaltigen auch das Serbische, er ïbersetste die Wukische Grammatik . . wir verdanken ihm bedeutende Ubersetzungen, die in Sinn und Sylbenmass jenes Nationelle wiedergeben (1825). In einer anderen Handschrift hat sich ein ausführlicher Auszug über die serbische Sprache aus Wuk-Grimm erhalten (4111. S. 451 und 463 ff.). Nach den Tagebuchnotizen beschäftigte ihn "die serbische Angelegenheit" ein ganzes Jahr von Dezember 1823 bis ebendahin 1824 (III. 9. 157 ff.). Wir sehen, die Anregung, die Grimms gelehrte Aus- 
führungen gaben, löste auch bei Goethe sprachliche Beobachtungen aus. Aus sich heraus wäre er kaum dazu gekommen. Wie auf allen Gebieten des Wissens eignete sich aber auch auf dem der Sprache sein universaler Geist die Ergebnisse hervorragender Forscher an; er durchdrang sie und wußte ihnen abzugewinnen, was seinen Zwecken und Zielen entsprach.

\section{FÜNFZEHNTES KAPITEL.}

\section{ÜBERSETZUNG.}

Goethe, der selbst viel und meisterhaft aus fremden Sprachen, namentlich dem Französischen und Italienischen, übersetzte, hat der Kunst des Übersetzens stete Aufmerksamkeit geschenkt und sich über Übersetzungstheorie, wenn auch nirgends zusammenhängend, so doch klar und bestimmt vielerorts ausgesprochen. Von den in unseren früheren Ausführungen schon darüber gebrachten Belegen wiederholen wir seiner Wichtigkeit wegen nur den aus der Rezension der Allemannischen Gedichte: I. 40. 303: . . wie es für eine Nation ein Hauptschritt der Cultur ist, wenn sie fremde Werke in ihre Sprache übersetzt. Goethe unterscheidet drei Epochen in der Übersetzung, die er in den Noten zum Divan charakterisiert: I. 7. 235. 7: Es gibt dreierlei Arten Übersetzung. Die erste macht uns in unserm eignen Sinne mit dem Auslande bekannt; eine schlicht-prosaische ist hirzu die beste [Luthers Bibel.] ... Eine zweite Epoche folgt hierauf, wo man sich in die Zustände des Auslands zwar zu versetzen, aber eigentlich nur fremden Sinn sich anzueignen und mit eignem Sinn wieder darzustellen bemüht ist. Solche Zeit möchte ich in reinstem Wortverständnis die parodistische nennen. [Wielands Übersetzungen.] . . Weil man aber weder im Vollkommenen noch Unvollkommenen lange verharren kann, sondern eine Umwandlung nach der anderen immerhin erfolgen muss, so erlebten wir den dritten Zeitraum, welcher der höchste und letzte ¿u nennen ist, derjenige nämlich, 
wo man die Übersetzung dem Original identisch machen möchte, so dass eines nicht anstatt des andern sondern an der Stelle des andern gelten solle. [Voß.] ... Warum wir aber die dritte Epoche auch zugleich die letzte genannt, erklären wir noch mit wenigem. Eine Übersetzung, die sich mit dem Original zu identificieren strebt, nähert sich zuletzt der Interlinear-Version und erleichtert höchlich das Verständnis des Originals, hierdurch werden wir an den Grundtext herangeführt, ja getrieben, und so ist denn zuletzt der ganze Cirkel abgeschlossen, in welchem sich die Annäherung des Freinden und Einheimischen, des Bekannten und Unbekannten bewegt (1819).

Auf die erste Art legt er für die Jugendbildung und für die Wirkung auf die Massen den größten Wert. I. 28. 73. 19: Ich ehre den Rhythmus wie den Reim, wodurch die Poesie erst zur Poesie wird, aber das eigentlich tief und gründlich Wirk. same und Fördernde ist dasjenige was vom Dichter ïbrig bleibt, wenn er in Prose ïbersetzt wird. Dann bleibt der reine vollkommene Gehalt, den uns ein blendendes Äussere oft, wenn er fehlt, vorzuspiegeln weiss, und wenn er gegenwärtig ist, verdeckt. Ich halte daher zum Anfang jugendlicher Bildung prosaische Über. setzungen für vorteilhafter als die poetischen, denn es lässt sich bemerken, dass Knaben, denen ja doch alles zum Scherse dienen muss, sich am Schall der Worte, an Fall der Silben ergötzen und durch eine Art von parodistischem Mutwillen den tiefen Gehalt des edelsten Werkes zerstören. Deshalb gebe ich zu bedenken, ob nicht zunächst eine prosaische Übersetzung des Homer zu unternehmen wäre... Nun will ich noch zu gunsten meines Vorschlags an Luthers Bibelübersetzung erinnern, denn dass dieser treffliche Mann ein in dem verschiedensten Stil verfasstes Werk und dessen dichterischen, geschichtlichen, und gebietenden lehrenden Ton uns in der Muttersprache wie aus einem Gusse lieferte, hat die Religion mehr gefördert als wenn er die Eigenthiimlichkeiten des poetischen Originals im einzelnen hätte nachbilden wollen. Fïr die Menge, auf die gewirkt werden soll, bleibt eine schlichte Übersetzung immer die beste. Fene kritischen 
Übersetzungen die mit dem Original wetteifern, dienen eigentlich nur zur Unterhaltung der Gelehrten untereinander. (D. W. II. I813.) Auch W. Grimm gegenüber spricht er I815 noch von einer Prosaübersetzung des Homer (G. III. 245) und Zauper wird IV. 37. I59 belobt, weil er an Stelle einer begonnenen rhythmischen Übersetzung der Ilias eine prosaische vornahm. (6. VIII. I823.) Noch I 827 faßt er seine Überzeugung dahin zusammen I. 42 II. 474: Nach unsrer oft geäusserten Meinung deshalb behaupten wir, dass jedes bedeutende Dichtwerk, besonders auch das Epische auch einmal in Prosa übersetzt zerden müsse. (Simrocks Nibelungen. Schema.) Vom pädagogischen Standpunkt der Neuzeit dürften diese Ausführungen abzulehnen sein. Der Vergleich mit Luther hinkt, da nicht in Betracht gezogen ist, was an poetischem Gehalt z. B. bei den Psalmen durch die Prosaübersetzung verloren gegangen ist. Wohlgemerkt äußert sich hier Goethe nur über den Vorzug prosaischer vor poetischer Übersetzung im Unterricht; die Streitfrage, ob Übersetzung oder Original wird hier nicht berührt.

Auf die zwei obersten Stufen der Übersetzung kommt Goethe noch mehrmals zurück: die eine sucht das Fremde dem Geiste der Muttersprache völlig anzugleichen, die andere die Ursprache in ihren Begriffen möglichst rein wiederzugeben. $\mathrm{DaB}$ Goethe mit dieser Theorie bei Novalis und Schleiermacher Schule gemacht hat, hat Bouke, der überhaupt zu diesem Kapitel nachzulesen ist, nachgewiesen (S. $287 \mathrm{ff}$.):

IV. 15. 233. 5: Man kann, wie es mir scheint, nach zweyerlei Maximen übersetzen, einmal wenn man seiner Nation den reinen Begriff eines fremden Autors überliefern, Fremde Zustände derselben anschaulich machen will, wobey man sich denn genau an das Original bindet; man kann aber auch ein solches fremdes Werk als eine Art Stoff behandeln, indem man es, nach eignen Empfindungen und Überzeugunngen dergestalt verändert, dass es unserer Nation näher gebracht und von ihr gleichsam als ein Originalwerk aufgenommen werden könne. (29. V. I80I 
an Holcroft, dem englischen Übersetzer von Hermann und Dorothea.) - G. II. 33I : „Über die doppelte Art von Übersetzungen der Alten und Neuen; die freien nach dem Genius und Bedürfnis des Volkes für das übersetzt wird, und die getreuen nach dem Genius des Volkes, aus dessen Sprache übersetzt wird." (I3. VII. I 8 IO mit Riemer.) - I. 36. 329. 23: Es gibt zwei Übersetzungsmaximen: die eine verlangt, dass der Autor einer fremden Nation zu uns herüber gebracht werde, dergestalt, dass wir ihn als den Unsrigen ansehen können; die andere hingegen macht an uns die Forderung, dass wir uns zu dem Fremden hinüberbegeben und uns in seine Zustände, seine Sprachreise, seine Eigenschaften finden sollen ... Unser Freund war beide zu verbinden bemüht, doch zog er als Mann von Gefïhl und Geschmack in zweifelhaften Fällen die erste Maxime vor. Niemand hat vielleicht so innig emptunden, welch verwickeltes Geschäft eine Übersetzung sei, als er. Wie tief war er überzeugt, dass nicht das Wort, sondern der Sinn belebe. (Wieland $18 \mathrm{I} 3$.

IV. 24. 43. 26: Griesens Übersetzung der Zenobia ist in jedem Sinn vortrefflich. Wenn er fortfährt, sich an den Calderon zu halten, so wird er. . . einen noch von niemand erreichten Ruhm erwerben, ich meine den, die beyden Übersetzungsweisen dem Original ganz treu und seiner Nation verständlich und behaglich zu seyn (sc. verbunden zu haben). (24. XI. I8I3 an Knebel.) Die Verbindung beider Arten kommt dem Ideal einer Übersetzung nahe: IV. 36. 61: In England hat ein Herr Soane meinen Faust bewunderungswerirdig verstanden und dessen Eigentümlichkeiten mil den Eigentümlichkeiten seiner Sprache und den forderungen seiner Nation in Harmonie zu bringen gewusst. (10. VI. 1822 an Reinhard.) - IV. 43. 163. 26: Zwei deutsche Ubersetzungen [von Manzonis I promessi sposi] kommen heraus: Die Berliner häl sich mehr an die Darstellungsweise des Originals und liejerl uns siemlich das Wie des Vorgehenden; die Leipsiger gibt uns auf alle Fiblle auch von dem, Was geschehen, historische Kenntnisse. 
Wem das Original zugänglich ist, und wer eine gewiss bald er. folgende französische Übersetzung zur Hand nimmt, wird sich freilich immer besser befinden. (4. XI. I827 an Sulp. Boissereé.)

Das Grundproblem Wort-Begriff macht sich auch hier geltend. Es gibt, so lautet es für Goethe auf dem Gebiet der Übersetzung, in jeder Sprache ein letztes, das überhaupt unübersetzbar ist, vor dem der Versuch der Übertragung Halt machen muß, wenn nicht der in der fremden Sprache zum Ausdruck gebrachte Begriff verschoben oder gar verloren gehen soll. $\left.{ }^{1}\right)$ Keine Übersetzung, auch die beste nicht, ist ein völlig treues Spiegelbild des Originals.

IV. IO. 346: Wie man mit eigenen Sachen selten fertig wird, so wird man es mit Übersetzungen niemals. (9. XII. I795 an Schiller.)

I. 40. 256. 2 I: Worte haben öfters in der einen Sprache ganz andere Bezüge zu den Gegenständen und unter sich selbst als in der andern, welches vorzüglich von ihren verschiedenen $A b$. leitungen herkommt, und sich am auffallendsten zeigt, wenn sie metaphorisch gebraucht werden. Das metaphorisch gebrauchte Wort hat gegen die einfache Darstellung, oder gegen den Begriff gehalten, immer etwas Trübes; metaphorische Redensarten und Perioden laufen noch grössere Gefahr, den Gegenstand zu entstellen, und wenn bei Gleichnissen vielleicht Subjekt, Prädicat, Zeitwort, Partikel in einer Sprache geschickt zusammen treffen, so wird man es doch in vielen Fällen für unmöglich erklären, eine solche Stelle in fremde Sprachen zu ïbersetzen. (Es folgen Beispiele, in denen der Übersetzer durch Beibehaltung der englischen Metapher den Sinn verfehlt.) (Rezension von Eschenburg: Vorlesungen über die Malerei. Jenaer Lit. Ztg., Februar I 804.)

I. 30. 123. 19: „Gute Nacht" so können wir Nordländer zu jeder Stunde sagen, wenn wir im Finstern scheiden, der Italiener sagt „Felicissima notte" nur einmal, und zwar wenn das Licht

I) Vgl. denselben Grundgedanken bei M. Bernays: Schriften zur Kritik und Literatur. I, $1 ; 0$. 
in das Zimmer gebracht wird, indem Tag und Nacht sich scheiden und da heisst es denn etwas ganz anderes. So unübersetzlich sind die Eigenheiten jeder Sprache; denn vom höchsten bis zum tiefsten Wort bezieht sich alles auf Eigentümlichkeiten der Nation, es sei nun in Charakter, Gesinnungen oder Zuständen. (Ital. Reise 5. X. I786.)

I. 42II 25I. I4: Mythologie: Luxe de Croyance. Beim Übersetzen muss man bis ans Unübersetzbare herangehen; alsdann wird man aber erst die fremde Nation und die fremde

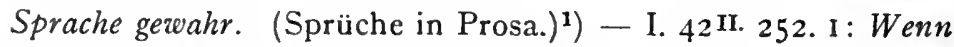
einem Autor ein Lexikon nachkommen kann, so taugt er nichts. - II. 3. 20I. 25: Auch die sorgfältigste Übersetzung bringt immer etwas Fremdes in die Sache wegen Verschiedenheit des Sprachgebrauchs. (Histor. Farbenl. IV. 1810.) - Soret 159: Es ist eine wunderliche Sache mein Theuerster, wenn man einen Gedanken zwischen zwey Sprachen hin und wieder wälzt; der Ausdruck verändert sich und der Sinn. (I7. VIII. I83I, betrifft eine von Soret $z u$ übersetzende Antwort an Cuvier.)

III. I I. 172: Wenn sich der Übersetzer nicht in seinen Autor vertieft und verliebt, so kommt oft gerade bei den Hauptstellen etwas Spielendes und Unsicheres zum Vorschein, wodurch der intentionierte Eindruck, die absichtlichste Darstellung gestört wird (28. I. I 828). Von Schlegels Calderonübersetzung wird Riemer gegenüber am 3. VIII. I 807 gesagt „Sie sei denn doch nur ein ausgestopfter Fasan gegen einen wirklichen, aber ein gut ausgestopfter". (G II. 182.)

Sogar scheinbare Äußerlichkeiten wie die Form der Worte, die Wortstellung müssen nach den strengen Forderungen Goethes beim Übersetzen beobachtet werden, wenn namentlich bei metrischen Übertragungen die Art und Wirkung des

1) F. VI. 265. Beim Ubersetzen muss man sich mur ja nicht in unmillelbaren Kampf mil der fremden Sprache cinlassen. Man muss bis an das Uniberselsbare herangehen und dicses respectiren: denn darin liegt eben der Wert und der Charakter einer jeden Sprache. (16. VIII. 1828 mit v. Müller.) 
Originals erhalten bleiben sollen. G. IV. 334: „Wir sprachen darauf von Übersetzungen, wobei er mir sagte, dass es ihm sehr schwer werde englische Gedichte in deutschen Versen wiederzugeben. Wenn man die schlagenden einsilbigen Worte der Engländer, sagte er, mit den vielsilbigen deutschen ausdrücken will, so ist gleich alle Kraft und Wirkung verloren." (30. XII. I823 mit Soret.) ${ }^{1}$ ) Die umgekehrte Übertragung des Deutschen ins Englische erscheint ihm nach einer Briefstelle an den Übersetzer von Hermann und Dorothea leichter: IV. 15. 212. 4: Die Verwandtschaft der englischen Sprache mit der deutschen begünstigt auch eine metrische Übersetzung. (2. IV. I80I an J. Holcroft.)

G. V. 218: Ungemein viel, sagt cr, kommt bei solcher Übersetzung fremder Volkslieder [serbischer] auf Beibehaltung der Wortstellung des Originals an. Ich kann eben so wenig serbisch als persisch, aber ich habe mir doch durch Ansicht der Originale die Wortstellung abstrahirt. (13. VI. I825 mit v. Müller.)

Bej jedem zu übersetzenden Werk ist die ihm eignende Art zu treffen und in erster Linie darauf $z u$ achten, daß seine Einheitlichkeit nicht durch die Übertragung gestört wird. IV. 11. 24I. I 3: Ihre Bemerkungen wegen Übersetzung und Umkleidung sind vollkommen richtig. Gewinnt man einer fremden Arbeit die Art nicht ab, wie sie behandelt werden will, so kann eine Übersetzung oder Umbildung nicht gelingen. (24. X. 1796 an Prinz Aug. v. Gotha.) - „Bei der Gelegenheit, sagte er (G.), es könnten allerdings mehrere an einem Werke übersetzen, nur sei dann notwendig, daß sie von einem einzigen redigiert und zur Einheit verschmolzen würden" (zu Voß d. J. I805. Gräf a. a. O. 69).

Die Form kommt dann erst in zweiter Linie. I. 6. 40. I:

In deine Reimart hoff' ich mich zu finden, Das Wiederholen soll mir auch gefallen, Erst werd ich Sinn sodann auch Worte finden,

I) Vgl. denselben Beleg nach der Burkhardtschen Ausgabe der Gespräche 20. 32. 3 mit geringen sprachlichen Abweichungen. 
Zum zweitenmal soll mir kein Klang erschallen, Er müsste denn besonderen Sinn begründen, Wie du's vermagst, Begünstigster vor allen... Zu gemess'ne Rythmen reizen freilich Das Talent erfreut sich wohl darin; Doch wie schnelle widern sie abscheulich, Hohle Masken ohne Blut und Sinn; Selbst der Geist erscheint sich nicht erfreulich, Wenn er nicht, auf neue Form bedacht Fener todten Form ein Ende macht.

(Divan 2. Buch Hafis 1814.)

I. 42 II. 39. 21: Eine deutsche Übersetzung [von Maturins Trauerspiel Bertram] ist nicht unmöglich, aber schwer, der abstruse Lakonismus der Sprache ist bei uns noch nicht einheimisch, man müsste einen Stil schaffen dem man erlaubte, sich vieles $z u$ erlauben (1817).

Seine nun schon des öfteren erwähnten und belegten ${ }^{1}$ ) Bestrebungen zur Begründung einer Weltliteratur mit gegenseitigem Austausch der Geistesprodukte der Völker konnten nur bei eingehender Pflege der Übersetzungen auf Verwirklichung hoffen. IV. 42. 28. 2: Ich bin überzeugt dass eine Weltliteratur sich bilde, dass alle Nationen dazu geneigt sind... Der Deutsche kann und soll hier am meisten wirken, er wird später eine schöne Rolle bey diesem grossen Zusammentreten zu spielen haben. (23. I. 1827 an Fr. StreckfuB, der Adelchi übcrsetzte.) G. VI. 45: Nalionallileratur will jetst nicht viel sagen, die Epoche der Weltliteratur ist an der Zeit. (31. I. 1827 zu Eckermann.) Ähnliche Äußerungen sind auch anderwärts zu belegen. Uns hat hier nur dic sprachliche, nicht die literarische und politische Seite der Frage zu beschäftigen. IV. 23. 222: Eben diese Bezüge vom Original zur Übersetzung sind es $j a$, welche dic Verhälnisse von Nation $\approx u$ Nation am allerdeullichsten aussprechen, die man zur Förderung der wor-

1) Vgl die sich auf die Frage be\%iehenden 7itate S. 167 f. u. $206 f$. 
und obwaltenden allgemeinen Weltliteratur vorzüglich zu kennen und zu beurteilen hat. (I. I. I 828 an Carlyle.) Deutlichen Bezug auf den Gedanken, das Deutsche als die Trägerin dieser Weltliteratur zu sehen, haben außer den schon an andern Stellen gebrachten die folgenden Äußerungen:

IV. I3. 96. 7: Übrigens wird es künftig ein wunderlich Amalgam geben, da so viele Franzosen und Engländer Deutsch lernen, so vieles übersetzt wird und unsere Litteratur in verschiedenen Fächern mehr Thätigkeit hat, als die beyden andern. (I7. III. I798 an Schiller.) - IV. 35. 75. 2: Liest man dergleichen Darstellungen [Cellini, Rameau] im Original, so sehen sie ganz anders aus und nöthigen uns um sie nur einigermassen 'zu geniessen und zu nützen in ganz fremde Kreise; bey Übersetzungen aber sind wir gefördert wie auf einer Handelsmesse, wo uns das Entfernteste seine Ware herbeybringt. (7. IX. I82 I an J. St. Zauper.) - I. 42 II. 149. 14: Übersetzer sind als geschäftige Kuppler anzusehen, die uns halbverschleierte Schöne als höchst liebenswürdig anpreisen; sie erregen eine unwiderstehliche Neigung nach dem Original (1826); ähnlich IV. 37. 315. 30 (29. IV. I823 an Peucer). - I. 4I 1. 3I3. 2 I: Man kann seinen Antheil an einer ausländischen Dicht- und Sinnesart nicht besser ausdrücken, als wenn man sich derselben durch Übersetzen und Nachbilden anzunähern sucht. (La Guzla K. u. A. VI. 2. I828.) - I. 4I11. 306. 23: Und so ist jeder Übersetzer anzusehen, dass er sich als Vermittler dieses allgemein-geistigen Handels bemüht und den Wechselaustausch zu befördern sich zum Geschäft macht. Denn was man auch von der Unzulänglichkeit des Übersetzens sagen mag, so ist und bleibt es doch eines der wichtigsten und würdigsten Geschäfte in dem allgemeinen Weltverkehr. Der Koran sagt: Gott hat jedem Volke einen Propheten gegeben in seiner eignen Sprache. So ist jeder Übersetzer ein Prophet in seinem Volke. Luthers Bibelübersetzung hat die grössten Wirkungen hervorgebracht... . Und was ist denn das ganze ungeheure Werk der Bibelgesellschaft anders, als das Evangelium einem jeden Volk in seine Sprache 
und Art gebracht zu überliefern. (Carlyle: German Romance. K. u. A. VI. 2. I828; auch IV. 42. 270. 17.) - I. 42 II. 420 : Übersetzungen sind ein wesentlicher Theil unserer Litteratur. (I808/09 Nachl.)

Nach Ausweis der Tagebücher beschäftigte Goethe I827 bis 1829 die Frage der Übersetzungstheorie auch in Gesprächen mit Riemer. III. I I. I52. I: Interessante, ästhetisch-kritische Gespräche, besonders Übersetzungen betreffend. - 153. 14: Mit ihm die Geschichte des Übersetzens durchgegangen. (25. I. 1827 desgl. 22. I. I829.) 


\section{SCHLUSSWORT.}

Es wird nicht schwer fallen, eine Nachlese nichtverzeichneter Zitate beizubringen. Manches wird bei der Masse des untersuchten Stoffes übersehen, manches vielleicht in seinen Beziehungen zum Thema verkannt worden sein, manches ist auch absichtlich abgelehnt worden, da die Ergebnisse nur auf unzweideutiges Material gestützt werden sollten und jede gezwungene Deutung vermieden werden sollte. An den Resultaten der Untersuchung dürfte aber durch weitere Belege keine Änderung eintreten. Überschauen wir sie, so tritt immer wieder das eine in den Vordergrund: Goethes an sich spärliche und nur aphoristische Äußerungen über Sprache und Muttersprache werden zum großen Teil hervorgerufen durch seine Anschauung von der Unvollkommenheit der Sprachmittel dem Denkinhalt gegenüber. Der Dichter sowohl wie der Gelehrte hatten diese Überzeugung gewonnen, der eine im Bestreben, die höchsten und hehrsten Gefühle in schönste und erhabenste Formen zu gießen, der andere im Kampfe um die Anerkennung seiner wissenschaftlichen Forschungsergebnisse durch die zünftige Gelehrtenwelt. Nicht nur die vielen mehr oder minder schroffen Urteile, die zahlreichen teils spottenden teils resignierten Äußerungen, die unmittelbar darauf Bezug nehmen, gehören hierher, sondern seine vermittelnde Stellung in Sachen der Sprachreinigung, sein Verhältnis zu den fremden Sprachen, seine Ansicht von der Übersetzung werden mit von dieser Grundanschauung bedingt. Und es hieße Goethes Anschauungen von der Sprache und von der deutschen Sprache in ein ganz falsches Licht setzen, wollte man das bei der Beurteilung seiner Ansichten außer acht lassen. Nur wer seinen Kampf ums Wort kennt und würdigt, wer den Druck mitempfindet, den er im „Gängel- 
bande der Schulworte" litt, der versteht den Zorn, mit dem er dem ,negativen Purismus" entgegentritt, versteht die Freude, die er an einem fremden Wort haben kann.

Es wäre einseitig und verkehrt, wollten wir alle Äußerungen Goethes zu sprachlichen Fragen unter diesem einen Gesichtswinkel betrachten. Eine weitere Gruppe hängt mit der Abneigung des Dichters allen nichtssagenden, wertlosen Äußerlichkeiten, allem Unwahren und Inhaltlosen gegenüber zusammen. Der nur niederreißende und nicht gleichzeitig wieder aufbauende Purismus erfährt seine Verurteilung auch auf dieser Linie. Sein Verhältnis zu den Lehren der Grammatik und Metrik, seine Grundansichten vom Stil, seine Geringschätzung aller die Schrift, die Zeichensetzung, die Rechtschreibung betreffenden Fragen verstehen sich in dieser Beleuchtung.

Und was weder in der einen noch in der anderen Gruppe unterzubringen ist, das wollen wir offen und ehrlich dadurch erklären, daß Goethe sprachlichen Fragen nicht im entferntesten das Verständnis und Interesse entgegenbrachte, womit er andere Zweige der Wissenschaft und Kunst bedachte. Da er deshalb nie aus rein wissenschaftlichem Interesse in sprachliche Probleme eindrang, sind seine Äußerungen über Sprachgeschichte, über das Verhältnis der Sprache zu anderen Mitteln, Denken und Gefühl auszudrücken, nur entweder nachempfunden oder einseitig und schwankend; aus demselben Grunde sind die Urteile über die Mundarten so spärlich und wenig hervorragend, die über Phonetik so bescheiden.

Bei allem aber, was Goethe über Sprache, Muttersprache und Fremdsprachen gedacht und ausgesprochen hat, offenbart sich sein warmes Herz für die deutsche Sprache. Gerade weil er sie liebt, will er sic vervollkommnen, legt er den Finger an ihre Schäclen und Unvollkommenheiten; gerade weil sie ihm ihre Schätzc offenbarte und noch größere unerschlossene ahnen ließ3, stellt er die höchsten forderungen an sic.

Stets hat er, alggesehen vielleicht von einigen aus augenblicklichen Unmut geborenen \%engnissen, dic Muttersprache 
und ihr Verhältnis zu den fremden gerecht beurteilt. Daß er die Vorzüge des Französischen als Hofsprache erkannte, daß ihn der Wohlklang des Italienischen entzückte, daß er den alten Sprachen nach Form und Inhalt den ihnen zukommenden Wert beimaß, ist das alles nicht auch heute noch völlig anzuerkennen? Er hielt das Deutsche für fähig, alles Fremde in sich aufzunehmen, die Trägerin einer die Produkte aller Kultursprachen umfassenden Weltliteratur $\mathrm{zu}$ werden und für weite Kreise dadurch fremde Sprachen überflüssig zu machen. Nur wer der Muttersprache mit Liebe und Stolz zugetan ist, wer von ihrem Reichtum und ihrer Ausdrucksfähigkeit voll überzeugt ist, kann ihr einen solchen Beruf zuweisen. Der engherzige Purismus des I8. Jahrhunderts, die einseitige Teutschtümelei dieser Zeit paßten freilich nicht in diesen Rahmen und mußten schroffe Abweisung erfahren. Ihm deshalb nationales Empfinden abzusprechen, wäre ebenso verfehlt, wie ihn als Kronzeugen radikaler Sprachreinigung aufzurufen. „Der wünschenswerte Mittelzustand" wird wie auf anderen Gebieten so auch in den Urteilen dem deutschen Vaterland und der deutschen Sprache gegenüber eingehalten. In dem Bewußtsein, daß es ihm verschlossen sei, in die Gänge der abstrakten Sprachwissenschaft einzudringen, zog er es vor, sich belehren zu lassen, den aufmerksamen Beobachter zu spielen, und lehnte er es ab, sich selbständige Urteile in größerem Umfange anzumaßen. „Das Vernünftige ist immer, dass jeder sein Metier treibe, wozu er geboren ist und was er gelernt hat." (Zu Eckermann 25. II. 1824. $\left.)^{\mathbf{1}}\right)$

I) Während der Drucklegung meines Buches erscheint die mit gleichem Preis vom Allg. deutsch. Sprachverein ausgezeichnete Arbeit von Seiler: Die Anschauungen Goethes von der Deutscheu Sprache. Stuttgart (Cotta) 1909. Soweit ein Überblick ein Urteil erlaubt, glaube ich, daß beide Untersuchungen in der Hauptsache zu denselben Ergebnissen gelangt sind, während sie in der Anlage und Methode wesentlich voneinander abweichen. 

ANHANG 

Wir stellen im folgenden eine Sammlung von Wortanalysen zusammen, die in erster Linie weiteres Material zu den im I. Kapitel gefundenen Ergebnissen bieten und Goethes namentlich in seiner wissenschaftlichen Arbeit hervortretendes Ringen mit dem sprachlichen Ausdruck belegen, sodann aber auch - soweit sie Fremdsprachliches betreffen - Beweise für seine im letzten Kapitel gesammelten Übersetzungsmaximen bringen und endlich auch Schlaglichter auf seine Stellung zur Sprachreinigung werfen sollen.

A ugengespenst: Wir haben den Ausdruck Augengespenst mit Fleiss gevëhlt und beibehalten, theils weil man dasjenige, was erscheint, ohne Körpergehalt zu haben, dem gewöhnlichen Sprachgebrauch nach ein Gespenst nennt, theils weil dieses Wort... das Bürgerrecht in der Farbenlehre sich hergebracht und erworben. Das Wort Augentäuschungen... wünschten wir ein für allemal verbannt. Das Auge täuscht sich nicht, es handelt gesetzmässig und macht dadurch dasjenige zu Realität, was man zwar dem Worte aber nicht dem Wesen nach ein Gespenst zu nennen berechtigt ist. (II. 4. 245. I. Histor. Farbenl. VI.)

Erin n e ru ng: „Als unter mancherlei ausgebrachten Toasten auch einer der Erinnerung geweiht wurde, brach er mit Heftigkeit in die Worte aus: Ich statuire keine Erinnerung in Eurem Sinne, das ist nur eine unbeholfene Art sich auszudrücken. Was uns irgend Großes, Schönes, Bedeutendes begegnet, muss nicht erst von aussen her wieder er-innert, gleichsam erjagt werden, es muss sich vielmehr, gleich von Anfang her, in unser Inneres verweben, mit ihm eins werden, ein neueres besseres Ich in uns erzeugen und so ewig bildend in uns fortleben und schaffen." (G. IV. 3II; am 4. XI. I823 zu Fr. v. Müller.) 
$\mathrm{g}$ e ge ns tä ndlich: Bedeutende Förderniss durch ein einziges geistreiches Wort. [Heinroth hatte in seiner Anthropologie für Goethes Denken den Ausdruck g. gebraucht.] Womit er aussprechen will, dass mein Denken sich von den Gegenständen nicht trenne. $Z u$ was für Betrachtungen jenes einzige Wort ... mich angeregt, mögen folgende wenige Blätter. aussprechen... Schon einige Fahre such' ich meine geognostischen Studien $z u$ revidiren, besonders in der Rücksicht, in wiefern ich sie ... der newen . . . Feuerlehre . . annähern könnte, welches mir bisher unmöglich fallen wollte. Nun aber durch das Wort gegenständlich ward ich auf einmal aufgeklärt, indem ich deutlich vor Augen sah, dass alle Gegenstände, die ich seit 50 Fahren betrachtet und untersucht hatte, gerade die Vorstellung und Überzengung in mir erregen mussten, von denen ich jetzt nicht ablassen kann. (II. II. 58. Zur Naturwiss.)

Geschmack: Die Franzosen gebrauchten zu Ende des I7. Fahrhunderts das Wort Geschmack noch nicht allein, sie bezeichneten vielmehr durch das Beiwort die besondere Bestimmung. Sie sagten ein böser, ein guter Geschmack und verstanden recht gut, was sie dadurch bezeichneten. Doch findet man schon in einer Anekdoten- und Spruchsammlung jener Zeit das gewagte Wort: Die französischen Schriftsteller besitzen alles, nur keinen Geschmack. (I. 45. I72. 3. Rameaus Neffe. Anm. 1805.)

Irren heisst, sich in einem Zustand befinden, als wenn das Wahre gar nicht wäre; den Irrthum sich und anderen entdecken, heisst rückz'ärts erfinden. (II. II. I05. I8. Zur Naturwiss.)

$K u n s t u n d W i s s e n s c h$ af $t$ sind Worte, die man so oft braucht und deren genauer Unterschied selten verstanden wird; man gebraucht oft eins für das andere. (I. 42II. 199. I6. Aus Makariens Archiv. W. M. W.)

Lagerstät te, falsches gefährliches Wort ... Das verfluchte Wort Lagerställe. (II. I 0.266. Lesarten. Paralip.zur Geologic.) 
L e ibstecke n p e r d: In jenen Sommertagen war mein Leibsteckenpferd, um mich dieses oft gebrauchten aber immer vortreflichen Wortes zu bedienen, die Zinnformation. (IV. 24. 40. 27; am 24. XI. I8I3 an v. Trebra.)

m e i n: Man bedient sich des Wortes mein, um ein Verhältniss zu Personen und Sachen anzuzeigen, mit denen man aus Neigung oder Pflicht verbunden ist, ohne sich darüber eine Herrschaft oder Eigenthum anzumassen. Ein Cassier sagt meine Casse, man sagt unsere Finanzen u. $s$. w. obgleich alles des Fürsten oder des Landes ist. Meine Herrn Cameralen konnte also wohl nichts weiter heissen, als die Herrn von der fürstlichen Cammer, die durch Serenissimi Willen in gewissen Dingen an mich gewiesen sind. (IV. 6. I59. 28; am 6. V. I783 an Min. Fritsch.)

Symmetrie: Bey dem Worte Symmetrie, im Deutschen Ebenmass, denkt man sich ein Verhältniss äusserer sich auf einander wohlgefällig beziehender Theile; meistens wird das Wort von regelmässig gegen einander über stehenden, auf eine Mitte sich beziehenden Theilen gebraucht. Wir haben das Wort $B$ ezug genommen, weil die Theile nicht insotern sie neben und gegen einander sondern nach einander beobachtet und gedacht werden, hierbey aber nicht allein nach einander identisch sich folgend, nicht Gleiches aus Gleichem immer auf derselben Stufe bleibend, sondern ein Erhöhtes aus dem Niederen ein Starkes aus dem Schwachen, ein Schönes aus dem Unscheinbaren. (II. 13. 60. 24. Morphol. I. Paralip. zu II. 6. 27. 62.)

$\mathrm{t} \mathrm{r}$ ü b: Der Ausdruck trüb ist hergenommen von der gestörten Ruhe solcher Theile, die in Unordnung geraten sind. Auf diese Weise drïcken sich auch die lateinische und deren Töchter. sprachen aus. (Die folgenden nicht einwandfreien etymologischen Bemerkungen stammen von Riemer.) (Il. $5^{\text {I. }}$ 394. Nachtr. z. Farbenl. I822.)

$Z$ us $t$ a $n d$ ist ein albernes Wort; weil nichts steht und alles bereglich ist. IV. 23. I64; am 23. XI. 18I2 an B. G. Niebuhr. 
A cheminement: Die französische Sprache hat, unter andern Worten die vir ihr beneiden müssen, das Wort s'acheminer und wenn es auch ursprünglich nur heissen mochte, sich auf den Weg begeben, so fühlte doch eine geistreiche Nation, dass jeder Schrilt, den der Wanderer vorwärts thut, einen anderen Gehalt, eine andere Bedeutung habe als der vorher. gehende, indem auf dem richtig eingeschlagenen Wege in jedem Schritt das zu erreichende Ziel schon vollkommener begriffen und enthalten ist; daher das Wort Acheminement einen sittlich lebendigen Werth in sich fasst. Man denkt sich dabey das Herankommen, das Vorschreiten aber in einem höheren Sinne. Wie denn ja die ganze Strategie eigentlich auf dem richtigsten, kräftigsten Acheminement beruht. (II. 6. 266. I9. Zur Morphol. I. 1829.)

Wenn wir diese der französischen Sprache in Absicht auf lebendigen Ausdruck hinderlichen Worte (insertion, appendiculaire) bemerkten, so müssen wir dagegen gestehen, dass sie ein beneidenswerthes Wort besitzt, welches um unse I dee a uszudrücken einzig und vollkommen gefunden wird. Es ist das Wort acheminement, was schon durch voir venir les choses ausgedrückt ist. Wenn man mit dem Worte acheminer im Anfang auch nur den Akt der Abreise bezeichnen mochte, so hat doch eine geistreiche Nation gefühlt, dass der von seinem letzten Nachtquartier aufbrechende Wanderer sich innerlich und geistig durchaus verändert, je näher er seiner Heimat kommt, wohin sein Geist gerichtet ist ... Seine Schritte werden schneller, jedes Hinderniss unangenehmer. Man verstehe uns! Wenn die Analogie im Physischen gill, warum nicht im Sittlichen? Fa wir setzen hinzu: der ganze Werth der. Strategie liegt in der Sicherheit des acheminement mehrerer Colonnen; ist dieses wohl gedacht und ausgeführt, so ist der Sieg vor der Schlacht entschieden. (Morphol. I. Paralip. zum Vorigen. 11. 13. 60. 6.)

Agrumen: Der wweyte Ausdruck Agrumen ist von mir aus dem ilaliänischen herüber genommen worden. Man 
bezeichnet hiermit die ganze Sippschaft der Citronen, Pommeranzen $u$. s. w. Und hat dadurch den Vortheil aus dem gewöhnlichen Leben einen leichten bezeichnenden Ausdruck in die Wissenschaft herüber zu nehmen. (Soret 5 I; I4. VII. 1828.) A p p endicula ire: Das Wort appendiculaire ist noch schlimmer (als insertion, s. u.), bey welchem man sich ein blosses, ausserwesentliches Anhängsel denken kann. Hier sage man nicht, dass man sich bey einem solchen Worte, das etwas völlig Todtes ausdrückt, auch etwas Lebendiges denken könne; die ursprüngliche etymologische Bedentung hat mehr Gewalt über die Vorstellung als man gewahr wird. (II. I3. 59. 20. Morphol. I. Paralip. 63.)

A t t i u d e: Diderot braucht das Wort Attitude schon einige Mal und ich habe es nach der Bedeutung übersetzt, die es mir an jenen Stellen zu haben schien; hier ist es aber nicht übersetzlich; denn es führt schon einen missbilligenden Nebenbegriff bei sich. Überhaupt bedeutet Attitude in der französischen, akademischen Kunstsprache eine Stellung, die eine Handlung oder Gesinnung ausdrïckt und insofern bedeutend ist. (I. 45. 277. 8. Diderots Versuch über die Mahlerei I. 1799.) Die betr. Stelle heißt: Etwas anders ist eine Attitude, etwas anders eine Handlung, alle Attitude ist falsch und klein, jede Handlung ist schön und wahr.

A t $\mathrm{t}$ a t iva: Auch ward ihm eine entschiedene Anziehungsgabe, welche auszudrücken die Italiener sich des schönen Wortes attrativa bedienen, kräftig verliehen. (Heinemann I 5. 146. Ital. Reise II. Dez. 1787.)

belvederean us: Man gedenkt den Pflanzenkatalog von Belvedere herauszugeben mit der Aufschrift Belvedereanus. Dieses Adjektivum will mir nicht gefallen, ohne dass ich ein anderes anzugeben wüsste. Möchten Sie mir hierüber zu einer Bestimmung verhelfen. (IV. 32. I5O. I; am 19. I. I820 an Eichstädt.) - Das Belvedereanus oder Belvederianus will nicht gefallen. Er schlägt vor Hortus Belvedera-Vimariensis. Bey der wohlklingenden Form Belvedera hat man die Analogie 
Belna (für Beulne in Burgund), Sodera (für Sodere in Schottland) und ähnliche zum Beyspiel. Außerdem weist er auch auf die Form Belvederiensis im lat. Schülerverzeichnis des Gymnasiums hin. (IV. 32. 156. 8; am 25. I. 1820 an Bertuch.) Schließlich behielt es bei der Form Belvedereanus sein Bewenden.

Composition, ein gleichfalls (wie matériaux s. u.) unglückliches Wort, mechanisch mit dem vorigen mechanischen verwandt. Die Franzosen haben solches, als sie über Künste zu denken und zu schreiben anfingen, in unsere Kunstlehren eingeführt; denn so heisst es: der Mahler componiert seine Gemählde; der Musicus wird sogar ein für allemal Componist genannt, und doch, wenn beide den wahren Namen eines Künstlers verdienen sollen, so setzen sie ihre Worte nicht zusammen, sondern sie entwickeln irgend ein inwohnendes Bild, einen höhern Anklang natur-und kunstgemäss. Eben so wie in der Kunst, ist, wenn von der Natur gesprochen wird, dieser Ausdruck herabuürdigend. Die Organe componiren sich nicht als vorher jertig; sie entwickeln sich ausund aneinander zu einem nothwendigen, in's Ganze greifen. den Dasein. (II. 7. 207. 27. Zur Morphol. II. I832.) Es ist ein ganz niederträchtiges Wort, das wir den Franzosen zu danken haben, und das wir sobald wie möglich wieder los zu werden suchen sollten. Wie kann man sagen, Mozart habe seinen Don Fuan componiert. Composition - als ob es ein Stiick Kuchen oder Biskuit wäre, das man aus Eiern, Mehl und Zucker zusammenrïhrt. Eine geistige Schöpfung ist es, das Einzelne wie das Ganze aus e $i$ ne $m$ Geiste und Guss und von dem Hauch eines Lebens durchdrungen, robei der Produciernde keineswegs versuchte und zerstückelte und nach Willkiir verfuhr, sondern wobei der dämonische Geist seines Genies ihn in der Gercalt hat, so dass er ausführen musste, was jener gebot. (20. VI. I83 I zu Eckermann.) Nicht weil das Wort fremd ist, wird - wie von verschicdenen Seiten, $u \mathrm{~m}$ der Sprachreinigung einen Dienst $\mathrm{zu}$ 
tun, behauptet wird, - es verworfen - ebensowenig wie aus diesem Grunde acheminement für beneidenswert erklärt wird -, sondern weil es den Begriff, den es ausdrücken soll, nach Goethes Ansicht, verkehrt zum Ausdruck bringt; das deutsche „Zusammensetzung" hätte geradeso wenig Goethes Beifall gefunden; das gleiche gilt von den Urteilen über Decomposition, Embranchement, Matériaux, Insertion (s. u.; vgl. auch S. I8).

$\mathrm{Dec}$ om position: Hier wollen wir zwei solcher falschen Synthesen namhaft machen: Die Decomposition des Lichts nämlich und die Polarisation desselben. Beides sind hohle Worte, die dem Denkenden gar nichts sagen und die doch so of von wissenschaftlichen Männern wiederholt werden. (II. I I. 69. I. Zur Naturwiss.) - So ganz leere Worte wie die von der Dekomposition und Polarisation des Lichts müssen aus der Physik hinaus, wenn etwas aus ihr werden soll. (- IIO. 8.)

Dociren kannst du tüchtiger freilich nicht, es ist wie das Predigen, durch unsern Zustand geboten, wahrhaft nützlich, wenn Conversation und Katechisation sich anschliessen, wie es auch ursprünglich gehalten wurde. Le hre n aber kannst du und wirst $d u$, das ist: wenn That dem Urtheil, Urtheil der That zum Leben hilft. (I. 42 II. 159. 5. Max. u. Refl.)

E $m$ branchement ist gleichfalls ein technisches Wort des Zimmerhandwerks (wie Matériaux und Composition) und drückt aus: die Balken und Sparren in- und aneinander fügen. Ein Fall wo dieses Wort zulässig und ausdrücklich erscheint, ist, wenn es gebraucht wird, um die Verwweigung einer Strasse in mehrere zu bezeichnen. Wir glauben hier... die Nachwirkung jener Epoche zu sehen, wo die Nation dem Sensualism hingegeben war, gewohnt sich materieller, mechanischer, atomistischer Ausdrücke zu bedienen, da denn der forterbende Sprachgebrauch zwar im gemeinen Dialog hinreicht, sobald aber die Unterhaltung sich in's Geistige erhebt, den höheren Ansichten vorzïglicher Männer offenbar viderstrebt. (II. 7. 208. 21. Zur Morphol. II. 1832.) H 
Esprit: „Wir redeten sodann über den Unterschied des deutschen Begriffs von $\mathrm{G}$ e ist und des französischen esprit. Das französische esprit, sagte G., kommt dem nahe, was wir Deutschen $W$ itz nennen. Unser Geist würden die Franzosen vielleicht durch esprit und âme ausdrïcken; es liegt darin zugleich der Begriff von Productivität, welchen das fransösische esprit nicht hat. Voltaire, sagte ich, hat doch nach deutschen Begriffen dasjenige, was wir Geist nennen. Und da nun das französische esprit nicht hinreicht, was sagen nun die Franzosen? - In diesem Falle, sagte G., drücken sie es durch gén $i$ e aus. " (G. VIII. 56. - 2I. III. I83 I mit Eckermann.)

G e n i e: Worte, Beiworte, Phrasen au ungunsten der höchsten Geistesgaben verbreiteten sich (in der sog. Geniezeit) unter der geistlos nachsprechenden Menge dergestalt, dass man sie noch jetzt im gemeinen Leben hie und da von Ungebildeten vernimmt, ja dass sie sogar in die Wörterbücher eindrangen und das Wort génie eine solche Missdeutung erlitt, aus der man die Notwendigkeit ableiten wollte, es gänzlich aus der deutschen Sprache zu verbannen. - Und so hätten sich die Deutschen ... um die schönste Blüte der Sprache, um das nur scheinbar fremde, aber allen Völkern gleich angehörige Wort vielleicht gebracht, wenn nicht der durch eine tiefere Philosophie wieder neugegründete Sinn fürs Höchste und Beste sie wieder glïcklich hergestellt hätte. (I. 29. I46. D. 1. W. 19. 1830.)

gullibjlity: ich merke wohl, es geht aul Schelmerey hinaus, aber ich wïnsche aus deinen lexicalischen Schätzen einige Beyspiele, wie es gebraucht zeard. (IV. 39. 2 II. 27; a in I. VII. 1825 an Ottilic.)

Fa is e u r: Ein beschränkter ehrlicher Mensch sieht oft die Schelmerei der feinsten Mächler (faiseurs) durch und durch. (1. 42 11. 128. 12; Sprüche 1823.)

ha leter: Vergebens versuchte ich das französische Wort holiter in seiner ganwen Bedeutung auswudrücken, selbst die 
mehreren gebrauchten Worte [schnaubt, ächzt, lechzt] fassen es nicht ganz in die Mitte; aber so viel scheint mir doch höchst wahrscheinlich, dass weder Rafael ... noch Correggio ... geschnaubt, geächzt, gelechzt, gestöhnt, haletirt habe. (I. 45 . 319. I. Diderot's Versuch über die Mahlerei. II. I799.) Wir sehen, G. ging zur Umgehung von Fremdwörtern sogar schon so weit, verschiedene deutsche Worte gleichzeitig zum Ersatz heranzuziehen.

I n sertion: Hier ist vielleicht der Ort zu bemerken, dass die französische Sprache bey ihren grossen Vorzügen doch an gewissen Worten leidet, welche, wenn sie von lebendig organischen Wesen reden wollen, mechanische Kunstbegriffe herbey führen. So ist das Wort insertion nicht glücklich, um zu bezeichnen, dass ein Blatt sich an dieser oder jener Stelle des Stengels entwickelt habe; es ist keineswegs an-oder eingeheftet, sondern nachdem es den Stengel hat bilden helfen, löst es sich wohl, aber nicht als ein fremdes, sondern als ein reifes. (II. I3. 59. I 5. Morphol. I. Paralip. 63.)

$\mathrm{K}$ a tzen jammer: Die Perser haben ein Wort, welches einen unbehaglichen Zustand andeutet, in welchem sich der Trinker den andern Morgen nach einem Rausch befindet, und was der Deutsche mit dem scherzhatten Namen Katzenjammer belegt. Ich hab es im Chardin gefunden, es bedeutet in wörtlicher Übersetzung einen „freudlosen Zustand“. (IV. 25. 4I8. Konzept an H. F. v. Diez. 20. V. 1815.)

$\mathrm{M}$ a té $\mathrm{r}$ i a u $\mathrm{x}$ : dieses Wortes bedient man sich, um die Theile eines organischen Wesens auszudrücken, die zusammen entweder ein Ganzes oder einen untergeordneten Theil des Ganzen ausmachen. In diesem Sinne wïrde man den Zwischenknochen, die obere Kinnlade, das Gaumenbein Materialien nennen, woraus das Gewölbe des Rachens zusammengesetzt ist ... Im allgemeinsten Sinne bezeichnen wir aber durch das Wort Materialien unzusammenhängende wohl auch nicht zusammengehörige, ihre Bezüge durch willkürliche Bestimmung erhaltende Körper. Balken, Bretter, Latten sind Materialien 
einer Art, aus denen man gar mancherlei Gebäude und so denn auch z. B. ein Dach zusammentügen kann. Ziegeln, Kupfer, Blei, Zink haben mit jenen gar nichts gemein und werden doch nach Umständen das Dach abzuschliessen nöthig. Wir müssen daher dem französischen Wort matériaux einen viel höheren Sinn unterlegen, als ihm zukommt, ob es gleich ungern geschieht, weil wir die Folgen voraussehen. (II. 7. 206. 3. Zur Morphol. II. I832.) - Aus derartigen für G.s neue morphologische Wissenschaft nötig werdenden $\mathrm{Be}$ deutungsveränderungen geläufiger termini technici erklärt sich zum Teil der geringe Anklang, den seine Ideen fanden; man verstand das Wort in seiner alten Bedeutung, G. verwandte es in einer modifizierten. Sein Unmut über die unzulänglichen Sprachmittel wird gerade an diesen Beispielen begreiflich (vgl, auch S. I 8).

$\mathrm{N}$ i c e: Die englischen Lobredner sprechen gar von nice experiments, welches Beiwort alles, was genau, streng, schart, ja spitzfindig, behutsam, vorsichtig, bedenklich, gewissenhaft und pünktlich bis zur Übertreibung und Kleinlichkeit, einschliesst. (II. 4. I26. 26. Histor. Farbenl.)

O p t i c s: Obgleich das englische Wort Optics ein etwas naiveres Ansehen haben mag, als das lateinische Optice und das deutsche Optik; so driickt es doch (als Titel von Newtons Werk) ohne Frage einen zu großen Umfang aus, den das Werk selbst nicht ausfïllt. Dieses handelt ausschliesslich von der Farbe, von farbigen Erscheinungen. Alles ïbrige, was das natïrliche oder künstliche Sehen betrifft, ist beinahe aus. geschlossen. (II. 2. 5. 18. Polem. Farbenl. Einltg. 9.)

Orga $\mathrm{n} \mathrm{sch}$ : Schon lange sagt man organisch, Organism, Organisation, Organismus ganz richtig; nur für die Negation dieser Begriffe hat sich ein unrichtig gebildetes, ganz etwas anders aussagendes Wort eingeschlichen. Von organisch kann der Gegensatz nur unorganisch heissen, oder wenn die Verneinung ebenfalls griechisch scin soll, anorganisch (àvópravos). Anorgisch würde als Nachbildung von àvopros zorn. 
los bedeuten. Die Sylbe an obgleich nicht Stammsylbe begründet im Deutschen wie im Griechischen den Unterschied zwischen Worten mit derselben Hauptsylbe org und darf deshalb nicht unterdrückt werden, die Kürze des Wortes ist keine Empfehlung desselben, wenn sie Zweideutigkeit veranlasst. Wir haben überdiess noch Orgien und orgisch (orgische Feier) aus dem Griechischen herüber genommen. Anorgisch und unorgisch würde demnach auch für die Negation dieses Begriffs genommen werden können. (I. 40. 334. I. Die Negation des Wortes organisch. Jen. Lit. Ztg. 13. V. 1805.) Schon 30. III. I 805 verlangt er in einem Briefe an Eichstädt, daß in einem für die Jen. Lit. Ztg. bestimmten Aufsatz das unglückliche anorgisch in anorganisch verwandelt wird.

P I a n: Noch ein Wort führen wir an, das Wort Plan. Weil sich, um die $M$ aterialien wohl zu componireneine gewisse voraus überdachte Anordnung nöthig macht, so bedienen sich jene (französ. Naturforscher) des Wortes Plan, werden aber sogleich dadurch auf den Begriff eines Hauses, einer Stadt geleitet, welche noch so vernünftig angelegt, immer noch keine Analogie zu einem organischen Wesen darbieten können. Dennoch brauchen sie unbedacht, Gebäude und Strassen als Gleichniss; da denn zugleich der Ausdruck Unité du plan zum Missverständnisse, zum Hin- und Widersprechen Anlass gibt und die Frage, worauf alles ankommt, durchaus verdüstert wird. Unité du Type würde die Sache schon näher auf den rechten Weg geleitet haben. (II. 7. 209. 7. Zur Morphol. II. 1832. Streit St. Hilaire-Cuvier.) $\mathrm{P}$ odhora: Im böhmischen heisst Podhora eigentlich unter dem Berge... In späterer Zeit, wo die Nationalnamen in deutsche verwandelt wurden, hat man Podhora-Berg gesagt; diess würde aber eigentlich heissen Berg unter dem Berg, wie wir ja dergleichen ähnliche pleonastische Verdoppelung be. lachen, wenn von einem Chapeaubas-Hut die Rede ist. Deshalb erlaube man uns die kleine Pedanterie durchaus Podhora zu sagen, und verstehe hier zu Land immer den PodhoraBerg darunter. (II. 9.63.7. Min. u. Geol. Marienbad I82 I.' 
Poesie de circonstance: Wenn wir im Deutschen Gelegenheitsgedicht sagen, so pflegen sich die Franzosen mit Poesies de circonstance auszudrücken. Dies veranlasst uns wirklich, einen Unterschied zwischen beiden anzuerkennen. Das Erste wäre, wenn der Dichter eine vorübergehende Gelegenheit ergreift und sie glücklich behandelt; das Zweite, wenn er einen Umstand glücklich zu benutzen weiss. (Hempel 29. 665. Einzelh. ü. franz. Lit.; Nachl.)

$\mathrm{R}$ a dotire $\mathrm{n}$ : Wenn ich in diese Bogen hineinschaue, so kommt mir's manchmal vor, dass ich älter werde und dass ich radotire: denn radotiren heisst nicht, wie das gemeine Lexikon sagt, allein albernes Zeug reden, sondern auch das Rechte zur unrechten Zeit sagen; welches dem sogenannten Verstande immer albern vorkommt. (IV. 21. 195. 21; am 21. II. 1810 an Reinhard.)

romantisch: Auf alle Fälle jedoch müssen die Romantiker auch dort (in Italien) in kurzem die meisten Stimmen für sich haben, da sie ins Leben eingreifen, einen jeden zum Zeitgenossen seiner selbst machen ... Wobei ihnen denn ein Missverständniss zu Gute kommt, dass man nämlich alles, was vaterländisch und einheimisch ist, auch zum Romantischen rechnet und zwar deshalb, weil das Romantische an Leben, Sitten und Religion herantritt, wo denn Muttersprache, Landesgesinnung als höchst lebendig und religiös erscheinen muss... Zugleich ist uns ein Beispiel gegeben, dass ein Wort durch Gebrauchsfolge einen ganz entgegengesetzten Sinn annehmen kann, da das eigentlich Romantische unseren Sitten nicht näher liegt als Griechisches und Römisches. (I. 4I I. I34. Klassiker u. Romantiker in Italien. K. u. A. II. 2. I820.) $S$ h a nd e is m (us): nennt er die Unmöglichkeit über einen ernsten Gegenstand zwei Minuten zu denken. (I. 42 II. 203. 20. Aus Makariens Archiv.)

curkpiveıv: Wir mögen anstatt der griechischen Worte curkpivelv und diakpiveiv in andern Sprachen setwen, was wir zeollen: Zusammenzichen, Ausdehnen, Sammeln, Ent- 
binden, Fesseln, Lösen, rétrécir und développer etc., so finden wir keinen so geistig-körperlichen Ausdruck für das Pulsiren, in welchem sich Leben und Empfinden ausspricht. Überdies sind die griechischen Ausdrücke Kunstworte, welche bei mehrern Gelegenheiten vorkommen, wodurch sich ihre Bedeutsamkeit jedes Mal vermehrt. (II. 3. II4. 3. Histor. Farbenl. II. Abt.)

T a r a t ella: Ich füge noch eine Bemerkung hinzu, dass dieser Tanz Tarantella genannt wird, nicht von dem Namen jenes Insekts, sondern Tarantola heisst eine Spinne, die sich vorzüglich im Tarentinischen findet und Tarantella ein Tanz, der vorzüglich im Tarentinischen getanzt wird. Sie haben also ihren ähnlichen Namen von dem gemeinschaftlichen Vaterlande, ohne deshalb unter sich eine Gemeinschaft zu bezeichnen... Ich merke dieses hier an, weil falsche Namensverwandtschaften oft den Begriff eines falschen Verhältnisses unterhalten. (Heinemann I4. 426. Über Italien 1788.)

virer: Die Franzosen bedienen sich, um diese Erscheinung bei der Färberei auszudrücken, des Wortes virer, welches von einer Seite nach der anderen wenden heisst und drücken dadurch auf eine sehr geschickte Weise dasjenige aus, was man sonst durch Mischungsverhältnisse zu bezeichnen und anzugeben versucht. (II. I. 2I6. 8. Didakt. Farb. III. $\S$ 532. I807.)

Vrille: An der Gegenseite des Knotens (der Rebe) ... erscheint das Gäbelchen ... Die Lateiner nennen es Böckchen, die Franzosen Vrille. Anmuth der letzten Bezeichnung. (II. 7. I36. II.) Diese Gabel (von den Lateinern Capreolus, von den Franzosen Vrille genannt). (II. 7. I42. 17. Zur Morphol. Weinbau. I828.)

wh ims ic a 1: Für seine Sinnesart (Lenz) wüsste ich nur das englische Wort whimsical, welches, wie das Wörterbuch ausweist, gar manche Seltsamkeiten in Einem Begriff zusammenfasst. (I. 28. 76. I8. D. u. W. I I. I8 I3.) w. = grillig, grillenhaft, wunderlich, sonderbar, seltsam, launisch. 
II.

Zu Kapitel 7 (vgl. S. III).

I. 37. 108. 3: Das Wort Weihe bedeutet heilig. Dieterich von Stade. Erklärung deutscher Wörter. S.717. (Ephemerides 1770.$)$

I. 34 I. 360. 6: Das Lehen heisst Schupf-Lehn desswegen, weil man ihn, wenn er seine Pfichten nicht erfüllt, aus dem Lehn herausschieben oder schuppen kann. (Reise in die Schweiz. 1797.) Die Erklärung trifft nahezu das Richtige: ein Schupf- oder Fallehen fällt nach dem Tode des Inhabers an den Lehnsherrn zurück, wenn die Erben nicht neu belehnt werden. Mhd. schupfen $=$ verdrängen.

IV. I2. 209. I0: Bey Ihrem Handschuh hat man den Zweifel erregt, ob man sagen könne ein Thier lecke sich die $Z$ ung $e$; ich habe wirklich darauf nicht bestimmt zu antworten gewusst. (29. VII. 1797 an Schiller.) Demnach scheint die von Schiller gewählte Fassung ,und recket die Zunge" durch Goethes Bemerkung hervorgerufen worden zu sein.

IV. 28. 41 I (Lesarten): Was mich aber sonst in der Welt genirt (um den Studentenausdruck zu gebrauchen) das sind ... (20. VII. I817 an Sartorius.) Kluge verzeichnet das Wort nicht als Bestandteil der Studentensprache.

IV. 31. 141. 14: Der Unterschied der Worte die Seine n und die Seinige $n$ ist nicht groß, das erste ist älter und ernster, das letzte neuer und gefälliger und so kann dieses bei gegenwärtiger Gelegenheit (Denkmalsinschrift für Blücher: Dem Fürsten Blücher die Seinigen) wohl stattfinden. (29. IV. I8I9 an Schadow.) Die Auskunft ist richtig; unser Sprachgebrauch würde aber wohl der älteren Form den Vorzug bei der Aufschrift gegeben haben.

IV. 46. 157. 7: Lässt man sich in historische und etymologische Untersuchungen ein, so gelangt man meistens immerfort ins Ungerwisse. Woher der Name Mephistopheles intstanden, wüsste ich direkt nicht zu beantworten; beyliegende 
Blätter mögen die Vermuthung des Freundes (Friedländers, die Zelter Goethe mitgeteilt hatte) bestätigen, welche demselben gleichzeitig-phantastischen Ursprung mit der faustischen Legende giebt; nur dürfen wir sie nicht wohl ins Mittelalter setzen: der Ursprung scheint ins I6. und die Ausbildung ins I7.Fahrhundert zu gehören (durch Teufelsbeschwörer frei erfunden). In der Beilage gibt Goethe einen Abschnitt aus D. Faustii Höllenzwang, wo im I. Kapitel Mephistophiel unter den 7 klugen Geistern aufgezählt ist. (20. XI. I829 an Zelter.) Eine befriedigende Erklärung des Wortes ist bekanntlich bis heute noch nicht gelungen,

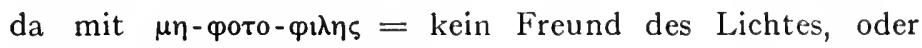
gar $\mu \eta$-fausto- $\varphi \lambda \eta \varsigma=$ kein Freund des Faust niemand gedient sein kann. Freie Erfindung des Namens anzunehmen, dürfte auch für uns noch die einfachste Lösung des Problems sein.

\section{III.}

Zu Kapitel 9 (vgl. S. I34).

I. 37. 109. 7: Im Elsas heisst die Terminei $B$ a $n n$, der Feldhüter $B$ annkert; II2. $25 S p a ̈ n n u n g$ en Irrungen; I12. $26 A m$ Staden noch in Strassburg gebräuchlich. Gay (Kai) gemauerter Platz vom Wasser an die Häuser wahrscheinlich von Gestade; II3. I Stumptreden Schimptreden. Das Geraib alles Eingeweide der abgeschlachten Tiere oder vielmehr alles was nicht als Fleischstück verkauft wird z. E. Kopf, Zunge; II3. $26 R$ ingerung, Gaffeln Zünften; II4. IO Panzerfegen zwingen und dringen. (Ephemeriden I770.)

IV. 2. 267. I8: Man kann frisch zuschneiden (für schneiden sagen sie hier hauen: Ein stück Brodt $a b$ h a ue n. (I2. VI. I775 aus Zürich an Sophie la Roche.)

IV. 4. 276. I: Man sagt auch hier zu land auf dem Wagen reiten. (9. X. I779 aus Lauterbrunn-Schweiz an Frau 
v. Stein.) - 84. 21: Hor $n$ heissen sie hier den höchsten Gipfel eines Felsens, der meist mit Schnee und Eiss bedekt ist und in einer seltsamen Horngestalt oft in die Luft steht. (I0. X. I779. Schweizerreise; an Frau v. Stein.)

III. 3. 22. I0: Die Sprache alles platt; z. B. In. Büber mut mae nits senken. Einem Bauer muss man nichts schenken. Wat saegt hae da dau. Was sagst du dazu. p. p. (Reise nach Pyrmont. Eimbeck-Wickenhausen - Eschershausen. I3. VI. I80I.)

III. 5. I24. I9: Mol tern: Bergm. Ausdruck. - Mollkanten, Moll, Maulwurf, Mollhubel Maulwurtshügel.

III. 5. 260. 12: Becherer neue Thüringische Chronic. Mühlhausen I60I: Miten für Pfennig; anfärben den Rock für anlegen; das unruhe weib, der untreue $H$ a $t z e n$. 261. 14: Thür. Chronic. wuschte er in Polen; Steuber. 263. I : Becherer Thüring. Chronic: Statt Meiler Kolkauz. (2. -6. VIII. I 8 I6.)

III. 2. I42.2 I : Sie nennen hier zu Lande einen Hemmschuh nicht ungeschickt einen Schleiftrog. (17. IX. 1797 aus Tuttlingen.)

IV. 38. 326: in vorstehendem bedeutet das Wort $M$ a l te r Gru $\beta$ oder Grand des aufgelösten Kalks, der in solchen Fällen (Erdstöße) von der Decke fällt. (8. IV. I824 an Karl August. Erläuterung $\mathrm{zu}$ einer Zeitungsnotiz.)

I. 2. 334: bid me n oberdeutsch für beben. Goethe verteidigt das Wort als oberdeutsche poetische Licenz Eichstädt gegenüber. (IV. 35. I 40 v. IO. I. I8I5.)

III. 1. 6. I4: Fische ge b a chen, geschmackt. (20. VI. I775. 1. Schweizerreise.) Auch andere mundartliche Ausdrücke sind im Tagebuch ohne weitere Erläuterung eingetragen, wodurch doch das rein sprachliche Interesse an ihnen verraten wird.

(i. IV. 33 ... richtete or (Goethe) an mich verschiedene Fragen dic auf den Kammerberg und auf die Kleidertracht, Sprache und Geschichte des Egerlandes Bezug hatten. (26. IV. 1820 mit. Grüner in Eger.) Das sprachliche Interesse tritt aber in weiteren Verkehr mit Polizeirat Grüner hinter den mineralogischen vollständig zurück. 
I. $25^{\mathrm{I}}$. $1 \mathrm{I} 2 \mathrm{ff} .:$... Kinder, welche sich ... beschäftigten ... die Samenkörner (aus der Baumwolle) wegzunehmen; sie nennen es erlesen. (W. M. W. III. 5. I829.) Desgl. werden weiterhin die Weberei- und Spinnereiausdrücke: Krämpel, Karden, Schnitz, aus dem Brief spinnen, Schneller, Brittli, Rispe, Gang, Werfte, dämmen erklärt. Der Exkurs über die Baumwollindustrie der Schweiz in den Wanderjahren geht jedoch zum großen Teil wörtlich auf eine von H. Meyer gelieferte Beschreibung zurück, die auch alle oben genannten Fachausdrücke mit Erklärungen enthält (vgl. das Manuskript Meyers I. 25 II. 262 ff.).

IV.

\section{LITERATURNACHWEISE}

(zur Einleitung S. I).

Goethes Werke, herausgegeben im Auftrage der Großherzogin Sophie von Sachsen-Weimar (abgekürzt: W.A.).

I. Abteilung: Werke im engeren Sinne; 50 Bände. (Band 32: 2. italienische Reise steht noch aus; Band 13, 15, 25, 34, 4I, 42, 49 sind Doppelbände.)

II. Abteilung: Naturwissenschaftliche Schriften. I3 Bände.

III. Abteilung: Tagebücher (I775-1832). I 3 Bände.

IV. Abteilung: Briefe; bis jetzt 46 Bände ( $1764-\mathrm{I} 830)$.

Für den zweiten Teil der italienischen Reise ist Band XIV der auch im übrigen benutzten Goetheausgabe des Bibliographischen Instituts, herausgegeben von Heinemann, herangezogen für die teilweise ebenfalls in der W.A. noch ausstehenden Aufsätze zur Literatur und die Sprüche, die Bände I9 u. 29 der Hempelschen Ausgabe, sowie der Band XXI der Schriften der Goethe-Gesellschaft (G. G.) mit den von M. Hecker herausgegebenen Maximen und Reflexionen Goethes (Weimar 1906).

Abkürzungen:

D. u. W.: Dichtung und Wahrheit.

W. M. L.: Wilhelm Meisters Lehrjahre.

W. M.W.: Wilhelm Meisters Wanderjahre.

K. u. A.: Kunst und Altertum.

Einzelbriefwechsel: (die Abkürzungen sind vorangestellt):

Carlyle: Goethes und Carlyles Briefwechsel. (Deutsche Ausgabe.) Berlin 1887.

Rausch, Goethe u. die deutsche Sprache. 
Frau v. Stein: Goethes Briefe an Frau v. Stein, herausgeg. von Ad. Schöll. 3. Aufl. v. J. Wahle. Frankfurt a. M. 1900.

Knebel: Briefwechsel zwischen Goethe und Knebel. II. Teil. Leipzig I 854. Schultz: Briefwechsel zwischen Goethe und Staatsrat Schultz, herausgeg. von Düntzer. Leipzig 1853 .

Riemer: Briefe von und an Goethe, herausgeg. von Fr. W. Riemer. Leipzig 1846 .

Boisserée: Sulpiz Boisserée. II. Bd. Briefwechsel mit Goethe. Stuttgart 1862 .

Eichstädt: Goethes Briefe an Eichstädt, herausgeg. von Biedermann. Berlin 1872 .

Strehlke: Goethes Briefe, herausgeg. von Fr. Strehlke. 3 Bde. Berlin I 884. Zelter: Briefwechsel $z$ wischen Goethe und Zelter, herausgeg. von Fr. W. Riemer, Berlin 1834. Bd. 3-6.

Humboldt: Goethes Briefwechsel mit den Gebrüdern v. Humboldt, herausgeg. von F. Th. Bratranek. Leipzig 1876. (Neue Mitteilungen ans Goethes NachlaB III.)

Soret: Goethes Briefe an Soret, herausgeg. von H. Uhde. Stuttgart 1877 . Reinhard: Briefwechsel zwischen Goethe und Reinhard 1807-1832. Stuttgart 1850.

Wolf: Goethes Briefe an Fr. August Wolf, herausgeg. von Mich. Bernays. Berlin 1868.

O'Donell: Goethe und Gräfin O'Donell, herausgeg. von R. M. Werner. Berlin I884.

Sternberg: Briefwechsel zwischen Gocthe und Kaspar Graf v. Sternberg, herausgeg. von Bratranek. Wien 1866.

Göttling: Bricfwechsel zwischen Gocthe und K. Göttling I824-I83I, herausgeg. von Kuno Fischer. Heidelberg 1889.

Nat. Korr.: Goethes Naturwissenschaftliche Korrespondenz 1812-1832, herausgeg. von Bratranek. 2 Bde. Leipzig 1874. (Neue Mitteilungen aus Goethes Nachlab I/II.)

(i. G. 13 und 14: Goethe und die Romantik. Schriften der GoetheGesellschaft. Bd. XIII und XIV.

\section{Gespräiche:}

Goethes Gespriiche, herausgegeben von W. v. Biedermann. 10 Bände. Weimar. (Abgekürzt: G.)

foethes Unterhaltungen mit Friedrich Soret, herausgegeben von H. Burkhardt. Weimar 1905. (Abgekürzt: Burkhardt.) 


\section{REGISTER.}

acheminement 252

Adelung, J. Chr. 99 f. 122 Akademie nützlicher

Wissenschaften 98

arabisch $202 \mathrm{f}$. $23 \mathrm{I}$

Archaismen 154

Arnold: Pfingstmontag $131 \mathrm{f}$.

Aussprache 183f.; griechische I9I

Babst, D. Gg. I3If.

\section{bepfählt 150}

Beredsamkeit 80

Bergmannsprache 31

Berufssprachen 133. 149

Bibelgesellschaft 241

Bibelübersetzung $233 \mathrm{f}$.

biblische Fragen, zwei 60

Blücherdenkmal (Inschrift) 121

Briefroman 190

Briefstil 47. 120

„Buchstabensparer" 97

Bühnensprache 96. 183f.

Byron 115. 229

Calderon (Übersetzung)

Campe, I. H. I 38 f. [238

Chaos (Zeitschrift) 206

chinesisch 204. 23 I

Composition 18. 254.

Dänisch 146

Deklination des Adjektivs I 02

„Deutsche Sprache“ (Aufsatz) 81. 88. I58f, 206 Deutscher Charakter 82 . Dialektdichtung $125 \mathrm{f}$. „Dictionnaire détractif“" Dikticren 42f. 97 [I IO Druckfehler 184

Eckermann 49

„Elbe" 123

embranchement 255 englisch 80. I19. I 82.

Anm. 189. I 98f. 229

„Eridanus “ 138

Erinnerung 249

esprit 256

Etymologie 106f.

„etymologisches Spiel“ 62

Euphemismus 80

Farbenlehre 23. 40

Faust (Übersetzung) 220.

Fichte $I_{1} 3$

finnisch 231

Flickwörter I I 2 f.

französisch 85. 90. II9. 168. I 89 . I 94 f. 2 I9f.

Fremdsprachen $205 \mathrm{f}$.

Fremdwort 68, 101. 1 $36 \mathrm{f}$

Gall (Phrenolog) 26

gälisch 205

gegenständlich 250

Geheimsprache 190

génie 256

Gesang $54 \mathrm{f}$.

Gesellschaft v. Sprachfreunden $138 \mathrm{f}$.

Gesellschaft f. d. Reinigung der deutschen Sprache 160

Gesellschaft f. deutsche Geschichte 74

Geßner 174

„Gleichnis" 207

Goethe :

Name 59. 99

Sprache 50.124. 144f.

Mundart $134 \mathrm{f}$.

Sprachkenntnisse 189

Schrift 94

Jugendstil I I I $\mathrm{f}$.

wissenschaftl. Tätigkeit

Bibelstudien $60 \quad[23 \mathrm{f}$. altdeutsche Studien 75 . 105

nationale Gesinnung 76

Göttling (Prof.) 94. $102 \mathrm{f}$.
Gottsched 123

Götz v. Berlichíngen 140

Grammatik Ioof. I 89 f.

Grammatik, deutsche v. Grimm 74

Graphologie 48f. 94

griechisch $77.191 \mathrm{f} .210 \mathrm{f}$.

Grimm, J. 65. 74. 161. 201. 231

Grimm, W. 74. 105. I 35.

Grübel, J. K. 124f. [161

haleter 256

Hamann 62

Handschriftensammlung 48. 94

Hebel, I. P. I $26 \mathrm{f}$.

hebräisch 194. 234

Heilsberger Inschrift $75 \mathrm{f}$.

Heine, H. 135

Herder 40 f. 59.61.83.123

Hermann und Dorothea (Übersetzung) 207.215

Hexameter $175 \mathrm{f}$.

Homer I92 f. 234

„Hör-, Schreib- u. Druckfehler" I 84

Humboldt, W. v. 7 f. 64 f. I 63 f. 177

Jakob, Therese v. 232

Jambus 174

Jean Paul 97. 106

Illustration 55

indisch 67

Inschriften I2 I

insertion 257

Interpunktion $94 \mathrm{f}$.

italienisch 78. 186. 199 f. $226 \mathrm{f}$

Judendeutsch I90. 194

Kayser (Komponist) 226

„,Kein Vergleich“ 106

Kepler 38

Klopstock 41 . 78,97.174. 176 
Kunst, bildende und portugiesisch $200 \mathrm{f}$. Sprache $52 \mathrm{f}$.

Provinzialismen 154.183

Purismus I $53 \mathrm{f}$.

Lateinisch 81. I 58, I 68 . I89. I $92 \mathrm{f}$. 2 IOf.

Lavater 30

Lessing 102

lettisch 205. 231

Luther 170.233 f. 241

Manzoni (Übersetzg.) 236 matérial 18.257

Mathematik 56. 223

Meißner Deutsch 122

Mephistopheles 262

Metrik I $72 \mathrm{f}$.

Mittelhochdeutsch 75. 104

Moritz, K. Ph. 63. 173

Morphologie 23

Mundarten I22f. (oberdeutsch 124 ;Nürnberger I 25 f. ; niederdcutsch I 26. I 29. I 31 ; allemannisch 127 f.; Straßburger $13 \mathrm{I}$.)

Musik und Sprache 5 I. 54f. 179

"Nativität" 87

"Neologen" I 60

neugriechisch 2 r 8

Newton 33

Nibclungenlied 75. 104 "Nichts anders als" I I 4 f.

Ochlenschläger $145 \mathrm{f}$.

Olivier 99

orientalische sprachen

202. 230

Orthographie $94 \mathrm{f}$.

"Pädagogische Provinz" perfid 224

persisch 202

Philosophie u. Poesic 27

Phonetik $182 \mathrm{f}$.

Phrasen 81. 112.

plan 259

llaten 86

polnisch 201
"Purist" I37. 138 Anm.

Radlof (Germanist) I 5 I

Rechtschreibung $94 \mathrm{f}$.

„Regeln für Schauspieler“ $\mathrm{I}_{3}$

Reichsanzeiger, Berliner

Reim $174 \mathrm{f}$.

Riemer 5 f. 192

romanische Sprachen

romantisch 266 [218f.

Ruckstuhl, K. I $52 \mathrm{f}$.

$\mathbf{s}$ (in Zusammensetzungen)

Sanskrit 204

Schiller I09. I 19. I 28 . I74

Schlegel, IV. I77. 202

Schreiben 40

Schreibfehler 184

Schrift 93 f. 128

Schriftsprache I $22 \mathrm{f}$.

serbisch 20I. 23 If.

Shakespeare 59

Silbenmessung 173

slawisch $20 \mathrm{rf}$. 230f.

Sophokles 193

spanisch $200 \mathrm{f}$.

Sprache: Surrogat 14; unzulänglich 14. 17; unvollkommen I7; Entstehung $60 \mathrm{f}$; Lob $57 \mathrm{f}$. „Sprache“ $83 \mathrm{f}$.

Sprache, deutsche: Tadel $80 \mathrm{f}$; Lob $82 \mathrm{f}$.

Sprachensozietiit, asiatische 230

"Sprachforscher" 138

Sprachkarte 65 .

Sprachkenntuisse $205 \mathrm{f}$. 2100 .

"Sprachreiniger" I 6 I

Siprachunterricht $69 \mathrm{f}$.

stiingeln $\mathrm{I}_{4} 8$

statistische Nitchweise If.

Siclla 140

Stil I I If.; philosophischer $117 \mathrm{f}$.
Studentensprache 76.262.

Symbolik $28 \mathrm{f}$.

Tagebücher $5 \mathrm{f}$. $73 \mathrm{f}$.

tamulisch 205

$\operatorname{Tan} z 53$

Terminologie 25. $3 \mathrm{If}$.

teutsch 98

Tropen $25 \mathrm{f}$.

tschechisch 202

Ubersetzung 90. $207 \mathrm{f}$. ung 106 [220. 233f.

Unterricht, altsprachlicher

Urphänomen $3^{8} \quad[2 \mathrm{I} 5 \mathrm{f}$.

Venetianische Epigramme 77. 205

Voß d. Ä. 109. 126.

175f. 234

Voß d. J. I09. 126 . I76f. I 93

Wallenstein (Schillers) 208

Weltliteratur 90. $167 \mathrm{f}$. 206 f. 240 f.

IVerner, Bergrat 6. 37

Werther (Übersetzg.) 226

Wieland I I 9.I 75.233.236

Wolf, Fr.A 52.175 f. 178

Wolke, Chr. H. 98. 160

Wort, hergebracht 12; arm 13; abstrus 16 ; unzulänglich 12; öd 15; schlecht 20; dürftig 22; falsch 25 ; bedenklich 19

Wortarbeit 13

Wörterbuch, deutsches $108 \mathrm{f}$.

Wuk (Professor) 23 I

W underhorn, Des Knaben 105

Xenien 123. 137f. 162

Zahl 13.56

\%cichnen 53

\%citungsdeutsch II 3

Zelter 120.179 


\section{Verlag von B. G. Ceubner in Leipzig und Berlín}

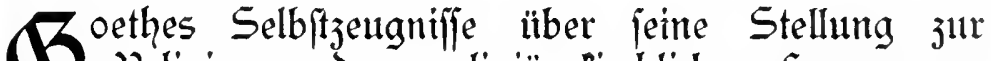 (1) Religion und $\mathfrak{j}^{\mathrm{ll}}$ religiös=Firchlithen fragen von Beh. Rat D. Dr. Theodor Dogel. 3. 2unfiage, Eehefitet 143.20 , in}


fammenjtellung von Uuspipräden des Diḑters äber Religlon und religiöje fragen, wie er fie in den veridiedenften perioden feines Eebens, in gehobenen whe georü den stmmungen, in feieriichen Kunftormen wie in ber zwanglofen Sprahe des Derfehrs nit Engvertrauten getan hat. Eler f́çauen wir ihn, ohne mit fremben 2lugen fehen ju mïffen, ganj wie er war, als grogen Kämpfer und harnonijaen Beftalter, ber intmer wieder zu den grofen fragen des Dajeins 3urüdfehrt und über Bott und Welt, über Kämpfen und Wirfen des menfąen, über chriftus

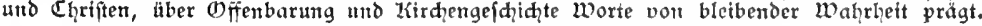

Wem daran liegt, daf die wahre Eimftht in Boethes wefen und 2urt, das ecte und rechte Derpänonis unferes Didłerfürften immer mehr gewonnen uno die Erfenntnis feiner Größze inmer Plarer, fiderer und intiger werbe, der wird es mit lebhafter freude begräfen, daf die vorliegende Shrift in neuer Uufiage erfhienten ift. . Das gejamte geiftige und pojiale Eeben unferes Dolles wird aus Dogels jhônem werfe reithen Bewinn jiehen, namentít aber ift der freant und Derehrer Boethes dent Derfaffer für feine mühevolle und felbitioje 2irbeit ju wärmptem Dant verpflidįtet. ..."

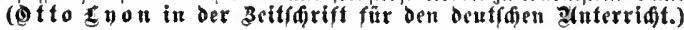

Eine fyitematif de einheltlidhe und abgerundete Weltanfhounng dar man nidht erwarten und foll nan niąt finden. Dajt war Boethe belanntliá jn vieljettig und fubjeftiviftid. Ja, Die Dertreter der verjhiedenartigiten ReIigionsbefenntniffe fönten bei dicfent reiden Beife Unleiken madien. OCft entjäft uns nidit das, was Boethe gefdurieben, fondern wie er es gejdrieben. 2lud für das biblifhe Ehriftentum fälit mandes herrlidie Plajifide wort ab neben iharf farfaftifhen 21 berungen. Jedenfalls ein 23 ah von bleibendem Werte, reht geeignet, jum zadifinen anjuregen."

(Strafburger zoft.)

,Die 2frbeit eines feinen Belftes und eines tiefen Bomütes ift ganz dazu geidhaffen, mandien zur 2lufflarung und jur Erbauung zu bienen." (马er Eürmer.)

,Es war nit eit Erbauungsbuh und wiro es nod lange jein. Mebr fann man Paum von etuent Bud? fagen."

(Die corenrfinft.)

"Das Bejte ûber Bothes Zieligion bieibt bod? Imner vogels reidhaltige und fein= finnige 2luswahl und Jnfammentellung, die in leidter Eachorduni, ohne die pritenfion eines

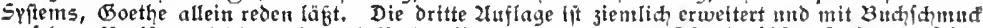
verfehen, Regifter erlefictern bas 2luffudien."

(êcofogiffier 3abresterifit.)

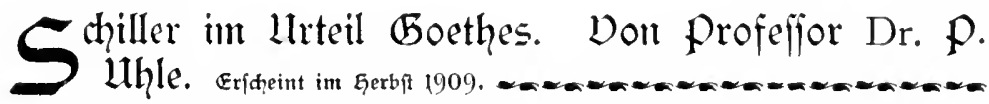

für Derfänonis und Würoigung Saillers als Diditer und Menjohen, für ote Kenntnis feines interfen Wejens gelten mit volffem Redt Boethes Urteile als untrüglidifte und juver= läffigfte Jeugniffe von unịhärbarer, von ausjilaggebender Bedeutung. Wenn ber Dlater über den Diditer, der freutd über den freund ipridt, fo folgen wir willigft, folgen wir blint fetner führung. Darum darf es wohl auf allgenteine Ceilgahnte hoffen, wenn das vorliegende Bud ble Boethejden Zengerungen, die in erjaunlider Jahl in Briefen, Mitteilungen 3 ur eigenen Eebensgefhidhte, Bejprädhen, Diditungen, ujw. vorlieger, ju einent Befamtbilde vereintat und diejem zur 2lbrundung und Dervolifändigung alle vollwertigen und zeitgenöfitiden $\mathcal{B}_{e}=$ Fundurgen uber Boethes Stellung und Derhălnis ju Sdiller cinfügt, voran die Jeugniffe Sdillers felbit, eines 5 umbolot und Körner. In diefem 3 ild fhauen wir dem die "3rüber auf dem "Chron", untfąlungen vom, ,herjlfhell "Band der wedifelmeigung", aus ihm leuditet uns entgegen die fiebevolle 2luteilnahme eines Did̨ters an eines Didhters Sđaffen, das weife Urteif über die Erjeugniffe eines Dithtergentes, das verfätiontsvolle und innige Der: fenfen eines edlen Menjahen in die "Kreije des Denfents, Empfindens und Wirfens" eines

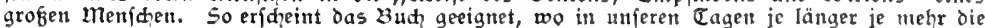
Bildung zu Menfकengüte und Sdaffensluft als eine Gauptaufgabe erfannt werden mag, int Shillerjaḩ, ein Saerflein jur Derberrlidung bes Betjesgewaitigen beizutragen.

$\mathcal{R a n f}$, Eoethes IInfquaungen. 


\section{Verlag von B.G. Ceubner in Leipzig und Berlin}

\section{1 rifere 2ltutteripradhe, ihr $\mathfrak{b}_{\text {erden }}$ und ihr $\mathfrak{w}_{\text {ejeen. }}$

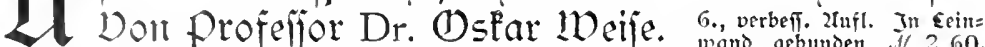

Die norliegenoe Edrift, die vom alfgemeinen bentiden Epradyerein mit einet Elatengabe

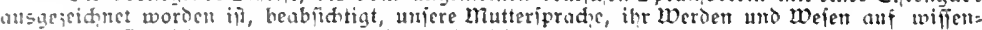

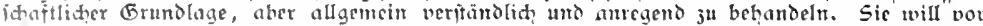

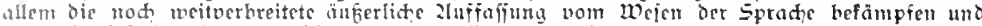

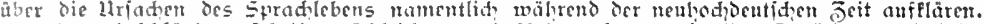

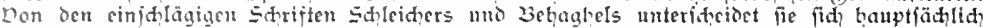

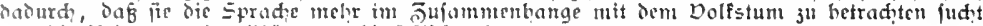

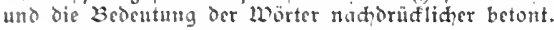



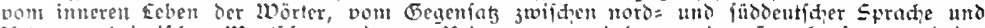

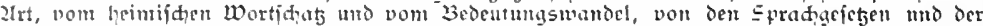

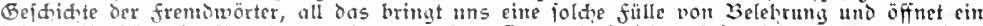
joldes Derlänonis für cines unfer temetfen Gäter, Dafj jeber fefer feine frende an dent

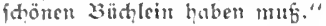

(Sdinci\}. (Evangef. Sdfultblaft.)

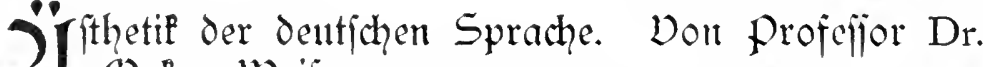 (1) sfar Weife. \\ 5., verbefierte 2lutiage. \\ Bebunden At 3 , -}



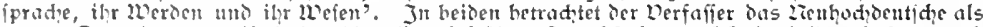

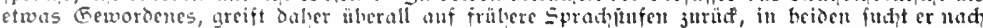



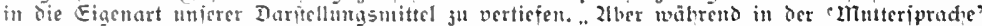

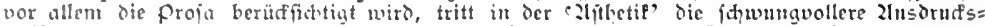
weije der foepie in den torderurund. Demt es foll hier alles das erörtert mb beleuditet werden,


D. h. Sinn und Exerjerfreut.

Dafid es nur aleid nut cinem Worte fage: id fenne fcin 3ud über bie Deutfae Sprade, das mir jo gefallen hätte wie diefe neueple Gabe bes hereits ourd? die trefflidiften Werle um miere herrlide llutterfprathe hodverdienten Deriallers; ith fente pein 3 ud?, das

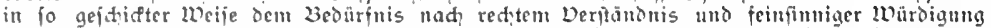
unferes edeliten Butes entgegenfäme mo fo aceinnet wäre, jedcm, wer es and fri, ber lide sult an

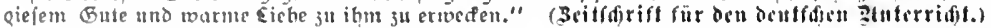

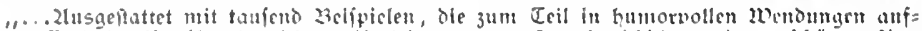

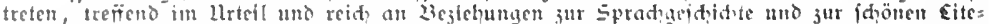

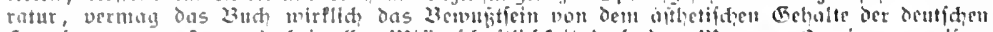

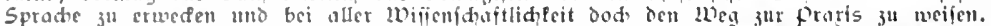

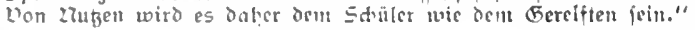

(Altip. siferulurbfatt.)

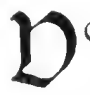

\section{on papienen Stil. Don Prof. (Dtto Schrocder.}

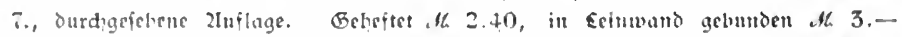

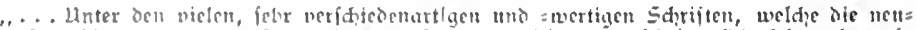

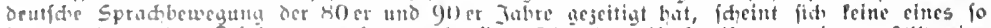
lange andanesnoen Erfolacs 34 erfreuen als (j)to Edroebers 23ud, , Lom papiernen Stil", eine

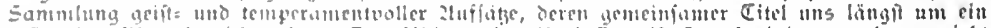

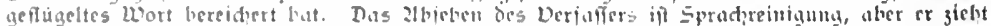

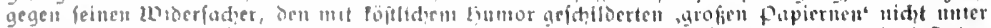

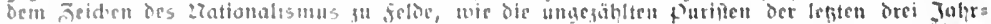

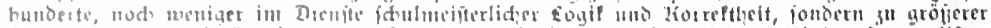

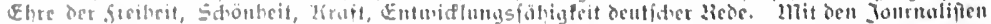



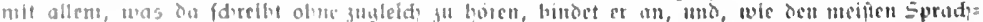

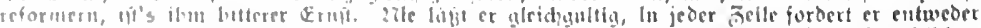

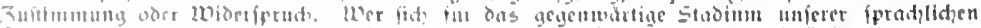

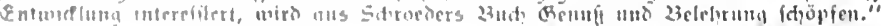

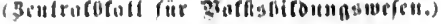




\section{Verlag von B. G. Ceubner in Leipzig und Berlin}

\section{Dipchologie der Dolfssoichtung. Don Dr. Dtto Böctel. \\ Beheftet Mh 7.-, in Eeinmand gebunden M. $8 .-$}

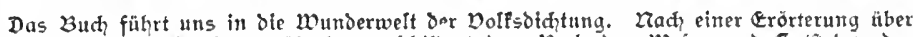
bell lltiprung bes Dolfsaefangs überhaupt fatidert das Bud bas Wefen und Entitehen bes

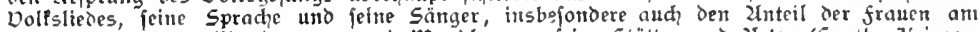
DolPsgefang, feine Wanderungen und Wandungen, feine Stätten und 2lrten (Spott=, Kriegs=, Gotjeitslicber und Cotenflagen), wïrbigt dam aber and das Dolfslied nad feinem inneren Bejalt indem es ien "Dptimisnus der Dolfsoldtung" aufjeigt, wie das in ihr herrictende verlältnis des Menfdien jur 27atur, dent im Dolfslied Itt allgeneinen, in Spott und Gumor

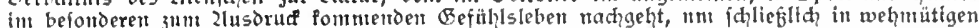
Betradtungen über das Derfinwhton hes Dolfsliedes ausjuflingen. So tit das vorliegende,

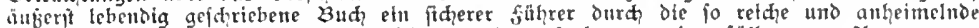

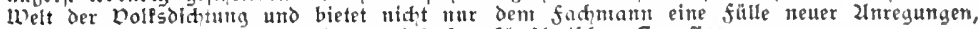
fondert jeden Gebildeten Etunden wahrhaften füptlerifden Benufies.

"Dies Buh tritt faltiht und anjpruthslos aut, ohne peos l'etangen, abueidende 2ln=

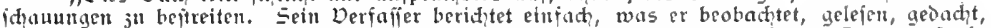
und er beriditet mit fo viel Gingebung uno anfridtiger Segeifternng für feinen (Fegenjand, fo

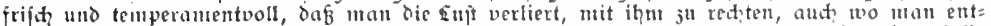

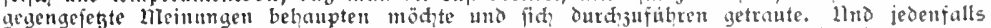
werben alle für das Volfslied Jnterefiterten bem 23 ache dafür meingefdränften Danf und 2iuhm fpenden, dab es ihnen ein ubberaus reities 2llaterial jur bequemiten Benutsung bereit ftellt."

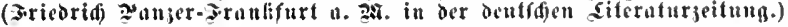

„Wie mäbten dod Gerber und Boethe, die 3räber Grintm und llhland voll freude "11t) voll Danfes fell itber diefes $\mathcal{B}_{4}$, die reife frudit eines dem Dolfstied gewionteten Eebenswerfes. Die pirfte des Dolfslieds hat fin ilhm in ihrer vollen Klatheit und Cotalität

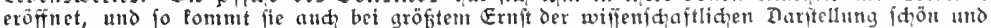

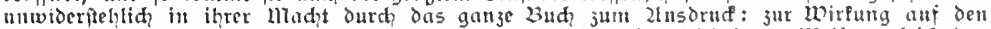
Eejer. So wird es betrn weriog 3 äd ger geben, deren Eeftite in gleich hoher weije zugleid oen aniprudisvollen Belehrten erfreut und burd Spenoung eines ganj auserlejenen Bennfies alle Kräfte des Befühls in jeinen Bam jieht."

(Tranlfurter Beifung.)

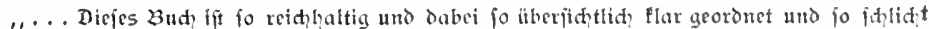

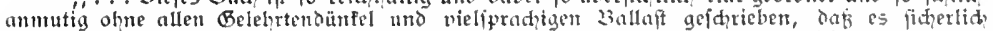
fehr viele mit freude lefen werden. Llto nientand wirb es ohue wifiensbereteterung aus oer Gand legen. Es hat doppelten Wert. Es bitet h fehem eigentliden eerte eme grobartig

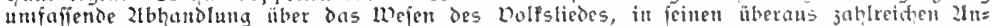
merfungen eine 3ibliographie jum chema und fonte einen llegweifer fur jeden, der die emp=

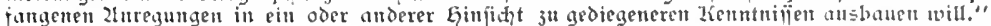

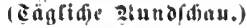

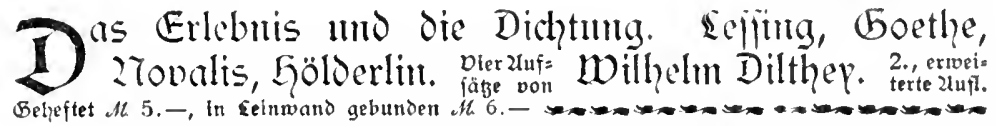

,.2man Penut Dilthey als Pfadjinder einer nenen fiphologie, der überall das Eebendige, Jrationale fah, dent man niht mit Geleln und Sţrauben beifommen fonnte. Jhm fonte das Eiteraturhiforifergerede von Dichteridulen, Beeinflujung, grofen Erlebuifien mibt genitgen.

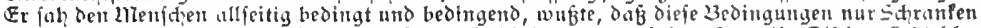
find, He denen fich die unendidye Kraft des Jnbividums entfalten Pann." Dilthey fieht lifer das lebendige Wadstum des Beifteslebens eines Dolfes, aus dem die grogen hianter nut Lotwendigfeit hervorgehen, bedingt und bedingend, und fo löf fith ber wiberifreit zwijhen ber

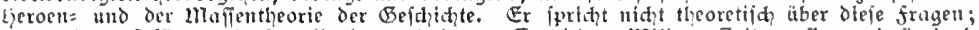
aber wie er Ecifing nto zovalis heransholt aus Erabition, Milieu, Jeitgenofien und fie bod?

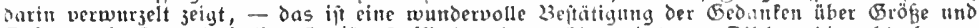

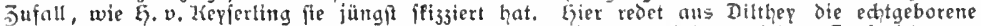
Sduvermut elnes Dihters, Der das fajit eines fiebziajâhrigen Eelens jiel)t. Er ipriat von der Cragif des nlenfipen, der eine mendidye forberung in Endidten ju exfillen hat, eine forderung, ote til fich wieder den furhtbaren Dualismus von joent und Zatur birgt, und er fiebt in diejer Cragif 5 dionheit und Jauber diefes tranrig=iüben Dajeins. "Wir haben ote Sdiötheit des Eebens in unjeren Derhältuiñen 3 ben llenjinen, und in jedem derjelben ilt dod insgehemt ein Erentendes, das nidt beritḩet werder darf."

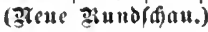




\section{Verlag von B. G. Ceubner in Leipzig und Berlin}

\section{Deut Tche Charakterköpfe}



\section{Begründet von đailhelm Capelle}

Dieje Samintung will veriuden, die periönlidfeiten, die an dem werben unierer nationalen Kultur nitgewirft, die entideidende perioben diefes werbens in ihrem wejen wiberipiegeln, in

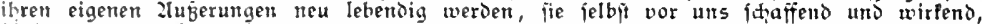
fiblent uno dertend hintreten laffen, wie fie einfi in threr Jeit und aus ihrer jeit heraus empifumben und gehandelt haben. So wird diefe Sammlung in aom bejonderer weife eine aründlidere Kenthis und ein befferes Verîtändnis unjerer natlonalen Kultur fördern, 3 ur Er=

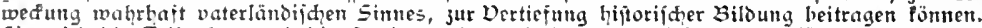
Sie wird die Ceilnabme und die freude an dem werden urd wirfen der perionticteit mehren,

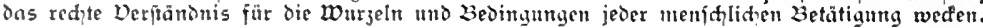

\section{Goethes freundinnen.}

Briefe ju threr Charafteriftif. 2lusgewăhlt und ein= mit 12 Bildnifjer. Bebunden \& 3 .-

Die Samminng bringt Dofumente aus den Eeben folgender fraten: Cornelia Boctle, Sufamna Klettenberg, Eotte 3 uff, Johanna fablmer, Sophic von Earodie, Eili, charlote

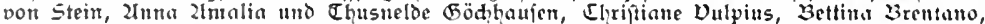
minna Eerjlieb, llarianme non willener und Lllrife vor Eeveţow, Die zlufaulse, fär alle biefe framen dorafterifitide perionlide Dopumente ausjuwäblen, if beshalb nid̆t lridt, weil

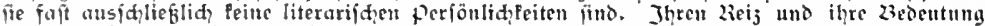
haben fie fait alle als Eebendige, als llenidien gebabt.

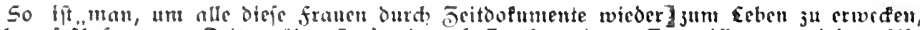

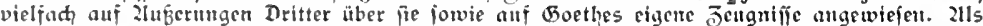

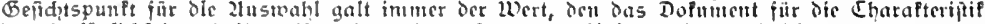
Der ferionlidfeit und ihrer lingebung bot. Ju erpier finie murde natürlid bevorjugt, was die Bejiehung 3 u 50 ethe beleudiet, in ztveiter aber and alles, was bic perjönlidifeit fonit

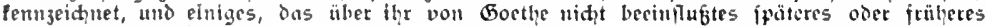
Eeben Zlusfunft gibt.

Gertrud 23ăumer will bem gebildeten Dcutiden fublifum, Goetles fremndinten', non

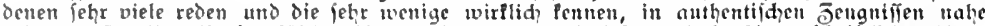
bringen; fie gibt alio forgfältige 24 sivahl aus ibren Zricfen und fonjtgen idriftlidien 2lus:


eiame, Pnappe Echens= und Sharafterbilocr, bite von cimem wahrlaft wohlutenien Streben nad

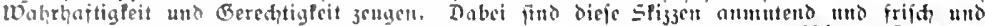
mit frarfer perionltiter Ziote gejdricber.".

(D)s Biffell für Alte.)

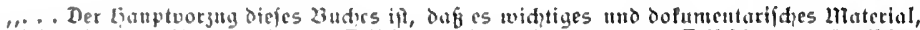

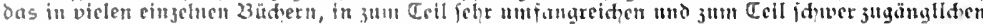

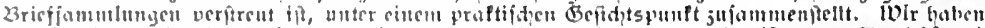

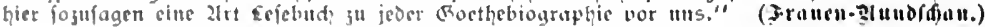

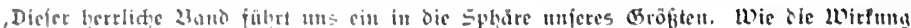

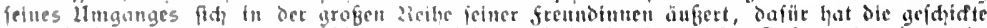

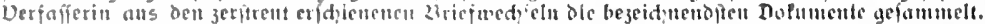

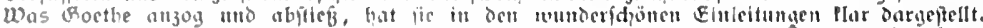

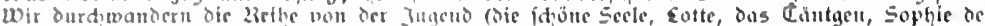

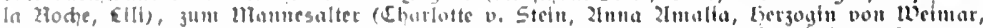

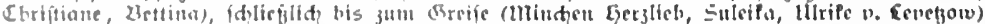

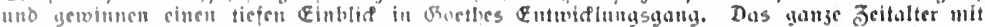

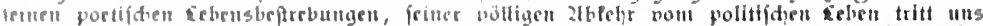

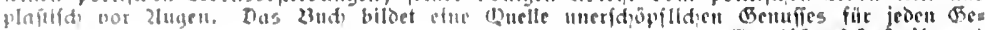
bilorter."

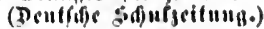




\section{Verlag von B. G. Ceubner in Leipzíg und Berlin}

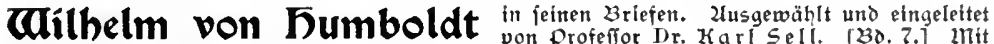
2 Bildnifen. Bebunden $\leadsto 2 .-$

Die 2lbfidt diefer Sammlung von Briefen, denen eine Eebensjlizje und Befamtalarafte= rlitif, Einleitungen in die einzelnen Eebertsabfhntitte und Purje Beridte hber alle widtigeren vorfommenden perfötlidfeiten beigegeben fitto, ift, eime Entmitilntusgejhidte des veritunonis= vollften freundes unjerer Klafiffer Sdiller und Boethe in Beftalt von Selbjtzeugnifïen ju geben, um den Menjden jo, wie er fid felbft eridien, den llugen der Zadjwelt ju jeigen. Es war nidht leidt, aus den vielen Gunderten von vorliegenden Briefen Gunbolots das für dieien Jowed Widtiaje herausjubeben, doh darf man bei der merfwitrofgen fefitgleit jeines Temperaments und jeiner frühen Beiftesteife hoffen, das zlel nicht verfehlt zu baber, wenn aud nur ein Ceil jeiner brieflichen Ginterlafienithaft hier erjeheint. Jugleich geleitet biefe Sammlumg intimfter

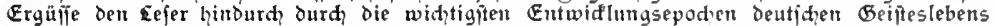
im 18. und 19. Jahrhundert.

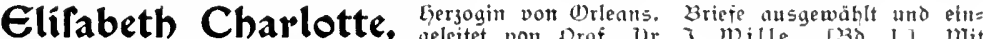

13 abbildungen. Bebumben on 2.-

"Wie diefes nrdentjde Weien fid ant Goje des "Sommenfönigs" 3 ur Cheltung gebradt hat


ben jerentontelf ten aller $50 ̈$ fe und fein ceben betrachtet lyat, alles das fömen wir in iluren unvergleidlid Hatürliden "no frijhen Briefen geniefien."

(Der ufte ofunbe.)

\section{Hlbrecht Dürer in feinen Briefen. Don Uberbibliothefar Dr. marfus ऊ̄uder.}

"Eine leerlidie Joee: aus dem gejdriebenen Wort das Bilo der perjönlidipit heran=

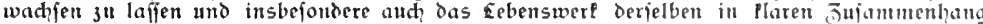
3u bringen mit den Entpfindungsgehalten und den 2lujataungen ihrer Jeit. Wis wirb bas

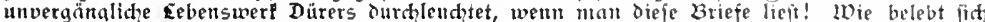
dic edle Gepalt Därers, went man an ber Ganto der intimfen 2lenterungen bineinfatut in das Seelenleben diejes gröen Menfiten. 27ad dem Eejen diejes Budbes, das aud äuberlid ver= wöhntefte Unfprïhe befriedigt, wird es flar, wie auberlid jelbit der lienter den ziünberaer Meifter befah."

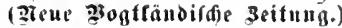

Бeinrich Deftalozzi. Eine 2 luswabl ans feinen zariefen und fleineren Sdriften. Eermann waliemann. [230. 3.] mit 19 2lbbildungen. Gebunden at. $2 .-$

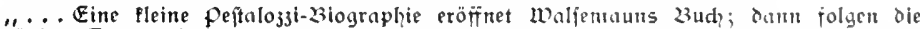
ausgewäblten Terte, mit henorzugenditer Derwertung des Briefwedijels zwifden pepalojzi uno



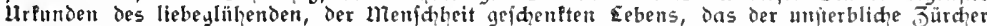
ahgefponnen hat, entnommen den bejen 2lusguben der Ulridriften, hat fid cin reides 23ilo gefultet, von bem die unmittelbare Wärme der grogen Seele ansgebt. Ein mädtiger Bemüts=

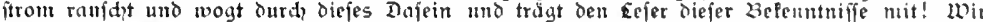

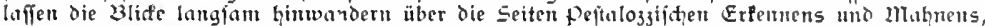
über all ole (1) ffenbarungen jeiner imig=feurigen llatur, ibler ben fluf feituer überredenden 23etraţtungen, und wieder und wieder flommen worte auf, die wie geprägt find fur 3iloungs: nöte now des lebenden तages, unjerer cigenen äeit."

(Babifage zum Eagelifalt der stadf st. bafien.)

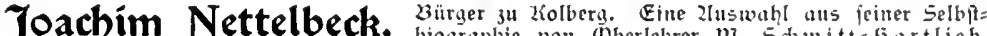 biograplice von Gberlelter 21 . $\Xi d$ mit $t=\mathfrak{l}$ artlieb.} [33. 4.] Intit 15 2lbbilonngen. Febuntien $\mathscr{M} 2 .-$

Die vorliegende 2luswahl geht vou der 2lbfint aus, das dentfoe Doll mit enem jeine

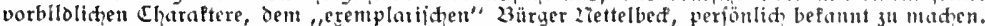

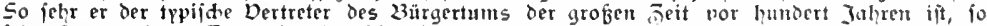

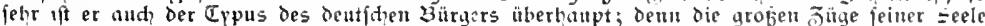
uni fefres Geiftes fino allerzeiten and allerorten möglfi, und von eminentem erzieherijdem Wert.

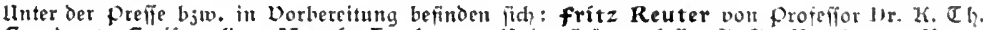
Baederţ, Greifisnald. - Martín Lutber von llniocritütsprofeffor D. Ir. Boe I? mer, Bonn. fermer find hu 2lusfidt genomnen : friedriḑ der Brofe, Königin Euife, Bneifenau, Eudwig Jahnu.a.

Husfübrlicher illuitr. Prolpekt umionit und poltfrei vom Verlag 


\section{Verlag von B. G. Ceubner in Leipzig und Berlín}

„Durd die điefe und Encrgie der Auffaiturg, die intenition Steigeruma des phnilithen Gus= oruds mo die wirfiante male= riit)=3eitnerishe Ausiilinung erideitt Bauer als berwiferet Interpret der phniognomien hervorragender mianter, der Gelden des $\overline{1}$ ciites. Es iit er= ftaunliá, weld fat ${ }^{+}$und fräjige malerifhellirtumen kater mit der feder ju erjielen weip und wie eindringlid er den feinteir belidtszüget, einer lltundwin= felpartie, dent jeurigen oder ernit finnenden Ausoruté eines Altiges, mit dem Spürftun bes Beidners 3u folgen vermag. Ein fait leiderimajtlides Kiinitlertem= perament fonmt in dell Bildern zun Ansornd. Die Auffaifun, dic der Kïnitler in ibnen wieder= gibt, it immer nell, frifo mo intereilant: man man wider. iprethen und anderer Meimmng leill, dic ielbitändige, gut ourt)= oadte Arbeit wird jederjeit fefich. (iltuitr, Butum!,

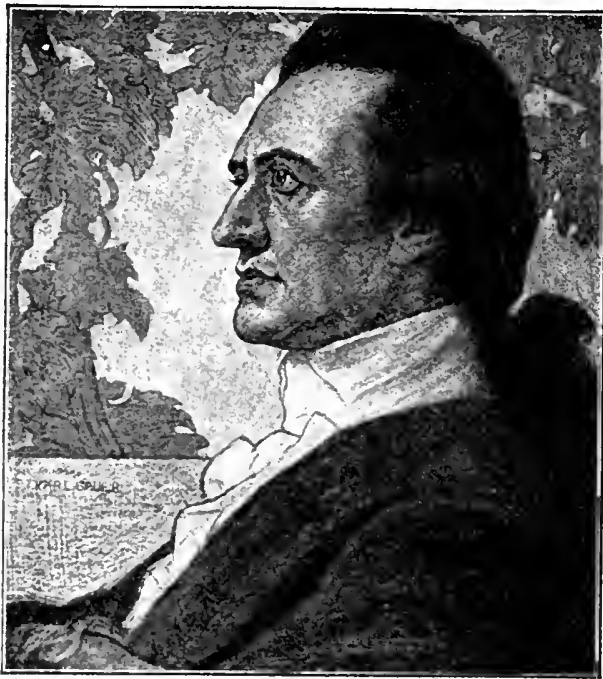

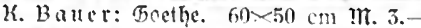

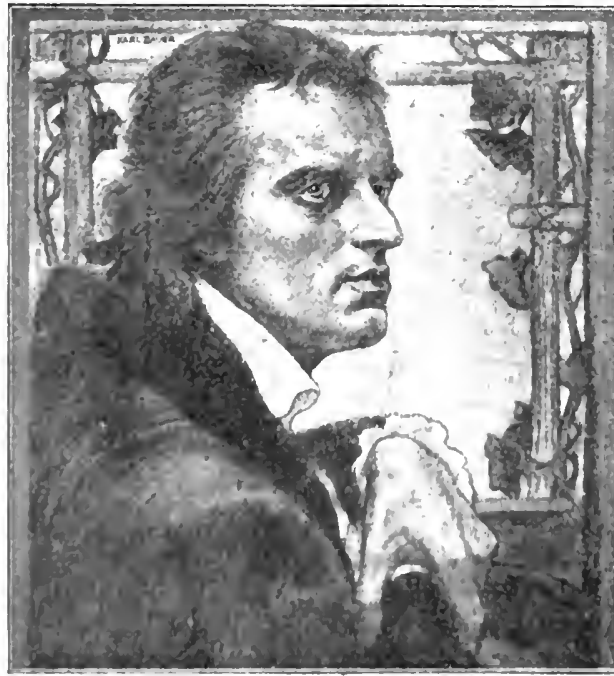

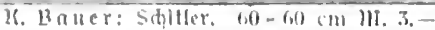

Karl Bauers neues Schillerbildnis, das die Beadtuma allec Sdiller= frembe werbient, wis es die lebhafteite Altertemmung der bedutemoiten sdillerfoluter acs funben laat, bermbt aut cill quhenden Studien mo muf det Dermenoma des gefanten wor: hunbenen llfaterials, nitht mur ber Cotenmoste, fonbern aud fintliderer bilder. Es iff non ciltem ber berufeniten Benr= teiler, ocm loritamb aer Sthiller. afellidyat und bes styitler.

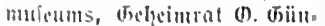
ther, ats oas gelumgenite wnd malyste non alfell sthiller hitonifien bezcidnet wotben.

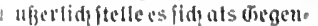
friid 3/1 bell bereits frïher er. fdictrenen Touthebilonis des. folturll Beldners one. 


\section{Verlag von B. G. Ceubner in Leipzig und Berlin}

\section{Der Kunftichatz des Lrelebuches}

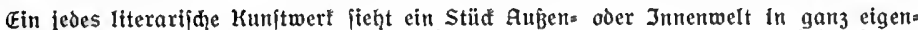
artiger weife mit ganz bejonderen Augen it feltiamer Belenhitung von cinen bedeutjamen Standpuntte aus, der den Durdbblic zu fernen Gedanfenmelten zuläß̈t. Erit wenn der Eehrer

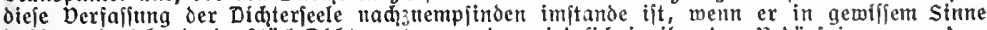

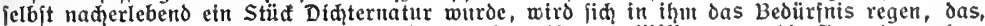
was er crfant und genoffen, aud anderen miszuteilen. - Will er mu die Jugend zu einer eđhten, irnigen Kunjtfrettoe führen, will ex inneres Eeben wedelt, Menland der Seele gewinnen,

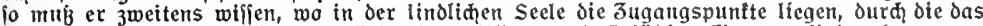
Sdriftmert hit feiner fülle von Gedantelt, Bildern und Gefïhlen Eingang finden tanit....

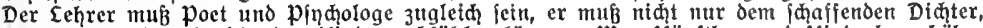
jondern aud bent Lufhenden Kinde nađ̧fïhlen fönnen. Was Künjtler= uno Kinderherz höher jळlagen ließ Giterbei freilid hat ber Eehrer oie Grenze des tünitlerifden Erfafiens für die Kinderfeele fejt. 3uhalten, er muB etn Künitlerherz und ein Kinderherz zugleid̆ bejitzen. - Don diejem bedanten getragen, find die Bänbe: "Der Kanjtiḑał des Eejebuhs" ausgearbeitet worden. Imt ein= lettenden Teil finden jedesmal die Grutofragen über Aufifaifung und Darbietuma ausführlidie Behandlung, im prattijđen Teil aber ift gezeigt, wie der Eehrer zu feinem völligen Einleben in das literaríf̧e Kunftwerf gelangen tam..... Dabei ift die größjte Mannigjaltigfeit der poetifden mögliḑletten angejtrebt worden. Stoffe der verihiedenfiten Shinlgattugen und



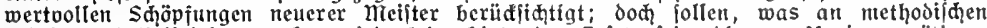
Winfen und Beifpieler gegeben wird, Feine bindenden бeję̧e fein, díe jum Kopieren nötigen. Auf dieje weife hofft das wert, den Eehrer 3 th einer größeren pädagogifđen Selbjtändigfett

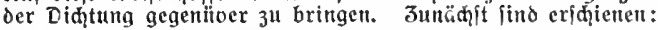

\section{Die lyrilche Díchtung}

\section{Don Tailhelm Deper}

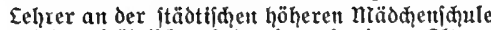
und dem jtäbtifक̨en Echrerimenjentinar, Altotta

[VI u. 203 S.] gr. 8. 1909. Беh. Mr. 3.40, in Eeinmand geb. Mr. 4.-

Inhalt: I. Der künftlerifche Gehalt des tyrifchen Gedichtes und reine Erfalfung. 1. Der Gefühlsgehalt des Gedidtes. 2. Der Bildgehalt des Eiedes. 3. Der Gedantengehalt des

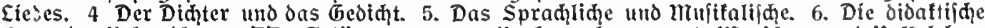
Sorm der Behandlung. II. Erläuterungen. Dorbemertungen. 1. Menjden= und Doltsleber.

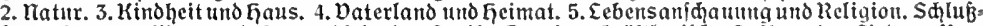



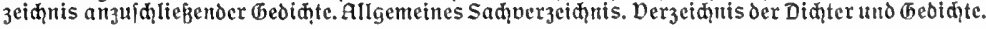

\section{Die epilche Dichtung}

\section{Don Dr. Ernit खacber in Münḑen}

[VIII u. 266 S.] gr. 8. 1909. Бeh. Mr. 3.40, in Eeinwand geb. Mr. 4.-

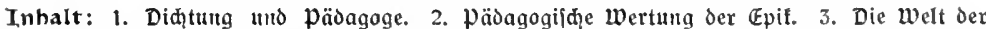
Stoffe. 4. Die Welt oer Diditer. 5.- Die Welt der epifđen formen. 6. Dou der Tedint des

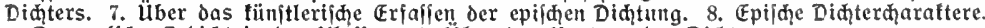



Weitere Bände, erzählende und belehrende proja behandelnd, befinden fich in Dorbereitung.

Ausfïhrl.proipeft mit probejtïafen umionit u.pojtfrei v. Derlag 


\section{Verlag von B. G. Ceubner in Leipzig und Berlin}

\section{Huss Naturund Geílteswelt}

Sammlung wifjenjđaftlid = gemeinveritändliđer Darftellungen aus allen бebieten des Wiffers in Bänden von 120-180 Seiten. Jeder Band ift

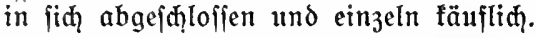

Jeder Band gebeftet M. 1.-, in Ioinwand gebunden M. 1.25.

In erjhöpfender und allgemein=verftändlicher Behandlung werden in $a b=$ gefकlofferen Bänden auf wiffenfकaftli(her Grundlage ruhende Daritellungen wiđhtiger (bebiete in planboller Bejđränfung aus allen 3weigen des Wiffens geboten, die von allgemeinem Intereffe find und dauernden lügen gewähren.

Jur Siteratur und Spraḑe erfhienen u. a.:

Sçiller: prof. Dr. Th. Ziegler. (74.)

Deutiche Romantik: prof. Dr. (D. Walzel. (232.)

Das deutiche Drama des 19. Jaḩrh.: Prof. Dr. (F. Wit= fowsti. (51.)

Friedriđ Gebbel: Dr. Anna Sđ̆apire=Kenrath. (238.)

Gerhart Gauptmann: prof. Dr. E. Sulger=(6ebing.

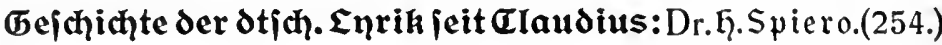

Das deutiçe Dolkslied: Dr. J. W. Bruinier.

Die dentiche Dolksiage: Dr. (1)t to Bödel. (262.)

Das Theater: Dr. Chr. (baehde. (230.)

Sđrift= und Budiweien: prof. Dr. (D. Weife. (4.)

Entitehung und Entwidulung unierer mutteripraḑe: prof. Dr. W. $\mathfrak{l l h l}$ l. (84.)

Die Spraçitämme o. Erdkreifes. Prof. Dr.fr.n.find. (267.) Die Gaupttnpelt des menfaliḑen Sprađ̧baues: prof. Dr. fr. IT. fint. (268.) 

8

c 
